\title{
Estimating the population at-risk of homelessness in small areas
}

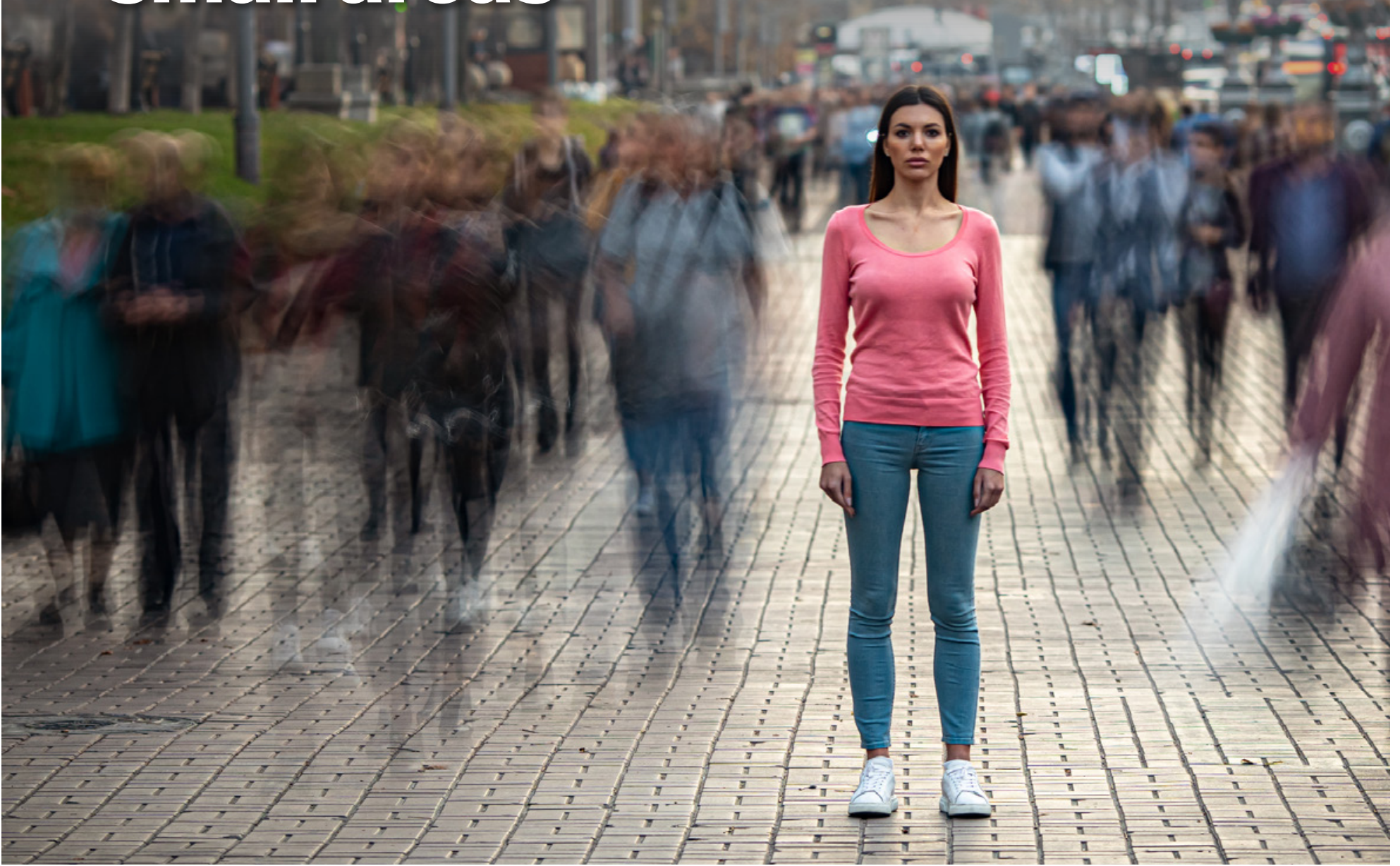

Authored by

Deborah Batterham, Launch Housing/Swinburne University of Technology

Christian A. Nygaard, Swinburne University of Technology Margaret Reynolds, Swinburne University of Technology Jacqueline de Vries, University of Tasmania
Publication Date November 2021 DOl 10.18408/ahuri5123501

\section{AHURi}


Title

Estimating the population at-risk of homelessness in small areas

\section{Authors}

Deborah Batterham, Launch Housing/Swinburne University of Technology

Christian A. Nygaard, Swinburne University of Technology Margaret Reynolds, Swinburne University of Technology Jacqueline de Vries, University of Tasmania

\section{ISBN}

978-1-922498-37-3

\section{Key words}

Homelessness, risk, small area estimation, geography, prevention.

\section{Series}

AHURI Final Report

\section{Number}

\section{ISSN}

1834-7223

\section{Publisher}

Australian Housing and Urban Research Institute Limited Melbourne, Australia

\section{DOI}

10.18408/ahuri5123501

\section{Format}

PDF, online only

URL

https://www.ahuri.edu.au/research/final-reports/370

\section{Recommended citation}

Batterham, D., Nygaard, C., Reynolds, M. and de Vries, J. (2021) Estimating the population at-risk of homelessness in small areas, AHURI Final Report No. 370, Australian Housing and Urban Research Institute Limited, Melbourne, https://www.ahuri.edu.au/research/finalreports/370, doi: 10.18408/ahuri5123501.

\section{AHURI}

AHURI is a national independent research network with an expert not-for-profit research management company, AHURI Limited, at its centre.

AHURI's mission is to deliver high quality research that influences policy development and practice change to improve the housing and urban environments of all Australians.

Using high quality, independent evidence and through active, managed engagement, AHURI works to inform the policies and practices of governments and the housing and urban development industries, and stimulate debate in the broader Australian community.

AHURI undertakes evidence-based policy development on a range of priority policy topics that are of interest to our audience groups, including housing and labour markets, urban growth and renewal, planning and infrastructure development, housing supply and affordability, homelessness, economic productivity, and social cohesion and wellbeing.

\section{Acknowledgements}

This material was produced with funding from the Australian Government and state and territory governments. AHURI Limited gratefully acknowledges the financial and other support it has received from these governments, without which this work would not have been possible.

AHURI Limited also gratefully acknowledges the contributions, both financial and in-kind, of its university research partners who have helped make the completion of this material possible.

This paper uses unit record data from the Household, Income and Labour Dynamics in Australia (HILDA) survey, which is funded by the Australian Government Department of Social Services (DSS) and managed by the Melbourne Institute of Applied Economic and Social Research. The findings and views reported in this paper, however, are those of the authors and should not be attributed to either DSS or the Melbourne Institute.

The authors would like to thank Professor Timo Schmid (University of Bamberg) and Sylvia Harmening (Freie Universitaet Berlin) for methodological advice on the production of Small Area Estimates. Any errors in execution or interpretation are solely those of the authors.

\section{Disclaimer}

The opinions in this report reflect the views of the authors and do not necessarily reflect those of AHURI Limited, its Board, its funding organisations or Inquiry Panel members. No responsibility is accepted by AHURI Limited, its Board or funders for the accuracy or omission of any statement, opinion, advice or information in this publication.

\section{AHURI journal}

AHURI Final Report journal series is a refereed series presenting the results of original research to a diverse readership of policy-makers, researchers and practitioners.

\section{Peer review statement}

An objective assessment of reports published in the AHURI journal series by carefully selected experts in the field ensures that material published is of the highest quality. The AHURI journal series employs a double-blind peer review of the full report, where anonymity is strictly observed between authors and referees.

\section{Copyright}

(C) Australian Housing and Urban Research Institute Limited 2021

This work is licensed under a Creative Commons Attribution-NonCommercial 4.0 International License, see http://creativecommons.org/licenses/by-nc/4.0/. 


\section{Contents}

$\begin{array}{ll}\text { List of tables } & \text { iii }\end{array}$

List of figures

Acronyms and abbreviations used in this report iv

Executive summary

1. Introduction $\quad 7$

1.1 Why this research was conducted

1.2 Prevention and risk - two interconnected concepts

$\begin{array}{lr}1.3 \text { Australian homelessness policy and prevention } & 10\end{array}$

1.4 Summary and structure of the report $\quad 11$

2. Data sources, spatial units and operationalisation of risk $\ldots$

2.1 Small area spatial units $\quad 13$

2.2 Data sources

2.2.1 Household Income and Labour Dynamics in Australia (HILDA) survey 13

2.2.2 Census of Population and Housing

$\begin{array}{lr}2.3 \text { Identifying those at-risk of homelessness } & 14\end{array}$

2.3.1 Conceptualising homelessness risk

2.3.2 Operationalising homelessness risk 16

2.3.3 Limitations 20

3. Small Area Estimation technique $\quad 22$

3.1 Unit-level model

$\begin{array}{lr}3.2 \text { Area-level model } & 27\end{array}$

4. Homelessness risk in Australia $\quad 31$

4.1 National estimates of the population at-risk of homelessness 32

4.2 Characteristics of the national population at-risk

4.3 State and territory incidence of homelessness risk

4.4 The characteristics of those at-risk within each state and territory 38

4.5 SA3 level consistency and comparison across estimation methods $\quad 42$

4.6 Mapping the incidence of homelessness risk, SA2 and SA3 43

4.7 Confidence and reliability of estimates $\quad 48$

4.8 Mapping the numbers of people at-risk $\quad 51$

4.9 Policy development implications $\quad 55$

5. Policy development options $\quad 57$

5.1 SAEs and prevention policy $\quad 57$

5.2 Primary prevention opportunities for state, territory and local governments $\quad 58$

5.3 Primary prevention opportunities for the Australian government $\quad 60$

$\begin{array}{ll}5.4 \text { Future research } & 61\end{array}$

5.5 Improved data access and coverage $\quad 61$

5.6 Final remarks $\quad 62$

$\begin{array}{ll}\text { References } & 64\end{array}$

Appendix 1: Detailed SAE modelling results $\quad 70$

Appendix 2: HILDA sampling coverage

$\begin{array}{lr}\text { Appendix 3: SAE data tables } & 74\end{array}$ 


\section{List of tables}

Table 1: Descriptive statistics, individual risk factors for responding persons, HILDA survey, waves 16 and $17 \quad 18$

Table 2: HILDA waves 16 and 17 initial incidence of risk factors, counts and per cent

Table 3: Descriptive statistics for variables used in the unit-based (probit) models 26

Table 4: Definition of variables used in the unit-based (probit) model 26

Table 5: Descriptive statistics, area-level (FH) model $\quad 29$

Table 6: Definition of variables used in area-level $(\mathrm{FH})$ model

Table 7: Aggregated SAEs, Australia, 2016

Table 8: Demographic profile of the estimated population aged 15 years and over at-risk of homelessness in 2016 (HILDA) Australia

Table 9: Unit-level SAE's aggregated to the state and territory level: rates and point estimates with confidence intervals, 2016

Table 10: Area-level SAE's aggregated to the state or territory level: rates and point estimates with confidence intervals, 2016.

Table 11: Pearson correlations between direct estimates, unit-based estimates and Area-based estimates at the SA3 level, 2016

Table A1: Unit-based (probit) results using HILDA 2016 data

Table A2: Area-based (FH) model results using HILDA 2016 and Census 2016 data

71

Table A3: The variable names and definitions contained in Table A4 and Table A5

Table A4: SA2 level estimates

Table A5: SA3 level estimates

113

\section{List of figures}

Figure 1: The research approach to producing small area estimates of homelessness risk

Figure 2: Unit-level SAE process

Figure 3: Area-level (FH) SAE process

Figure 4: Key characteristics of the population at-risk of homelessness compared to general population* 36

Figure 5: Characteristics of the at-risk population by state and territory (unit-based, probit estimates) 38

Figure 6: Risk of homelessness (rate per 10,000 people), comparing unit-level (probit - map A) and arealevel (Fay-Herriot - map B) estimates, national overview, SA3s

Figure 7: Risk of homelessness (rate per 10,000 people), unit-level (probit) estimates, capital city SA2s

Figure 8: Confidence interval ranges, unit-level (probit) estimates: percentage points and +/- variations in point estimates, Australia, SA3s

Figure 9: Confidence interval ranges, unit-level (probit) estimates: percentage points and +/- variations in point estimates, capital city SA2s

Figure 10: Confidence interval ranges, area-level (FH) estimates: percentage points and +/- variations in point estimates, Australia, SA3s

Figure 11: Point estimates: persons* at-risk of homelessness, comparing unit-level (probit - map A) and area-level (FH-map B) estimates, national overview, SA3s

Figure 12: Point estimates, persons* at-risk of homelessness, unit-level (probit) model, capital city SA2s

Figure A1: FH SAE estimate comparison with direct estimates (HILDA) 


\section{Acronyms and abbreviations used in this report}

\begin{tabular}{|c|c|}
\hline ABS & Australian Bureau of Statistics \\
\hline ACT & Australian Capital Territory \\
\hline AHURI & Australian Housing and Urban Research Institute Limited \\
\hline AlHW & Australian Institute of Health and Welfare \\
\hline ASGS & Australian Statistical Geography Standard \\
\hline ATR & At-risk of homelessness indicator \\
\hline CC/RoS & Capital City or Rest of State \\
\hline CDF & Cumulative Distribution Function \\
\hline $\mathrm{FH}$ & Fay-Herriot model \\
\hline GCCSA & Greater Capital City Statistical Area \\
\hline HILDA & Household Income and Labour Dynamics in Australia \\
\hline LGBTI & People who are lesbian, gay, bisexual, transgender or intersex \\
\hline NFP & Not for profit \\
\hline NHHA & National Housing and Homelessness Agreement \\
\hline NSW & New South Wales \\
\hline NT & Northern Territory \\
\hline QLD & Queensland \\
\hline SA & South Australia \\
\hline SA2 & Statistical Area level 2 \\
\hline SA3 & Statistical Area level 3 \\
\hline SAE & Small Area Estimation \\
\hline SHS & Specialist Homelessness Services \\
\hline SHSC & Specialist Homelessness Services Collection \\
\hline SIH & Survey of Income and Housing \\
\hline SND & Standard Normal Distribution \\
\hline TAS & Tasmania \\
\hline VIC & Victoria \\
\hline WA & Western Australia \\
\hline
\end{tabular}




\section{Executive summary}

\section{Key points}

- Successful primary prevention of homelessness requires a detailed understanding of the incidence and profile of the at-risk population, at the national, local and regional (or small area) levels.

- This research produces Small Area Estimates (SAE) of the population at-risk of homelessness in Australia. The incidence of homelessness risk is measured as a rate per 10,000 residents at Statistical Area level 2 (SA2) and Statistical Area level 3 (SA3) level.

- A person is considered at-risk of homelessness if residing in rental housing and experiencing at least two of the following: low-income; vulnerability to discrimination; low social resources and supports; needing support to access or maintain a living situation; and a tight housing market context. By definition, a person residing in owner-occupied housing is not considered at-risk.

- This research combines data from the Household, Income and Labour Dynamics in Australia (HILDA) survey, waves 16 and 17, and the 2016 Census of Population and Housing. In an attempt to deal with significant data limitations, two model-based SAE methods are employed: a unit-level and an area-level approach.

- The unit-level approach utilises HILDA responding person characteristics and Census data. The area-level approach combines direct SA3-level homelessness risk and variance estimates from HILDA and SA3-level Census data. Both approaches utilise regression models to generate SAE of homelessness risk. 
- Findings suggest that at a national level, the estimated rate of risk per 10,000 persons (across all tenures combined) ranges between 846.9 per 10,000 ( $8.5 \%$ of the total population aged 15 years and over) and 1,165 per 10,000 (11.7\%). This range equates to between 1.5 and 2 million Australians at-risk of homelessness-all of whom reside in rental housing.

- The highest rates of risk (per 10,000 persons) are found in remote areas and in selected areas of capital cities. The greatest number of people atrisk are living in greater capital cities on the eastern coast of Australia, in both central and suburban locations.

- The two different methods used to produce the small-area estimates do not generate a consistent picture of homelessness risk in Australia in all areas, with greater variability in remote parts of the country.

- The profile of those at-risk suggests primary prevention policies require policy and service responses at national and state and territory levels that are beyond the usual scope of homelessness policy.

- Homelessness risk SAEs provide policy makers, not-for-profit (NFP) service providers and funders with quantified estimates of demand (need) for different types of services. They also provide locational information to maximise and monitor the benefits of investment in spatial and aspatial homelessness prevention initiatives.

- Aspatial primary prevention policies include: increasing income support payments; improving the incomes of the lowest paid; and enhancing coordination on homelessness prevention across all levels of government.

- Spatial primary prevention policies include: increasing the supply of rental housing affordable to those on the lowest incomes; ensuring access to health and disability supports for those on low incomes; increasing school engagement and retention; and enhancing support to Indigenous Australians in remote communities. 
The overall incidence of homelessness cannot be reduced by responding to those experiencing homelessness alone. Upstream interventions are required to prevent homelessness from occurring in the first place. Such interventions must target those at-risk of homelessness, and so an understanding of the population at-risk of homelessness is required. Yet, little is known about the population at-risk of homelessness in Australia (apart from Batterham 2021), including the geographical distribution of this population.

The overarching policy issue guiding this project is therefore: how can homelessness be prevented more effectively based on a detailed understanding of the distribution of the population at-risk of homelessness across small areas in Australia?

Existing research demonstrates that area-level disadvantage (Vinson, Rawsthorne et al. 2017), homelessness (Parkinson, Batterham et al. 2019) and rental stress (Hulse, Reynolds et al. 2019; Hulse, Reynolds et al. 2014; Rahman and Harding 2014), all vary significantly across space. The incidence of homelessness risk and the characteristics of those affected are also likely to vary spatially. Without a nuanced understanding of spatial differences and characteristics associated with these differences, identification of service need (demand) and location of different services may be undermined.

Two research questions address the policy issue:

- RQ1: What is the incidence of homelessness risk in small areas across Australia, including within states, territories and capital cities?

- RQ2: What is the profile of those at-risk and what are the geographical differences in the profile of this population in small areas across Australia and within states, territories and capital cities?

Both the number and profile of the population at-risk of homelessness can be used to guide the focus of preventative policies and assess their effectiveness (Batterham 2021). The quantification of social and economic phenomena is key to the development of many social policies and strategies. SAEs of homelessness risk provide policy makers, not-for-profit service providers and funders with quantified estimates of demand/need for different types of services by area to maximise the efficiency of preventative policy initiatives.

\section{Key findings}

\section{Producing an estimate of homelessness risk in Australia}

No official source of homelessness risk data exists in Australia. This research, therefore, employed Small Area Estimation (SAE) techniques to generate homelessness risk indicators at two (small scale) Census geographies, SA2 and SA3. The estimates of homelessness risk are produced utilising data from the Household, Income and Labour Dynamics in Australia (HILDA) survey, and the 2016 Census of Population and Household. SAE methods combine survey data (i.e. HILDA) and additional data (i.e. Census) with better sampling or geographic coverage to produce model-based predictions of homelessness risk. Both unit-level and area-level models were used in estimation. The variation in the predicted rates of homelessness risk, in part, reflect underlying data availability considerations.

Our results show that 'behind' the number of people experiencing homelessness, is a much larger number of Australians who are at-risk. The results in this research estimate the population at-risk of homelessness at the national level and are expressed as a rate of risk per 10,000 persons (total population, all tenures combined) to range between 846.9 and 1,165 per 10,000 people, or some 8.5 to 11.7 per cent of the total population aged 15 years and over. 


\section{Spatial distribution and characteristics of the at-risk of homelessness population}

The rate of homelessness risk at SA2 and SA3 level varies considerably. At the SA2 level the rate of homelessness risk ranges from 87.3 (Gelorup-Stratham, WA) to 5,040 (Aurukun, QLD) per 10,000; and 206.9 (Nillumbik-Kinglake, $\mathrm{VIC}$ ) to 3,366.4 (East Arnhem, NT) per 10,000 at the SA3 level. More generally, the highest rates of risk are in the Northern Territory (NT), followed by Queensland (QLD) and South Australia (SA). The lowest rates of risk are in the Australian Capital Territory (ACT) followed by Victoria (VIC).

At finer spatial levels the highest rates of risk are typically found in remote areas and select areas in capital cities. However, the greatest numbers of people at-risk are located in capital cities on the eastern coast of Australia. These high numbers extend well beyond inner city areas and into the suburbs.

Areas with moderate/average rates of risk in capital cities, such as the outer west in Melbourne, or substantial segments of the eastern 10 kilometre ring of Perth, can still have high numbers of people at-risk, due to their larger population size.

Analyses at finer spatial scales reveal distinct nuances within and between states and territories. In several states, including QLD, New South Wales (NSW), Western Australia (WA), and SA, high rates of homelessness risk are spread across greater capital cities and regional areas. In the NT, however, risk is highly concentrated in remote areas, whereas in VIC, risk is concentrated in inner Melbourne.

Importantly, SAEs are estimates and as such, a product of the availability and quality (detail and sampling coverage) of the data. Data considerations affect both the point estimates and the variability of those point estimates, per SAE method. Testing for consistency across the different SAEs suggests the precision of estimates and consistency across the two approaches is greatest in capital cities, although there are exceptions. The precision of estimates (the confidence intervals around the estimates) is poorer in remote and sparsely populated areas. Many of the areas with the highest predicted homelessness rates also have large confidence intervals.

Compared to the national population, those at-risk are more likely to be female, Indigenous, and be living in a lone person or lone parent household. They are more likely to identify as lesbian, gay or bisexual, and report fair or poor health. They are more likely to be low-income, unemployed or outside the labour force, and in receipt of income support payments. Those at-risk have lower levels of educational attainment, are more likely to report difficulty paying bills and rent on time, and are more likely to experience rental stress and a range of indicators of material deprivation such as skipping meals and being unable to heat their home.

\section{Policy development options}

The sheer number of people at-risk of homelessness-between 1.5 million and 2 million people aged 15 years and over-demands a stronger focus on primary prevention of homelessness in Australia. While we do not know how many people transition from risk into actual homelessness, results from the General Social Survey (Australian Bureau of Statistics 2020) suggest that transition rates could be high, with some 11 per cent of the population aged 15 years and over having experienced homelessness in their lifetime.

Successful prevention requires a detailed understanding of the incidence of homelessness risk in the population, and the profile of those at-risk, at the national as well as local levels. The findings in this report suggest that primary prevention initiatives require both spatial and aspatial approaches, some of which sit beyond the usual scope of homelessness policy and sit across all levels of government.

Both spatial and aspatial policy delivery and monitoring can be enhanced by SAE of homelessness risk that provide quantified estimates of need for different types of services and areas to maximising the benefit of investment in homelessness primary prevention initiatives. 


\section{Increasing income support and earnings for the low paid}

The majority of those at-risk of homelessness are in low-income households. The significance of low-income is highlighted by the higher rates of rental stress as well as material deprivation experienced by those at-risk in terms of skipping meals and being unable to heat their homes.

Given that many are in receipt of income support payments (both for those who are unemployed and those outside the labour force), an increase in the rate of these payments could make substantial impact in reducing the risk of homelessness. Around a quarter of the at-risk population are in paid employment suggesting a need to increase the rates of pay or income stability among this group: A substantial increase in income would help to boost purchasing power in the private rental market for this group, with the COVID-19 and Job Keeper supplements effectively bolstering incomes during the pandemic to address some of these issues (Pawson, Martin et al. 2021; Verdouw, Yanotti et al. 2020). This is important given the well documented shortage of rental housing affordable to those in the lowest income quintile (Hulse, Reynolds et al. 2019) and particularly those on income support payments (Anglicare Australia 2021; Department of Health and Human Services (VIC) 2021).

\section{Increasing the supply of rental housing affordable to those on low-incomes}

By definition, those at-risk of homelessness in this study are residing in the rental sector (private rental and social housing). The lack of affordable rental housing for low-income households-be it private rental (Hulse, Reynolds et al. 2019) or social housing (Lawson, Pawson et al. 2018)-intersects with the low-incomes of those at-risk amplifying the multiple and intersecting forms of disadvantage they experience. These shortages are cumulative and have evolved over the last two decades (Burke, Nygaard et al. 2020). There is a need for greater provision of rental housing that is specifically targeted to those on low-incomes and/or those at-risk of homelessness. Scaling up the provision of social and affordable housing options (with income tied requirements) provides one possibility for achieving this. SAEs of the population at-risk of homelessness can provide valuable estimates of local demand, which are critical for planning for affordable housing at the local level.

Our results highlighted much higher rates of rental stress and many forms of material deprivation among those at-risk, suggesting opportunities for enhancing existing secondary prevention initiatives. Specifically private rental access programs that provide ongoing rent subsidies for people at imminent risk of homelessness, as well as the payment of rent arrears and advocacy with landlords. Such services could be targeted to areas with larger numbers of people at-risk of homelessness.

\section{Ensuring access to health and disability supports for those on low-incomes}

Those at-risk are likely to report living with a disability and fair or poor health. This is consistent with existing research, which documents the role of poor physical and mental health in precipitating homelessness as well as the substantial health impacts of homelessness (Johnson and Chamberlain 2011; Min Park, Fertig et al. 2011). There is a clear role for state and territory governments to ensure access to health and disability supports across areas, especially for those on low-incomes. These findings also highlight the importance of national safety net schemes such as Medicare, the Pharmaceutical Benefit Scheme (PBS) and the National Disability Insurance Scheme (NDIS).

\section{Focus on education, school engagement and retention}

Those at-risk have lower levels of educational attainment and many of those at-risk have children living with them. Given what is known about intergenerational transmission of poverty, homelessness, and low educational attainment (Cobb-Clark 2019; Cobb-Clark and Zhu 2015), state and territory government investments supporting educational engagement for disadvantaged students could pay off in-terms of reducing future risk of homelessness. Additional supports for further education and training for adults with low educational attainment may also be required. SAEs can be used to enhance and expand preventative services based at educational facilities. 


\section{Targeted support for remote Indigenous communities}

Indigenous Australians are overrepresented in the at-risk population, especially in remote areas, and are also overrepresented in the homelessness population. Targeted support for this group, developed in consultation with the communities themselves, is warranted. Given known issues with the standard and quantum of housing in remote Indigenous communities, our SAEs of homelessness risk could inform a revamped National Partnership on Remote Housing and/or state level strategies on remote Indigenous housing.

\section{Improving data access and coverage}

Combining survey data with Census, and other administrative data with detailed population coverage provides an important (and lower cost) way of producing a range of policy-relevant statistics at finer spatial scales. However, the quality of SAE production is dependent on the sampling frame and sampling uncertainties, and the quality and accessibility of auxiliary data from other data sources. For the purposes of this project, it is clear that the low-sampling (or no sampling) in remote and sparsely populated areas generates systematic variability in the quality of the estimates that can be produced. However, the production of SAEs is also restricted by the availability of Census data. Firstly, through restrictions on the cross-tabulations that can be conducted when using the Australian Bureau of Statistics' (ABS) TableBuilder product. Secondly, through restrictions (exacerbated by the COVID-19 pandemic) of accessing the 5 per cent unit record file from the Census. Altering the sampling properties of large-scale surveys may not always be feasible. However, improving access to Census products will also assist in the production of SAEs. Similarly, altering rules around perturbation and confidentiality measures can assist in improving precision of SAE techniques.

\section{The study}

The data developed for this research provides policy makers and service providers with a base-level understanding of the at-risk population's spatial distribution and preliminary information about the varying profile of those at-risk. This information can be used to aid in the development of primary prevention initiatives, aid in tailoring them to local environments, and provide metrics that may be used to assess the effectiveness of primary prevention initiatives.

We employ Batterham's (2019a) definition of homelessness risk and operationalise it using a nationally representative household panel survey (HILDA) for 2016. To provide estimates of homelessness risk in small areas (SA2 and SA3) across Australia, we employ Small Area Estimation (SAE) techniques. SAE is a method for generating area-based statistics or indicators where direct measurement is not feasible or where the precision of direct estimates is limited because of small sample sizes. SAE utilises auxiliary data to improve the precision of the estimates that can be derived directly from the survey itself (Pfeffermann 2013).

Two methods for producing SAEs are applied: a unit-level and an area-level approach. Using two SAE methods enables us to compare results and provide some assessment of the relative strengths and weaknesses of the two approaches. The unit-level approach uses HILDA Survey data matched to the data and category availability in the Census to predict risk indicators. We then estimate risk of homelessness at the small-area level using the results of this modelling in combination with customised cross tabulations from the Census. In the area-level approach, we generate SA3-level direct estimates of homelessness risk, and variance of risk, in HILDA and then develop a model to predict these direct estimates using area-level data from the Census based on the Fay-Herriot $(\mathrm{FH})$ method. We report both a rate of homelessness risk per 10,000 persons and the estimated number of persons at-risk across small areas. Confidence intervals for these estimates are provided the national, state and territory, and small area level. 


\section{Introduction}

- Successful prevention requires a detailed understanding of the incidence of risk in the population, and the profile of those at-risk, at local and regional levels, technically referred to as small area levels. In this project, Census geographies SA2 and SA3 are considered small areas.

- This research produces small area estimates of the at-risk of homelessness population in Australia to assist policy makers and stakeholders to develop homelessness prevention strategies.

- This research draws on Household Income and Labour Dynamics in Australia (HILDA) survey data and 2016 Census of Population and Housing data and employs two methods of Small Area Estimation (SAE): a unit-based and an area-based approach.

\subsection{Why this research was conducted}

Homelessness is a surprisingly common experience in the Australian population (see footnote 1 for definition of homelessness in Australia). More than 116,000 Australians, or 50 in every 10,000 people, experience homelessness on any given night (Australian Bureau of Statistics 2018b). On any given day, 66,100 people are supported by a specialist homelessness service, while between July 2011 and July 2020, some 1.3 million people received assistance from specialist homelessness services (SHS) (Australian Institute of Health and Welfare 2020). Other data suggests that 7 per cent of Australians (approximately 1.5 million people) experienced homelessness over the 10 years to 2010 (ABS 2015)'.

Homelessness is traumatic and has significant and wide-ranging impacts on those who experience it. People struggle to meet their basic needs of food, shelter and safety (Commonwealth of Australia 2008) and to maintain relationships with family, friends and their community (Goodman, Saxe et al. 1991). Homelessness can make it

1 Homelessness can be defined in various ways. In Australia most definitions are broad by international standards and include more than those sleeping rough or staying in short term accommodation such as shelters and refuges. The ABS define homelessness as lacking one or more of the Anglo-European elements of home: privacy, stability, a sense of security, safety, and control over living space. Specifically, they consider a person to be homelessness when a person is living in a dwelling that: is inadequate; or has no tenure, or their initial tenure is short and not extendable; or does not allow them to have control of and access to space for social relations, and; the person does not have alternative suitable accommodation. This definition is used to produce area-based estimates of homelessness from the Census of Population and Housing. 
difficult to maintain or find employment and participate in education and training (Mavromas, King et al. 2011). It can bring about significant physical and mental health issues (Beer, Baker et al. 2011; Chamberlain, Johnson et al. 2007; Mallett, Bentley et al. 2011; Westmore and Mallett 2011), which persist long after the period of homelessness is resolved. An experience of homelessness also has significant negative effects on children's development and education (Buckner 2008; Kirkman, Keys et al. 2010; Kolar 2019).

Homelessness also has high costs to the broader community and governments. People experiencing or at-risk of homelessness have been shown to have higher use of health, justice, and other welfare services both in Australia (Flatau, Zaretzky et al. 2008; MacKenzie, Flatau et al. 2016; Zaretzky and Flatau 2013) and internationally (Gaetz 2012; Pleace, Baptista et al. 2013). An Australian study that examined potential offsets related to health and justice services, welfare and taxation forgone, and eviction rates from public tenancies (Zaretzky and Flatau 2013; Zaretzky, Flatau et al. 2013), estimated the annual cost offset of addressing homelessness at $\$ 29,450$ per client per year. Preventing homelessness has the potential to reduce government expenditure across a range of social policy areas.

The overall incidence of homelessness cannot be reduced by responding to those experiencing homelessness alone. Upstream interventions are required to prevent homelessness from occurring in the first place. Such interventions must be targeted to those at-risk of homelessness, hence an understanding of the population at-risk of homelessness is required.

Yet little is known about the population at-risk of homelessness in Australia (apart from Batterham 2021), including the geographic distribution of this population. Successful prevention requires a detailed understanding of the incidence of risk in the population, and the profile of those at-risk, at local and regional levels, technically referred to as small area levels.

Existing research demonstrates that area-level disadvantage (Vinson, Rawsthorne et al. 2017), homelessness (Parkinson, Batterham et al. 2019) and rental stress (Hulse, Reynolds et al. 2019; Hulse, Reynolds et al. 2014; Rahman and Harding 2014), all vary significantly across space. The incidence of homelessness risk and the characteristics of those affected are also likely to vary spatially. Indeed, preliminary research by Batterham (2021) suggests that this is the case. Without a nuanced understanding of these spatial differences and the dynamics underlying them, attempts at primary prevention may be undermined.

Based on these considerations, the overarching policy question guiding the project is: how can homelessness be prevented more effectively based on a detailed understanding of the distribution of the population at-risk of homelessness across small areas in Australia?

Two research questions will address this policy issue:

- RQ1: What is the incidence of homelessness risk in small areas across in Australia, including within states, territories and capital cities?

- RQ2: What are the geographical differences in the profile of the population at-risk of homelessness in small areas across Australia and within states, territories and capital cities?

Both the number and profile of the population at-risk of homelessness can be used to guide the focus of preventative policies and assess their effectiveness (Batterham 2021). The quantification of social and economic phenomena at local levels is key to the development of many social policies and strategies (such as place-based strategies). SAEs of the population at-risk of homelessness provide policy makers, NFP service providers and funders with quantified estimates of need for services and the areas where it is most needed to maximise the effectiveness primary preventative initiatives

Understanding the geography of homelessness risk at the small area level, both its incidence and the profile of that population, enables tailoring of prevention initiatives to local environments. 


\subsection{Prevention and risk - two interconnected concepts}

Prevention, especially primary prevention, relies on understanding and addressing risk of homelessness in the broader population (Edgar, Harrison et al. 2007). The importance of understanding the population at-risk of homelessness lies in its critical role in informing and guiding primary prevention policies.

Academic and policy work has outlined numerous frameworks for understanding prevention (e.g. Apicello 2010). Some have distinguished between prevention and early intervention (Pawson 2007); universal, selected and indicated prevention (Shinn, Baumohl et al. 2001); and, borrowing from the health sciences, primary, secondary and tertiary prevention (Busch-Geertsema and Fitzpatrick 2008; Culhane, Metraux et al. 2011; Gaetz and Dej 2017; Parsell and Marston 2012). In this research, we draw on Gaetz and Dej's (2017) definition of, and framework for, homeless prevention.

Gaetz and Dej (2017) define homeless prevention as:
... policies, practices, and interventions that reduce the likelihood that someone will experience homelessness. It also means providing those who have been homeless with the necessary resources and supports to stabilize their housing, enhance integration and social inclusion, and ultimately reduce the risk of the recurrence of homelessness ( $p 35)$.

They draw on the public health model of prevention, which distinguishes between primary, secondary and tertiary prevention, with these three types of prevention existing on a continuum of proximity to actual homelessness.

Primary prevention involves universal programs or interventions for whole communities as well as targeted interventions for at-risk groups. These interventions address the broader contextual factors that make homelessness more likely such as poverty, family violence and child abuse, discrimination and inequality, lack of affordable rental housing, low social security payments, chronic ill health and disability, addiction, and gaps in the social safety net. Recent examples of policies aimed at preventing homelessness have occurred during the COVID-19 pandemic where additional supplements were given to those who were unemployed and receiving income support payments. A number of states and territories also placed moratoriums on evictions from rental properties. Such interventions aim to reduce the risk of homelessness among key target groups and the population in general and 'strengthen protective factors' (Gaetz and Dej 2017: 36), increase access to supports and improve housing stability. This is done to reduce the number of people who ever become homeless in the first place. Because of its focus on communities and the general population, primary prevention initiatives will benefit those at-risk as well as some people who may have never experienced homelessness without such interventions.

Secondary prevention is targeted to those at imminent risk of homelessness or those who have only just become homeless and could also be referred to as early intervention. Secondary prevention interventions aim to stabilise a person's housing situation or to rapidly rehouse those that have lost their housing. Much of the work done by the SHS sector for those at-risk of homelessness falls under the banner of secondary prevention or early intervention. For example, work to identify people at imminent risk of homelessness (Department of Communities (WA) 2020; Department of Human Services (VIC) 2010; NSW Government 2019), preventing exits into homelessness from institutions, supporting at-risk tenancies in the private rental market and in social housing as well as ongoing tenancy support programs.

Tertiary prevention aims to reduce the recurrence of homelessness. This means providing long-term housing solutions and the necessary supports for that housing to be maintained. For example, by providing permanent supportive housing to people experiencing chronic homelessness or social housing for other cohorts in the homeless population. ${ }^{2}$

2 Gaetz and Dej (2017) are also clear about what prevention is not. They argue that whilst someone is in a state of homelessness, interventions cannot be said to be preventing that homelessness. It is not the provision of crisis responses and material aid, providing supports for alcohol and other drugs and mental health for people currently experiencing homelessness, or expanding existing crisis accommodation and refuge options. While critical and valuable interventions these are not part of the spectrum of prevention activities. 
Primary prevention, implementation and evaluation strategies cannot be effectively developed or implemented without knowledge of the population at-risk at national and local levels. The data developed for this research provides policy makers and service providers with a base-level understanding of the at-risk population's spatial distribution and preliminary information about the varying profile of those at-risk.

\subsection{Australian homelessness policy and prevention}

This section provides a brief overview of homelessness prevention policy in Australia.

For more than 50 years, SHS in Australia have been funded through multi-year joint Australian, state and territory government agreements. The most recent iteration of this agreement commenced in 2018 and is valid for five years -the National Housing and Homelessness Agreement (NHHA) (Commonwealth of Australia 2017). The NHHA requires each state and territory to develop a homelessness strategy that outlines how it will address and reduce homelessness. Services are then provided by non-government organisations who are contracted by state and territory governments.

Funding for services includes the provision of short and medium-term accommodation (including crisis accommodation, family violence and youth refuges and transitional housing) as well as support in the form of case management. The NHHA also funds social housing and other housing related programs in each state and territory.

The NHHA aims to prevent and address homelessness and improve access to affordable, safe and sustainable housing across the housing spectrum (Australian Institute of Health and Welfare 2020). The NHHA also outlines three key policy reform areas to be addressed within each state and territory homelessness strategy:

- achieving better outcomes for people

- early intervention and prevention

- evidence-based service and program design.

Early intervention and prevention is a key reform area in the NHHA. It was also one of three key strategies in The Road Home (2008) - Australia's first national policy framework for homelessness. Prevention of homelessness is a key focus in most state and territory homelessness strategies (see for example Department of Communities (WA) 2020; Department of Human Services (VIC) 2010; Government of SA 2019; NSW Government 2019) and in homelessness policy internationally (Department for Communities and Local Government (England) 2012; Parsell and Marston 2012; United States Interagency Council on Homelessness 2010).

However, despite its importance in reducing overall homelessness, most of the work undertaken in Australia under the banner of prevention is early intervention. The area with perhaps the most success has been youth homelessness where early intervention efforts, such as the long running program Reconnect, have worked to prevent or quickly address youth homelessness (Mission Australia 2016). However, these efforts have largely fallen under the purview of youth policy rather than homelessness policy more broadly. Generally, SHSs remain largely focussed on crisis responses once someone becomes homeless (Spinney, Beer et al. 2020). SHSs are funded to work with both those experiencing and those at-risk of homelessness, However, the 'definition' of 'atrisk' proposed for use in SHS in Australia (Australian Institute of Health and Welfare 2013:8-9) is simply a list of 19 risk factors that varies from staying in a boarding house, to experiencing financial stress.

Recently there have been significant calls to reorient the homelessness services system (which comprises mainstream agencies as well as SHS) away from crisis responses toward a focus on prevention and early intervention (e.g. Spinney, Beer et al. 2020). However, it is uncertain how prevention can be successful when it remains unclear how risk of homelessness should be defined and who precisely should be considered at-risk. 
In summary, despite the focus on prevention in numerous policy documents at multiple levels of government, progress toward prevention has stalled due to the significant gap in knowledge about the population at-risk of homelessness. This research project provides policy makers and service providers with base-level data on the incidence of homelessness risk, spatial distribution of the at-risk population, and profiles of personal characteristics associated with homelessness risk.

\subsection{Summary and structure of the report}

The report proceeds as follows. In the next chapter (Chapter 2 ) we describe the data sources and spatial units used in this report. We also provide a brief overview of different approaches to understanding risk of homelessness in the Australian and international literature, describe the definition of homelessness risk used in the present study, and describe how we operationalise risk of homelessness in HILDA.

Chapter 3 provides a detailed explanation of our approach to Small Area Estimation (SAE). Here we detail the two approaches used to produce small area estimates in this report, including model specification, as well as the highlighting the various strengths and weakness of these approaches.

In Chapter 4 we present the main empirical results. We compare estimates of the population at-risk at the Australian, state and territory government levels and provide a detailed analysis at the SA3 and SA2 level for greater capital cities. We also provide a detailed profile of the national population at-risk of homelessness and describe variations in the profile of those at-risk between states and territories and smaller areas.

The report concludes with a discussion of the implications for policy on primary prevention and discuss the implications of our empirical approach for the use of small area estimation and the need for improved data collections. 


\section{Data sources, spatial units and operationalisation of risk}

- This research combines data from the Household, Income and Labour Dynamics in Australia (HILDA) survey, waves 16 and 17, and the 2016 Census of Population and Housing to produce Small Area Estimates (SAE).

- We produce Small Area Estimates of the population at-risk of homelessness in Australia at the ABS Census geographies of SA2 and SA3

- There are multiple approaches to understanding risk of homelessness in the literature - the most common being the risk-factor approach and the pathways approach. However, none provide a clear definition of homelessness risk.

- We apply the Batterham (2019a) definition of homelessness risk in the present study, which considers someone at-risk of homelessness if they are residing in rental housing and exhibit at least two of the following: low-income; vulnerability to discrimination; low social resources and supports; needing support to access or maintain a living situation; and a tight housing market context.

- In wave 16 of HILDA (for the year 2016) 2,453 people or 13.9 per cent of responding persons meet the criteria for being at-risk of homelessness. This operationalisation excludes people currently living in owneroccupied housing. This remains an area for further research. 


\subsection{Small area spatial units}

'Small areas' in this research are defined using spatial units from the Main Structure of the ABS Australian Statistical Geography Standard (ASGS). Small Area Estimates of the population at-risk of homelessness are produced at the ABS defined spatial scales: SA2 and SA3. SA2s typically have a population ranging from 3,000 to 25,000 persons and can be thought of as analogous to a suburb or small group of related suburbs. SA3s are an aggregation of SA2s and have a population ranging from 30,000 to 130,000. In urban areas, SA3s closely align to an area serviced by a major transport and commercial hub while in regional areas, they represent the areas serviced by regional cities. In outer regional and remote areas SA3s have similar social and economic characteristics and are recognised as having a distinct identity (Australian Bureau of Statistics 2018a).

Certain SA2S and SA3s are excluded from the analysis due to low, and out-of-scope populations. Specifically, those coded: 'other territory'; 'migratory-offshore-shipping'; and 'no usual address'. When reporting results below the state and territory level (i.e. at small areas) SA2s and SA3s with populations below 500 were also excluded. ${ }^{3}$

\subsection{Data sources}

To produce Small Area Estimates of the population at-risk of homelessness this study draws on two secondary data sources the HILDA panel survey; and the 2016 ABS Census of Population and Housing. The HILDA Survey is a nationally representative survey sample, but only enables construction of at-risk measures at the national, and to an extent, state and territory level. Census data is available at finer spatial levels, but do not contain detailed information on all risk factors, or the complex intersection between them among individuals. Through the use of two different small area estimation techniques, we combine data from these two sources to estimate risk of homelessness at the small area level.

\subsubsection{Household Income and Labour Dynamics in Australia (HILDA) survey}

The HILDA Survey is a nationally representative longitudinal household panel survey that has followed a sample of people at annual intervals since 2001. The survey covers a range of topics necessary for identifying homelessness risk including: income; housing; health; social connections and supports; household change and formation; and other background and lifestyle items (Summerfield, Freidin et al. 2016:2). HILDA 2016 samples some 17,694 individuals in 9,750 households across Australia (excluding remote and sparsely populated areas) (Wilkins and Lass 2018). The basic sampling unit is the household, using a multistage stratified approach (Watson and Wooden 2002). Households were randomly sampled within 22-34 dwellings, in 488 collection districts (1996 basis), stratified by state and territory. Watson and Wooden (2002) provide detailed information on the sampling procedures for HILDA.

While all members of the selected households in HILDA are counted through the household questionnaire, only those aged 15 years and over are asked to complete additional questionnaires (person questionnaire and self-completion questionnaire). These people are referred to as 'responding persons' in HILDA. The specific information required to operationalise risk is only collected for responding persons, and so our risk estimates in this study are only available for those aged 15 years and over. The HILDA survey includes a selection of weights that account for sample selection and non-response as well as those that enable generalisation to the national population. The responding person population and scaled sample weights were used in this project. Wave 16 of the HILDA survey was analysed in this research because it includes data collected in 2016 - the same year as the most recent release of Census data. Some additional items were taken from wave 17 (2017) as they collected data on substance use and mental health that were not available in wave $16^{4}$.

3 A small number of SA2s and SA3s have populations below 500. These are typically larger areas without a permanent population (e.g. airports), sparsely populated areas resulting in geographic areas too large to be a meaningful unit, isolated geographic areas (e.g. islands), and areas designed to avoid arbitrary subdivision (www.abs.gov.au). Given the special status or geographically less meaningful nature of these units they have been excluded. In mapping these results the SA2 level output is only mapped for capital cities. Other areas are mapped by SA3.

4 Additional waves of HILDA were not used as our main focus was to match with the timing of the Census. Given that the model fit for the unit level models is quite good for this type of model, we don't believe a larger sample size across multiple waves would improve the model fit. 
The survey nature of HILDA raises two issues for this research. First, HILDA does provide detail on household or persons location down to SA1 level5. However, the sample sizes, even at SA2/SA3 level, are often small, which results in direct estimates of the at-risk population becoming imprecise and subject to considerable variability. Second, HILDA is a nationally representative sample, but households/persons are not sampled across every SA2/SA3. For some areas, therefore, direct estimation of the at-risk of homelessness population is not possible. This is particularly the case in remote and sparsely populated areas, which are excluded from the sampling frame all together. For instance, most of the NT is not sampled, except for Darwin and four smaller urbanised areas (Watson and Wooden 2002). WA, SA and QLD are similarly affected by non-sampling in remote areas. The non-sampling of sparsely populated and remote areas presents a challenge with respect to estimating the at-risk of homelessness population, since the population within more urbanised locations, such as Alice Springs, cannot be assumed to be representative of the population outside these urbanised areas. The estimation of the population at-risk in these areas is, therefore, entirely reliant on the predictive ability of the SAE modelling. Figure A2 in Appendix 2 illustrates the SA2 level sampling coverage of HILDA.

\subsubsection{Census of Population and Housing}

Due to the spatial limitations of HILDA data, we also draw upon area-level data from the 2016 Census of Population and Housing. Census data was extracted at both the SA2 and SA3 level using the TableBuilder portal, an online tool developed and supported by the ABS to allow users to extract customised tables of Census variables at a range of spatial scales. A suite of data items were extracted including: household income; household type; age; gender; education; country of birth; Indigenous status; labour market engagement and employment; disability; volunteering and care work; and internet access. These variables were then included in the area-based SAE models (see Chapter 3 ).

There are limits to the number and type of variables that can be combined at smaller spatial scales in TableBuilder. Consequently, customised data were also obtained from the ABS for use in the unit-based SAE approach. Filters were applied to ensure that only those aged 15 years and over were included (matching the HILDA sample); and that overseas visitors were excluded. Further, because some of the data items were sourced from the 'Place of Enumeration' Census count (rather than 'Place of Usual Residence') it was necessary to exclude any visitors to a dwelling and include only those persons who were 'at home' on Census night, reducing the population to 17,994,437 people. Table 4 in section 3.1 lists the variables and definitions of this customised data set.

\subsection{Identifying those at-risk of homelessness}

\subsubsection{Conceptualising homelessness risk}

There is a growing body of Australian research on homelessness, including the spatial distribution of homelessness (Parkinson, Batterham et al. 2019; Wood, Batterham et al. 2014; Wood, Batterham et al. 2015). However, the body of work examining the risk of homelessness is comparatively less prolific, both in Australia and internationally.

The prevailing 'consensus' view is that homelessness is caused by the interaction of individual characteristics, behaviours and experiences (such as poverty, substance abuse issues, mental ill health and family violence) and broader structural risk factors (such as housing and labour markets) (Fitzpatrick and Christian 2006; Lee, Tyler et al. 2010; O'Flaherty 2004; Pleace 2000). Yet there remains a lack of clarity about how precisely individual and structural level causes interact to produce risk.

Most commonly, a person is considered at-risk of homelessness if they have one or more characteristics, behaviours or experiences that are overrepresented in the homeless population (Bramley and Fitzpatrick 2017; Fertig and Reingold 2008). For example, having low educational attainment, being an Indigenous Australian, or experiencing family violence (Commonwealth of Australia 2008; Scutella and Johnson 2012). Studies working within this paradigm

5 SA1s are the smallest Census spatial unit for which cross-tabulated Census variables are available. They have an average population of 400 persons. https://www.abs.gov.au/websitedbs/D3310114.nsf/home/Australian+Statistical+Geography+Standard+(ASGS) 
typically estimate the probability of experiencing homelessness given a particular characteristic, behaviour or experience. Some studies also quantify the impact of housing and labour market conditions in local areas (e.g. Parkinson, Batterham et al. 2019; Wood, Batterham et al. 2015), or the combination of both individual-level and area-level factors (Bramley and Fitzpatrick 2017; Johnson, Tseng et al. 2015). A recent report by Lester and Faulkner (2020) takes a different approach and argues that homelessness risk should be understood as housing stress and examines the characteristics of older women in housing stress to work back to the causes of homelessness risk. This data-driven approach is useful for generating lists of risk factors but does not outline the number and combination of risk factors that would be required for someone to qualify as at-risk of homelessness, nor does it articulate a causal story as to why these individuals should be considered at-risk.

The pathways approach overcomes some of the drawbacks of the risk factor approach by providing more detailed insights into the causal pathways particular cohorts follow into homelessness. Using this approach, particular pathways (including trigger events) are articulated for specific cohorts, with those deemed to be on one of these pathways considered at-risk. This has been a common approach to understanding and addressing youth homelessness in Australia (Mission Australia 2016). However, in some cases pathways have been reduced to trigger events alone, for example, those exiting an institution or women experiencing domestic violence (Commonwealth of Australia 2008). Despite showing promise, the pathways approach has not led to a way to define the population at-risk of homelessness overall.

Two Australian studies have developed indices of relative risk for homelessness (Beer, Baker et al. 2019; D'Souza, Tanton et al. 2013). These studies produce a score, either for individuals or for areas, which indicates higher or lower risk relative to each other. When applied to areas, this approach can give a sense of areas with higher or lower risk of homelessness, however, neither study clearly defines what is meant by risk of homelessness. Further, risk is always relative using this approach and no threshold or cut-off-point has been articulated at which a person is considered to be part of the population at-risk of homelessness.

In contrast, Batterham (2019a; 2021) took a conceptual approach and proposed a definition of homelessness risk that connects the broader causes of homelessness, and the mechanisms through which they act, to the concept of risk. In effect, Batterham argues that the mechanisms that are common to multiple causes of homelessness should be taken to indicate risk of homelessness. She articulated seven types of causes for homelessness: housing markets; labour markets and economic capital; institutional (organisations); health and wellbeing; relationships; past experiences of homelessness; and social stratification and inequalities. Then, after reviewing the international literature on homelessness, identified five key mechanisms through which these broader causes act to bring about homelessness.

These five mechanisms include:

- low-income

- vulnerable to discrimination

- low social resources and supports

- needing support to access or maintain a living situation

- a tight housing market.

Based on how the causes of homelessness intersects to produce risk, Batterham (2019a) argues that a person must have two or more of these five mechanisms to be considered 'at-risk'.

Using HILDA survey data, Batterham (2021) operationalised the first four of these five risk mechanisms-excluding a tight housing market. She estimated that 7.9 per cent of people aged 15 years and over, just under 1.5 million people, were at-risk of homelessness in Australia in 2015. In this report, all five risk mechanisms are operationalised to estimate the population at-risk at national and local levels. 
Following Batterham (2021), two additional steps are undertaken in this research to refine the definition of who is at-risk: household composition is considered; and those living in owner-occupied households are excluded. The details of these refinements, as well as the specific operationalisation of each risk mechanism is described in detail in the next section.

In the Australian context, only one previous study has examined the geography of homelessness risk. D'Souza, Tanton et al. (2013) used microsimulation techniques to construct an index of risk of homelessness (with values ranging from 1-5) at Statistical Local Area (SLA) level (2006 Census geography). The current research extends this work in three important ways. First, Batterham's (2019a) definition of 'at-risk' identifies people with a particular intersection of characteristics (two or more) across five key areas, rather than the presence of one particular characteristic. Second, this project obtains finer spatial estimates (SA2, in addition to SA3s) based on more recent data. Third, the project produces an estimate of the rate of homelessness risk, that is, the number of people at-risk of homelessness per head of population. This further enables direct comparison with the distribution of homelessness which is also expressed as a rate.

\subsubsection{Operationalising homelessness risk}

Below we describe how each of the five key mechanisms outlined in Batterham's (2019a) definition have been operationalised in the present study, along with exclusionary criteria. As mentioned, the specific information required to operationalise risk is only collected for responding persons in HILDA, and so our risk estimates only apply to those aged 15 years and over.

\section{Low-income}

Household income information in the 2015-16 ABS Survey of Income and Housing (Basic CURF) was used to define 'low-income' for this study. ${ }^{6}$ Low-income households are defined as those with incomes in the bottom 20 per cent of the equivalised disposable household income distribution of their region (see below), excluding households in the lowest two percentiles unless their main source of income was government pensions and allowances. This broadly follows the ABS approach (Australian Bureau of Statistics 2017), differing only in that households in the lowest two percentiles are included if their main source of income was government benefits. Other households in the bottom two percentiles often have wealth and expenditure characteristics that do not reflect low levels of economic wellbeing (Australian Bureau of Statistics 2017) and are thus excluded. The 2015-16 survey was used, as it aligns best to the 2016 Census.

To account for the variation in household income levels between capital cities and the rest of state areas, lowincome cut-off points were calculated for each of these regions. Namely, for eight greater capital city statistical areas (GCCSAs) and for six balance of state areas, with the ACT and the NT treated as whole GCCSAs due to data availability in the Survey of Income and Housing. These quintile values calculated in the survey were then used in the HILDA data to identify people within low-income households.

\section{Vulnerable to discrimination}

This risk mechanism indicates whether a person is vulnerable to discrimination in the housing or labour market. Characteristics that were included in this risk mechanism were: being young (Australian Institute of Health and Welfare 2015; Batterham 2012; Wood, Batterham et al. 2015); being an Indigenous Australian (Australian Bureau of Statistics 2012; Australian Institute of Health and Welfare 2015; Batterham 2012; Wood, Batterham et al. 2015); being a single parent (Australian Institute of Health and Welfare 2015; Batterham 2012); or being on income support payments (Johnson, Tseng et al. 2015; Walsh 2011). Only those who were on income support but did not qualify as low-income were included in this category as low-income is captured separately.

6 CURF stands for Confidentialised Unit Record Files. 
People who are lesbian, gay, bisexual, transgender or intersex (LGBTI), are argued to experience both discrimination and homelessness at higher rates. However, the research evidence on LGBTI overrepresentation in the homeless population is in its infancy (Durso and Gates 2012; McNair, Andrews et al. 2017; Ray 2006). Discrimination in the Australian labour market has been documented for people from non-English speaking backgrounds (Blair, Dunn et al. 2017), and it seems plausible that they may also experience discrimination in the housing market. Finally, there are multiple definitions of youth or young people. The age range of 15-24 years was selected for this study and is consistent with the AlHW's reporting on young people who access specialist homeless services (Australian Institute of Health and Welfare 2020), and the statistical definition of youth used by the United Nations ${ }^{7}$.

Low social resources and supports

Batterham (2019a) suggested that limited social resources and supports could be due to:

- recent separation from a long-term partner

- death of a spouse or child

- a social network that lacks the capacity to provide material support-specifically financial but ideally also accommodation or childcare

- a very small or non-existent social network that does not provide sufficient emotional support and connection.

To operationalise this concept the four items listed above were created and a person was considered to have low social resources if they were experiencing two or more of these factors.

Experiences of homelessness, as well as longer durations of homelessness, are associated with feelings of isolation and not having someone to lean on (Chigavazira, Johnson et al. 2013; Chigavazira, Johnson et al. 2014; Scutella, Johnson et al. 2012). Further, Johnson and Tseng (2014) found that people experiencing primary homelessness were more likely to report having no friends and having no or limited contact with family. To determine a very small or unsupportive social network, we followed the approach used in (Wilkins and Lass 2018). This approach uses 10 items to assess the quality of a person's social networks. Once half of these items were reverse scored, they were summed and divided by 10 . If a person received a score of five or more, they were deemed to have a small or unsupportive social network.

A social network was deemed to lack the capacity to provide material support if a person could not borrow $\$ 2,000$ $-\$ 3,000$ from a friend or relative or, if they had children, did not receive any assistance with childcare from family friends or neighbours.

Specific items were available in HILDA indicating a recent separation from a long-term partner and the death of a spouse of child.

Needs support to access or maintain a living situation

Batterham (2019a) also argued that the key factors that may lead someone to require support to access or maintain a living situation include:

- having a disability or long-term health condition (including a cognitive disability)

- having a mental health issue

- having problematic drug or alcohol use.

While each of these characteristics or behaviours may also lead to discrimination, for clarity, they have been measured only in this category.

7 https://www.un.org/esa/socdev/documents/youth/fact-sheets/youth-definition.pdf 
Problematic drug and alcohol use was the most difficult of these to operationalise. As Spooner and Hetherington (2004) note, what constitutes problematic drug use is contestable. Some argue that any illicit use is problematic while others see use that does not have any other negative consequences - apart from being illegal-as unproblematic.

The National Drug Strategy (Commonwealth of Australia, Department of Health, 2017: 10) argues that a range of factors impact on whether the use of substance is harmful to the user, including: the amount used and the frequency of use; the method of consumption; the context of the use; and how these interact with other individual factors such as age and existing health conditions. Because of this, no specific guidelines are available to indicate whether someone's use of a substance can be considered problematic based on frequency and amount of use.

According to the Australian Institute of Health and Welfare (2017) consuming more than four standard drinks on any occasion, and doing this at-least once a month, increases the risk of alcohol related harm. As such, we operationalised problematic alcohol use as usually consuming five to six standard drinks or more when drinking, and drinking more than once a month. Problematic use of illicit substances was operationalised as weekly use-apart from cannabis, which was deemed problematic when used daily.

Items from HILDA waves 16 and 17 were used to operationalise problematic substance use as frequency of use variables were only collected in wave 17.

Specific items were available in HILDA measuring the presence of long-term health conditions, cognitive disability and mental health issues.

Tight private rental market

The fifth mechanism in the Batterham (2019a) definition is a tight rental market. This could mean unaffordable rental housing, low vacancy rates or an undersupply of rental dwellings. We believe it is not just the overall state of the private rental market that is relevant, but in particular, the conditions in the private rental market for lowincome households. As such, we operationalised living in an area with a tight rental market using a measure of rental stress: the 30/40 rule (Yates and Gabriel 2006). Consistent with the practice for determining low-income, equivalised disposable household income quintiles were derived separately for each greater capital city and balance of state area and the bottom two per cent of the income distribution was excluded from calculations. Once those households with incomes in the bottom 40 per cent of the income distribution were identified, their weekly rent was divided by their gross household weekly income. Those who were spending more than 30 per cent of this income on rent, and who were in the bottom 40 per cent of the income distribution of their region, were classified as in housing stress.

Table 1 details the number and per cent of observations in HILDA with each of the five risk mechanisms and their component parts.

Table 1: Descriptive statistics, individual risk factors for responding persons, HILDA survey, waves 16 and 17

\begin{tabular}{|c|c|c|}
\hline & \multicolumn{2}{|c|}{ HILDA } \\
\hline & \multicolumn{2}{|c|}{ Total obsv $=17,693$} \\
\hline & $n$ & $\%$ \\
\hline \multicolumn{3}{|l|}{ 1. Low-income } \\
\hline Individuals in low-income households & 2,586 & 14.6 \\
\hline \multicolumn{3}{|l|}{ 2. Discrimination characteristics } \\
\hline Youth & 3,017 & 17.1 \\
\hline Indigenous & 532 & 3.0 \\
\hline Single Parent & 1,061 & 6.0 \\
\hline
\end{tabular}




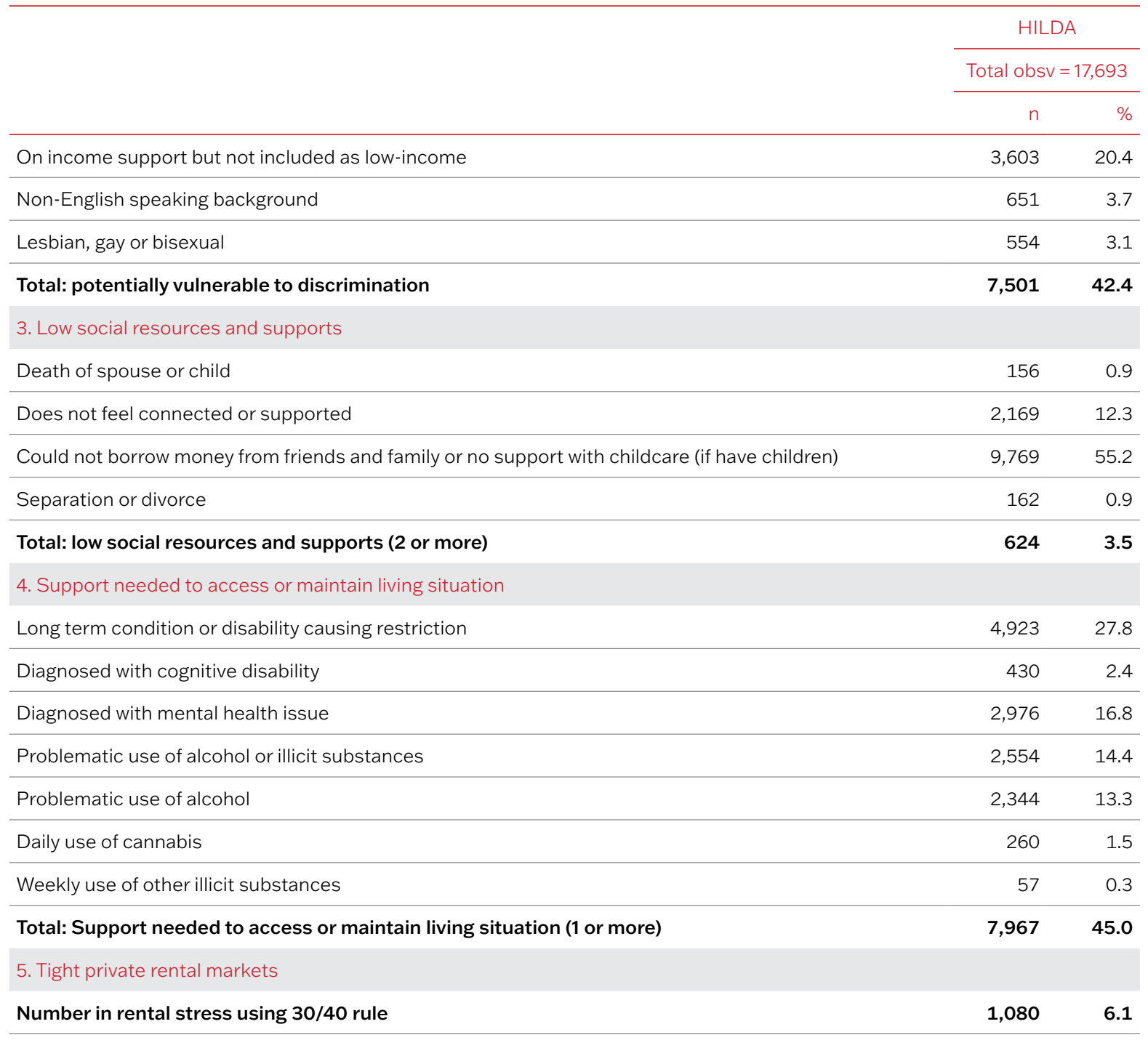

Source: Author's calculations derived from HILDA survey, waves 16 and 17.

\section{Exclusionary criteria}

We followed Batterham (2021) and excluded those living in owner-occupied housing from the risk measure. There is evidence to suggest that for some, owner-occupation is precarious and some exiting the tenure do not return (Ong, Wood et al. 2015; Wood, Smith et al. 2013). Indeed Ong, Wood et al. (2015: 2,992) note that 'unfavourable biographical events' such as separation or death of a spouse, unemployment, disability or long-term health problems were important for understanding those who lost home ownership who were subsequently dependent on housing assistance. These are important aspects of the at-risk definition. However, in most cases home ownership (whether outright or with a mortgage) provides a level of insurance (Stone, Sharam et al. 2015) that may slow (Wiesel 2014) or prevent a transition into homelessness. Once someone exits home ownership, perhaps following a separation or divorce, they are then eligible to be considered at-risk.

Dwelling tenure, including owner-occupation, is applied to all members of a household residing in a dwelling. This means, for example, that young people living in the parental home would be classed as residing in an owner -occupied household (if their parents owned the dwelling) and so excluded from being at-risk of homelessness. 


\section{Accounting for household composition}

Relationships between people in a household can provide a buffer against individual-level risk (Bramley and Fitzpatrick 2017; Johnson, Tseng et al. 2015). For example, if one adult in a couple family household qualifies as at-risk of homelessness, but their partner does not, they should be thought of as having a lower level of risk than someone in a lone person household or a single parent. The relationships within multi-adult households may provide some level of protection.

To account for household composition all responding persons were grouped according to household type, which was simplified into four main categories: couple households, single parent households, lone person households (including group households) and extended family households. If either lone persons or single parents qualified as at-risk by having two or more of the five risk components, they retained their risk status. If responding persons in a couple household or extended family grouping were deemed at-risk of homelessness, they only retained their at-risk status if another member of their household was also deemed at-risk of homelessness.

Initially, 5,795 responding persons were identified as at-risk of homelessness. This was reduced to 2,850 after those living in owner-occupied housing were excluded from the sample. It was then reduced further to 2,453 responding persons at-risk of homelessness after accounting for household composition.

Table 2 provides a summary of the number of people at-risk of homelessness as well as the number of risk mechanisms present among those considered at-risk. The percentage of those considered at-risk is calculated from the total number of responding persons in wave 16 of HILDA $(n=17,693)$, while the percentage of persons with different numbers of risk mechanisms is calculated from the number of responding persons deemed at-risk of homelessness.

Table 2: HILDA waves 16 and 17 initial incidence of risk factors, counts and per cent

\begin{tabular}{lrr}
\hline Incidence of risk factors & Count & Percent \\
\hline $\begin{array}{l}\text { Number of those at-risk with two or more of the five mechanisms after accounting for household } \\
\text { composition }\end{array}$ & 2,453 & $13.9^{8}$ \\
\hline Number of those at-risk with 2 risk mechanisms & 1,420 & $57.9^{9}$ \\
\hline Number of those at-risk with 3 risk mechanisms & 806 & 32.9 \\
\hline Number of those at-risk with 4 risk mechanisms & 217 & 8.9 \\
\hline Number of those at-risk with all five risk mechanisms & 10 & 0.4 \\
\hline
\end{tabular}

Source: HILDA survey, waves 16 and 17.

\subsubsection{Limitations}

While we endeavoured to make our research approach and operationalisation of homelessness risk as rigorous as possible, some limitations persisted.

- Those living in owner-occupied housing were excluded from the risk definition ${ }^{10}$. As discussed, while owneroccupation provides a level of insurance against homelessness, this is unlikely to be the case in instances of family violence (including child and elder abuse). There is a conceptual issue as to how we might understand the connection between family violence and homelessness. Using the definition of homelessness developed by the ABS, someone experiencing family violence is not considered homeless until they leave the family home.

8 This percentage calculated from the total number of responding persons in wave 16 of HILDA $(n=17,693)$

9 Percentages for the at-risk group are calculated from the total population of those at-risk in HILDA $(n=2,453)$

10 We were unable to identify and exclude households who lived in rental housing but owned an investment property. While these people could be identified in the HILDA survey, they could not be identified within Census data and so for consistency reasons were kept in We assume that these households are unlikely to qualify as low-income. 
However, others have argued that experiences of violence and abuse in the home constitutes a form of homelessness in and of itself (Batterham 2019b) regardless of a person's housing situation. The estimates of risk presented in this report do not include family violence in their conceptualisation. Depending on whether one considered family violence a form of homelessness, this could be considered a limitation of the present work.

- The overall definition of risk and to an extent, our operationalisation, does not include any ranking or priority to the five risk mechanisms. This is despite existing international research highlighting the importance of poverty (specifically low-income) in precipitating homelessness (e.g. Bramley and Fitzpatrick). More research is definitely needed in relation to this and was also noted by Batterham (2019a). However, our operationalisation of the 'tight housing market' mechanism is based on the 30/40 rule for housing affordability and so includes household income and provides additional weight to the role of low-income in homelessness (albeit at the 40th rather than 20th percentile).

- A drawback of the HILDA survey is that it does not include items measuring experiences of homelessnesshampering efforts to assess transitions between risk and homelessness and the factors driving these transitions.

- Because we relied on the detailed information available for only responding persons in HILDA, our estimates of the at-risk population are only for those aged 15 years and over. More work is needed to examine how children can be included in estimates of homelessness risk.

The next chapter details our approach to small area estimation which is used to convert the measure of homelessness risk developed in HILDA into estimates of risk at the small area level. 


\section{Small Area Estimation technique}

- Small Area Estimation methods combine survey data and auxiliary data from additional data sources (such as Census or administrative data) to improve the precision of indicators derived from the survey data. This technique is used by many statistical agencies to produce area-level statistical information.

- There are a number of SAE techniques. These can broadly be categorised as unit-level and area-level models. Unit-level models make use of unit records, such as person or household records in both survey and auxiliary data. Area-level models, on the other hand, only require area-level auxiliary data.

- Many statistical agencies make Census and area-level data available through their web-portals but place greater restrictions on unit-record data. As a result, area-level models are frequently used in applied research.

\footnotetext{
In Australia, there is no official definition of homelessness risk, nor is information collected specifically for the purpose of identifying the population at-risk of homelessness. As discussed, Batterham (2019a) provides a conceptual approach to defining someone at-risk of homelessness. As described in Chapter 2, this definition can be operationalised in HILDA to produce a direct estimate of homelessness risk in Australia.
}

Each respondent in the HILDA survey data can be coded as either 'at-risk' or 'not at-risk' of homelessness, giving a binary variable $[0,1]$. At the national and state level, an at-risk measure can then be generated by simply aggregating the number of respondents that are identified as at-risk for each area and applying the supplied population weights. This indicator can be generated using only the data from the HILDA survey. At finer spatial scales, however, the precision and coverage of HILDA-based estimates become more unreliable due to small sample sizes and incomplete spatial coverage.

For instance, the HILDA sampling frame excludes those living in sparsely populated and remote areas (see Appendix 2 for a visual depiction of the areas sampled in HILDA in 2016). As a result, much of central and remote Australia was not sampled. From a policy and recognition perspective, these are also parts of Australia that are of particular interest and importance to Indigenous communities.

At the same time, the at-risk indicator cannot be established using only Census or other administrative data sources due to a lack of detailed respondent information, even though these data sets are available for small areas. Therefore, to provide estimates of homelessness risk in small areas across Australia (RQ1) the research employs Small Area Estimation techniques. 
SAE is concerned with generating area-based statistics or indicators where direct measurement is not feasible (for instance due to lack of geographic coverage), or where the precision of direct estimates is limited because of small sample sizes. SAE is based on combining information from survey-based data (such as HILDA), with information from Census or administrative data to produce precise and reliable estimates of proportions or means at finer spatial scales. Auxiliary data can be used to model, estimate and predict the risk of homelessness for individuals themselves or for areas as a whole.

SAE models can be broadly divided into unit and area-based models (Tzavidis et al. 2018). Unit-level models are based on unit record observations, such as individuals or households, in both survey and auxiliary data. Area-level models only require area-level auxiliary data, for instance the proportion or number of people in an area with a particular socio-economic characteristic that is assumed to correlate with the statistics to be estimated. In many countries, Australia included, area-level data is more accessible than unit-record data. Hence area-level models have become popular in applied research. A frequently used area-level model is the Fay-Herriot (FH) model. This report draws on both the unit-level and area-level approach.

The primary benefit of employing two approaches is to serve as a form of robustness testing. Each approach can draw on particular strengths that are traded off against weaknesses in other aspects. Comparing the outcomes thus enables the researchers to critically assess the precision of the different SAEs.

A secondary benefit is around data requirements and the need to produce evidence-based policy in Australia. Academic, policy and private sector researchers are reliant on good quality data to produce evidence. While comprehensive, collecting detailed economic and social data through the Census is costly. Survey data, on the other hand, suffers from lack of local coverage. The two SAE techniques also serve to inform data collection in Australia, outside the Census, to enable high quality local level data.

The following diagram provides a high-level summary of the two approaches to SAE used in this report.

Figure 1: The research approach to producing small area estimates of homelessness risk

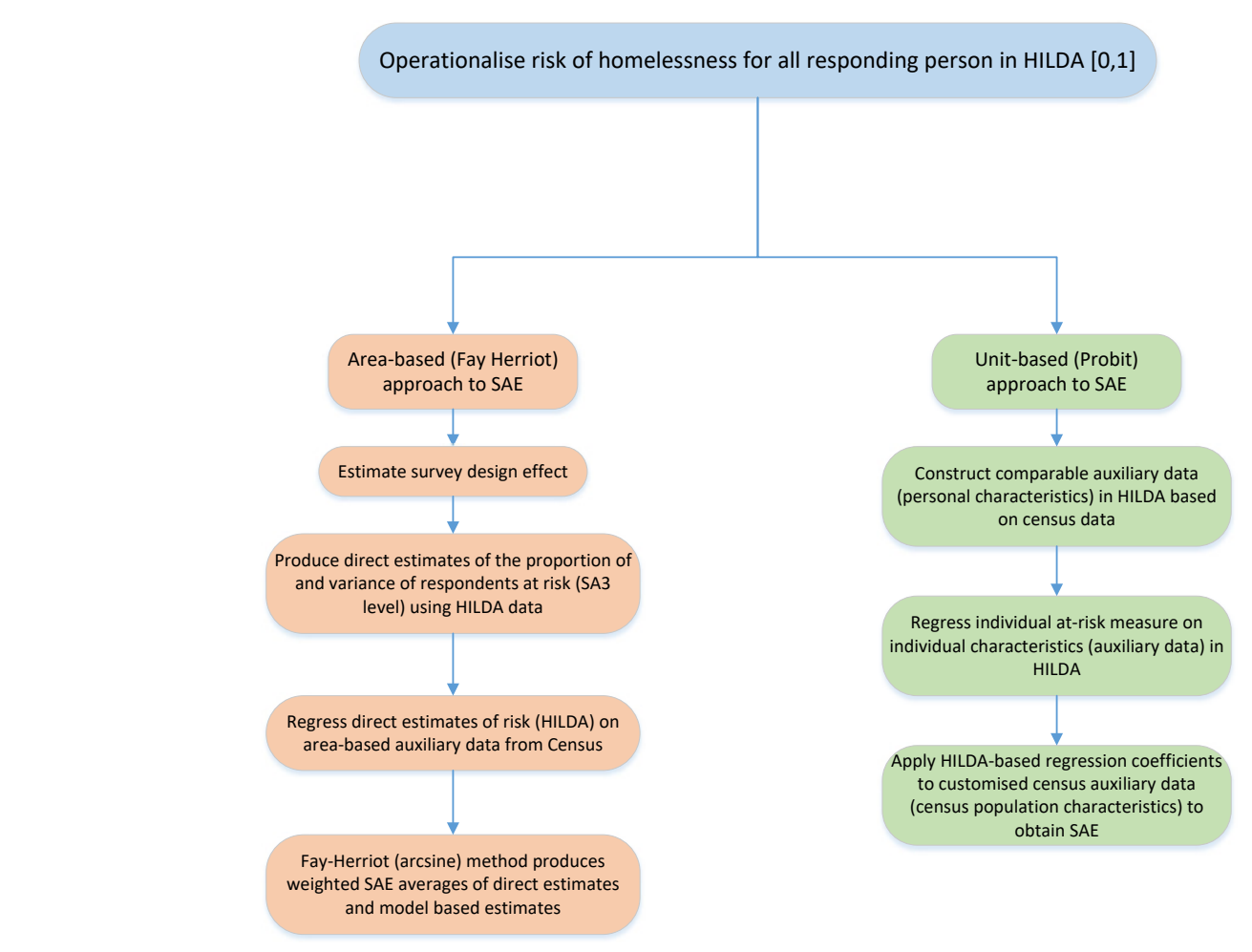

Source: Authors. 


\subsection{Unit-level model}

To produce SA2/SA3 level estimates using a unit-level model, the risk of homelessness indicator for each individual (at-risk=1, not at-risk=0) is regressed on a series of socio-economic indicators (auxiliary variables) using a discrete choice model (probit). ${ }^{11}$ Predictor (auxiliary) variables are also drawn from HILDA but constructed to match as closely as possible, equivalent categories in 2016 Census data. Variables tested include country of birth, housing tenure, household income, disability, Indigenous status, volunteer and caring work and more.

A series of probit models were run to determine the model that explained the most variance in our risk indicator (in our case pseudo $r^{2}=0.3443$ ) with the least number of variables (a parsimonious model). Probit models belong to a class of parametric regressions models. Probit coefficients measure the change a given explanatory variable has on the cumulative normal probability outcome of the at-risk measure. That is, the effect of the independent variable on the $z$-value of the at-risk measure. ${ }^{12}$ The sum of probit coefficients for a given set of characteristics can thus be converted into a probability of being at-risk for all people with the same characteristics.

The final model (Equation 1) contained seven key predictor variables (for detailed results see Appendix 1).

$$
\operatorname{Pr}\left(A T R_{i}=1 \mid X_{i}\right)=\Phi\left(X_{i}^{T} \beta\right) \quad(\text { Equation } 1)
$$

Where $P r$ is the probability that individual $i$ is at-risk $(A T R)$ of homelessness (yes=1) or not (no=0), $X^{T}$ is a vector of variables used to model ATR (usual hours worked, labour force status, household type, disability, low-income, Indigenous status, number of children ever had), $\Phi$ is the cumulative distribution function (CDF) of the standard normal distribution, ${ }^{13}$ and $\beta$ are the coefficients (effects) to be estimated (and subsequently summed).

To overcome the small sample limitations at SA2/SA3 levels in HILDA, a request for customised data from the 2016 Census was obtained from the ABS. This customised data request provided the number of people $(p)$ in each SA2/SA3 $(k)$ with each possible combination of our seven predictor variables from the final probit model. This produced a table with 128 columns (j). For each column a probability (of individual homelessness risk) was calculated based on the relevant combination of the seven predictor variables $(i j)$. Each probability was then weighted by the corresponding population share in each SA2/SA3 $\left(p_{j k} / p_{k}\right)$. The weighted probabilities were then summed for each SA2/SA3 to produce the SA2/SA3 homelessness risk measure. The per cent of the population with each of the combinations of characteristics is also used to describe variations in the profile of those at-risk in different regions (states and territories, greater capital cities and small areas) across Australia.

The unit-level model process is set out in Figure 2 below. To produce the at-risk SAE estimates, the coefficients from the probit regressions are summed for each combination of the explanatory variables. In all, this gives 128 combinations ( $j$ ). Each sum can then be converted into a probability of at-risk ranking $0-1 .{ }^{14}$ For instance, Combination $1=0.30 \ldots$ combination $2=0.04 \ldots$ combination $j=0.07$. Each combination $(j)$ is then multiplied by the corresponding SA2/SA3 level population proportion (pjk). For instance, if the proportion of people with combination $1=0.25 \ldots$ combination $2=0.35 \ldots$ combination $j=0.40$, then the risk of homelessness for this spatial unit is: $(0.30 * 0.25)+(0.04 * 0.35)+(0.07 * 0.40)=0.117$ or a rate of 1,170 per 10,000 people.

11 Probit models are used in regression where the dependent variables have two discrete outcomes - someone is at-risk (=1), or someone is not at-risk (=0). Probit models estimate the probability that someone falls into one or the other of the two categories as a function of a set of characteristics.

12 Z-values (or standardised values) describes an observed outcome relative to a mean, in terms of units of standard deviations. Z-values are related to the standard normal distribution (SND), bell shaped and symmetrical distribution with mean zero and standard deviation of one. Under the SND assumptions, 65 per cent of observations lie within 1 standard deviation of the mean, 95 per cent lie within 2 standard deviations.

13 The cumulative distribution function (CDF) of the SND describes the probability that the estimated Z -value takes a value less than or equal to its observation. Z-values are frequently used in hypothesis testing when comparing means and proportions, or in this case the probability that the effect of an explanatory variable (and the sum of the effects of the explanatory variables) is equal to zero.

14 The NORMDIST function in excel was used for this. 
Figure 2: Unit-level SAE process

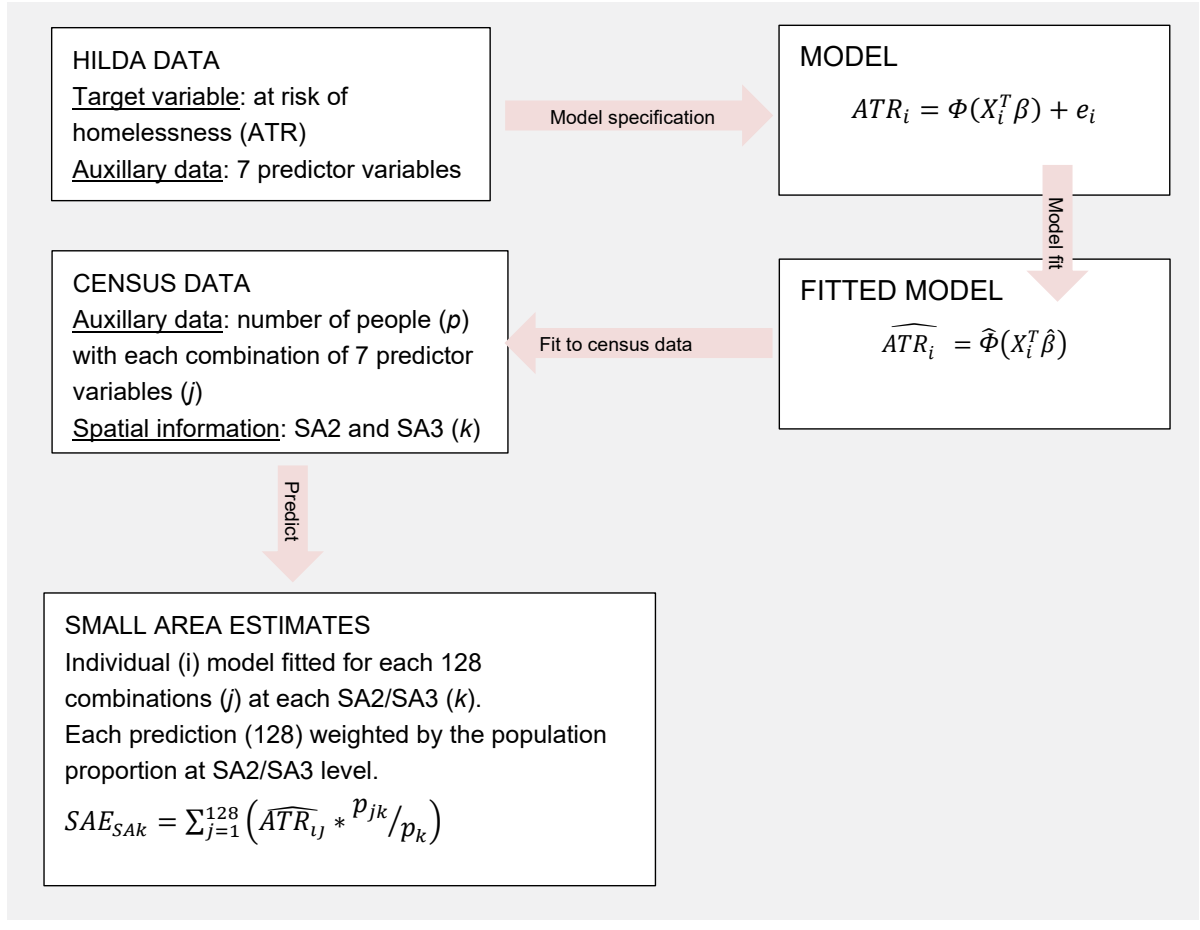

Source: Adapted from Martinez Jr (2019)

The unit-level (probit) approach is entirely model driven and uses the characteristics of those at-risk in the HILDA sample to impute levels of homelessness risk in small areas based on those characteristics. A key strength of this approach is the use of Census data, which has excellent coverage of population characteristics at the small-area level right across Australia. A drawback with this model is that neither the direct (individual) estimate, nor the model itself contains specific spatial variables. While this highlights the effect of personal characteristics and their association with homelessness risk, it does not control for (potentially) unobserved spatial variation in the importance (effect) of the personal characteristics. A particular characteristic is assumed to have the same effect in Sydney as it does in Alice Springs.

In the calculation of unit-level SAE confidence intervals of the SAEs two conventions are followed. Where estimates are aggregated to national or regional levels, the 95 per cent confidence interval (Cl) around a particular homelessness risk estimates is calculated as

$C I=A T R \pm 1.96 * \sqrt{A T R} *(1-A T R) / N$, where $N$ is the HILDA sample size at national or state and territory levels. When confidence intervals are calculated at SA2/SA3 level the regression derived 95 per cent $\mathrm{Cl}$ for each of the 7 predictors are used to calculate the upper and lower $\mathrm{Cl}$ limits. In terms of Figure 2, $\beta$ is the regression derived upper and lower (95\%) range of the coefficients, rather than the central estimate of the coefficient.

Table 3 below provides descriptive statistics for the predictor variables used to estimate Equation 1. Each of the predictor variables are measured as 1 or 0 , the mean in Table 3, therefore, provides the proportion of respondents in the HILDA sample with each of the characteristics. Table 4 provides the definitions of each of the dichotomous variables used in the unit-based (probit) models as well as the relevant population for each measure. 
Table 3: Descriptive statistics for variables used in the unit-based (probit) models

\begin{tabular}{lllr}
\hline Variable & $N$ & Mean Standard deviation \\
\hline At-risk of homelessness & 17,693 & 0.139 & 0.346 \\
\hline Housing tenure (renting, living rent free or in life tenure scheme) & 17,693 & 0.340 & 0.474 \\
\hline Usual hours worked<35/week & 17,693 & 0.589 & 0.492 \\
\hline Unemployed/not in the labour force & 17,693 & 0.376 & 0.484 \\
\hline Household type (one parent, group, lone or multi-fam household) & 17,693 & 0.298 & 0.458 \\
\hline Disability present & 17,693 & 0.038 & 0.192 \\
\hline Low household income & 17,693 & 0.309 & 0.462 \\
\hline Indigenous & 17,693 & 0.030 & 0.171 \\
\hline Number of children ever had 5+ & 17,693 & 0.040 & 0.196 \\
\hline
\end{tabular}

Source: Authors calculations, HILDA survey waves 16 and 17.

Table 4: Definition of variables used in the unit-based (probit) model

\begin{tabular}{|c|c|c|c|}
\hline Variable & Population & 1 (= has these characteristics) & $\mathrm{O}$ (= has these characteristics) \\
\hline Housing tenure & $\begin{array}{l}\text { All persons aged } 15 \text { years } \\
\text { and over not classified as } \\
\text { visitors on Census night }\end{array}$ & $\begin{array}{l}\text { - Lives in a dwelling that is: } \\
\text { - Rented } \\
\text { - Being occupied rent-free } \\
\text { - Being occupied under a } \\
\text { life tenure scheme }\end{array}$ & $\begin{array}{l}\text { - Lives in a dwelling that is owned } \\
\text { outright } \\
\text { - Owned with a mortgage } \\
\text { - Being purchased under a shared } \\
\text { equity scheme } \\
\text { - Other tenure type } \\
\text { - Not stated, Not applicable }\end{array}$ \\
\hline Usual hours worked <35/wk & $\begin{array}{l}\text { All persons aged } 15 \text { years } \\
\text { and over not classified as } \\
\text { visitors on Census night } \\
\text { and classed as in the } \\
\text { labour force. }\end{array}$ & - 34 hours or less per week & $\begin{array}{l}\text { - } 35 \text { hours or more per week } \\
\text { - Not stated } \\
\text { - Not applicable }\end{array}$ \\
\hline $\begin{array}{l}\text { Unemployed/not in the } \\
\text { labour force }\end{array}$ & $\begin{array}{l}\text { All persons aged } 15 \text { years } \\
\text { and over not classified as } \\
\text { visitors on Census night }\end{array}$ & $\begin{array}{l}\text { - Unemployed, looking for } \\
\text { full-time or part-time work } \\
\text { - Not in the labour force }\end{array}$ & $\begin{array}{l}\text { Employed, worked full-time, } \\
\text { part-time or away from work } \\
\text { - Not stated, not applicable }\end{array}$ \\
\hline $\begin{array}{l}\text { Household type (one } \\
\text { parent, group, lone or } \\
\text { multi-fam household) }\end{array}$ & $\begin{array}{l}\text { All persons aged } 15 \text { years } \\
\text { and over not classified as } \\
\text { visitors on Census night }\end{array}$ & $\begin{array}{l}\text { - One parent family } \\
\text { - Group household } \\
\text { - Multi-family households } \\
\text { (all types of two and three } \\
\text { or more family h'holds) } \\
\text { - Lone person household }\end{array}$ & $\begin{array}{l}\text { - One family household: Other } \\
\text { family, Couple family with children, } \\
\text { Couple family with no children } \\
\text { - Other non-classifiable household } \\
\text { - Not applicable }\end{array}$ \\
\hline Disability present & $\begin{array}{l}\text { All persons aged } 15 \text { years } \\
\text { and over not classified as } \\
\text { visitors on Census night }\end{array}$ & $\begin{array}{l}\text { - Has need for assistance } \\
\text { with core activities }\end{array}$ & $\begin{array}{l}\text { - Does not have need for assistance } \\
\text { with core activities, Not stated }\end{array}$ \\
\hline Low household income & $\begin{array}{l}\text { All persons aged } 15 \text { years } \\
\text { and over not classified as } \\
\text { visitors on Census night }\end{array}$ & $\begin{array}{l}\text { Living in a household with } \\
\text { less than } \$ 1250 \text { weekly } \\
\text { gross household income. }\end{array}$ & $\begin{array}{l}\text { - All other values, \$1250 and above, } \\
\text { Partial income stated, All incomes } \\
\text { not stated, Not applicable, } \\
\text { Negative income, Nil income }\end{array}$ \\
\hline
\end{tabular}




\begin{tabular}{|c|c|c|c|}
\hline Variable & Population & 1 (= has these characteristics) & $\mathrm{O}$ (= has these characteristics) \\
\hline Indigenous & $\begin{array}{l}\text { All persons aged } 15 \text { years } \\
\text { and over not classified as } \\
\text { visitors on Census night }\end{array}$ & $\begin{array}{l}\text { - Aboriginal } \\
\text { - Torres Strait Islander } \\
\text { - Both Aboriginal and Torres } \\
\text { Strait Islander }\end{array}$ & $\begin{array}{l}\text { - Non-Indigenous } \\
\text { - Not stated }\end{array}$ \\
\hline $\begin{array}{l}\text { Number of children ever } \\
\text { had } 5+\end{array}$ & $\begin{array}{l}\text { All women aged } 15 \text { years } \\
\text { and over not classified as } \\
\text { visitors on Census night }\end{array}$ & - Five or more children & $\begin{array}{l}\text { - Four or fewer children, including } 0 \\
\text { - Not stated, not applicable }\end{array}$ \\
\hline
\end{tabular}

Note: 'not stated' and 'not applicable' were included in the 0 category for our predictor variables to enable the creation of dichotomous predictors. The inclusion of a third category would have added an enormous number of additional columns to our table producing the weighted probabilities, as each possible combination of variables and their options had to be generated.

Source: ABS 2016 Census of Population and Housing.

\subsection{Area-level model ${ }^{15}$}

Unlike the unit-level model, area-level models only require area-level auxiliary data (Pfeffermann 2013, Halbmeier, Kreutzmann et al. 2019). For many Census indicators, SA2/SA3 level data is readily available from TableBuilder. ${ }^{16}$ Area-level models can then be produced by combining area-level calculations of homelessness risk and variance from HILDA with SA2/SA3 level Census data.

The SA2/SA3 level direct estimate from HILDA was calculated by dividing the number of respondents with two or more risk factors over the relevant SA2/SA3 level sample size. The rescaled cross-sectional responding person population weight was used to ensure the sample was representative of the national population. As noted earlier, small sample sizes at SA2/SA3 level make these direct estimates subject to sampling variability and imprecision.

To estimate the area-level model we use Halbmeier, Kreutzmann et al. (2019)'s 'fayherriot' command in Stata. This command implements the Fay-Herriot model (Fay and Herriot 1979). 'fayherriot' is used to produce an empirical best linear unbiased predictor (EBLUP) of the SA2/SA3 level at-risk measure based on a linear combination of the area-level direct estimator and a regression-synthetic component. By drawing on both the observed (as measured in HILDA) at-risk information, the variance of the at-risk measure, and the regression model information, the precision of direct estimates is improved.

The FH model consists of two elements: a sampling model and a linking model. In the following explanation the general $\mathrm{FH}$-model is set out. In our estimation the $\mathrm{FH}$-model is run with arcsine transformation to account for the dependent variable ranging between 0 and 1 .

The direct at-risk of homelessness measure is subject to sampling variability. The sampling model therefore assumes that the observed direct measure consists of a true value and an error component:

$$
A \widehat{T R}_{S A k}=A T R_{S A k}+e_{S A k} \quad(\text { Equation 2) }
$$

where is the direct at-risk measure calculated from HILDA at SA2/SA3 level (where $k$ is an index of SA at level 2 or 3) adjusted for sample weight, ${ }^{17} A T R_{S A k}$ is the true at-risk of homelessness indicator at SA2/SA3 level, and $e_{S A k}$ is the deviation of the observe at-risk measure from its true value (the sampling error component with mean zero and variance $\sigma_{e_{S A k}}^{2}$ ).

15 The description of the FH model draws heavily on Halbmeier, Kreutzmann et al. (2019).

16 Restrictions on cross tabulations introduced in 2020 necessitated the ABS customised data request to estimate the unit-level model.

17 The rescaled cross-section responding person population weight was used. This population weight is rescaled to sum to the number of responding persons in the relevant wave. 
In the linking model $A T R_{S A k}$ is explained by a set of area-specific covariates (variables), $X^{T}$, regression parameters, $\beta$, and a random effect, $u_{S A k}$ (that is normally (identically and independently) distributed):

$$
A T R_{S A k}=X_{S A k}^{T} \beta+u_{S A k} \quad(\text { Equation 3) }
$$

The FH combines these two elements, in a linear mixed model form (Halbmeier, Kreutzmann et al. 2019). As such, it combines information from the direct estimate (HILDA) and a predictive estimate (regression model):

$$
\widehat{A T R}_{S A k}=X_{S A k}^{T} \beta+u_{S A k}+e_{S A k} \quad \text { (Equation 4) }
$$

The FH empirical best linear unbiased predictor (EBLUP) of the at-risk of homelessness is then given by the linear combination of the estimated regression coefficients and the estimated random effect. In practice the FH SAE estimate is a weighted average of the direct at-risk measure and the synthetic at-risk estimator generated by the regression model. Each component is weighted by the ratio of the random error to the random error plus sampling error. ${ }^{18}$ The weight of the direct at-risk measure in the $\mathrm{FH}$ estimate decreases with the sampling error variance. That is, the less precise the direct estimate is (assumed to be), the less its weight in the final (combined) at-risk estimate. The 'fayherriot' command enables prediction of homelessness risk also for SA3s without any observations in HILDA. In these cases, the SAEs are entirely model-based (that is, the result of predicting an outcome from the model).

In estimating the $\mathrm{FH}$ at-risk measure, the report uses the arcsine transformation of the direct (weighted) at-risk measure. This transformation is particularly suitable for proportions that are bounded [0,1] (Halbmeier, Kreutzmann et al. 2019). The variance component $\left(\hat{u}_{S A k}\right)$ can then be approximated by $1 /(4 x$ Effective Sample). Following Lohr (2010), the effective sample is estimated by dividing the SA2/SA3 level HILDA sample size by the design effect. That is, the design effect provides a measure of how well the variance of a sample design, such as HILDA's multistage stratification, compares to the variance that would be obtained under a simple random sample.

The accuracy of the at-risk measure depends on the HILDA sample size and the effect of the sampling design (Watson and Wooden 2002). To estimate the design effect for HILDA, a wave 16 survey design (sampling plan) was created using SPSS' complex sample function based on stratification (xhhstrat), clustering (xxhraid, randomised original area id), and the responding person's population weight (hhwtrp). Design effects (and effective samples) were then produced at a range of spatial levels of aggregation. A common method of smoothing sampling variability is to use design effects calculated at higher levels of aggregation. In estimation, however, greater precision was achieved using the design effect from the corresponding SA2/SA3 level.

The area-level model process is set out in Figure 3 below.

Unlike the unit-level model, the area-level ( $\mathrm{FH}$ model) makes use of information from both the direct estimates (HILDA), which also are adjusted for the survey design effect, and the regression model components. A key strength of this approach is that with and without the inclusion of specific spatial variables, some spatial information is retained (and used). The $\mathrm{FH}$ model produces SAEs that are the weighted average of the direct estimates (which implicitly includes spatial information) and the model estimates. As per the model description in Appendix 1, the estimated area-level model also includes a greater capital city dummy that captures additional unobserved spatial heterogeneity.

18 The weighted FH estimates are: $\widehat{A T R_{S A k}^{F H}}=\hat{\gamma}_{S A k} \widehat{A T R_{S A k}}+\left(1-\hat{\gamma}_{S A k}\right)\left(X_{S A k}^{T} \hat{\beta}\right)$, where $\hat{\gamma}_{S A k}=\hat{\sigma}_{u}^{2} /\left(\hat{\sigma}_{u}^{2}+\hat{\sigma}_{e_{S A k}}^{2}\right)$ is the weight. 
Figure 3: Area-level (FH) SAE process

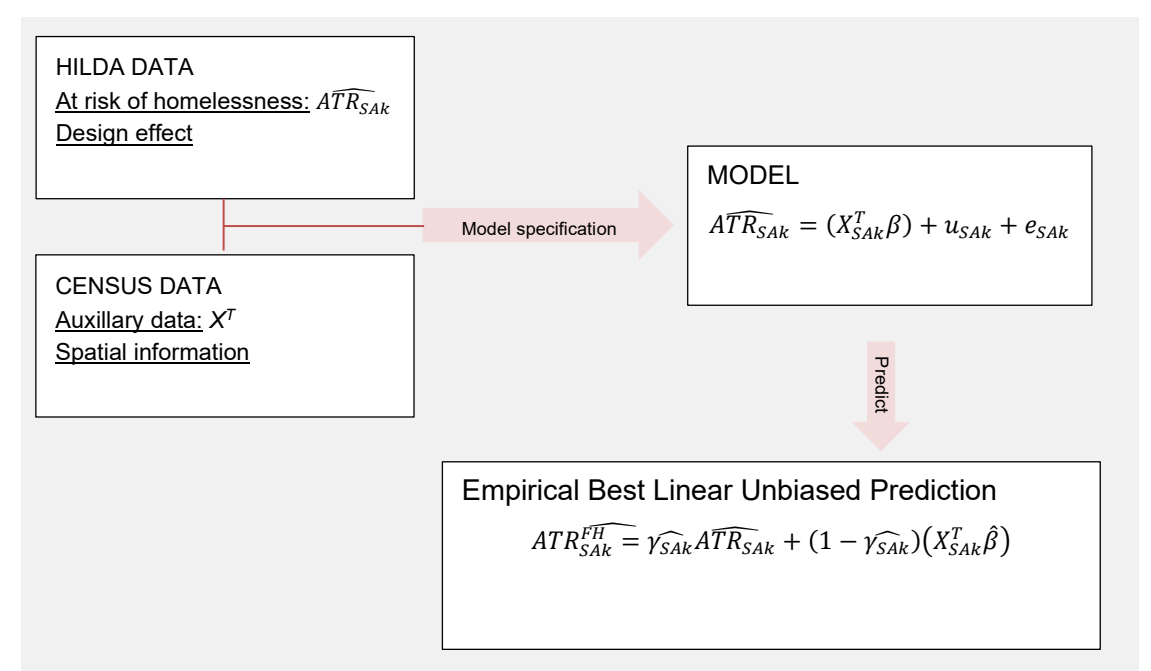

Source: Adapted from Martinez Jr (2019).

In the calculation of area-level SAE confidence intervals, two conventions are again followed. Where estimates are aggregated to national or regional levels, the 95 per cent confidence interval around a particular homelessness risk estimates are calculated as: $A T R \pm 1.96 * \sqrt{(A T R *(1-A T R)) / N}$, where $N$ is the HILDA sample size (national and state or territory). When confidence intervals are calculated at SA3 level the software produced confidence intervals are reported $\left(C I=A T R \pm 1.96 * S E_{\beta}\right)$, where $S E$ is the standard error of the coefficient estimate.

Table 5 provides key descriptive statistics for the predictor variables used to estimate Equation 4. Unlike the variables used for the unit-level model, most of the predictor variables range from 0-1 (rather than binary values). Each of the variables are calculated as the proportion of the population aged 15 years and over (see Table 6 for more information). Variable descriptions are provided in Table 6. Of note is the difference in typical sample sizes between capital and non-capital city SA3s.

Table 5: Descriptive statistics, area-level $(\mathrm{FH})$ model

\begin{tabular}{|c|c|c|c|c|c|}
\hline Variable & Obs & Mean & St Dev & Min & Max \\
\hline Never married & 292 & 0.345 & 0.064 & 0.215 & 0.660 \\
\hline Year of arrival before 1945 & 292 & 0.003 & 0.003 & 0.000 & 0.021 \\
\hline Not in the labour force & 292 & 0.357 & 0.066 & 0.174 & 0.565 \\
\hline Population volunteering & 292 & 0.219 & 0.053 & 0.095 & 0.397 \\
\hline Total number of children 1 or 3 & 292 & 0.292 & 0.032 & 0.125 & 0.339 \\
\hline Private rental tenure & 292 & 0.251 & 0.084 & 0.077 & 0.605 \\
\hline Group household & 292 & 0.040 & 0.034 & 0.009 & 0.264 \\
\hline Manufacturing employment & 292 & 0.067 & 0.029 & 0.012 & 0.189 \\
\hline Accommodation and hospitality employment & 292 & 0.074 & 0.023 & 0.034 & 0.259 \\
\hline Ln^ Family weekly income, median & 292 & 7.446 & 0.248 & 6.972 & 8.128 \\
\hline Capital city (1=yes) & 292 & 0.589 & 0.493 & 0.000 & 1.000 \\
\hline SA3 sample sizes (population weighted) & 292 & 58.83 & 41.54 & 1.438 & 209.0 \\
\hline Capital city sample size & 172 & 68.52 & 46.55 & 2.67 & 209.0 \\
\hline Non-capital city sample size & 120 & 44.94 & 27.85 & 1.44 & 124.6 \\
\hline
\end{tabular}

Note: $\wedge$ Ln is the natural log.

Source: Authors' calculation from Table Builder, ABS 2016 Census of Population and Housing. 
Table 6: Definition of variables used in area-level $(\mathrm{FH})$ model

\begin{tabular}{|c|c|c|}
\hline Variable & Population & Definition \\
\hline Never married & $\begin{array}{l}\text { Place of usual residence }(\mathrm{PoU}) \text { basis. } \\
\text { Aged } 15+\end{array}$ & $\begin{array}{l}\text { Proportion of population never married (registered marital } \\
\text { status). }\end{array}$ \\
\hline Year of arrival before 1945 & $\begin{array}{l}\text { Place of usual residence (PoU) basis. } \\
\text { Aged } 15+\end{array}$ & $\begin{array}{l}\text { Proportion of population born overseas arriving in Australia } \\
\text { before } 1945 .^{\wedge}\end{array}$ \\
\hline Not in the labour force & $\begin{array}{l}\text { Place of usual residence (PoU) basis. } \\
\text { Aged } 15+\end{array}$ & Proportion of population not in the labour force. \\
\hline Population volunteering & $\begin{array}{l}\text { Place of usual residence (PoU) basis. } \\
\text { Aged } 15+\end{array}$ & $\begin{array}{l}\text { Proportion of population volunteering in group or } \\
\text { organisation. }\end{array}$ \\
\hline $\begin{array}{l}\text { Total number of children } \\
1 \text { or } 3\end{array}$ & $\begin{array}{l}\text { Place of usual residence (PoU) basis. } \\
\text { Aged } 15+\end{array}$ & Proportion of female population with 1 OR 3 children.^ \\
\hline Private rental tenure & Place of Enumeration (PoE) basis & Proportion of population in private rental tenure. \\
\hline Group household & Place of Enumeration (PoE) basis & $\begin{array}{l}\text { Proportion of population in a group household } \\
\text { composition. }\end{array}$ \\
\hline Manufacturing employment & $\begin{array}{l}\text { Place of usual residence (PoU) basis. } \\
\text { Aged } 15+\end{array}$ & $\begin{array}{l}\text { Proportion of employed population employed in } \\
\text { manufacturing employment. }\end{array}$ \\
\hline $\begin{array}{l}\text { Accommodation and } \\
\text { hospitality employment }\end{array}$ & $\begin{array}{l}\text { Place of usual residence }(\mathrm{PoU}) \text { basis. } \\
\text { Aged } 15+\end{array}$ & $\begin{array}{l}\text { Proportion of employed population employed in } \\
\text { accommodation/hospitality employment. }\end{array}$ \\
\hline $\begin{array}{l}\text { Ln Family weekly income, } \\
\text { median }\end{array}$ & $\begin{array}{l}\text { Place of usual residence }(\mathrm{PoU}) \text { basis. } \\
\text { Aged } 15+\end{array}$ & Median total family income. Natural log. \\
\hline Capital city (1=yes) & & $\begin{array}{l}\text { SA3 lies within greater capital city (Sydney, Melbourne, } \\
\text { Brisbane, Adelaide, Perth, Hobart, Darwin, Canberra). }\end{array}$ \\
\hline SA3 sample size & & $\begin{array}{l}\text { Number of HILDA observations per SA3. Weighted by } \\
\text { responding person }\end{array}$ \\
\hline
\end{tabular}

Note: ^ Alternative measurements were tested and found significant, but the listed definition resulted in better model fit. Source: TableBuilder, ABS 2016 Census of Population and Housing.

Detailed modelling results for both the unit-level and area-level models are reported in Appendix 1.

The next chapter presents our estimation of the national population at-risk of homelessness using HILDA data, and provides incidence measures at the state, territory and small area levels. A profile of those at-risk of homelessness is also provided at the national level, with components of the unit-level estimations used to describe differences in profiles at the state, territory and greater capital city and balance of state levels. 


\section{Homelessness risk in Australia}

- The incidence of homelessness risk is expressed as a rate per 10,000 persons (total population, all tenures combined). The estimated rate of risk per 10,000 persons ranges between 846.9 per 10,000 ( $8.5 \%$ of the total population aged 15 years and over) and 1,165 per 10,000 (11.7\%).

- Those at-risk are more likely than the national population to be female, Indigenous, and be living in a lone person or lone parent household. They are more likely to identify as lesbian, gay or bisexual, and report fair or poor health. They are more likely to be low-income, unemployed or outside the labour force, and in receipt of income support payments. Those at-risk have lower levels of educational attainment, are more likely to report difficulty paying bills and rent on time, and are more likely to experience a range of indicators of material deprivation such as skipping meals and being unable to heat their home.

- The highest rate of risk is in the Northern Territory followed by Queensland and South Australia. The lowest rates of risk are in Australian Capital Territory followed by Victoria.

- In many states (Queensland, New South Wales, Western Australia, South Australia) high rates are spread across greater capital city and rest of state areas, however, risk is highly concentrated in remote areas in the Northern Territory and in inner Melbourne in Victoria.

- While the highest rates of risk can be found in remote areas and select areas of capital cities, the greatest number of people at-risk are located in capital cities on the eastern coast of Australia. These high numbers extend well beyond inner city areas and into the suburbs of most capital cities. 
- Areas with moderate/average rates of risk in capital cities, such as the outer west in Melbourne, or substantial segments of the eastern $10 \mathrm{~km}$ ring of Perth, still can have higher concentrations of people at-risk, due to their larger population size.

\section{- The precision of the estimates varies across methods with the smallest confidence interval for HILDA and the largest for the area-based approach. These confidence intervals are larger (indicating decreased precision and reliability) in remote parts of Australia (and some capital cities).}

\footnotetext{
This chapter addresses RQ1 and RQ2 by documenting the incidence of risk of homelessness across Australia for persons 15 years and over at the small area level and explores geographical variations in the profile of those at-risk. By definition (see section 2.3), people residing in owner-occupied housing are not considered at-risk. The regression and modelling output for the unit and area-level models is presented in Appendix 1.
}

The chapter follows a higher level of spatial aggregation to lower level of aggregation structure. We begin by presenting estimates of the national population at-risk of homelessness using the responding person population weights in HILDA. These weights also enable us to generate a detailed profile of this population at the national level.

Next, we provide a broad national level comparison of the at-risk of homelessness estimates, comparing the directly estimated (from HILDA) at-risk rates to the rates generated on the basis of the two estimation methods. Similarly, the direct estimate and model-based at-risk rates are compared for states and territories. Detailed SA2 and SA3 level model output is presented in Appendix 3.

At each level (national, state or territory, SA3), we report the profile of those at-risk of homelessness and describe geographical variations in this profile.

In reporting the incidence of homelessness risk in small areas, we use a rate per 10,000 persons (total population 15 years and over, combined across all tenures. See footnote 19 for detail). The rate measure gives a sense of homelessness risk in an area after accounting for total population size. It is calculated by dividing the number of persons at-risk in an area by that areas' total population and multiplying it by 10,000. ${ }^{19}$ This measure can be used to identify areas with a higher rate of people at-risk of homelessness per head of population and can also be compared with the homelessness estimates produced by the ABS. We then translate the homelessness risk estimates into estimates of number of people at-risk for each geography.

\subsection{National estimates of the population at-risk of homelessness}

We begin by reporting national level estimates of homelessness risk for two reasons. Firstly, these national estimates are the first time all five elements of the Batterham (2019a) risk definition have been operationalised to date in Australia and are themselves an important finding. Secondly, aggregating our SAEs up to the national level and comparing them with the national estimate from HILDA provides an important point of comparison and a robustness check on our SAEs.

19 Note that while the risk measure excludes those living in owner-occupied housing, the denominator used to calculate the rate of risk per 10,000 persons includes people living in all tenures, not just those renting. This was done to follow the convention in homelessness reporting used by the ABS. This approach also smooths the impact of varying rates of home ownership. In a hypothetical area with 100 people, 99 may be living in owner-occupied housing while one person is renting. That one person may be at-risk of homelessness. We could report that as 100 per cent of renters in this area are at-risk, or we could report that 1 per cent of the total population at-risk We have chosen the latter. 
Application of the cross-sectional responding person population weights in HILDA enables us to generalise to the national (total) Australian population aged 15 years and over. This analysis suggests that 11.7 per cent of the population aged 15 years and over qualified as at-risk of homelessness in 2016. This equates to 2,227,607 people [Cl 95: 2,137,939; 2,317,280] spread across 1,360,643 households (13.9\% of households).

Table 7 compares this direct (national) estimate from HILDA to the unit-based and area-based methods of small area estimation. Here, the Small Area Estimates are aggregated up to the national level for the rate per 10,000 persons and the number of people at-risk of homelessness based on the population base in each area (point estimates). The unit-level (probit) results were produced at both SA2 and SA3 levels. All SA2s are nested within SA3s and should, in principle, produce identical outcomes. The minor variation in the output is the result of perturbation that is used by the ABS to maintain confidentiality.

Table 7: Aggregated SAEs, Australia, 2016

\begin{tabular}{|c|c|c|c|c|c|c|c|c|}
\hline Estimate & $\begin{array}{r}\text { Sample size } \\
\text { (number of } \\
\text { spatial units) }\end{array}$ & $\begin{array}{r}\text { Population } \\
\text { base }^{\&}\end{array}$ & $\begin{array}{r}\text { Rate of risk } \\
\text { per } 10,000 \\
\text { persons }\end{array}$ & Lower $\mathrm{Cl}$ & Upper Cl & $\begin{array}{r}\text { Point } \\
\text { estimate }\end{array}$ & Lower Cl & Upper Cl \\
\hline $\begin{array}{l}\text { HILDA using population } \\
\text { weights^ }\end{array}$ & $\begin{array}{r}1 \\
\text { (national) }\end{array}$ & $19,119,468$ & $1,165.1$ & $1,118.2$ & $1,212.0$ & $2,227,607$ & $2,137,939$ & $2,317,280$ \\
\hline Probit (SA2)\# & 2,161 & $17,994,437$ & 853.9 & 813.0 & 894.8 & $1,536,545$ & $1,462,948$ & $1,610,142$ \\
\hline Probit (SA3)\# & 332 & $17,994,437$ & 846.9 & 806.2 & 887.6 & $1,523,949$ & $1,450,712$ & $1,597,186$ \\
\hline Fay-Herriot SA3! & 332 & $18,990,928$ & $1,038.2$ & 993.6 & $1,082.8$ & $1,971,638$ & $1,886,939$ & $2,056,338$ \\
\hline
\end{tabular}

Note: $\mathrm{Cl}=$ confidence interval. $\mathrm{Cl}$ calculated on a consistent sample size assumption. Sample size based on HILDA sample. 95Cl= ATR+/$\left.1.96 * \operatorname{SQRT}^{*}\left(\operatorname{ATR}^{*}(1-A T R) / 17,693\right)\right]$.

$\wedge \quad$ Indicates weighted population totals derived from HILDA $16(19,119,468)$. Population base includes all Australians aged 15 and over, across all tenures.

! The FH estimates are based on the population counts (15 years and over, across all tenures) provided by TableBuilder.

\# The Probit estimates are based on custom data obtained from the ABS (aged 15 and over, across all tenures). Probit estimates are based on the unit-level model, FH estimates are based on the area-level model. The FH estimates produce SA3 level at-risk measures also in areas where HILDA does not have any observations. As a result, the population bases also differ. The HILDA (direct) estimates are based on weighing the HILDA sample by their corresponding population weights.

Source: Author's calculations derived from ABS 2016 Census of Population and Housing, and HILDA survey, waves 16 and 17

When aggregated to the national level, both the unit and area-level methods produce results that are lower than the direct estimates. In both cases the estimated national at-risk measures are statistically different from the direct estimate $\left(p<0.00\right.$, two-tailed). ${ }^{20}$ The two model-based estimates are, however, also different from each other, with the unit-level results significantly lower than the area-based estimates ( $p<0.00$, two-tailed). This raises two issues.

First, based on the comparison of direct estimates to model estimates (both unit and area-level basis), the estimates derived directly from HILDA potentially overestimate the incidence of homelessness risk. This may be a result of the design effect and the national weights attached to individuals, particularly in remote and sparsely populated areas. The use of SAE methodologies can thus assist in improving our understanding of the overall incidence of homelessness risk.

20 Based on two-tailed test for population proportions. 
Second, alternative homelessness risk estimates are sensitive to the method used, and as a consequence of data availability. As discussed in Chapter 3, the unit-level estimates attempt to overcome the small sample size issue in HILDA by drawing on the strengths of the Census. However, the model (equation 1) is inherently aspatial and does not include spatial variables that may capture unobserved spatial variations. Moreover, limitations in how Census variables can be combined also results in loss of some population characteristics that may further bias the results. When comparing the distribution of characteristics of the populations contained in the customised ABS data to national level characteristics derived from TableBuilder, there are some critical differences that suggest that the unit-level estimates are downward biased. ${ }^{21}$

The area-level models, on the other hand, draws on both model predictions and direct estimates that (where relevant) also embody spatial variations differences. However, the area-level estimates also remain more sensitive to the HILDA sampling frame and under-sampling in remote and sparsely populated areas.

The rates reported in Table 7 can also be translated into estimates of the number of people at-risk. Columns 7-9 report the estimated number of people at-risk of homelessness, as well as upper and lower estimates corresponding to the 95 per cent confidence intervals in column 5-6. In line with the rates themselves, the two model-based estimates generate somewhat lower estimates of the total number of people at-risk of homelessness. ${ }^{22}$

\subsection{Characteristics of the national population at-risk}

In addition to knowing how many people are at-risk of homelessness and where they are, it is also important to understand who they are, and their characteristics. This information may be useful in focussing primary prevention efforts towards particular cohorts, as well as measuring the impact of any such initiatives through consistent monitoring over time.

The Table below uses the responding person population weights in HILDA to produce a profile of the population at-risk of homelessness and compares it to the national population aged 15 years and over. While some of the differences between those at-risk and the national population (including those at-risk) are a result of how risk was operationalised (e.g. low-income and marital status), the range of indicators reported here paint a picture of a population experiencing multiple and intersecting forms of disadvantage.

Table 8 reveals that those at-risk are more likely than the national population to be female, Indigenous, and living in a lone person or lone parent household. They are more likely to identify as lesbian, gay or bisexual and report fair or poor health. They are more likely to be low-income, unemployed or outside the labour force and in receipt of income support payments. Those at-risk have lower levels of educational attainment, are more likely to report difficulty paying bills and rent on time, and are more likely to experience a range of indicators of material deprivation such as skipping meals and being unable to heat their home. They are also far more likely to be in rental stress.

21 In the customised dataset obtained from the ABS the number of private renters is under-counted (relative to the regular Census output). The reason for this is that our variables include household level data which are (only) counted at the dwelling's place of enumeration. A consistent dataset can therefore only be produced based on respondents at home on Census night. Since more private renters were not at home on Census night than owner-occupiers, private renters are under-represented. Based on the operationalisation of homelessness risk (see Section 2.3) this results in private renters being under-represented and consequently a smaller number of estimated individuals at-risk. The research team decided against a general scaling of the results as the distribution of low-income households and household type (including lone person, group households, lone parents and multi-family households) in the private rented sector cannot be assumed to be uniform across the areas.

22 We have chosen to present the numbers estimates as a function of the population bases used in the modelling (see note to Table 7). Readers may choose to apply the rates to the same population base, but given the systematic variation in the population compositions (see footnote 17), we have opted here for using the relevant population bases. 
Table 8: Demographic profile of the estimated population aged 15 years and over at-risk of homelessness in 2016 (HILDA) Australia

\begin{tabular}{|c|c|c|c|}
\hline & $\begin{array}{r}\text { Population weighted } \\
\text { HILDA sample } \\
\text { characteristics }\end{array}$ & $\begin{array}{l}\% \text { of the } 2016 \text { at- } \\
\text { risk population }{ }^{23}\end{array}$ & $\begin{array}{l}\% \text { of the Australian } \\
\text { population } 2016^{24}\end{array}$ \\
\hline Female & $1,227,514$ & 55.1 & 50.9 \\
\hline Mean age & $43.4^{\wedge}$ & - & $45.2^{\wedge}$ \\
\hline Indigenous & 209,411 & 9.4 & 2.4 \\
\hline Married/de facto & 626,297 & 28.1 & 57.5 \\
\hline Self-assessed health rated as fair or poor* & 658,894 & 29.6 & 15.2 \\
\hline Lone person household & 750,915 & 33.7 & 17.0 \\
\hline One parent with children & 441,972 & 19.8 & 6.1 \\
\hline Couple with children & 343,050 & 15.4 & 42.2 \\
\hline Couple without children & 356,882 & 16.0 & 25.6 \\
\hline Has children in their care & 599,832 & 26.9 & 30.9 \\
\hline Lesbian, gay or bisexual & 146,163 & 6.6 & 2.8 \\
\hline Bachelor degree or higher & 286,861 & 12.9 & 26.8 \\
\hline Year 11 and below & 880,658 & 39.5 & 25.7 \\
\hline Employed full-time & 378,679 & 17.0 & 41.6 \\
\hline Employed part-time & 443,793 & 19.9 & 20.5 \\
\hline Unemployed & 158,125 & 7.1 & 3.6 \\
\hline Not in labour force & $1,243,974$ & 55.8 & 34.2 \\
\hline Receiving income-support payments & $1,596,707$ & 71.7 & 30.0 \\
\hline Low-income & $1,007,719$ & 45.2 & 13.1 \\
\hline Could not pay bills on time & 438,682 & 24.0 & 10.6 \\
\hline Asked for financial help from friends and family & 491,037 & 27.0 & 10.7 \\
\hline Was unable to heat home & 179,210 & 9.9 & 2.7 \\
\hline Went without meals & $2,22,141$ & 12.2 & 3.3 \\
\hline Asked for help from welfare/community organisations & 273,989 & 15.0 & 3.3 \\
\hline In social housing & 470,863 & 21.1 & 3.4 \\
\hline Receives DSP & 400,067 & 18.0 & 4.7 \\
\hline Rental stress (30/40rule) & 908,979 & 40.8 & 5.1 \\
\hline
\end{tabular}

Note: ${ }^{\wedge}$ mean years, not a per cent or count.

Source: Author's calculations using HILDA waves 16 and 17

23 Number of observations: 2,453; population size: 2,227,507.

24 Estimates produced using population weights for all responding persons in HILDA. Population size $=19,119,468$. Note population size varies for some questions, such as the material deprivation set. 
The variables used to predict the at-risk indicators can also be used to further explore the characteristics of the population that are associated with higher/lower rates of risk. An important caveat here is that the primary purpose of the modelling exercise was to generate a well-specified model. As such, variable selection was not driven by theory or attempts to test causal relationships. Therefore, they do not necessarily tell us much about why certain characteristics are associated with a higher risk of homelessness. Similarly, the at-risk measure itself relies on individuals having at least two risk factors present. Variable selection therefore also does not say anything about particular risk factors and/or combinations of risk factors.

Figure 4 compares these (unit-based model) characteristics for the at-risk population to the same characteristics for the population as a whole. Nationally, 70.4 per cent of those at-risk live in households with less than \$1,250 weekly gross household income compared with 27.9 per cent of the national population aged 15 years and over. The majority of those at-risk (67.7\%) are living in a household type comprising one-parent families, group households, multi-family households or lone person households (compared with $29.1 \%$ nationally). The majority (57.1\%) are either unemployed or not in the labour force (compared with 37.2\%). Further, 12.5 per cent had a disability with a core need for assistance compared with 5.7 per cent of the national population, 7.9 per cent were Indigenous and 4.4 per cent had five or more children.

Figure 4: Key characteristics of the population at-risk of homelessness compared to general population*

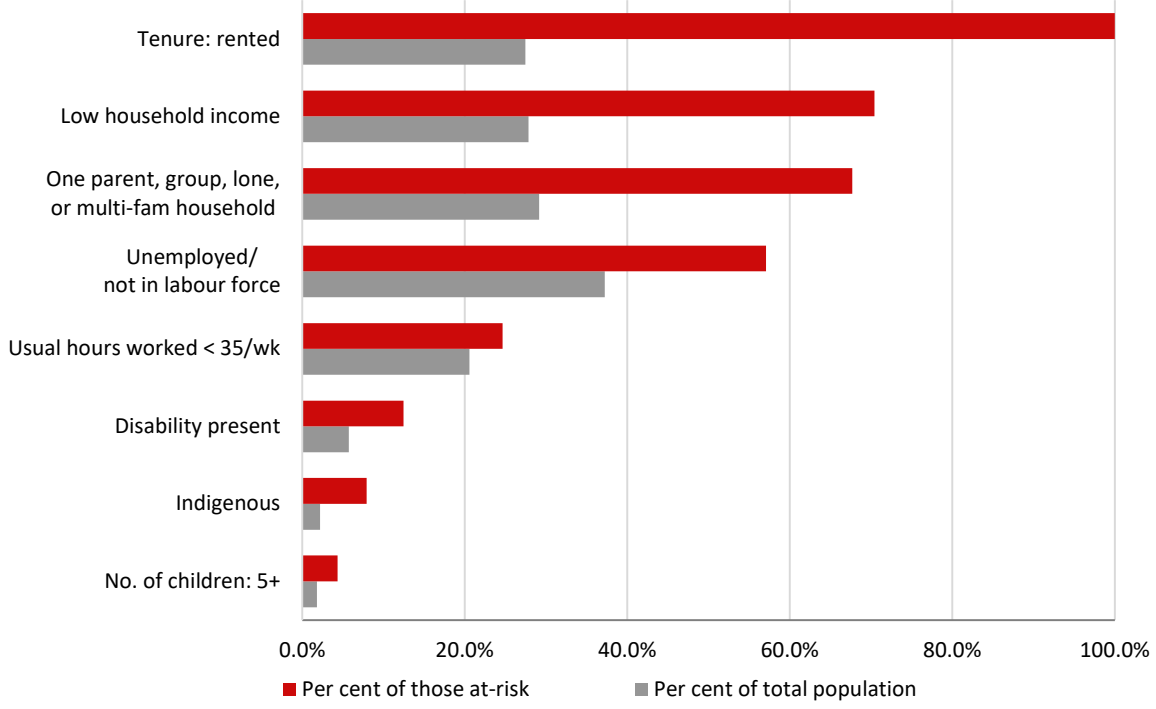

* Persons aged 15 years and over, enumerated at home on Census night.

Source: Author's calculations derived from: ABS 2016 Census of Population and Housing, and HILDA survey, waves 16 and 17.

\subsection{State and territory incidence of homelessness risk}

The distribution of risk varies across geographic scales. Table 9 and Table 10 report the homelessness risk estimates and corresponding person numbers at state and territory levels. Homelessness risk varies across each of the states and territories. However, for most of the states/territories the confidence intervals of the estimates include the national average. The exemption here is the NT, where homelessness risk is significantly greater than national homelessness risk.

The NT has the highest rate of its population (aged over 15 years) at-risk of homelessness of all the states and territories, with an estimated risk of 1,384.3 per 10,000 persons. Notably, apart from the NT, where the effects of non-sampling in remote and sparsely populated areas is most evident, the variation from the national average is moderate. The confidence interval for the at-risk measure based on the unit-level estimates in the NT is consistently higher than the national average. Moreover, there is no overlap in the confidence interval for the NT and the national average (and its confidence interval). For the area-based estimates QLD, Tasmania (TAS) and the NT all have somewhat higher rate of homelessness risk $(p<0.05)$. 
When translating the rate of risk into number of people, differences in totals first and foremost reflect differences in population sizes. Consequently, the greatest numbers of people at-risk of homelessness are estimated to be in NSW, VIC and QLD, the three most populous states. The NT, which has the highest rate, on a number of people basis has the second lowest number of people at-risk. Only the ACT has a lower number of estimated people at-risk.

Table 9: Unit-level SAE's aggregated to the state and territory level: rates and point estimates with confidence intervals, 2016

\begin{tabular}{lrrrrrrrr}
\hline & \multicolumn{1}{c}{$\begin{array}{c}\text { Number } \\
\text { of SA3s }\end{array}$} & $\begin{array}{r}\text { Rate per } \\
10,000\end{array}$ & Lower Cl & Upper Cl & $\begin{array}{r}\text { Point } \\
\text { estimate }\end{array}$ & Lower Cl & Upper Cl \\
\hline NSW & 89 & 842.5 & 760.4 & 924.6 & 488,285 & 440,718 & 535,851 \\
\hline VIC & 66 & 770.7 & 687.0 & 854.4 & 354,718 & 316,193 & 393,243 \\
\hline QLD & 82 & 968.7 & 872.1 & $1,065.3$ & 345,135 & 310,709 & 379,560 \\
\hline SA & 28 & 951.5 & 826.0 & $1,077.0$ & 124,067 & 107,703 & 140,431 \\
\hline WA & 34 & 749.5 & 627.9 & 871.2 & 140,170 & 117,421 & 162,919 \\
\hline TAS & 15 & 980.5 & 767.7 & 1193.3 & 38,197 & 29,906 & 46,488 \\
\hline NT & 9 & $1,384.3$ & $1,137.1$ & $1,631.5$ & 22,888 & 18,801 & 26,975 \\
\hline ACT & 9 & 719.4 & 522.7 & 916.0 & 21,864 & 15,886 & 27,842 \\
\hline Australia & 332 & 853.9 & 812.4 & 894.1 & $1,536,545$ & $1,462,948$ & $1,610,142$ \\
\hline
\end{tabular}

Note: $\mathrm{Cl}=$ confidence interval. Cls calculated on a consistent sample size assumption. Sample size based on HILDA sample at state level (SL). $95 \mathrm{Cl}=A T R+/-1.96^{*} \operatorname{SQRT}\left[\left(A T R^{*}(1-A T R) / N\right)\right]$. The denominator in rate calculation is based on all Australians aged 15 and over, across all tenures.

Source: Author's calculations derived from: ABS 2016 Census of Population and Housing, and HILDA survey, waves 16 and 17.

Table 10: Area-level SAE's aggregated to the state or territory level: rates and point estimates with confidence intervals, 2016.

\begin{tabular}{lrrrrrrr}
\hline State or Territory & $\begin{array}{r}\text { Number } \\
\text { of SA3s }\end{array}$ & $\begin{array}{r}\text { Rate per } \\
10,000\end{array}$ & Lower Cl & Upper Cl & $\begin{array}{c}\text { Point } \\
\text { estimate }\end{array}$ \\
\hline NSW & 89 & 999.5 & 910.9 & $1,088.1$ & 607,867 & 553,967 & 661,766 \\
\hline VIC & 66 & 926.1 & 835.1 & $1,017.0$ & 448,118 & 404,094 & 492,143 \\
\hline QLD & 82 & $1,196.2$ & $1,090.2$ & $1,302.2$ & 451,999 & 411,942 & 492,056 \\
\hline SA & 28 & $1,206.1$ & $1,066.8$ & $1,345.4$ & 166,562 & 147,325 & 185,799 \\
\hline WA & 34 & 879.0 & 748.2 & $1,009.8$ & 175,080 & 149,025 & 201,134 \\
\hline TAS & 15 & $1,446.3$ & $1,194.6$ & $1,698.0$ & 605,780 & 50,036 & 71,124 \\
\hline NT & 9 & $1,888.9$ & $1,608.8$ & $2,169.0$ & 33,432 & 28,474 & 38,390 \\
\hline ACT & 9 & 870.2 & 655.6 & $1,084.7$ & 28,009 & 21,103 & 34,915 \\
\hline Australia & 332 & $1,038.2$ & 993.6 & $1,082.8$ & $1,971,647$ & $1,886,934$ & $2,056,360$ \\
\hline
\end{tabular}

Note: $\mathrm{Cl}=$ confidence interval. Cls calculated on a consistent sample size assumption. Sample size based on HILDA sample at state level (SL). 95Cl=ATR+/- 1.96* SQRT[(ATR*(1-ATR)/SL)]. The denominator in rate calculation is based on all Australians aged 15 and over, across all tenures.

Source: Author's calculations derived from: ABS 2016 Census of Population and housing, and HILDA survey, waves 16 and 17. 


\subsection{The characteristics of those at-risk within each state and territory}

The profile of those at-risk in NSW, VIC, QLD and WA are quite similar, with the greatest variation being for Indigenous status. In VIC, 2.18 per cent of those at-risk are Indigenous while around 10 per cent of those at-risk in QLD, WA and TAS are Indigenous (see Figure 5).

Except for Indigenous status, TAS and SA have similar profiles for their at-risk populations. With labour force status and disability featuring more strongly than other states. The majority of those in both these states are in low-income households ( $82.46 \%$ and $79.31 \%$ respectively).

Those at-risk in the territories have quite different profiles to the states. In the NT, the majority of those at-risk are Indigenous (62.9\%) and are unemployed or outside the labour force (63.5\%). A smaller proportion of the at-risk population are working less than 35 hours per week (15.5\%) and a lower proportion of those at-risk are in low-income households (52.7\%). The ACT has a lower proportion of persons at-risk who are unemployed or outside the labour force (49.2\%) and who are Indigenous (4.2\%) than the NT. However, they have a higher proportion of their at-risk population working 35 hours or less (26.9\%) and living in low-income households (62.5\%). These differences in profile are summarised in Figure 5 below.

Figure 5: Characteristics of the at-risk population by state and territory (unit-based, probit estimates)

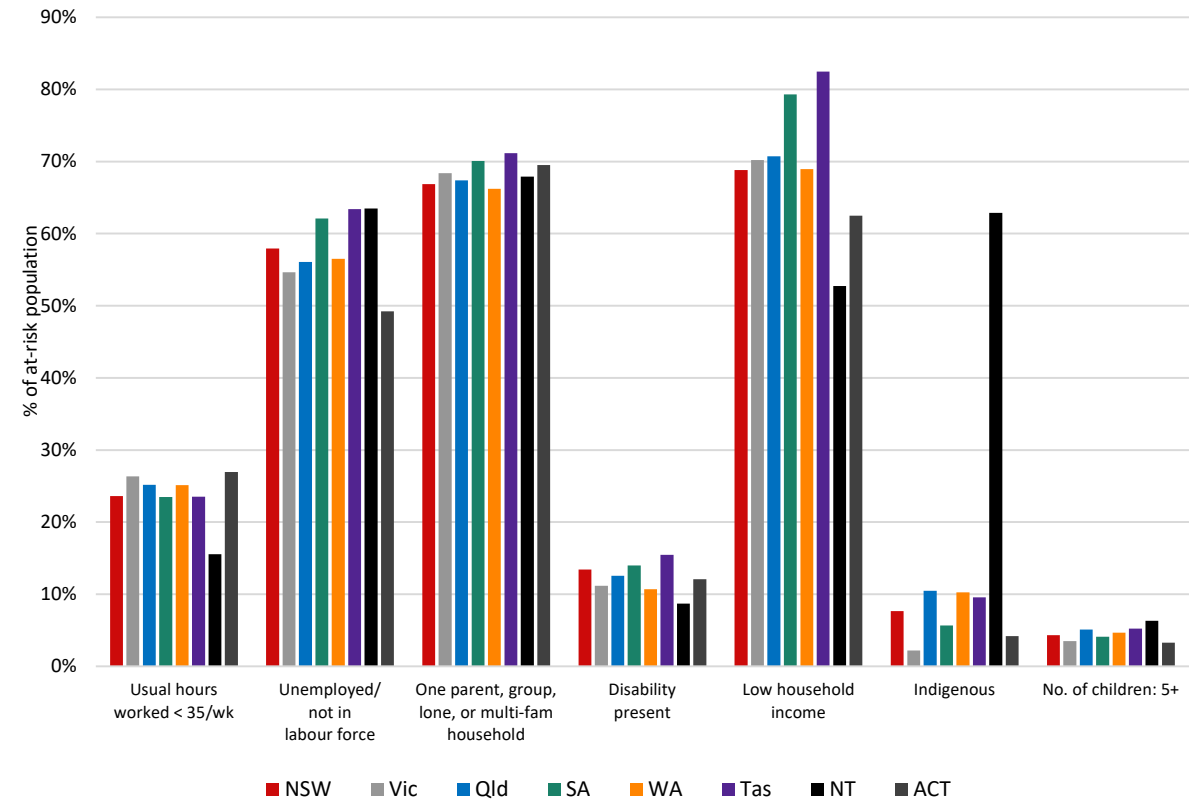

Note: The comparative statistics in Figure 5 are based on the population at-risk, rather than all Australians. By definition (see Section 2.3) the population at-risk is based on people aged 15 and over in rental housing.

Source: Author's calculations derived from: ABS 2016 Census of Population and Housing, and HILDA survey, waves 16 and 17.

For most states and territories there is little variation in the proportion at-risk between Greater Capital City and Rest of State areas. For example, 8.11 per cent of those in Greater Sydney are at-risk of homelessness compared with 9.1 per cent of those in rest of state areas. The NT is the exception with a far greater per cent at-risk in rest of state areas (23.8\%) compared with Greater Darwin (7.8\%). 


\section{Northern Territory}

The SA3s in the NT with the highest estimated rate of homelessness risk are all situated in the Rest of NT area. ${ }^{25}$ These include:

- East Arnhem

- Daly-Tiwi-west Arnhem

- Barkly

- Katherine

- Alice Springs
3,366 per 10,000
3,265 per 10,000
2,793 per 10,000
2,218 per 10,000
1,688 per 10,000

Those at-risk in the rest of the NT are highly likely to be Indigenous (85.4\%), be unemployed or outside the labour force $(72.1 \%)$ to be in a one parent family, group household, multi-family household or lone person household (70.5\%).

The highest risk SA2 within Greater Darwin is Moulden (within Palmerston SA3) with 1,637 per 10,000 persons estimated to be at-risk of homelessness. Most commonly, those at-risk in Moulden are in one parent families, multi-family households, group or lone person households (74.6\%). The majority are also unemployed or outside the labour force (74\%) and have household incomes below $\$ 1,250$ per week (73.8\%). Many of those at-risk (43.2\%) in this SA2 are Indigenous.

\section{Queensland}

The SA3s with the highest rate of homelessness risk in QLD are:

- Far North (Rest of QLD)

- Southport (Rest of QLD)

- Cairns-South (Rest of QLD)

- Caboolture (Greater Brisbane)

- Brisbane Inner (Greater Brisbane)

- Beenleigh (Greater Brisbane)
2,327 per 10,000

1,358 per 10,000

1,364 per 10,000

1,369 per 10,000

1,361 per 10,000

1,338 per 10,000

The majority of those at-risk in these six SA3s are low-income (70.1\%) in households that are one parent families, multi-family households, group households or lone person households (69.8\%) and are unemployed or outside the labour force (56.9\%). It is worth noting that while 20.6 per cent of those at-risk across these six SA3s were Indigenous, 84.9 per cent of those in Far North were Indigenous.

Within Greater Brisbane, the SA2s with the highest rate of homelessness risk are: Logan Central (2,110 per 10,000 persons); Woodridge (2,099 per 10,000) and Kingston (1,662 per 10,000) all within the SA3 of Springwood-Kingston. The SA2 of Inala-Richlands (in the SA3 of Forest Lake-Oxley) has the next highest rate of homelessness risk (2,004 per 10,000), followed by Leichhardt - One Mile (1,929 per 10,000) and Riverview (1,834 per 10,000) both within the SA3 of Ipswich Inner.

25 Rate calculations use the total population aged 15 and over across all tenures as the denominator (see footnote 19 for details) 


\section{Victoria}

In VIC, those SA3s with the highest rate of homelessness risk can all be found within Greater Melbourne.

- Melbourne City (Greater Melbourne)

- Yarra (Greater Melbourne)

- Maribyrnong (Greater Melbourne)

- Port Phillip (Greater Melbourne)

- Stonnington-West (Greater Melbourne)

- Brunswick-Coburg (Greater Melbourne)

- Darebin-North (Greater Melbourne)
1,634 per 10,000

1,251 per 10,000

1,187 per 10,000

1,144 per 10,000

1,138 per 10,000

1,070 per 10,000

1,064 per 10,000

The majority of those at-risk in these SA3s were in one-parent families, multi-family households, group households or lone person households (74.4\%), living in low-income households (62.5\%), with many unemployed or outside the labour force (47.4\%).

Those SA2s with the highest rate of homelessness risk within Greater Melbourne are: Carlton (2,258 per 10,000); Melbourne (1,975 per 10,000); Flemington (1,969 per 10,000); North Melbourne (1,736 per 10,000); Clayton (1,680 per 10,000); Collingwood (1,675 per 10,000) and Footscray (1,673 per 10,000).

\section{New South Wales}

The SA3s with the highest rate of homelessness risk in NSW are:

- Sydney Inner City (Greater Sydney)

1,330 per 10,000

- Bourke-Cobar-Coonamble (Rest of NSW)

1,286 per 10,000

- Moree-Narrabri (Rest of NSW)

1,172 per 10,000

- Mount Druitt (Greater Sydney)

1,138 per 10,000

- Fairfield (Greater Sydney)

1,097 per 10,000

The majority of those at-risk in these SA3s are in one-parent families, multi-family households, group households or lone person households (68.8\%), have low-income (63.7\%) and are unemployed and looking for work or outside the labour force (60.5\%).

Within Greater Sydney, the SA2s with the highest rate of homelessness risk include: Warwick Farm (2,108 per 10,000); Fairfield (2,002 per 10,000)); Ashcroft - Busby - Miller (1,822 per 10,000); Bidwill-Hebersham—Emerton (1,767 per 10,000)); and Riverwood (1,756 per 10,000).

\section{Western Australia}

The SA3s with the highest rate of homelessness risk in WA are:

- Kimberley (Rest of WA)

- Belmont-Victoria Park (Greater Perth)

- Perth City (Greater Perth)

- East Pilbara (Rest of WA)

$$
\begin{array}{r}
2,072 \text { per } 10,000 \\
1,131 \text { per } 10,000 \\
979 \text { per } 10,000 \\
976 \text { per } 10,000
\end{array}
$$

In the Kimberley SA3 the majority of those at-risk in this SA3 are Indigenous (77.1\%), are unemployed or outside the labour force (68.8\%) and live in low-income households (64.0\%). 
Across these three remaining top four SA3s, 66.9 per cent of those at-risk are in one-parent families, multi-family households, group households or lone person households, while 61.9 per cent are in low-income households and 47.7 per cent are unemployed or outside the labour force. Only 9.9 per cent of those atOrisk in these four SA3s are Indigenous.

Within Greater Perth, the SA2s with the highest rate of homelessness risk are Mandurah (within Mandurah SA3) (1,859 per 10,000) and Bentley-Wilson-St James (within Canning SA3) (1,640). Across both SA2s, those at-risk are most likely to be low-income (74.5\%), in one-parent families, multi-family households, group households or lone person households (73.6\%), and unemployed or outside the labour force (65.1\%).

\section{South Australia}

The SA3s with the greatest risk of homelessness in SA are:

- Adelaide City (Greater Adelaide)

- Playford (Greater Adelaide)

- Outback-North and East (Rest of SA)

- Port Adelaide-West (Greater Adelaide)

- Port Adelaide-East (Greater Adelaide)
1,496 per 10,000

1,415 per 10,000

1,379 per 10,000

1,265 per 10,000

1,257 per 10,000

Of those four SA3s within Greater Adelaide mentioned above, those at-risk are most commonly in low-income households (79.5\%), in one-parent families, multi-family households, group households or lone person households (71.4\%) and unemployed or outside the labour force (67.5\%). Only 5.5 per cent are Indigenous.

Within Outback-North and East, 51.9 per cent of those at-risk are Indigenous, and the majority are in one-parent families, multi-family households, group households or lone person households (67.5\%), in low-income households (66.9\%), and unemployed and outside the labour force (64.5\%).

Within Greater Adelaide, the SA2s with the highest rate of homelessness are Elizabeth, Smithfield-Elizabeth North and Davoren Park (within Playford SA3), Christie Downs and Hackham West - Huntfield Heights (within Onkaparinga SA3), The Parks (within Port Adelaide SA3) and Adelaide SA2 (within Adelaide City SA3).

\section{ACT}

The North Canberra SA3 has the highest rate of risk $(1,047$ per 10,000) in the ACT. 76.8 per cent of those at-risk in this SA3 are in one-parent families, multi-family households, group households or lone person households, while 61.3 per cent are in low-income households.

The highest risk SA2 in the ACT is Reid (1722 per 10,000) within North Canberra SA3, followed by Belconnen (in the Belconnen SA3, 1,470 per 10,000), and Turner (1,457 per 10,000), Dickson (1,399 per 10,000) and Braddon $(1,359$ per 10,000), the last three of which are all within the North Canberra SA3.

\section{Tasmania}

The SA3s with the highest rate of homelessness risk in TAS are:

- Hobart - North West (Greater Hobart)

$1,292 \operatorname{per} 10,000$

- Brighton (Greater Hobart)

1,260 per 10,000

- Launceston (Rest of TAS)

1,183 per 10,000

- Hobart Inner (Greater Hobart)

1,108 per 10,000

- Burnie-Ulverstone (Rest of TAS)

1,105 per 10,000

- Devonport (Rest of TAS)

1,050 per 10,000 
Those at-risk in these six SA3s are highly likely to be in low-income households (82.5\%), in one-parent families, multi-family households, group households or lone person households (72.6\%) and unemployed or outside the labour force (63.7\%).

Within greater Hobart, Bridgewater-Gagebrook SA2 (within the SA3 of Brighton) has the highest rate of homelessness risk (2,313 per 10,000). Other SA2s with a high rate of homelessness within Greater Hobart include: Rokeby (Hobart North East) (1,691 per 10,000), Glenorchy (Hobart North East) (1,659 per 10,000), Hobart (Hobart Inner) (1,592 per 10,000) and Mornington-Warrane (Hobart North East) (1,592 per 10,000).

\subsection{SA3 level consistency and comparison across estimation methods}

Table 11 tests how well the SA3 level estimates correlate overall and for greater capital cities and balance of state areas. Correlations range from -1 to +1 and provide a measure of how closely the different SA3-level results relate to each other. For instance, a correlation of 1 implies that the area with the highest at-risk rate using the direct estimates from HILDA also has the highest at-risk rate using either the unit or area-level based estimates; the second highest (direct estimate) has the second highest rate also in the unit or area-level estimations; and so on.

The correlation coefficient in column two shows that the relation between the direct estimates (HILDA) and the unit-level (probit) estimates is very low $(r=0.16)$; the correlation between the area-level $(\mathrm{FH})$ estimates and the direct estimates (HILDA) overall is low-moderate $(r=0.46)$. The difference in the correlations between the different model-based estimates and the direct (HILDA) estimates reflect the methodological differences discussed in Chapter 3 (unit level is entirely model driven; area-level combines direct, and regression based estimates).

The correlation between the two model-based estimates is moderate-high ( $r=0.71$, column 2 ), showing a degree of consistency between the two different approaches. As discussed in Chapter 3 , the sampling coverage of HILDA is particularly poor in remote and sparsely populated areas. When correlating the SAEs for unit-level and area-level results by capital city the correlation remains similar. However, the unit-level estimates are more highly correlated with the direct estimates in greater capital city areas than balance of state areas. Indeed, the unit-level SA3s are not correlated with direct estimates at all in balance of state areas. The area-level estimates show a similar level of correlation with the direct estimates (HILDA) in both capital cities and rest of state.

Correlations are likely higher in greater capital cities because HILDA sample sizes are larger here. As a result, the HILDA direct estimates become more precise, and both models do a better job of estimating at-risk. Outside capital cities HILDA direct estimates are poor, in part because of small sample sizes. The FH results still retain a higher degree of correlation because they include a weighted element of the direct HILDA estimates. The higher correlation between the two SAE methods within capital cities also has a bearing on later presentation of the detailed results. As noted in Appendix 1, SA2 level estimates are only produced using the unit-level method due to non-normality (violation of model assumptions) in the two error terms when estimating the FH-models at SA2 level. The higher correlation within capital cities also increases our confidence in the representativeness of the SA2 level results within capital cities. 
Table 11: Pearson correlations between direct estimates, unit-based estimates and Area-based estimates at the SA3 level, 2016

\begin{tabular}{|c|c|c|c|}
\hline & Direct estimate & Unit-based (probit) & Area-based $(\mathrm{FH})$ \\
\hline Direct estimate & $1.00^{\star \star \star}$ & & \\
\hline Unit-based (probit) & $0.16^{\star \star \star}$ & $1.00^{\star * \star}$ & \\
\hline Area-based (FH) & $0.46^{\star \star \star}$ & $0.71^{\star \star \star}$ & $1.00^{\star \star \star}$ \\
\hline \multicolumn{4}{|c|}{ Greater capital cities only } \\
\hline Direct estimate & $1.00^{\star \star \star}$ & & \\
\hline Unit-based (probit) & $0.38^{\star \star \star}$ & $1.00 * \star \star$ & \\
\hline Area-based (FH) & $0.72^{\star \star \star}$ & $0.68^{\star \star \star}$ & $1.00^{\star \star \star}$ \\
\hline \multicolumn{4}{|c|}{ Balance of state areas only } \\
\hline Direct estimate & $1.00 * \star \star$ & & \\
\hline Unit-based (probit) & -0.02 & 1.00 & \\
\hline Area-based (FH) & $0.30 \star \star \star$ & $0.70^{\star \star \star}$ & $1.00^{\star \star \star}$ \\
\hline
\end{tabular}

Note: $* * * / * * *$ is statistically significant at 0.1/0.05/0.01 level.

Source: Author's calculations derived from ABS 2016 Census of Population and Housing, and HILDA survey, waves 16 and 17.

This section now turns to mapping the incidence of homelessness risk across small areas in Australia. Tables detailing the estimated rates of homelessness risk for SA2s and SA3s are presented in Appendix 3 [separate excel file]. The following maps compare and contrast the estimates by location, highlighting areas with higher and lower rates of homelessness risk.

\subsection{Mapping the incidence of homelessness risk, SA2 and SA3}

The maps showing Australia as a whole are based on SA3-level estimates. Capital city maps present the results at an SA2 level. The maps group areas together using five categories. Specifically, the middle 50 per cent of the distribution reflects a moderate or average level of risk (shaded in apricot). The next 20 per cent of the distribution reflects areas with either moderately high (light blue) or moderately low (light green) rate of at-risk, while the next 5 per cent show areas with the highest rate of those at-risk (dark blue) or the lowest at-risk rate (dark green). The range of the at-risk rates for each category is reported in the legends of the figures below.

On this basis, Figure 6, maps A and B, show the risk of homelessness (per 10,000 people) by SA3, based on the unit and area-level estimates, respectively. 
Figure 6: Risk of homelessness (rate per 10,000 people), comparing unit-level (probit - map A) and area-level (Fay-Herriot - map B) estimates, national overview, SA3s

Map A: Risk of homelessness (rate per 10,000 people), unit-level SA3 estimates

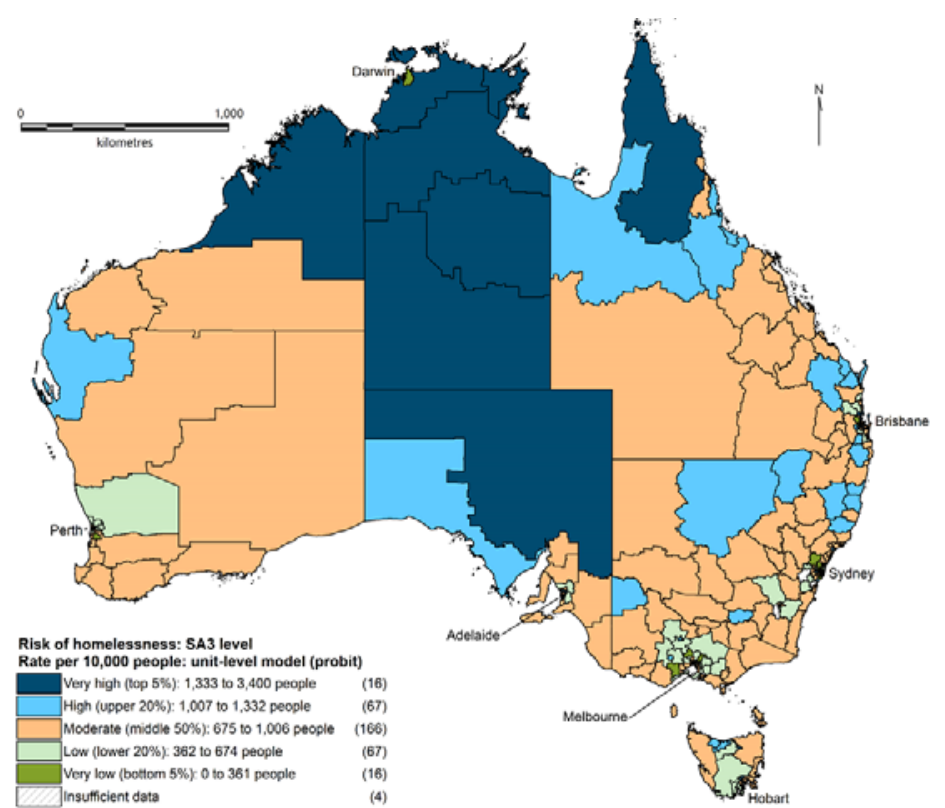

Note: Maps exclude SA3s coded: 'Other Territory'; 'Migratory - Offshore - Shipping'; and, 'No Usual Address'. Insufficient data includes SA3s with population $<500$.

Source: Author's calculations derived from: ABS 2016 Census of Population and Housing, and HILDA survey, waves 16 and 17; ABS digital spatial boundaries.

Map B: Risk of homelessness (rate per 10,000 people), area-level (FH) SA3 estimates

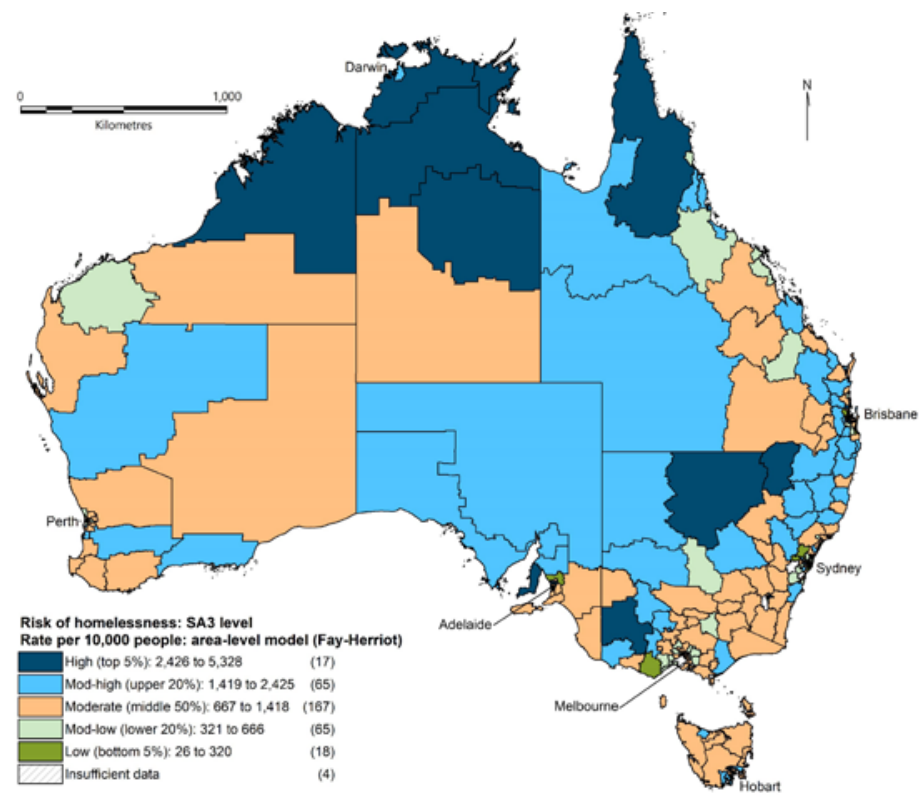

Note: Maps exclude SA3s coded: 'Other Territory'; 'Migratory - Offshore - Shipping'; and, 'No Usual Address'. Insufficient data includes SA3s with population $<500$.

Source: Author's calculations derived from: ABS 2016 Census of Population and Housing, and HILDA survey, waves 16 and 17; ABS digital spatial boundaries. 
Figure 6, map A, shows that the rate of homelessness risk is particularly high in remote and sparsely populated areas of the NT, SA and, to a lesser extent, QLD (measures of estimate precision are shown in Section 4.7). In these areas the at-risk of homelessness rate ranges from 1,333 to 3,400 people per 10,000 residents. From a modelling perspective, the higher rate of homelessness risk in the NT is, in part, driven by the greater proportion of Indigenous residents.

Of those SA3s with the highest rate of homelessness risk, four out of the top five are found in the NT: East Arnhem (3,366 per 10,000), Daly-Tiwi-West Arnhem (3,265 per 10,000 persons), Barkly (2,793 per 10,000 persons) and Katherine (2,218 per 10,000 persons). Far North in QLD also makes the top five with a rate of homelessness risk at 2,327 per 10,000 persons.

QLD has a further four SA3s with some of the highest proportions at-risk in the country: Caboolture (1,369 per 10,000); Cairns - South (1,364 per 10,000); Brisbane Inner (1,361 per 10,000) and Southport (1,358 per 10,000).

SA has three SA3s with particularly high rates of homelessness: Adelaide City (1,496 per 10,000); Playford (1,415 per 10,000) and Outback - North and East (1,379 per 10,000). In WA, Kimberley has a rate of homelessness risk of 2,073 per 10,000, while in VIC, Melbourne City has a rate of 1,634 per 10,000 persons at-risk of homelessness.

Finally, when comparing Figure 6, map A and map B, it is evident that both modelling methods predict a higher rate of homelessness risk in central and remote areas of Australia. While there are some differences in these areas, the overall correlation between the unit-level and area-level models remains largely the same for capital and balance of state homelessness risk rates alike (Table 11).

Figure 7, maps A and B, zoom in to SA2 level for the capital cities. These maps highlight some important insights about the risk of homelessness in Australia.

First, there are concentrations of areas where the rate of homelessness risk is high and very high throughout each of the cities. That is, the risk of homelessness is not geographically confined to particular parts (such as inner or outer parts) of any of the cities.

Second, and as a result, areas with (very) high and (very) low risk are sometimes located close to each other. From a policy perspective, this suggests that many local governments will have areas of both high and low risk within their jurisdiction.

Third, very low rate areas, tend to be located away from the inner CBD areas of each of the cities. Thus, while there is evidence of growing suburbanisation of low-income households (Randolph and Tice 2014), it is also clear that suburbs tend to have lower rates of homelessness risk. This contrast is likely a function of higher rates of home ownership in suburbs than in inner city areas. 
Figure 7: Risk of homelessness (rate per 10,000 people), unit-level (probit) estimates, capital city SA2s Figure 7A: Sydney and Melbourne SA2S

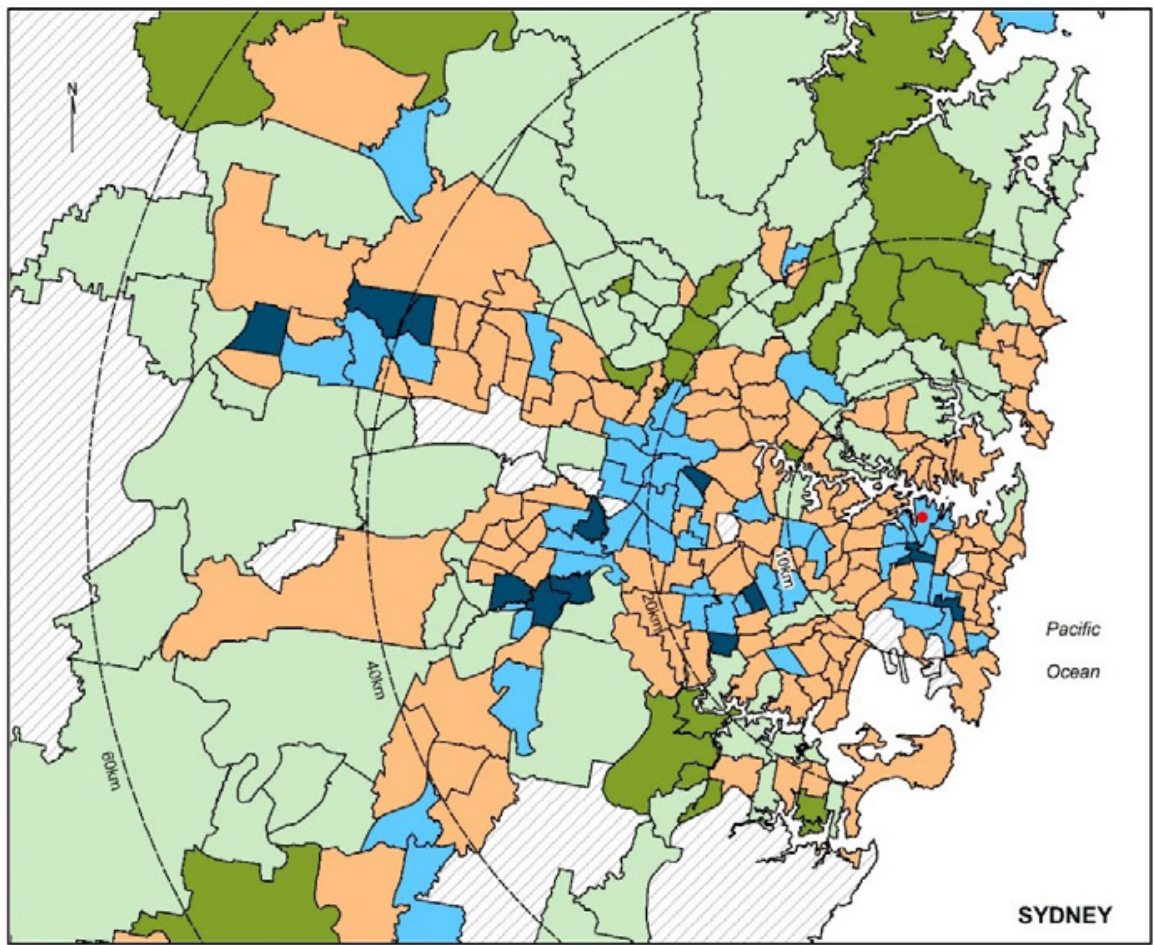

Risk of homelessness: rate per 10,000 people, SA2s (unit-level)
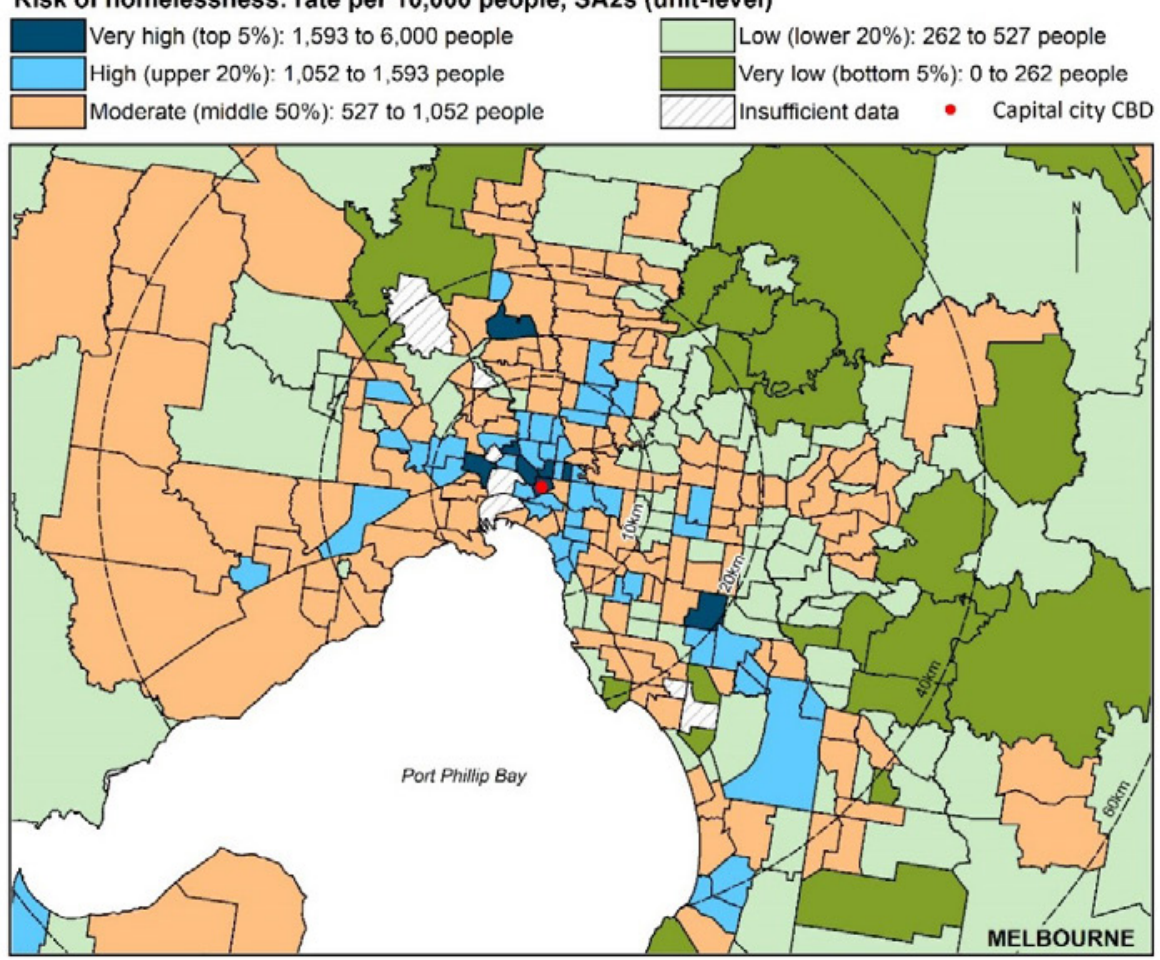

Note: Maps exclude SA2s coded: 'Other Territory'; 'Migratory - Offshore - Shipping'; and, 'No Usual Address'. Insufficient data includes SA3s with population $<500$.

Source: Author's calculations derived from: ABS 2016 Census of Population and Housing, and HILDA survey, waves 16 and 17; ABS digital spatial boundaries. 
Figure 7B: Brisbane, Perth, Adelaide and Hobart SA2s

\section{BRISBANE}

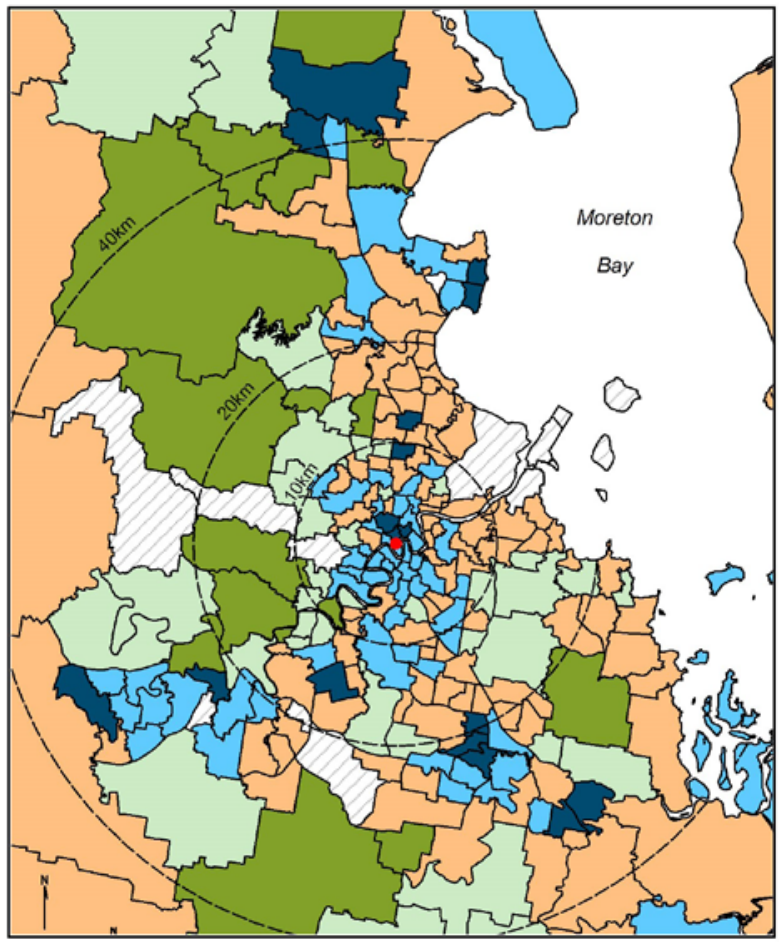

PERTH

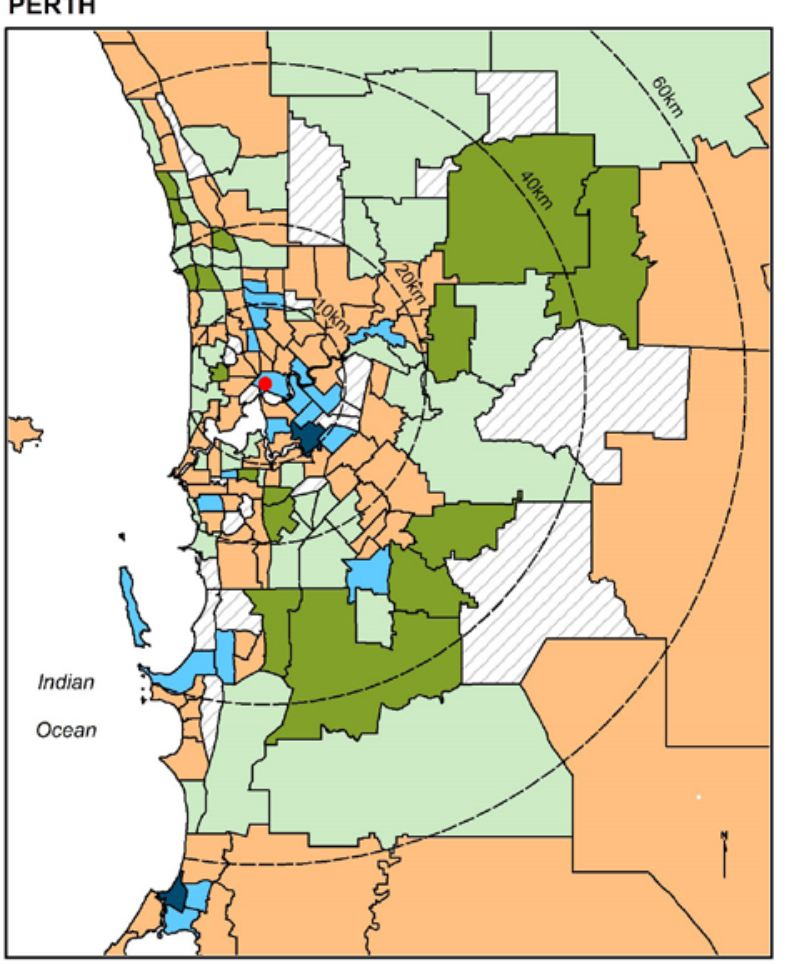

ADELAIDE

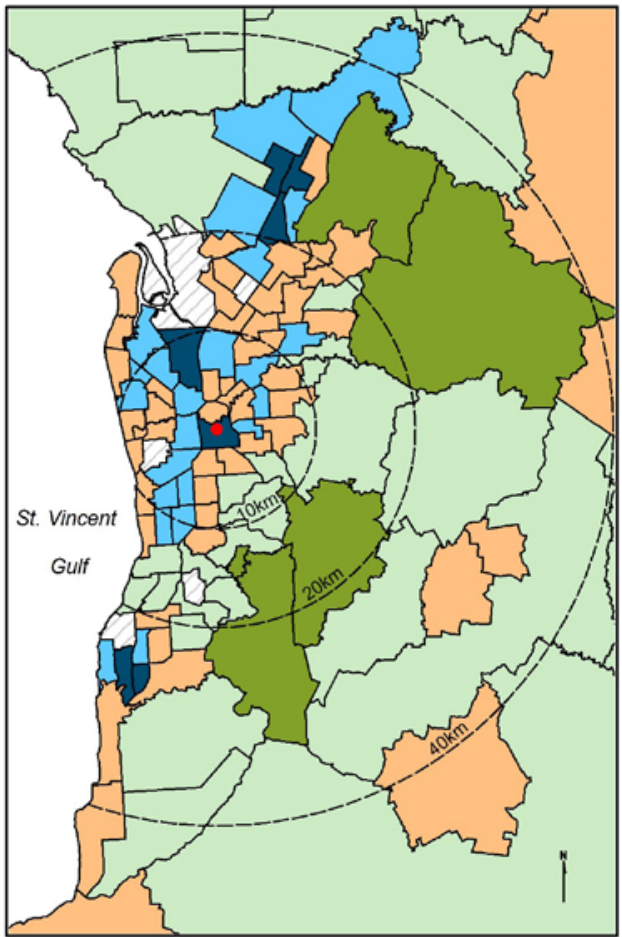

Risk of homelessness: rate per 10,000 people

SA2s (unit-level)

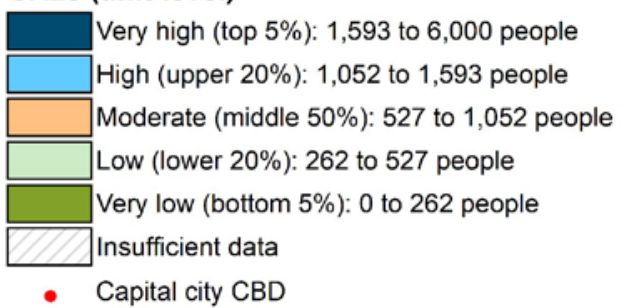

HOBART

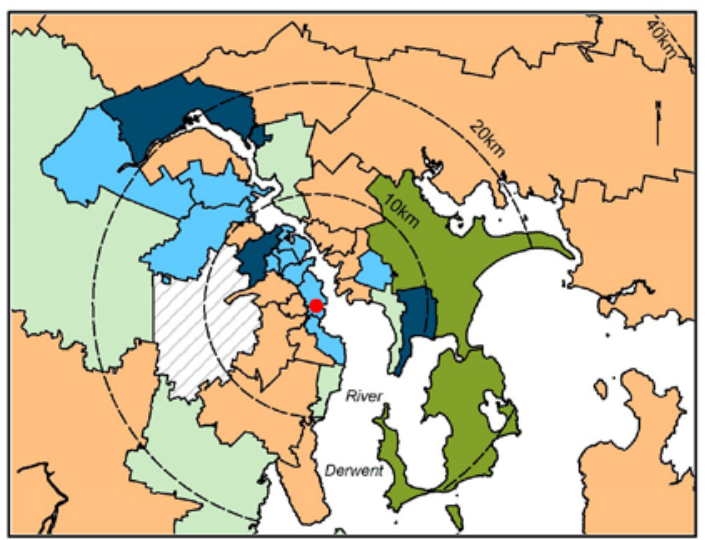

Note: Maps exclude SA2s coded: 'Other Territory'; 'Migratory - Offshore - Shipping'; and, 'No Usual Address'. Insufficient data includes SA3s with population $<500$.

Source: Author's calculations derived from: ABS 2016 Census of Population and Housing, and HILDA survey, waves 16 and 17; ABS digital spatial boundaries. 


\subsection{Confidence and reliability of estimates}

A key issue in making inference from the above estimates is how precise they are. The confidence intervals in Section 4.1 (national) and 4.3 (state or territory) already demonstrate that precision varies. This is even more so at SA2 and SA3 level.

To assist in visualising the precision of our estimates, the confidence intervals for both sets of Small Area Estimates are presented below in map form. Those areas with the largest confidence interval are shaded in brown; those with a moderate confidence interval are shaded orange, while those areas with a small confidence are shaded cream. For clarity, the range of the confidence interval (in percentage points) and corresponding range of persons per 10,000 is also shown in the legend. Population number point estimates and confidence intervals for both unit-based and area-based results are reported for each small area in Appendix 3 (Excel file).

By way of example, the SA3 of Far North in QLD, one of the SA3s with the largest confidence intervals, has a point estimate of 2,327 per 10,000 persons at-risk of homelessness. The confidence interval is +/- 572 per 10,000 persons, or it ranges from 1,755 per 10,000 to 3,001 per 10,000.

Figure 8 and Figure 9 show the areas with the largest confidence intervals using the unit-based approach. Those areas for which we have less precise estimates are clustered in the northern most parts of Australia. This broad pattern suggests that those areas with the highest point estimates of risk also have the largest confidence intervals and should be considered least reliable. Importantly, these are also the areas where HILDA has the poorest sampling outcome (from the perspective of the analysis in this report). Figure 10 reports confidence intervals for the area-level results at the SA3 level only, and shows a broadly similar pattern.

Figure 8: Confidence interval ranges, unit-level (probit) estimates: percentage points and +/- variations in point estimates, Australia, SA3s

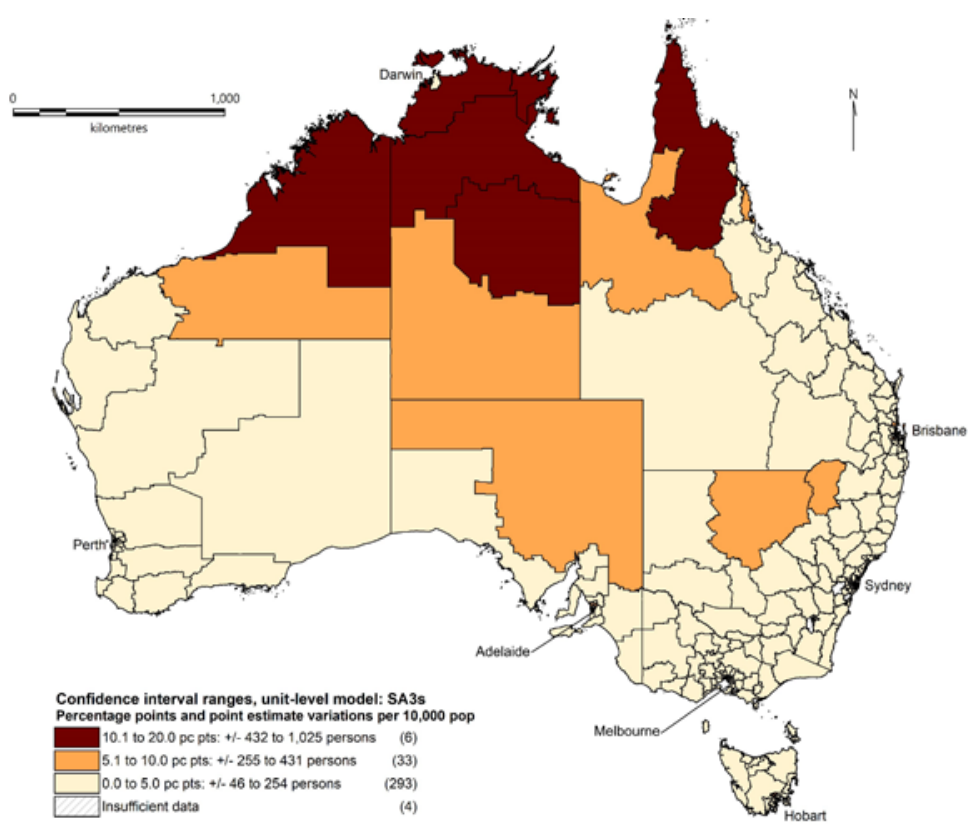

Note: Maps exclude SA3s coded: 'Other Territory'; 'Migratory - Offshore - Shipping'; and, 'No Usual Address'; Insufficient data includes SA3s with population $<500$.

Source: Author's calculations derived from: ABS 2016 Census of Population and Housing, and HILDA survey, waves 16 and 17 ; ABS digital spatial boundaries. 
Figure 9: Confidence interval ranges, unit-level (probit) estimates: percentage points and +/- variations in point estimates, capital city SA2s

Figure 9A: Sydney and Melbourne, SA2S

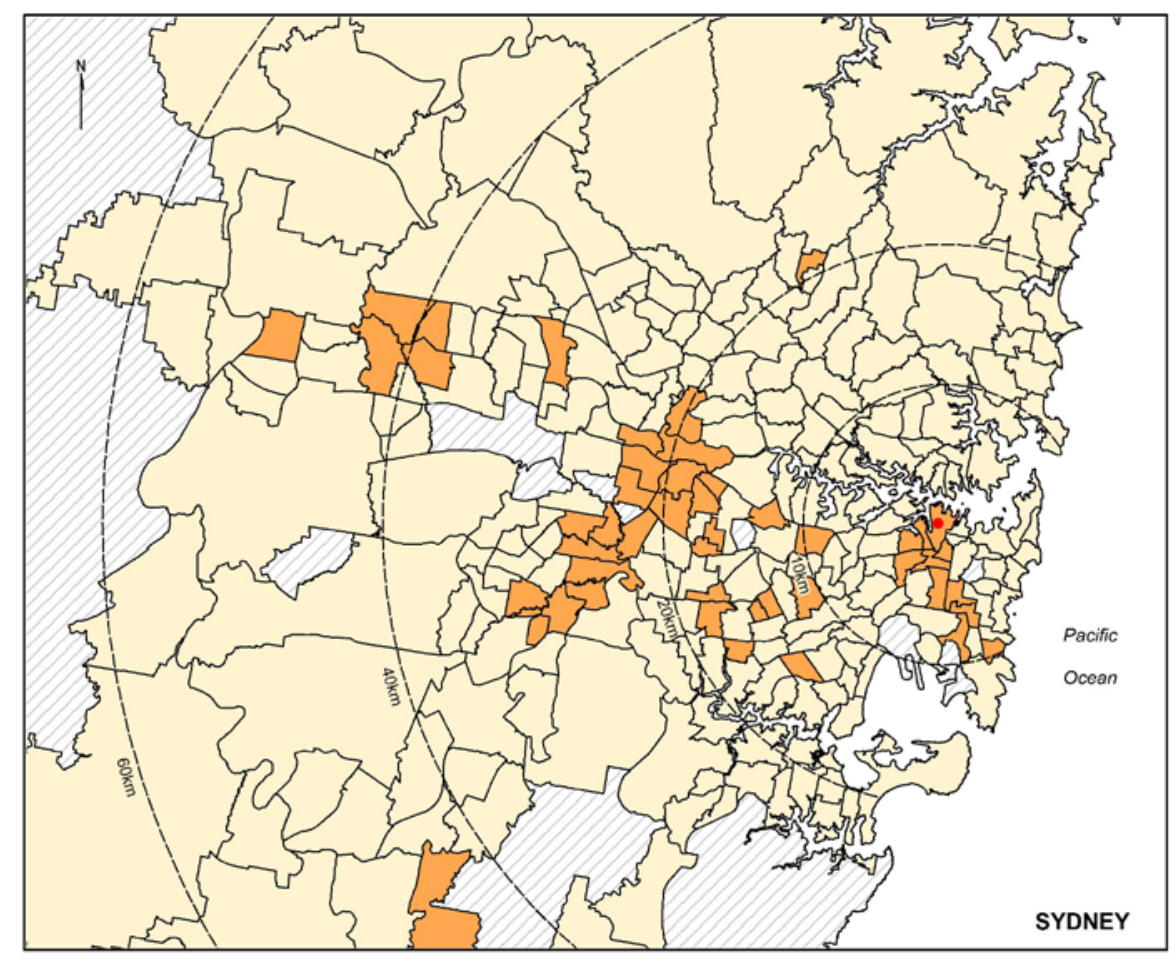

Confidence interval ranges, unit-level, SA2s: percentage points \& point estimate variations per 10,000 pop

10.1 to $27 \mathrm{pc}$ pts: $+/-490$ to 1,362 persons
5.1 to $10.0 \mathrm{pc}$ pts: $+/-255$ to 490 persons
0.0 to $5.0 \mathrm{pc}$ pts: $+/-20$ to 254 persons

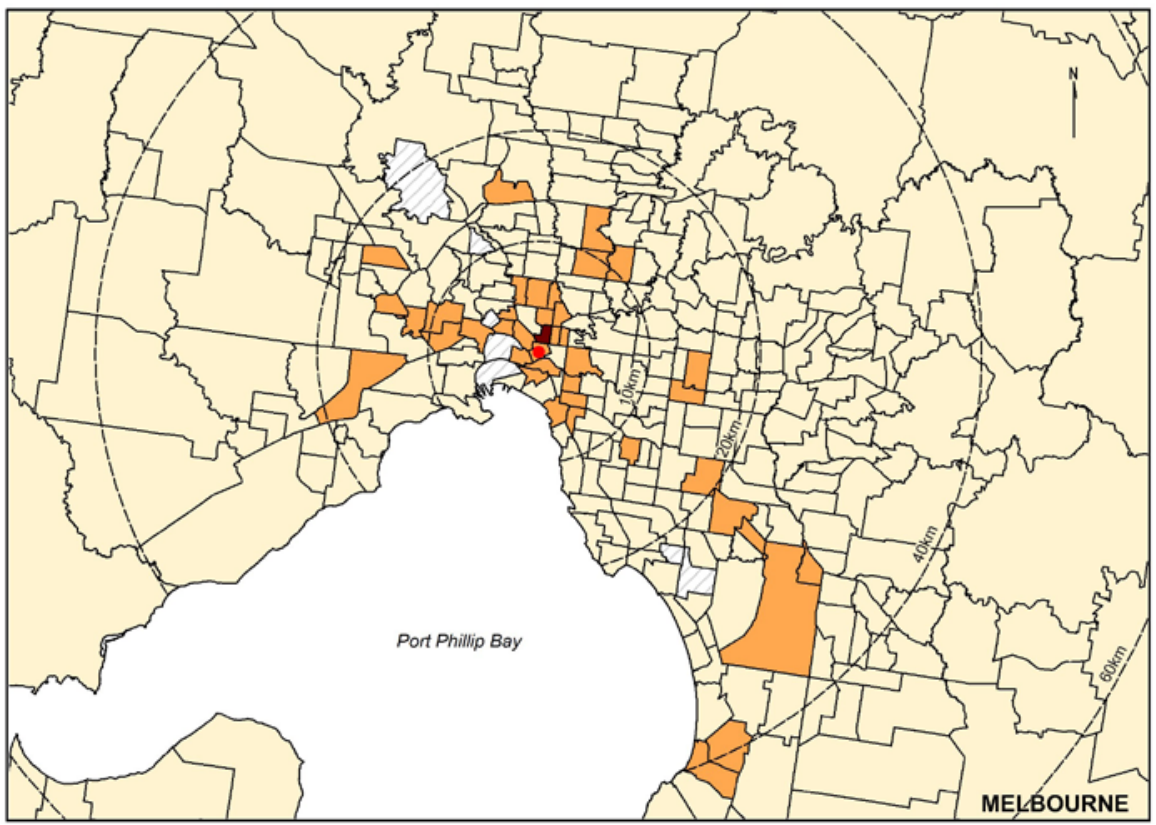

Note: Maps exclude SA2s coded: 'Other Territory'; 'Migratory - Offshore - Shipping'; and, 'No Usual Address'; Insufficient data includes SA3s with population $<500$.

Source: Author's calculations derived from: ABS 2016 Census of Population and housing, and HILDA survey, waves 16 and 17 ; ABS digital spatial boundaries. 
Figure 9B: Brisbane, Adelaide, Perth and Hobart, SA2S

BRISBANE

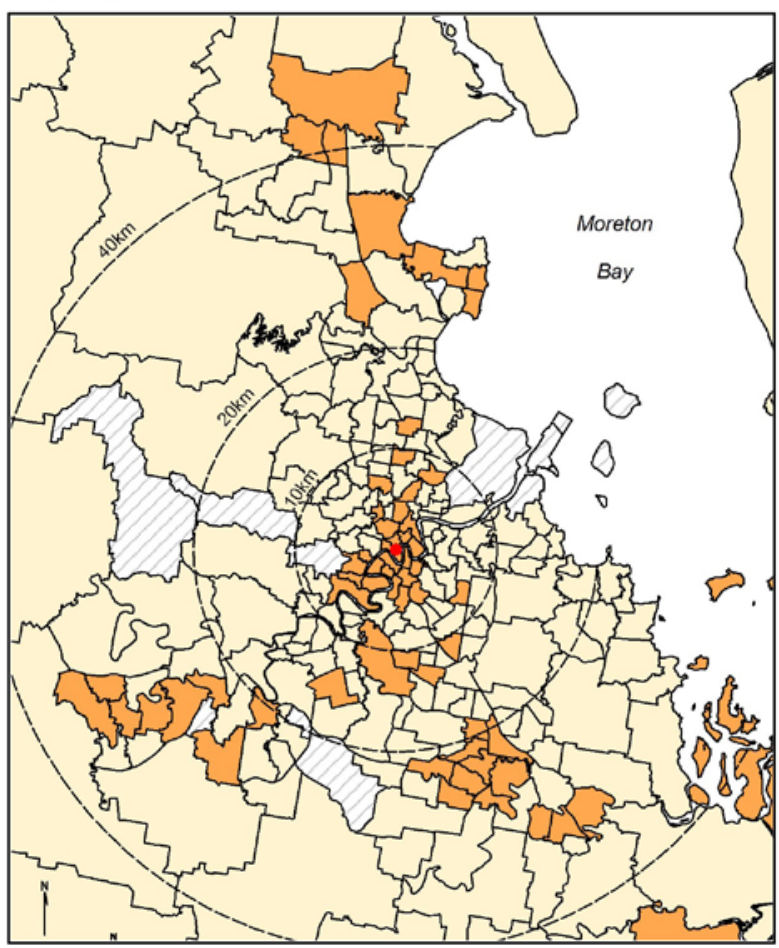

\section{ADELAIDE}

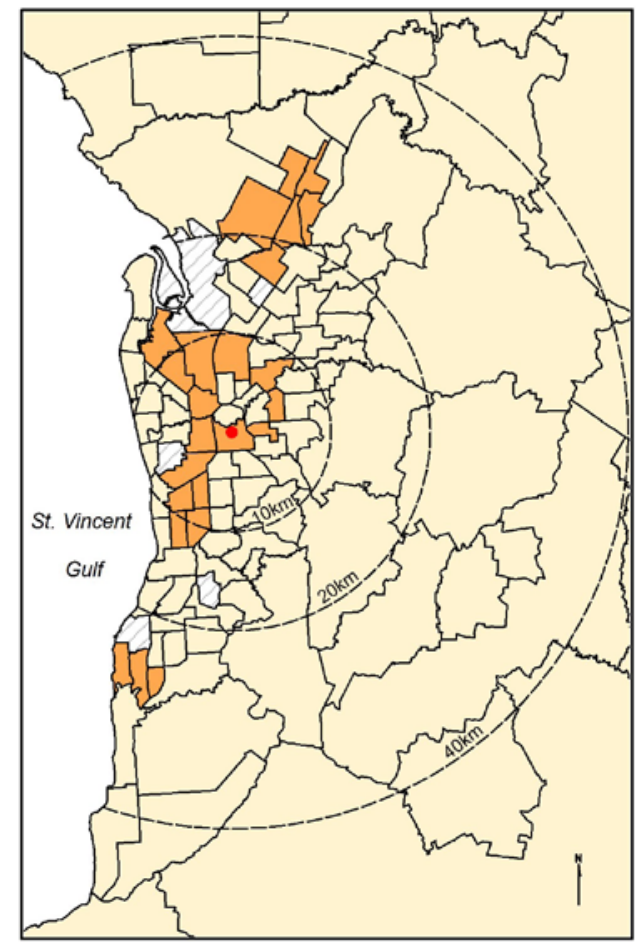

PERTH

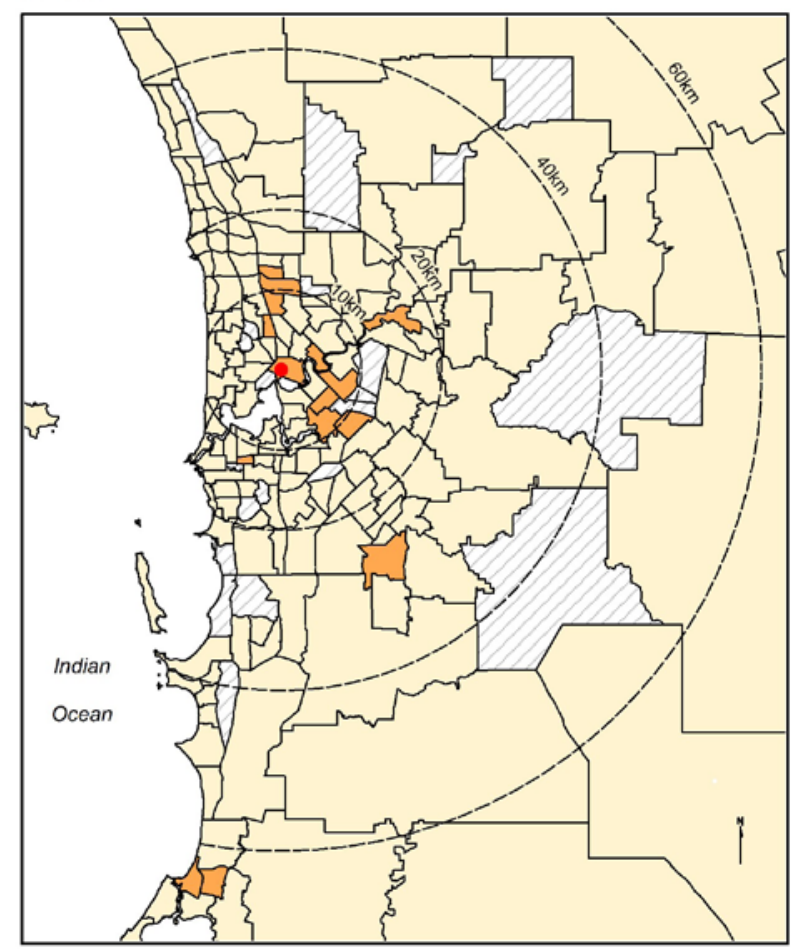

Confidence interval ranges, unit-level, SA2s Percentage points \& point estimate variations per 10,000 pop 10.1 to 27 pc pts: $+/-490$ to 1,362 persons 5.1 to 10.0 pc pts: $+/-255$ to 490 persons 0.0 to 5.0 pc pts: $+/-20$ to 254 persons Insufficient data

- Capital city CBD

\section{HOBART}

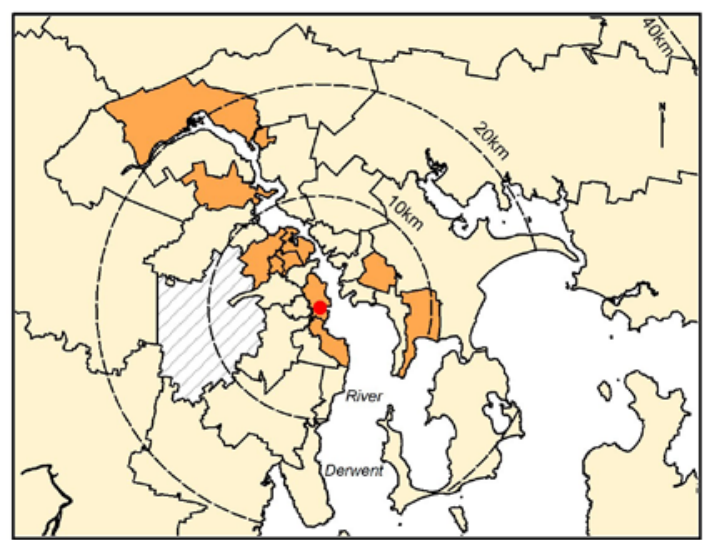

Note: Maps exclude SA2s coded: 'Other Territory'; 'Migratory - Offshore - Shipping'; and, 'No Usual Address'; Insufficient data includes $S A 3 s$ with population $<500$.

Source: Author's calculations derived from: ABS 2016 Census of Population and housing, and HILDA survey, waves 16 and 17 ; ABS digital spatial boundaries. 
Figure 10 repeats the mapping of the confidence interval range based on the area-level model (FH model). The comparison scale used for the area-level model differs from that of the unit-level model given the wider confidence intervals produced using this method. Nevertheless, a similar pattern emerges, the precision of the estimated homelessness risk is poorer in remote and sparsely populated areas, and in particular areas where, in the case of the area-level model, the predicted homelessness risk is entirely based on the model's predictive ability. These are the areas where there is no direct estimate available from HILDA due to non-sampling.

Figure 10: Confidence interval ranges, area-level $(\mathrm{FH})$ estimates: percentage points and +/- variations in point estimates, Australia, SA3s

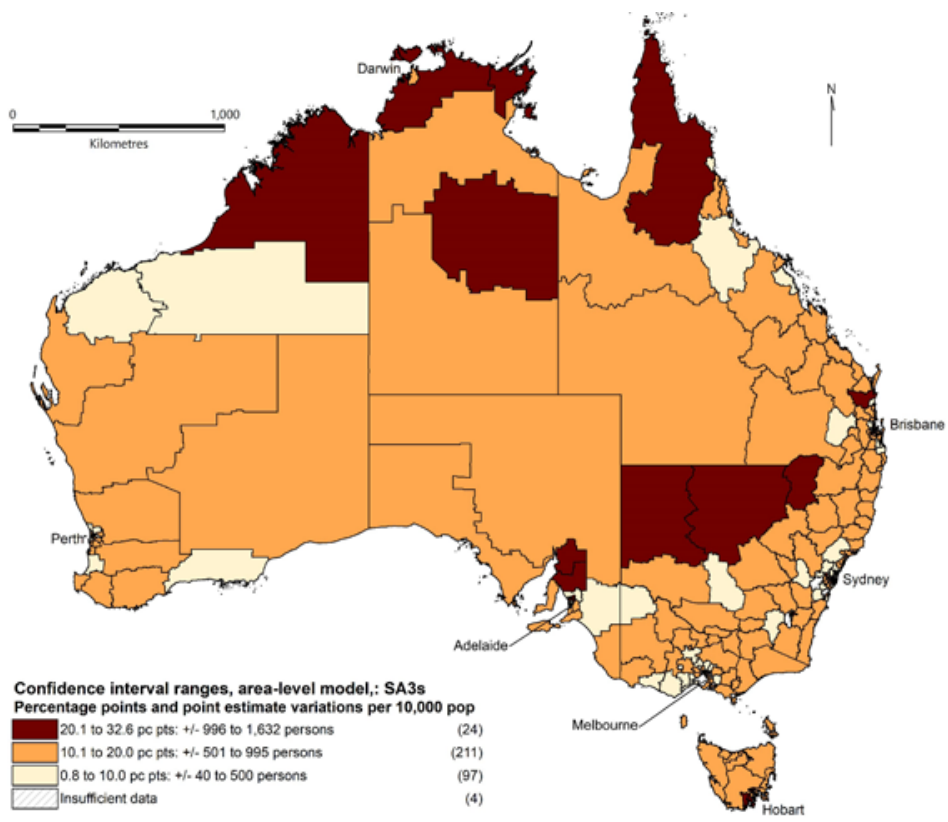

Note: Maps exclude SA3s coded: 'Other Territory'; 'Migratory - Offshore - Shipping'; and, 'No Usual Address'; Insufficient data includes SA3s with population $<500$.

Source: Author's calculations derived from: ABS 2016 Census of Population and housing, and HILDA survey, waves 16 and 17; ABS digital spatial boundaries.

\subsection{Mapping the numbers of people at-risk}

Finally, in this section we translate the at-risk rates into population numbers at SA3/SA2 level. We first report the number at-risk per SA3 in a national map and zoom into capital cities to examine numbers per SA2. Invariably, the numbers of people at-risk in each area is a function of the rate and the number of resident people. The categorisation of the map legend follows the structure used for examining rates of homelessness risk.

Figure 11 and Figure 12 reveal that the greatest number of people at-risk of homelessness can be found in greater capital city areas, with some areas in regional NSW and along the coast in QLD also having high numbers. In contrast to the rate maps, the number of people at-risk in the NT is comparatively low, which highlights the importance of considering the rate of homelessness risk together with the number of people at-risk. 
Figure 11: Point estimates: persons* at-risk of homelessness, comparing unit-level (probit - map A) and arealevel (FH-map B) estimates, national overview, SA3s

Figure 11A: Unit-level point estimates, SA3s

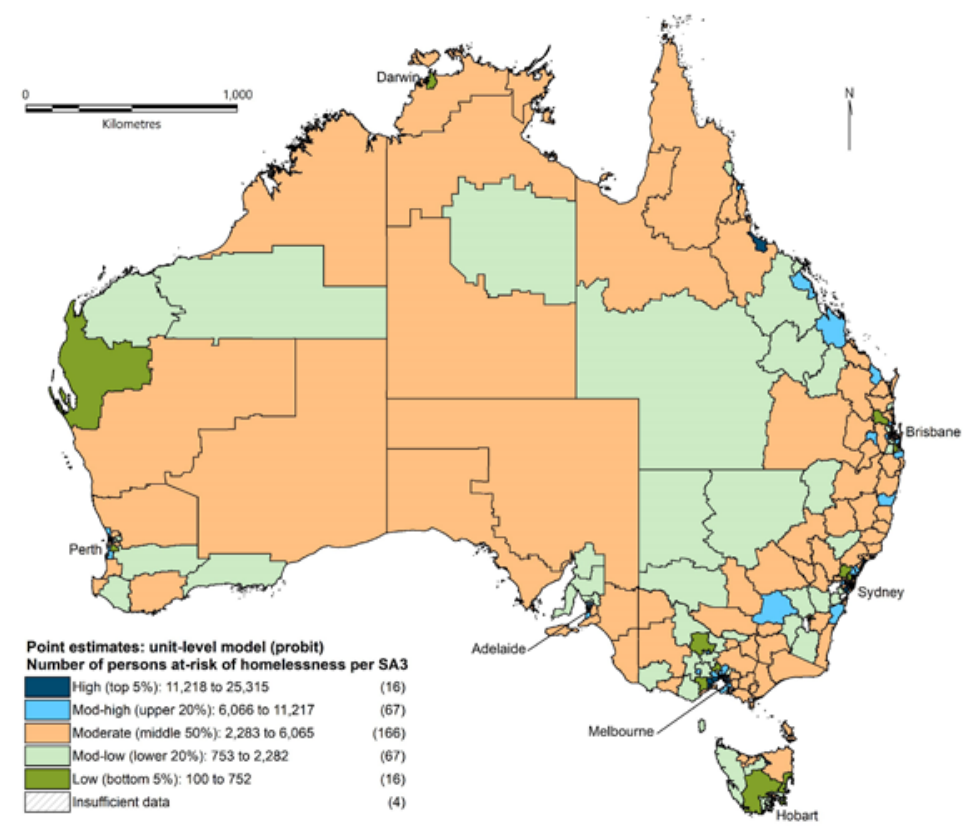

Notes: * 'Persons' are aged 15 and over and reside in a rental property. Maps exclude SA3s coded: 'Other Territory'; 'Migratory - Offshore Shipping'; and 'No Usual Address'. Insufficient data includes SA3s with population < 500

Source: Author's calculations derived from: ABS 2016 Census of Population and Housing, and HILDA survey, waves 16 and 17; ABS digital spatial boundaries

Figure 11B: Area-level point estimates, SA3s

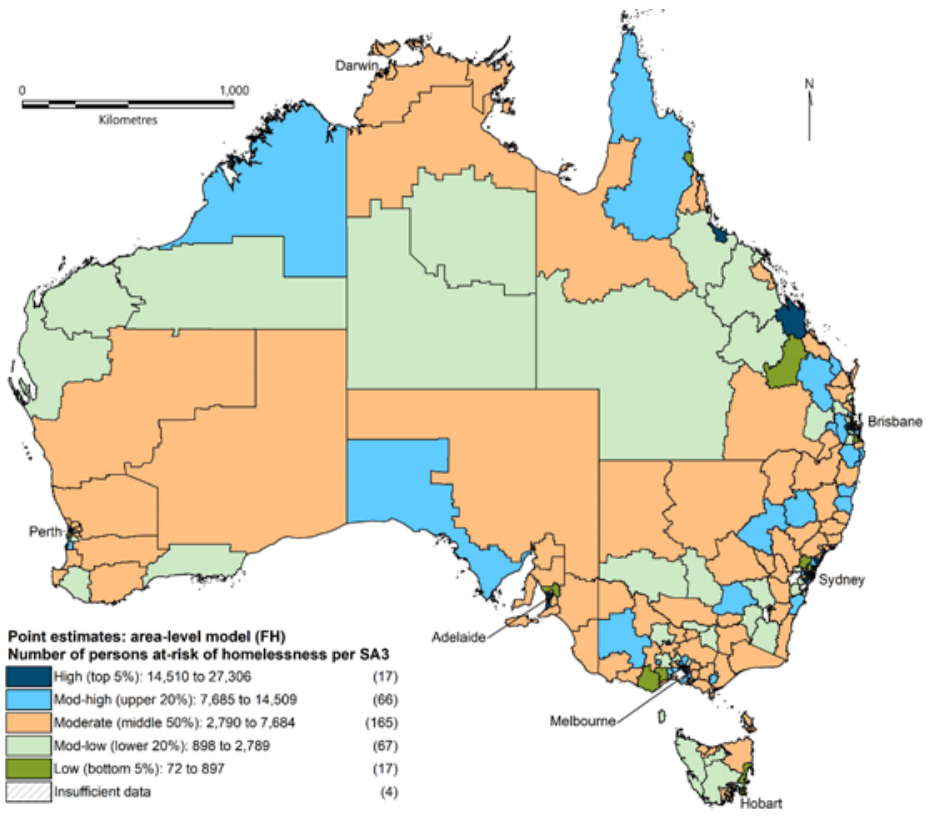

Notes: * 'Persons' are aged 15 and over and reside in a rental property. Maps exclude SA3s coded: 'Other Territory'; 'Migratory - Offshore Shipping'; and 'No Usual Address'. Insufficient data includes SA3s with population < 500.

Source: Author's calculations derived from: ABS 2016 Census of Population and Housing, and HILDA survey, waves 16 and 17; ABS digital spatial boundaries. 
The number of people at-risk adds further insight on understanding the at-risk population. As with the geographic distribution of the rate of homelessness risk (Section 4.6), there are concentrations of high and low numbers of people at-risk across the capital city areas. In addition, the numbers map highlights that areas with moderate risk levels, such as the outer west in Melbourne (Figure 12A), or substantial segments of the eastern 10 kilometre ring of Perth (Figure 12B), can still have higher concentrations of people at-risk due to their larger population size.

In general, this pattern is replicated throughout the capital cities, with the number of blue (high and very high) areas increasing relative to the rate maps in Section 4.6.

Figure 12: Point estimates, persons* at-risk of homelessness, unit-level (probit) model, capital city SA2s

Figure 12A: Sydney and Melbourne SA2S
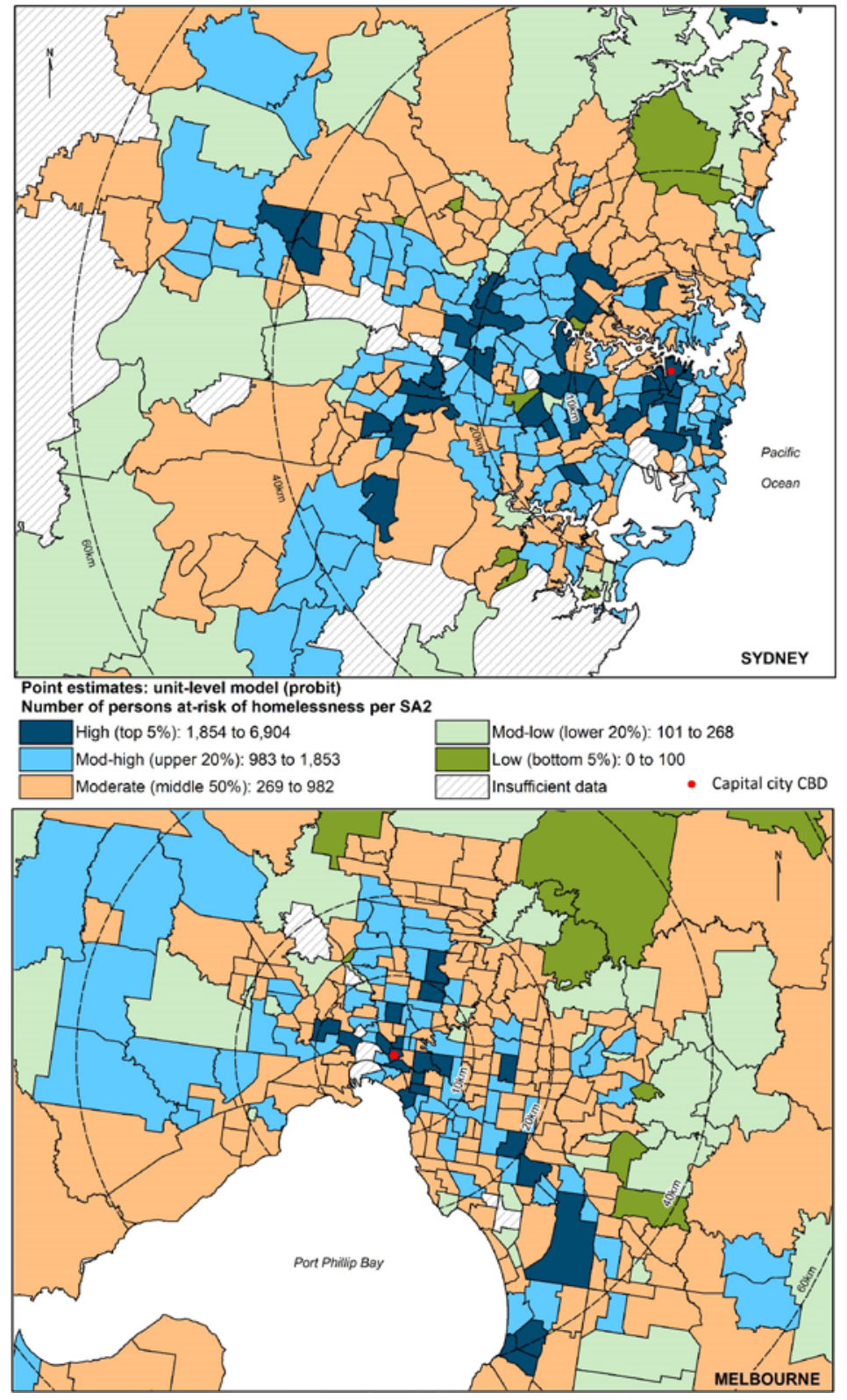

Notes: *'Persons' are aged 15 and over and reside in a rental property. Maps exclude SA2s coded: 'Other Territory'; 'Migratory - Offshore Shipping'; and 'No Usual Address'. Insufficient data includes SA3s with population < 500.

Source: Author's calculations derived from: ABS 2016 Census of Population and Housing, and HILDA survey, waves 16 and 17; ABS digital spatial boundaries. 
Figure 12B: Brisbane, Adelaide, Perth and Hobart SA2s

\section{BRISBANE}

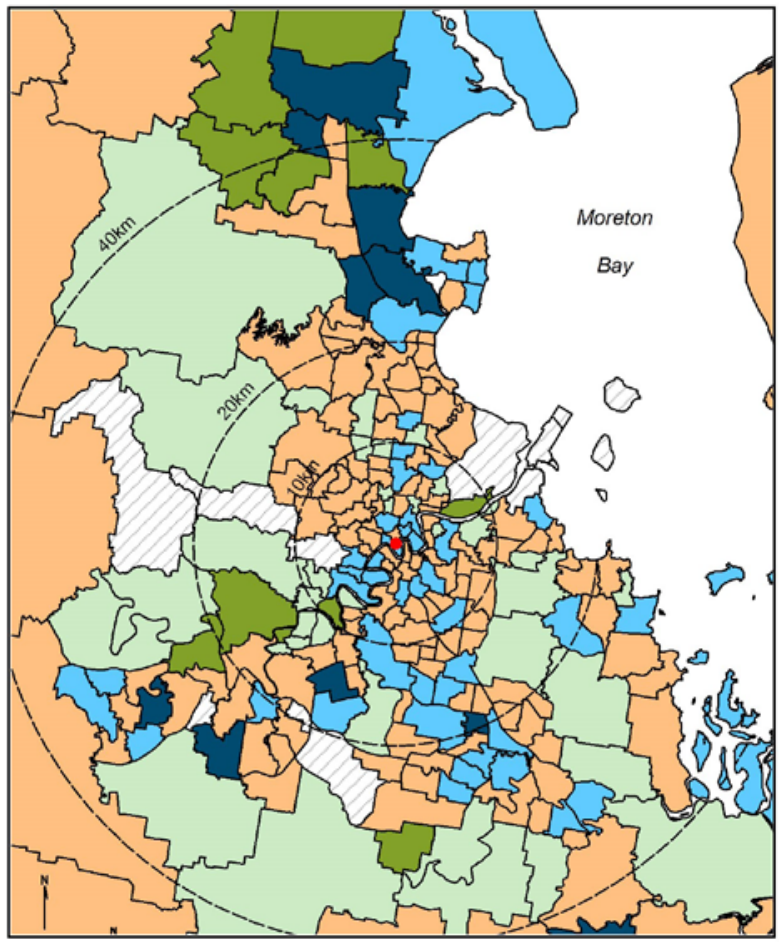

PERTH

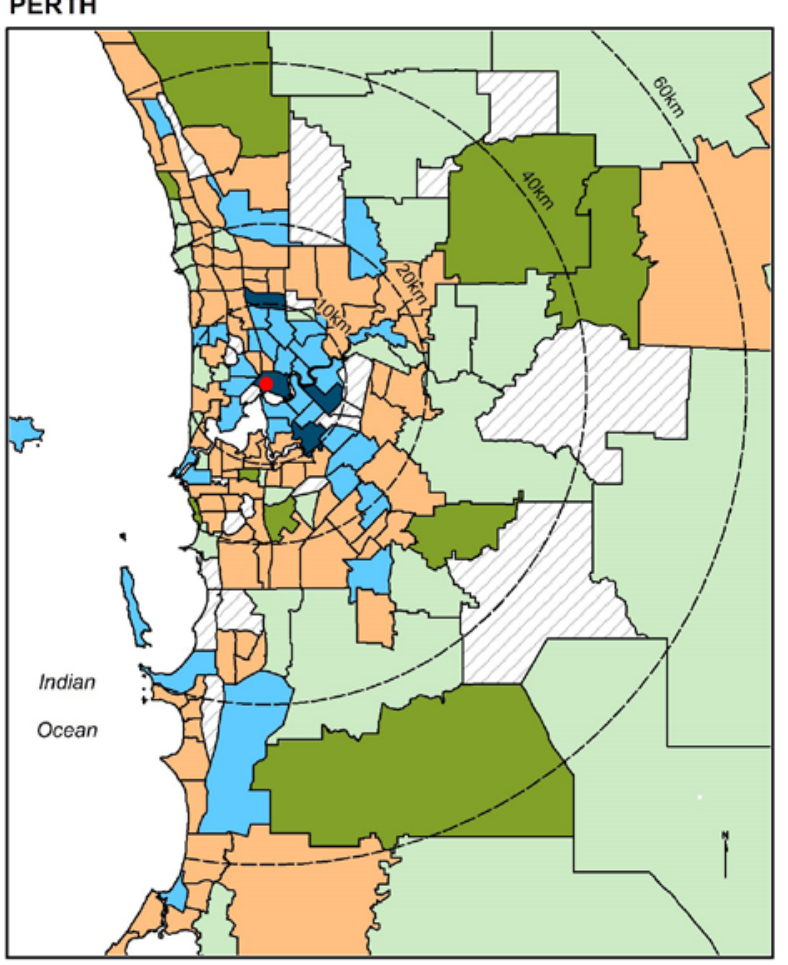

ADELAIDE

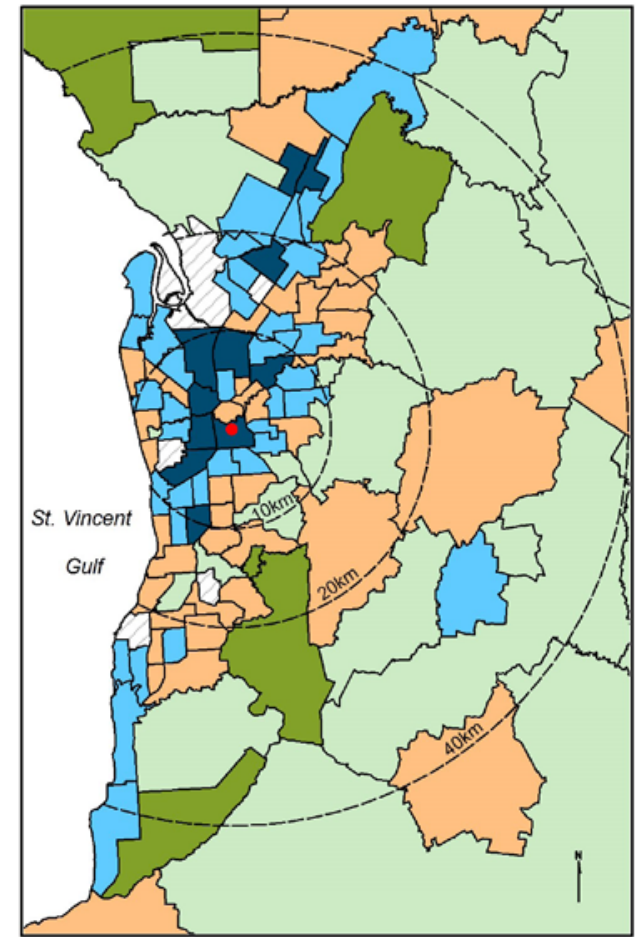

Point estimates: unit-level model (probit)

Number of persons at-risk of homelessness per SA2

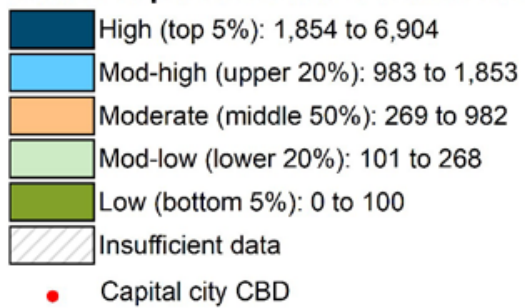

HOBART

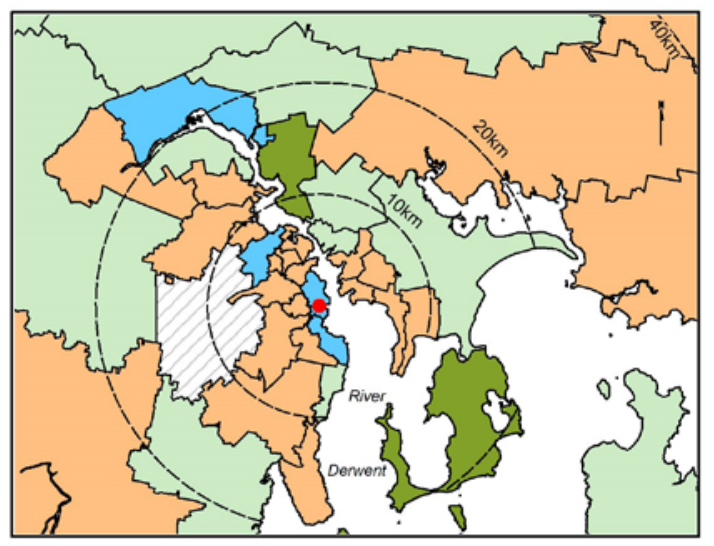

Notes: *'Persons' are aged 15 and over and reside in a rental property. Maps exclude SA2s coded: 'Other Territory'; 'Migratory - Offshore Shipping'; and 'No Usual Address'. Insufficient data includes SA3s with population < 500.

Source: Author's calculations derived from: ABS 2016 Census of Population and Housing, and HILDA survey, waves 16 and 17; ABS digital spatial boundaries. 
Within Greater Sydney, higher numbers at-risk of homelessness are evident in the city centre with corridors of high and moderately high risk extending to the west and south of the city. In Melbourne, high numbers of persons at-risk are evident in the central city area, in the middle north and inner west with a corridor extending through the south eastern suburbs. A corridor of moderately high numbers of people at-risk is also evident through the inner, middle and outer west of Melbourne and into the northern suburbs.

In Brisbane, the highest numbers of those at-risk can be found in outer suburban locations with patches of moderately high risk emanating from the central city area. In Adelaide, many of those at-risk are concentrated in the central city area with areas of moderately high risk extending to the south and north east of the city. In Perth, areas with higher numbers of people at-risk are evident in the central city area and in the inner north and inner south east of the city. Moderately high numbers of people at-risk are also concentrated around the central city areas with some extensions to the south, north and eastern suburbs. In contrast, Hobart does not have any areas with high numbers at-risk. However, it does have a cluster of moderately high risk in its city centre, with pockets extending into the north-western suburbs.

\subsection{Policy development implications}

The results in this chapter show that a large number of Australians are at-risk of experiencing homelessness. The estimates suggest that somewhere between 1.5 and 2 million Australians, aged 15 and above, may come to experience homelessness. By definition (see Section 2.3), these estimates apply to Australians currently living in rental housing. The sheer number of people at-risk of homelessness-be it 1.5 million or just over 2 millionmakes a strong case for a focus on primary prevention of homelessness in Australia.

Targeted prevention is made difficult, however, by a lack of detailed information on where those at-risk live, and their characteristics. This information can assist in developing prevention strategies at both national and local levels. The small area estimates generated by this research provides policy makers with a base level of information around the characteristics of people and areas associated with homelessness risk.

Recent research suggests that those at-risk are more likely than other private renters to change address between waves in HILDA. However, they tend to move short distances and are not highly geographically mobile (Batterham 2020). While some targeted polices towards individuals is valuable, area-based interventions remain relevant for this group.

The results highlight several implications for policy:

- There is a distinction between the rate of homelessness risk and the magnitude (number of people at-risk) of the policy challenge. SAEs provide evidence on-and distinguish between-both of these aspects.

- Many areas with an estimated high rate of homelessness risk (and thus share of people at-risk) — such as parts of the NT-have comparatively small populations. As such, the number of people at-risk, in comparative terms, small. Nevertheless, because of the higher share, more people will be living alongside other people who are at-risk.

- Conversely, many capital city areas have low or moderate rates of homelessness risk. However, due to the much larger number of people in these areas, this translates into a much larger number of people at-risk and potentially a more substantial commitment of resources.

- The policy challenge is two-fold. Firstly, addressing the factors that put an individual at-risk of homelessness, in particular localities. This requires policies that target individuals and groups at particular risk. Secondly, just because the rate of homelessness risk is low, this does not mean that the magnitude of the issue necessarily is small. This requires policy awareness and agenda-setting also in some areas where the risk of homelessness otherwise is moderate or low. Specific policy and service areas are discussed in greater detail in Chapter 5.

- The focus in this analysis has been on the risk of homelessness among Australians that are renters (private, social, community housing). In part, this constitutes a partial analysis and should not reduce or detract from known risk factors in the owner-occupied sector, such as loss of a partner in old age, household break-ups or domestic violence. 
Key characteristics of those at-risk did not vary much spatially apart from Indigenous status. However, the profile remains useful and suggests prevention and interventions policies should also target key areas at the national level, largely policy areas beyond the usual scope of homelessness policy.

- Many of those at-risk of homelessness are in receipt of income support payments (both for those who are unemployed and those outside the labour force). An increase in the rate of these payments could make substantial impact in reducing the risk of homelessness. A substantial increase in these payments would help to boost purchasing power in the private rental market for this group.

- Those at-risk were more likely to report living with a disability and fair or poor health. This is consistent with existing research that documents the role of poor physical and mental health in precipitating homelessness, as well as the substantial health impacts of homelessness (e.g. Johnson and Chamberlain 2011; Min Park, Fertig et al. 2011). There is a clear role for state and territory governments in ensuring access to supports across areas, especially for those on low-incomes.

- Indigenous Australians are overrepresented in the at-risk of homelessness population-especially in remote areas. They are also overrepresented in the homelessness population. The reasons for the heightened at-risk in the Indigenous population is only partially captured in this research. For instance, many Indigenous Australians have lower incomes. Given these factors are controlled for separately in the analysis, it is likely that homelessness risk in the Indigenous population also reflects behavioural determinants such as racism and discrimination.

The different methods used to produce the Small Area Estimates do not generate a consistent picture of homelessness risk in Australia in all areas. However, precision is greater in capital cities where sample sizes are generally larger.

- When using the estimated rates, policy makers, researchers and service providers should carefully consider the different outcomes and the degree of consistency/variability for particular areas of interest.

- When assessing whether an area should be considered to have low or high homelessness risk, care should be taken to compare an areas' position across both model-based outcomes. 


\section{Policy development options}

The overall incidence of homelessness cannot be reduced by responding to those experiencing homelessness alone. Upstream interventions are required to prevent homelessness from occurring in the first place. Such interventions must be targeted to those at-risk of homelessness, and so an understanding of the population at-risk of homelessness is required.

This project addresses the overall policy issue: how can homelessness be prevented more effectively based on a detailed understanding of the distribution of the population at-risk of homelessness across small areas in Australia?

In this chapter we discuss how a detailed understanding of the distribution of the population at-risk of homelessness across small areas in Australia can be instrumental in homelessness primary prevention. The first section focuses on how SAE can support policy planning and service delivery. The second section focuses on the national, state, and local government area level primary prevention opportunities. The policy prevention perspectives are reflective of the distribution of responsibilities across these levels and their interaction with specific at-risk factors.

\subsection{SAEs and prevention policy}

From the analysis in this report it is clear that risk of homelessness, much like homelessness itself, is a complex social, economic and spatial phenomenon. In practice, this means that no single policy or initiative will solve the challenges associated with homelessness risk. In practice, social policies are rarely delivered in a coordinated manner across multiple departments or organisations and are also guided by institutional and organisational structures. There are exceptions, particularly around youth homelessness, where place-based (or collective impact approaches) have been adopted and have also shown promise in reducing the transition of young people at-risk into homelessness (MacKenzie 2018). Similarly, housing first approaches provide a more holistic model of addressing complex social challenges. Place-based approaches require identifying the relevant population and connecting this population to appropriate supports.

Considerable data are already produced at small area levels through the Census and are used for local and statewide policy planning and service delivery. The production of SAEs for other social and economic phenomena is of particular interest to researchers and planners for improved allocation of services, as well as the basis for more dynamic systems' modelling of social processes. A summary of how SAEs can be used to support planning and delivery of a range of social services and housing policy is provided below.

First, numerous social services are delivered through partnership models that are funded through grants or needs-based assessments. To obtain grants or funding, social problems need to be quantified. SAEs provide two forms of quantification for development of local prevention policies and responses:

- In some cases, a precise number of potential service users (demand) will be required. For instance, a service provider may tender for funding intended to prevent homelessness. Both the tendering institution and the service provider will want to identify how many people form part of the potential client group. Quantification can thus be critical to obtaining funding in the first instance. 
- In other cases, it is the relative magnitude of an issue that matters in a local population. For instance, in developing local strategies or allocation of funds to particular issues, what matters is how big the issue of homelessness risk is, relative to other issues in an area. A rate measure here can be instrumental in fixing attention to specific social risks, and also in the ranking of issues relative to each other.

- The results in Chapter 4 also show that some areas with (very) high rates of homelessness risk are located next to areas with (very) low rates. The combination of estimated homelessness risk rate, and numbers at SA2-level in capital cities, can thus also improve understanding of equitable spatial housing opportunity across metropolitan areas, and within local government areas.

Second, the location of services is instrumental in the efficacy of service delivery. For instance, an increase in distance of welfare services is often associated with a decrease in service uptake (e.g. Allard, Tolman et al. 2003). Evidence on the spatial distribution and location of potential service users is therefore key to planning and targeting services and enabling uptake of service use to ensure efficacy of public and not-for-profit investment. Additional profiling and mapping of risk factors can further contribute to the locational decision of specific services.

Third, local and state governments, as well as NFP service providers and funders (including philanthropic) are concerned with evidencing and tracing impacts or policy efficacy. SAEs quantify local populations of those at-risk of homelessness and so provide a basis for developing evidence informed 'success' indicators and criteria for monitoring service delivery and impact.

In summary, quantification of social and economic phenomena is key to the development of many social policies and strategies. SAEs of homelessness risk provide policy makers, NFP service providers and funders with quantified area-based estimates of need to assist in maximising the efficiency preventative initiatives, by reducing the distance between potential service users and location of service provision.

In the next section, we detail a range of policy options for primary prevention of homelessness for different levels of government. Targeting and monitoring of policy impact-whether the policy initiative is spatial or aspatial in nature-is enhanced through SAE of homelessness risk.

\subsection{Primary prevention opportunities for state, territory and local governments}

Many state, territory and local government policies and services have a specific spatial dimension such as administrative boundaries, spatial location of specific services. Our findings suggest numerous opportunities for state, territory and local governments to enact primary homelessness primary prevention initiatives that often have a spatial dimension.

\section{Increasing the supply of rental housing affordable to those on low-incomes}

There is a well-documented shortage of affordable private rental for low-income households (Anglicare Australia 2021; Hulse, Reynolds et al. 2019) and social housing options (Lawson, Pawson et al. 2018). By definition (see Section 2.3), all those at-risk of homelessness in this study will be residing in these tenures. To address risk factors, but also maximise any risk-reducing effect of income increases, an increase in availability of rental housing options for low-income households is required. The ongoing COVID-19 environment has resulted in some reductions in rental levels (particularly for apartment style dwellings in central city locations (National Housing Finance Investment Corporation 2020). However, it seems unlikely that these changes will be permanent. Firstly, the current overall housing shortage is a cumulative effect that has evolved over the last two decades (Burke, Nygaard et al. 2020); secondly, at the very least some migration will resume in the medium term. ${ }^{26}$ Addressing the housing availability

26 The halt to migration as a consequence of COVID-19 has resulted in a decline in rents in segments of the private rental markets, particularly central and CBD parts of capital cities (NHFIC 2020). 
and cost aspect of homelessness risk will-in an environment of a housing shortage-require provision of housing options that also are specifically linked to those on low-incomes and/or those at-risk of homelessness. Scaling up the provision of social and affordable housing options (with income tied requirements) provide one option for achieving this.

States and territories have strategies to increase the supply of social and affordable housing. In the case of the Social and Affordable Housing Fund in NSW (NSW 2019), proposals for tenders were required to demonstrate local need or demand for affordable housing. The geographical distribution of the at-risk population is a highly valuable metric in planning affordable rental housing in such schemes.

Further, there is ongoing monitoring of the supply of affordable private rental housing in other states (see Department of Health and Human Services (VIC), 2021). The distribution of those at-risk could be combined with this supply data to inform where new affordable rental supply is most needed. In VIC for example, our SAEs suggest that this is in a number of middle and inner suburbs of Greater Melbourne. Future research could explore the detailed demographic profile of those at-risk in each SA3 to tailor further policy interventions.

The profile of those at-risk also suggests opportunities for enhancing existing secondary prevention initiatives. This includes private rental access programs that provide ongoing rent subsidies for people at imminent risk of homelessness, as well as the payment of rent arrears and advocacy with landlords. Given the proportion of those at-risk accessing existing material aid services, such agencies could provide initial engagement and refer on to, or have co-located, secondary prevention housing services. Such services could be targeted to areas with larger numbers of people at-risk of homelessness.

As housing policy sits across all three levels of government in Australia, there is an important role for cooperation to increase the supply of affordable housing for this population.

\section{Targeted support for Indigenous communities}

Being Indigenous is associated with greater homelessness risk - with the majority at-risk in remote areas being Indigenous. Indigenous persons are also much more likely to experience actual homelessness. This heightened risk is incorporated in Batterham's (2019a) definition. In modelling homelessness risk an effect remains after controlling for socio-economic variation so it is unlikely that the heightened risk of being Indigenous merely reflects systematic differences in socio-economic characteristics. While Indigenous status may capture some unobserved socio-economic characteristic that are correlated with homelessness risk, we believe that Indigenous status is associated with higher risk of homelessness due to discriminatory practices and the ongoing legacy of colonialism in Australia. It is essential that targeted support for Indigenous communities is developed in consultation with those communities.

While our SAEs in remote areas show greater variability, it is noteworthy that a number of regional and remote areas in the NT, WA, QLD and SA have high rates of homelessness risk. A large proportion of those at-risk in these areas are Indigenous. These areas also have some of the highest rates of homelessness in the country and would benefit from targeted support. Given known issues with the standard and quantum of housing in remote Indigenous communities, our SAEs of homelessness risk could inform a revamped National Partnership on Remote Housing and/or state level strategies on remote Indigenous housing.

\section{Health and disability}

Those at-risk are more likely to report living with a disability and fair or poor health. This is consistent with existing research which documents the role of poor physical and mental health in precipitating homelessness as well as the substantial health impacts of homelessness (e.g. Johnson and Chamberlain 2011; Min Park, Fertig et al. 2011). There is a clear role for state and territory governments to ensure access to health and disability supports across areas, especially for those on low-incomes. SAEs can be used to enhance and expand services in areas with higher demand from those at-risk. These findings also highlight the importance of national safety net schemes such as Medicare, the pharmaceutical benefit scheme (PBS) and the national disability insurance scheme (NDIS). 


\section{Education}

The detailed national profile produced in HILDA highlights that those at-risk have lower levels of educational attainment and many of those at-risk have children living with them. Given what is known about intergenerational transmission of poverty, homelessness, and low educational attainment (Cobb-Clark 2019; Cobb-Clark and Zhu 2015), state and territory government investment in educational engagement for disadvantaged students could pay off in-terms of reducing future risk of homelessness. This is consistent with the existing work of the Reconnect program, which aims to stabilise family relationships (where appropriate) and keep young people connected to education and employment (Mission Australia 2016). Additional supports for further education and training for adults with low educational attainment may also be required. SAEs can be used to enhance and expand preventative services based at educational facilities.

\subsection{Primary prevention opportunities for the Australian government}

Many national policies are less spatial in nature or targeting. Nevertheless, quantification at small-area levels provide critical information for monitoring impacts of policies and particularly in understanding differences in the efficacy of national policies across different population groups and areas.

\section{Increasing incomes and coordinating efforts across all levels of government}

In terms of national levers for primary prevention of homelessness risk, key priority areas include: increasing the levels of income support payments; increasing labour market earnings for the lowest paid; and playing a coordinating role in primary prevention policy.

The majority of those at-risk of homelessness are in low-income households. The significance of low-income is highlighted by the higher rates of rental stress and material deprivation experienced by those at-risk, such as skipping meals and being unable to heat their homes. Low-income is associated with both federal level and state level policies, such as the level at which benefits and social security payments are set; but, also the functioning of labour markets and industrial relations policy (typically an issue for states except for VIC), such as low pay, reduced working hours or insecure employment. An increase in income levels would reduce the risk of homelessness across the population, by improving the ability of individuals to obtain housing and maintain tenancies.

Given that many are in receipt of income support payments (both for those who are unemployed and those outside the labour force), an increase in the rate of these payments could make substantial impact in reducing the risk of homelessness. Around a quarter of the at-risk population are in paid employment suggesting a need to increase the rates of pay or income stability among this group. A substantial increase in income levels would help to boost purchasing power in the private rental market and reduce rental stress, as seen with Australian Government supplements during the pandemic (Pawson, Martin et al. 2021; Verdouw, Yanotti et al. 2020).

There is also a need for all levels of government to work together on homelessness primary prevention. The Australian Government is best positioned to play a coordinating role through the development of a national housing and homelessness policy.

The capacity to operationalise a definition of homelessness risk in HILDA provides important opportunities to monitor the size and profile of the national population at-risk of homelessness over time. This information will be useful in evaluating the impacts of primary prevention initiatives at the national level. Comparing differences in profile to those experiencing homelessness and those at-risk can suggest particular cohorts in need of targeted interventions to mitigate the risks they face. 


\subsection{Future research}

The work presented in this report opens a space for further research on homelessness risk in Australia, which is essential to further developing evidence-based prevention policies.

Preliminary work on mobility among those at-risk (Batterham 2020) indicates this group are no more geographically mobile than those not at-risk but renting privately. Spatially informed prevention policies are clearly relevant.

More work is needed to understand why those at-risk transition into homelessness and how these reasons may vary for different groups within the population at-risk. It also seems likely that the drivers of transitions into and out of homelessness may vary between areas due to location-specific factors. For example, existing research suggests that local private rental market conditions have an impact on homeless exits (Johnson, Scutella et al. 2019) - with people more likely to exit homelessness in areas with lower rents. Other research suggests that rent levels have an impact on entries into homelessness, but only in greater capital city areas (Batterham 2020).

The definition of risk used is in its infancy and more work is needed to refine and improve its utility. Most existing risk mechanisms are weighted equally in the definition and work is needed to understand the relative priority of different risk mechanisms, not just on transitions into or out of homelessness, but in terms of the duration and complexity of homelessness. Our operationalisation of the 'tight housing market' criteria as experiencing rental stress has meant that income is prioritised as a risk mechanism. How and why other mechanisms should be weighted remains a question to be addressed in future empirical work.

As mentioned in the section on limitations, experiences of interpersonal violence were not included in the risk definition. There is ongoing debate about whether experiences of violence and abuse themselves constitute a form of homelessness or whether they merely place people at-risk of homelessness. Future research is needed to explore how experiences of violence and abuse might be included in the risk definition and the consequences of doing so. Relatedly, more research is needed exploring the dynamics of transitions into homelessness from home ownership-especially when that transition involves violence and abuse.

A consequence of the detailed data items required to operationalise risk in HILDA is that those under 15 years of age have not been included in our estimates of the at-risk population. One option is to include any children in at-risk households as also at-risk. However, this seems likely to produce an underestimate with certain cohorts of young people at particular risk. Specifically, youth identifying as sexually and gender diverse, as well as those experiencing violence in the home. Detailed work is needed in this area.

Much of this future work requires detailed longitudinal data. Specifically, it requires an indicator of homelessness in longitudinal surveys such as HILDA and the resurrection of a data collection such as Journeys Home (a longitudinal survey of people experiencing or vulnerable to homelessness).

\subsection{Improved data access and coverage}

The Census provides an invaluable resource for social and economic research in Australia. At the same time, it is impractical to significantly expand the collection of Census data. Survey data, such as HILDA, the Survey of Income and Housing and the General Social Survey are based on sampling to nationally representative standards. This leaves a gap in detailed social and economic data provision at small area levels. SAE techniques, such as those applied in this research, provide a solution to this gap. However, as highlighted by our results, the quality of SAE production remains dependent on the sampling frame and sampling uncertainties, as well as the quality and accessibility of auxiliary data from other data sources. 
With respect to sampling in HILDA it is clear that areas that are of particular interest to homelessness primary prevention-such as remote and sparsely populated areas-are under-represented or not sampled at all (see Figure A2 in Appendix 2). Therefore, the production of SAEs in these areas becomes overly reliant on the ability of the model component of SAE technique to predict variables of interest (i.e. homelessness risk). The direct incorporation of spatial heterogeneity (representative of these areas) is reduced and/or the lower sample sizes in non-capital city areas are subject to greater variability and uncertainty. Sampling variability goes somewhat beyond the pure technical or methodological aspects of SAE production. Under-sampled areas are also areas that are of particular interest/value for targeting policies to 'closing the gap'. There is, therefore, an important ethical dimension to ensuring survey sample design reflects the presence, needs and rights of remote Indigenous communities.

Throughout this report, the key source of auxiliary (non-HILDA) data is the Census. However, the ability to fully utilise Census data is restricted by access constraints. In the first instance, the value of TableBuilder for the production of SAE is severely limited by restrictions on cross-tabulating some variables of interest (e.g. income and housing tenure). Obtaining custom data from the ABS is, in and of itself, straight forward, but comes at an additional cost that inhibits model refinement or adaptation. In the second instance, access to the 5 per cent unit record sample is unnecessarily restrictive and during COVID-19 significantly curtailed by the requirement to undertake specific face-to-face training (suspended during 2020) before accessing the data.

Finally, any work on the dynamics of risk and transitions into homelessness requires longitudinal or panel data. That includes those at-risk of homelessness and also those experiencing homelessness. Including an indicator of homelessness in HILDA would help with some of this work. However, the detailed understanding of homelessness made possible with Journeys Home is also critical.

\subsection{Final remarks}

This report offers the first full operationalisation of the Batterham (2019a) definition of homelessness risk and provides a national enumeration and profile of the population at-risk in Australia. The report also established the incidence of homelessness risk in small areas across Australia; and explored geographical differences in the profile of this population in small areas. Understanding the quantum, location and profile of those at-risk of homelessness can enable more nuanced development of primary prevention initiatives. This information can be used to measure impact and also to guide the spatial allocation of resources - in particular affordable rental housing, homeless secondary prevention interventions and health and disability services.

Two SAE techniques were used to develop estimates of the rate of homelessness risk (per 10,000 persons) and the number of people at-risk within each SA2/SA3. The different techniques used bring different strengths and weaknesses to the research. As discussed above, improving sampling coverage and/or access to existing Census data would enable researchers to improve small area estimates of homelessness risk.

To conclude, it is worthwhile to reiterate some of the methodological issues that remain in estimating homelessness risk in small areas across Australia. Poor coverage in remote areas of Australia in the HILDA survey has a flow-on effect to the reliability and precision of SAEs. While the unit-level approach enables us to predict risk at small areas, the model itself is aspatial. That is, the model assumes that the characteristics that predict being at-risk of homelessness do so in urban as well as regional and remote areas, and this may not be the case. It is conceivable that people's characteristics intersect with area-level factors in varying ways geographically. Indeed, Parkinson, Batterham et al. (2019) found that the relationship between rates of homelessness and area-based factors (including regional demographic profiles) changed across area types, with unique circumstances in remote areas. It seems plausible that this could be the same for risk of homelessness. This is an issue for small area estimation using the unit-level approach employed here. Alternative forms of unit-level approaches-such as those based on the 5 per cent Census sample-may potentially overcome this issue. 
The area-level approach addresses this issue in part by combining direct estimates (at SA3 level) in HILDA (although subject to small sample issues) with regression synthetic estimates. The area-level model, in addition, includes an indicator for capital cities. Other spatial indicators were not found significant. However, the direct estimates these models draw on remain (to varying degrees) reliant on the sampling frame and variability of HILDA. This sampling frame is known to exclude remote and very remote parts of Australia, which limits the reliability of our estimates in these areas.

Confidence intervals indicate that our estimates from both approaches are less reliable in remote areas of Australia, particularly the northern remote areas. In essence, this suggests that our estimates for remote parts of Australia should be used with caution.

Notwithstanding issues around sampling, data availability and access, the results in this report demonstrate that a large number of Australians (1.5-2.0 million) are at-risk of homelessness. By definition, the at-risk population in this study lives in rental housing. The number, spatial distribution, and profile of those at-risk has enabled the identification of policy development options for the focus of primary prevention policy in Australia. Additional research is needed in a variety of areas to further explore risk and test and refine the definition of homelessness risk used in this study. 


\section{References}

Allard, S., Tolman, R. and Rosen, D. (2003) 'Proximity to Service Providers and Service Utilization Among Welfare Recipients: The Interaction of Place and Race', Journal of Policy Analysis and Management, vol. 22, no. 4: 599-613.

Anglicare Australia (2021) Rental Affordability Snapshot, Anglicare Australia, Canberra.

Apicello, J. (2010) 'A Paradigm Shift in Housing and Homeless Services: Applying the Population and High-Risk Framework to Preventing Homelessness', The Open Health Services and Policy Journal, vol. 30: 41-52.

Australian Bureau of Statistics (2012) Census of Population and Housing: Estimating Homelessness, Cat. No. 2049.0, ABS, Canberra.

Australian Bureau of Statistics (2015) General Social Survey: Summary Results, Australia, 2014, Cat. No 4159.0 [Online], ABS, Canberra, http://www.abs.gov.au/ausstats/abs@.nsf/mf/4159.0, accessed 16 August 2016.

Australian Bureau of Statistics (2017) Household Expenditure Survey and Survey of Income and Housing, User Guide, Australia, 2015-16, Cat. No. 6503.0, ABS, Canberra, https://www.abs.gov.au/AUSSTATS/abs@.nsf/Lookup/6503.0 Glossary12015-16? OpenDocument, accessed 3 June 2020.

Australian Bureau of Statistics (2018a) Australian Statistical Geography Standard (ASGS), ABS, Canberra. Available at: https://www.abs.gov.au/websitedbs/d3310114.nsf/home/australian+statistical+geography+standard+(asgs).

Australian Bureau of Statistics (2018b) Census of Population and Housing: Estimating homelessness, 2016, Cat. No 2049.0 [Online], ABS, http://www.abs.gov.au/AUSSTATS/abs@.nsf/Lookup/2049.0Main+Features12016?OpenDocument, accessed 3 June 2018.

Australian Bureau of Statistics (2020) General Social Survey, Summary Results, Australia, 2019, Table 12, ABS, Canberra, https://www.abs.gov.au/statistics/people/people-and-communities/general-social-survey-summary-results-australia/ 2019\#social-experiences, accessed 27 April 2021.

Australian Institute of Health and Welfare (2013) Specialist Homelessness Services Collection Manual, Cat. No. HOU 268, AlHW, Canberra, http://www.aihw.gov.au/WorkArea/DownloadAsset.aspx?id=60129543495, accessed.6 June 2020

Australian Institute of Health and Welfare (2015) Specialist Homelessness Services 2014-2015, Cat. No. WEB 99 [Online], AlHW, Canberra, http://www.aihw.gov.au/homelessness/specialist-homelessness-services-2014-15/\#toc, accessed 12 March 2016.

Australian Institute of Health and Welfare (2017) National Drug Strategy Household Survey 2016: detailed findings, Cat. No: PHE 214. https://www.aihw.gov.au/reports/illicit-use-of-drugs/2016-ndshs-detailed/summary, accessed 15 May 2020.

Australian Institute of Health and Welfare (2020) Specialist Homelessness Services 2019-2020, Cat. No: HOU 322, AlHW, Canberra, https://www.aihw.gov.au/reports/homelessness-services/specialist-homelessness-services-annual-report/ contents/clients-services-and-outcomes, accessed 12 June 2020.

Batterham, D. (2012) 'The Structural Drivers of Homelessness: Exploring the Relationships Between Housing Market, Labour Market, Demographics, Service Availability and Homelessness in Victoria', Sixth Australasian Housing Researchers' Conference, University of Adelaide.

Batterham, D. (2019a) 'Defining “At-risk of Homelessness”: Re-connecting Causes, Mechanisms and Risk', Housing, Theory and Society, vol. 36, no. 1: 1-24, doi:10.1080/14036096.2017.1408678. 
Batterham, D. (2019b) ‘Homelessness as Capability Deprivation: A Conceptual Model', Housing Theory and Society, vol. 36, no. 3: 274-297.

Batterham, D. (2020) Clarifying the relationship between homelessness and private rental markets in Australia: Capabilities, Risk, Mobility and Geography, PhD Thesis, Swinburne University of Technology.

Batterham, D. (2021) 'Who is At -risk of Homelessness? Enumerating and Profiling the Population to Inform Prevention', European Journal of Homelessness, vol. 15, no. 1: 59-83.

Beer, A., Baker, E., Lester, L. and Lyrian, D. (2019) ‘The Relative Risk of Homelessness among Persons with a Disability: New Methods and Policy Insights', International Journal of Environmental Research and Public Health, vol. 16, no. 22: 4304-,4316 doi:10.3390/ijerph16224304.

Beer, A., Baker, E., Mallett, S., Batterham, D., Pate, A. and Lester, L. (2011) Addressing Homelessness Amongst Persons with a Disability: Identifying and Enacting Best Practice, A FaHCSIA National Homelessness Research Project, The University of Adelaide, Hanover Welfare Services, Melbourne Citymission, The University of Melbourne, Australia.

Blair, K., Dunn, K., Kamp, A. and Alam, O. (2017) Challenging Racism Project 2015-16 National Survey Report, Western Sydney University, Sydney.

Bramley, G. and Fitzpatrick, S. (2017) 'Homelessness in the UK: Who is Most at-risk?', Housing Studies, vol. 33, no. 1: 96-116, doi:10.1080/02673037.2017.1344957.

Buckner, J. C. (2008) 'Understanding the Impact of Homelessness on Children: Challenges and Future Research Directions', American Behavioral Scientist, vol. 51, no. 6: 721-736, doi:10.1177/0002764207311984.

Burke, T., Nygaard, C. and Ralston, L. (2020) Australian home ownership: past reflections, future directions, AHURI Final Report No. 328, Australian Housing and Urban Research Institute Limited, Melbourne, http://www.ahuri.edu.au/ research/final-reports/328, doi:10.18408/ahuri-5119801.

Busch-Geertsema, V. and Fitzpatrick, S. (2008) 'Effective Homelessness Prevention? Explaining Reductions in Homelessness in Germany and England', European Journal of Homelessness, vol. 2: 69-95.

Chamberlain, C., Johnson, G. and Theobald, J. (2007) Homelessness in Melbourne: Confronting the Challenge, Centre for Applied Social Research, RMIT University, Melbourne.

Chigavazira, A., Johnson, G., Moschion, J., Scutella, R., Tseng, Y. and Wooden, M. (2013) Journeys Home research report No. 2, Wave 1 and 2 findings, Melbourne Institute of Applied Economic and Social Research, Melbourne.

Chigavazira, A., Johnson, G., Moschion, J., Scutella, R., Tseng, Y. and Wooden, M. (2014) Journeys Home Research Report No. 5, Findings from Waves 1 to 5: Special Topics, Melbourne Institute of Applied Economic and Social Research, Melbourne.

Cobb-Clark, D. A. (2019) Intergenerational Transmission of Disadvantage in Australia: Life Course Centre Working Paper Series, 2019, Institute for Social Science Research, The University of Queensland, Queensland.

Cobb-Clark, D. A. and Zhu, A. (2015) Childhood Homelessness and Adult Employment: The Role of Education, Incarceration, and Welfare Receipt, Melbourne Institute Working Paper, No. 18/15, Melbourne Institute of Applied Economic and Social Research, Melbourne.

Commonwealth of Australia (2008) The Road Home: A National Approach to Reducing Homelessness, Commonwealth of Australia, Canberra.

Commonwealth of Australia (2017) A New National Housing and Homelessness Agreement, Federal Budget Fact Sheet 1.7 [Online], Commonwealth of Australia, Canberra, http://www.budget.gov.au/2017-18/content/glossies/factsheets/ download/FS_17_Housing_Affordability.pdf, accessed 19 July 2017.

Commonwealth of Australia (Department of Health) (2017) National Drug Strategy 2017-2026, Publications Number: 11814, Commonwealth of Australia (Department of Health), Canberra, available at: https://www.health.gov.au/sites/ default/files/national-drug-strategy-2017-2026_1.pdf.

Culhane, D., Metraux, S. and Byrne, T. (2011) 'A Prevention-Centered Approach to Homelessness Assistance: A Paradigm Shift?', Housing Policy Debate, vol. 21, no. 2: 295-315, doi:10.1080/10511482.2010.536246.

D'Souza, G., Tanton, R., Abello, A., Mohanty, I. and Thurecht, L. (2013) Geographical Analysis of the Risk of Homelessness, NATSEM, University of Canberra, Canberra. 
Department for Communities and Local Government (England) (2012) Making Every Contact Count: A Joint Approach to Preventing Homelessness, Department for Communities and Local Government London, U.K., https://www.gov.uk/ government/publications/making-every-contact-count-a-joint-approach-to-preventing-homelessness, accessed 12 August 2016.

Department of Communities (WA) (2020) All paths lead to a home: Western Australia's 10 year Strategy on Homelessness, 2020-2030, Government of Western Australia, Perth.

Department of Health and Human Services (VIC) (2021) Rental Report: December quarter 2020, Department of Health and Human Services, Melbourne, https://www.dhhs.vic.gov.au/publications/rental-report, accessed 15 October 2021

Department of Human Services (VIC) (2010) A Better Place: Victorian Homelessness 2020 Strategy - New Directions to Reduce Homelessness in Victoria, Victorian Government Department of Human Services, Melbourne.

Durso, L. E. and Gates, G. J. (2012) Serving Our Youth: Findings from a National Survey of Services Providers Working with Lesbian, Gay, Bisexual and Transgender Youth Who Are Homeless or At-risk of Becoming Homeless, Williams Institute, UCLA with True Colors Fund and The Palette Fund, Los Angeles, available at http://escholarshi:org/uc/ item/80x75033.

Edgar, W., Harrison, M., Watson, and Busch-Geertsema, V. (2007) Measurement of Homelessness at European Union Level, European Commission, Employment Social Affairs and Equal Opportunities DG, Brussels.

Fay, R. and Herriot, R. (1979) ‘Estimates of income for small places: An application of James-Stein procedures to census data', Journal of the American Statistical Association, vol. 74: 269-277.

Fertig, A. R. and Reingold, D. A. (2008) 'Homelessness Amoung At-risk Families: A Study of 20 American Cities', The Social Service Review, vol. 82, no. 3: 485-510.

Fitzpatrick, S. and Christian, J. (2006) 'Comparing Homelessness Research in the US and Britain', International Journal of Housing Policy, vol. 6, no. 3: 313-333.

Flatau,P., Zaretzky, K., Brady, M., Haigh, Y. and Martin, R. (2008) The cost-effectiveness of homelessness programs: a first assessment, AHURI Final Report No. 119, Australian Housing and Urban Research Institute Limited, Melbourne, https://www.ahuri.edu.au/research/final-reports/119.

Gaetz, S. (2012) The Real Cost of Homelessness: Can We Save Money by Doing the Right Thing?, Canadian Homelessness Research Network Press, Toronto.

Gaetz, S. and Dej, E. (2017) A New Direction: A Framework for Homelessness Prevention, COH Research Report No. 15, Canadian Observatory on Homelessness Press, Toronto.

Goodman, L., Saxe, L. and Harvey, M. (1991) 'Homelessness as Psychological Trauma - Broadening Perspectives', American Psychologist, vol. 46, no. 11:1219-1225.

Government of South Australia (2019) Our Housing Future 2020-2030, Government of South Australia, Adelaide.

Halbmeier, C., Kreutzmann, A.K., Schmid, T. and Schröder, C. (2019) 'The fayherriot command for estimating small-area indicators', The Stata Journal, vol. 19, no. 3: 626-644, doi:10.1177/1536867X19874238.

Hulse, K., Reynolds, M., Nygaard, C., Parkinson, S. and Yates, J. (2019) The supply of affordable private rental housing in Australian cities: short-term and longer-term changes, AHURI Final Report No. 323, Australian Housing and Urban Research Institute Limited, Melbourne, http://www.ahuri.edu.au/research/final-reports/323, doi: 10.18408/ahuri5120101.

Hulse, K., Reynolds, M. and Yates, J. (2014) Changes in the Supply of Affordable Housing in the Private Rental Sector for Lower Income Households, 2006-11, AHURI Final Report No. 235, Australian Housing and Urban Research Institute, Melbourne. https://www.ahuri.edu.au/research/final-reports/235.

Johnson, G. and Chamberlain, C. (2011) 'Are the Homeless Mentally III?', Australian Journal Of Social Issues, vol. 46, no. 1: 29-48.

Johnson, G. and Tseng, Y. (2014) Social Networks and Social Support, in A. Chigavazira, G. Johnson, J. Moschion, R. Scutella, Y., Tseng and M. Wooden (eds), Journeys Home Research Report No. 5, Findings from Waves 1 to 5 : Special Topics, Melbourne Institute of Applied Economic and Social Research, Melbourne, 37-52.

Johnson, G., Tseng, Y., Scutella, R. and Wood, G. (2015) How do Structural Factors and Individual Characteristics Interact to Effect Homelessness: A Provisional Analytical Framework, AHURI Positioning Paper 161, Australian Housing and Urban Research Institute, Melbourne, https://www.ahuri.edu.au/research/final-reports/248. 
Johnson, G., Scutella, R., Tseng, Y. P. and Wood, G. (2019) 'How do housing and labour markets affect individual homelessness?', Housing Studies, vol. 34, no. 7: 1089-1116, doi:10.1080/02673037.2018.1520819.

Kirkman, M., Keys, D., Bodzak, D. and Turner, A. (2010) 'Are We Moving Again This Week? Children's Experiences of Homelessness in Victoria, Australia', Social Science and Medicine, vol. 70, no. 7: 994-1001, doi:10.1016/j. socscimed.2009.12.004.

Kolar, V. (2019) Evaluation Report, 'No Child Misses Out': Education Pathways Program, Launch Housing, Melbourne.

Lawson, J., Pawson, H., Troy, L., van den Nouwelant, R. and Hamilton, C. (2018) Social housing as infrastructure: an investment pathway, AHURI Final Report 306, Australian Housing and Urban Research Institute Limited, Melbourne. https://www.ahuri.edu.au/research/final-reports/306 doi: 10.18408/ahuri-5314301

Lee, B. A., Tyler, K. A. and Wright, J. D. (2010) 'The New Homelessness Revisited', Annual Review of Sociology, vol. 36, no. 1: 501-521, doi:10.1146/annurev-soc-070308-115940.

Lester, L. and Faulkner, D. (2020) At-risk: Understanding the population size and demographics of older women at-risk of homelessness in Australia, Social Ventures Australia, Sydney.

Lohr, S. (2010) Sampling: design and analysis, Brooks/Cole, Cengage Learning, Boston, MA.

MacKenzie, D. (2018) Interim report: The Geelong Project 2016-2017, Swinburne University and Barwon Child Youth and Family Services, Melbourne, apo.org.au/node/133006

MacKenzie, D., Flatau,P:, Steen, A. and Thielking, M. (2016) The cost of youth homelessness in Australia, research briefing, Swinburne University, Melbourne, available at: https://apo.org.au/node/63479.

Mallett, S., Bentley, R., Baker, E., Mason, K., Keys, D., Kolar, V. and Krnjacki, L. (2011) Precarious Housing and Health Inequalities: What are the Links?, Hanover Welfare Services, University of Melbourne, University of Adelaide, Melbourne Citymission, Australia.

Martinez Jr, A. (2019) 'Small area estimation and big data', International Workshop on SDG Disaggregation, 28-29 January, available at https://unstats.un.org/sdgs/files/meetings/sdg-inter-workshop-jan-2019/Session\%207.a_ADB_Small\%20 Area\%20Estimation\%20-\%20jan29.pdf

Mavromas, K., King, D., Macaitis, K., Mallett, S. and Deb, B. (2011) Finding Work: Homelessness and Unemployment, National Institute of Labour Studies, Flinders University, Adelaide.

McNair, R., Andrews, C., Parkinson, S. and Dempsey, D. (2017) GALFA LGBTI Homelessness Research Project Stage 1 Report: LGBTI Homelessness: Preliminary findings on risks, service needs and use, University of Melbourne, Swinburne University of Technology, Melbourne, http://www.lgbtihomeless.com/.accessed 9 June 2020.

Min Park, J., Fertig, A. R. and Metraux, S. (2011) 'Changes in Maternal Health and Health Behaviors as a Function of Homelessness', Social Service Review, vol. 85, no. 4: 565--585, doi:10.1086/663636.

Mission Australia (2016) Reconnect evaluation 2016, Mission Australia, Sydney, available at: https://www.missionaustralia. com.au/publications/research/homelessness-research.

National Housing Finance Investment Corporation (2020) State of the nation's housing National Housing Finance Investment Corporation, Sydney.

NSW Government (2019) NSW Homelessness Strategy 2018-2023, NSW Government, Sydney, available at: https://www. facs.nsw.gov.au/download?file=590515.

O'Flaherty, B. (2004) 'Wrong Person and Wrong Place: For Homelessness, the Conjunction is what Matters', Journal of Housing Economics, vol. 13, no. 1: 1-15, doi:10.1016/j.jhe.2003.12.001.

Ong, R., Wood, G. and Colic-Peisker, V. (2015) 'Housing older Australians: Loss of Homeownership and Pathways into Housing Assistance', Urban Studies, vol. 52, no. 16: 2979-3000, doi: 10.1177/0042098014550955.

Parkinson, S., Batterham, D., Reynolds, M. and Wood, G. (2019) The Changing Geography of Homelessness: A Spatial Analysis from 2001 to 2016, AHURI Final Report No. 313, Australian Housing and Urban Research Institute Limited, Melbourne. https://www.ahuri.edu.au/research/final-reports/313, doi: 10.18408/ahuri-5119601.

Parsell, C. and Marston, G. (2012) 'Beyond the At-risk Individual: Housing and the Eradication of Poverty to Prevent Homelessness', Australian Journal Of Public Administration, vol. 71, no. 1: 33-44, doi:10.1111/j.1467-8500.2012.00758.x. 
Pawson, H. (2007) 'Local authority homelessness prevention in england: Empowering consumers or denying rights?', Housing. Studies., vol. 22, no. 6: 867-883, doi:10.1080/02673030701387572.

Pawson, H., Martin, C., Sisson, A., Thompson, S., Fitzpatrick, S. and Marsh, A. (2021) COVID-19: Rental housing and homelessness impacts - an initial analysis'; ACOSS/UNSW Poverty and Inequality Partnership Report No. 7, ACOSS/UNSW, Sydney, http://povertyandinequality.acoss.org.au/wp-content/uploads/2021/02/COVID19_Rentalhousing-and-homelessness-impacts_report-1.pdf, accessed 27 April 2021.

Pfeffermann, D. (2013) 'New Important Developments in Small Area Estimation', Statistical Science, vol. 28, no. 1: 40-68.

Pleace, N. (2000) 'The New Consensus, the Old Consensus and the Provision of Services for People Sleeping Rough', Housing Studies, vol. 15, no. 4: 581-594, doi:10.1080/02673030050081113.

Pleace, N., Baptista, I., Benjaminsen, L. and Busch-Geertsema, V. (2013) The Costs of Homelessness in Europe, An Assessment of the Current Evidence Base, EOH Comparative Studies on Homelessness, European Observatory on Homelessness, Brussels, available at: https://www.feantsaresearch.org/download/feantsa-studies_03_. web8038170339305812402.pdf.

Rahman, A. and Harding, A. (2014) 'Spatial analysis of housing stress estimation in Australia with statistical validation', Australasian Journal of Regional Studies, vol. 20, no. 3: 452-486.

Ray, N. (2006) Lesbian, Gay, Bisexual and Transgender Youth: An Epidemic of Homelessness, National Gay and Lesbian Task Force Policy Institute and the National Coalition for the Homeless, New York.

Scutella, R. and Johnson, G. (2012) Locating and Designing 'Journeys Home': A Literature Review, Melbourne Institute Working Paper Series, Melbourne Institute of Applied Economic and Social Research, Melbourne.

Scutella, R., Johnson, G., Moschion, J., Tseng, Y. and Wooden, M. (2012) Journeys Home Research Report No. 1, Wave 1 Findings, Melbourne Institute of Applied Economic and Social Research, Melbourne.

Shinn, M., Baumohl, J. and Hopper, K. (2001) 'The Prevention of Homelessness Revisited', Analyses of Social Issues and Public Policy, vol. 1, no. 1: 95-127, doi:10.1111/1530-2415.00006.

Spinney, A., Beer, A., MacKenzie, D., McNelis, S., Meltzer, A., Muir, K., Peters, A. and valentine, k. (2020) Ending homelessness in Australia: A redesigned homelessness service system, AHURI Final Report No. 347, Australian Housing and Urban Research Institute Limited, Melbourne, https://www.ahuri.edu.au/research/final-reports/347, doi:10.18408/ahuri5119001.

Spooner, C. and Hetherington, K. (2004) Social Determinants of Drug Use, Technical Report Number 228, National Drug and Alcohol Research Centre, University of New South Wales, Sydney.

Stone, W., Sharam, A., Wiesel, I., Ralston, L., Markkanen, S. and James, A. (2015) Accessing and Sustaining Private Rental Tenancies: Critical Life Events, Housing Shocks and Insurances, AHURI Final Report No. 259, Australian Housing and Urban Research Institute Limited, Melbourne, https://www.ahuri.edu.au/research/final-reports/259.

Summerfield, M., Freidin, S., Hahn, M., La, N., Li, N., Macalalad, N., O'Shea, M., Watson, N., Wilkins, R. and Wooden, M. (2016) HILDA User Manual-Release 15, Melbourne Institute of Applied Economic and Social Research, Melbourne.

Tzavidis, N., Zhang, L., Luna Hernandez, A., Schmid, T. and Rojas-Perilla, N. (2018) ‘From start to finish: a framework for the production of small area official statistics', Journal of the Royal Statistical Society. Series A: Statistics in Society, vol.181, no.4: 927-979. doi:10.1111/rssa.12364.

United States Interagency Council on Homelessness (2010) Opening Doors: Federal Strategic Plan to Prevent and End Homelessness, United States Interagency Council on Homelessness, Washington, D.C., https://www.usich.gov/ opening-doors, accessed 12 August 2016.

Verdouw, J., Yanotti, M., De Vries, J., Flanagan, K. and Ben Haman, O. (2020) Pathways to regional recovery from COVID-19, AHURI Discussion Paper, Australian Housing and Urban Research Institute Limited, Melbourne, https:// www.ahuri.edu.au/research/covid-19/pathways-to-regional-recovery-from-covid-19, doi:10.18408/ahuri4126501.

Vinson, T., Rawsthorne, M., Beavisand, A. and Ericson, M. (2017) Dropping off the edge 2015: Persistent communal disadvantage in Australia, Jesuit Social Services and Catholic Social Services Australia, available at: https://dote. org.au/findings/full-report/.

Walsh, T. (2011) Homelessness and the Law, The Federation Press, Annandale. 
Watson, N. and Wooden, M. (2002) The Household, Income and Labour Dynamics (HILDA) Survey: Wave 1 Methodology, HILDA Project Technical Paper Series, No. 1/02, May 2002, Melbourne Institute of Applied Economic and Social Research, Melbourne.

Westmore, T. and Mallett, S. (2011) Ageing in What Place: The Experience of Housing Crisis and Homelessness for Older Victorians, Hanover Welfare Services, Melbourne.

Wiesel, I. (2014) 'Mobilities of Disadvantage: The Housing Pathways of Low-income Australians', Urban Studies, vol. 51, no. 2: 319-334, doi: 10.1177/0042098013489739.

Wilkins, R. and Lass, I. (2018) The Household, Income and Labour Dynamics in Australia Survey: Selected Findings from Waves 1 to 16, Melbourne Institute: Applied Economic and Social Research, University of Melbourne, Melbourne.

Wood, G., Batterham, D., Cigdem, M. and Mallett, S. (2014) The Spatial Dynamics of Homelessness in Australia 2001-2011, Final Report No. 227, Australian Housing and Urban Research Institute Limited, Melbourne. https://www.ahuri.edu. au/research/final-reports/227.

Wood, G., Batterham, D., Cigdem, M. and Mallett, S. (2015) The Structural Drivers of Homelessness in Australia 2001-2011, Final Report No. 238, Australian Housing and Urban Research Institute Limited, Melbourne, https://www.ahuri.edu. au/research/final-reports/238.

Wood, G., Smith, S. J., Ong, R. and Cigdem, M. (2013) The Edges of Home Ownership, AHURI Final Report No. 216, Australian Housing and Urban Research Institute Limited, Melbourne, https://www.ahuri.edu.au/research/finalreports/216.

Yates, J. and Gabriel, M. (2006) Housing Affordability in Australia, National Research Venture 3: Housing Affordability for Lower Income Australians, Research Paper 3, Australian Housing and Urban Research Institute Limited, Melbourne https://www.ahuri.edu.au/_data/assets/pdf_file/0018/2682/NRV3_Research_Paper_3.pdf.

Zaretzky, K. and Flatau, : (2013) The cost of homelessness and the net benefit of homelessness programs: a national study, AHURI Final Report No.218, Australian Housing and Urban Research Institute Limited, Melbourne. https:// www.ahuri.edu.au/research/final-reports/218.

Zaretzky, K., Flatau, :, Clear, A., Conroy, E., Burns, L. and Spicer, B. (2013) The cost of homelessness and the net benefit of homelessness programs: a national study, AHURI Final Report No.205, Australian Housing and Urban Research Institute Limited, Melbourne, https://www.ahuri.edu.au/research/final-reports/218. 


\section{Appendix 1: Detailed SAE modelling results}

Below we report the outcome of estimating Equation 1, our unit-level (probit) model. Table A1 summarises the regression output. The dependent variable was the risk measure as operationalised in HILDA (and detailed in Chapter 2). This model was restricted to those who were renting, occupying a dwelling rent-free or occupying a dwelling under a life tenure scheme ${ }^{27}$. The psudo-r2 of the model is 0.34 .

Table A1: Unit-based (probit) results using HILDA 2016 data

\begin{tabular}{|c|c|c|}
\hline VARIABLES & Coefficient $(\beta)$ & St Error \\
\hline Usual hours worked<35/wk & $0.589 * \star \star$ & 0.058 \\
\hline Unemployed/not in the labour force & $0.444^{\star * \star}$ & 0.057 \\
\hline Household type (one parent, group, lone or multi-fam household) & $0.626^{\star \star \star}$ & 0.053 \\
\hline Disability present & $0.836^{\star \star \star}$ & 0.104 \\
\hline Low household income & $1.055^{\star \star \star}$ & 0.053 \\
\hline Indigenous & $0.519 * \star \star$ & 0.097 \\
\hline Number of children ever had $5+$ & $0.424^{\star \star \star}$ & 0.112 \\
\hline Constant & $-1.688^{\star \star \star}$ & 0.054 \\
\hline Wald chi2 & $1308.33^{\star \star \star}$ & \\
\hline Log pseudolikelihood & -2661.9701 & \\
\hline Pseudo R2 & 0.3443 & \\
\hline Observations & 6,017 & \\
\hline
\end{tabular}

Notes: ${ }^{* * *} p<0.01,{ }^{* *} p<0.05,{ }^{*} p<0.1$.

Source: Author's calculations derived from: ABS 2016 Census of Population and Housing, and HILDA survey, waves 16 and 17.

The FH estimations are based on the area-level model described in Section 3.2. Based on the model diagnostics, estimates are only presented for SA3 level results. The area-level model was also fitted to SA2 level data, but neither of the error terms in Equation 2 and Equation 3 met the model assumptions. The Moran test for spatial dependence (error lag) was not statistically significant $(p=0.77)$.

27 We also ran a model which included a tenure variable which explained much more of the variance in the risk indicator (pseudo $\mathrm{R}$ squared $=0.61$ ). However, as only those who were renting (including those living rent free or occupying a dwelling under a life tenure scheme) could be at-risk according to the definition of risk that we used, we proceeded with the model focussed on this group only. Results that include the tenure indicator are available from the authors on request. 
Table A2 below details the regression results and diagnostics for the SA3 level results. The predicted at-risk values obtained from the area-level model is a weighted average of the at-risk proportions estimated directly from the population weighted HILDA sample, and the synthetic at-risk estimator generated by the regression model. Modelling followed a general to specific strategy, with insignificant variables removed sequentially.

Table A2: Area-based (FH) model results using HILDA 2016 and Census 2016 data

\begin{tabular}{|c|c|c|}
\hline & Coefficient $(\beta)$ & St Error \\
\hline Never married & $1.968^{\star \star \star}$ & 0.292 \\
\hline Year of arrival before 1945 & $-7.353^{\star \star}$ & 3.130 \\
\hline Not in the labour force & $0.892^{\star * \star}$ & 0.211 \\
\hline Population volunteering & $0.773^{\star \star \star}$ & 0.183 \\
\hline Total number of children 1 or 3 & $1.943^{\star \star}$ & 0.816 \\
\hline Private rental tenure & $0.607^{\star \star \star}$ & 0.150 \\
\hline Group household & $-1.855^{\star \star}$ & 0.759 \\
\hline Manufacturing employment & $-0.924^{\star \star \star}$ & 0.282 \\
\hline Accommodation and hospitality employment & $-1.031^{\star \star \star}$ & 0.341 \\
\hline Ln Family weekly income, median & $-0.217^{\star \star \star}$ & 0.069 \\
\hline Capital city (1=yes) & $0.059^{\star * \star}$ & 0.022 \\
\hline Constant & 0.251 & 0.766 \\
\hline Adj $R^{2}$ & 0.32 & \\
\hline $\mathrm{FH} \mathrm{R} \mathrm{R}^{2}$ & 0.53 & \\
\hline Number of SAs & 292 & \\
\hline Out of sample SAs & 42 & \\
\hline Variance of the random effect $\left(\hat{\sigma}_{u}^{2}\right)$ & 0.0047 & \\
\hline Residuals $e_{S A k}$ & 1.591 & 0.138 \\
\hline Random effects $u_{S A k}$ & $9.827^{\star \star \star}$ & 0.000 \\
\hline
\end{tabular}

Notes: Clustered standard errors in column $3,{ }^{* *} p<0.01,{ }^{* *} p<0.05,{ }^{*} p<0.1$.

$\hat{\gamma}_{S A k}=\hat{\sigma}_{u}^{2} /\left(\hat{\sigma}_{u}^{2}+\hat{\sigma}_{e_{S A k}}\right) \hat{\gamma}_{S A k}: \operatorname{Min}(0.039) ; 5 \%$ (0.1143); Median (0.4045); 95\% (0.7182); Max (0.9696).

Source: Author's calculations derived from: ABS 2016 Census of Population and Housing, and HILDA survey, waves 16 and 17.

HILDA only provides observations on a subset of SA3s in Australia. For the remaining SA3s (42) the at-risk measure is entirely based on the models-driven synthetic at-risk estimator. Overall, the results in Table A2 shows that areas with a greater proportion of residents long established in Australia (arriving before 1945), higher family incomes, greater proportion of group households and greater proportions of residents employed in manufacturing or accommodation/hospitality sectors tend to have lower proportions of people at-risk of homelessness. Conversely, areas with a higher proportion of private rental, capital city SA3s, greater proportion of residents not in the labour force and greater proportion of residents involved in volunteering activities, tend to have higher proportions of people at-risk. Notably, the primary objective of the model is to explain variation in the at-risk measure - there is no suggestion of causality. 
Overall the regression model explains some 32 per cent of the variation in the at-risk measure. The improvement in the model fit, as a result of combining the direct estimates with the regression-synthetic estimates, is shown by the $\mathrm{FH}$ r-squared. When taking into consideration that some of the variation in the at-risk measure is the result of sampling error, the model fit increases to 53 per cent. Notwithstanding the improvement in model fit there is some model misspecification. The final two rows in Table X report the Shapiro-Wilk tests for normality. The residuals $\left(e_{S A k}\right)$ meet the model assumptions requirement, but the random effects error $\left(u_{S A k}\right)$ cannot be considered normally, identically and independently distributed.

Together with the sampling error, the variance of the random effect $\left(\hat{\sigma}_{u}^{2}\right)$ determines the weighing of the direct (HILDA) and regression-synthetic predictions. For small sample sizes a larger weight is given to the regressionsynthetic prediction. For the model in Table A2 the distribution of this weight ranges from 0.0339 to 0.9696 (see note to Table A2). The impact of the adjustment (weighing) is shown in Figure A3 (panel A), Panel B shows the range of the 95 per cent confidence interval for the at-risk estimate, ordered by HILDA sample size. A ratio of 1 indicates that the direct (HILDA) estimate and the predicted FH estimate are the same. In this case there is considerable variation around this benchmark, although declining with the increase in HILDA sample size. Panel B shows that estimates improve in precision with larger samples.

Figure A1: FH SAE estimate comparison with direct estimates (HILDA)

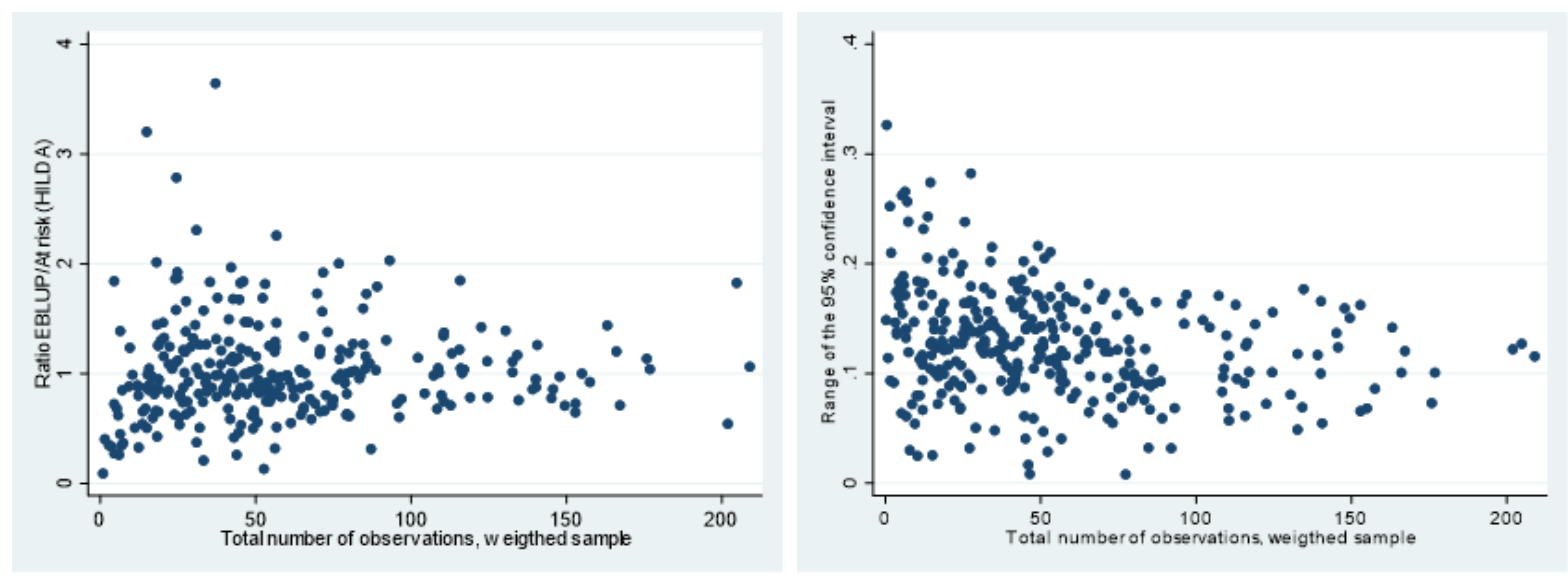

Source: Author's calculations derived from: ABS 2016 Census of Population and Housing, and HILDA survey, waves 16 and 17. 


\section{Appendix 2: HILDA sampling coverage}

Figure A2: HILDA national sampling coverage, SA2 level (2016)

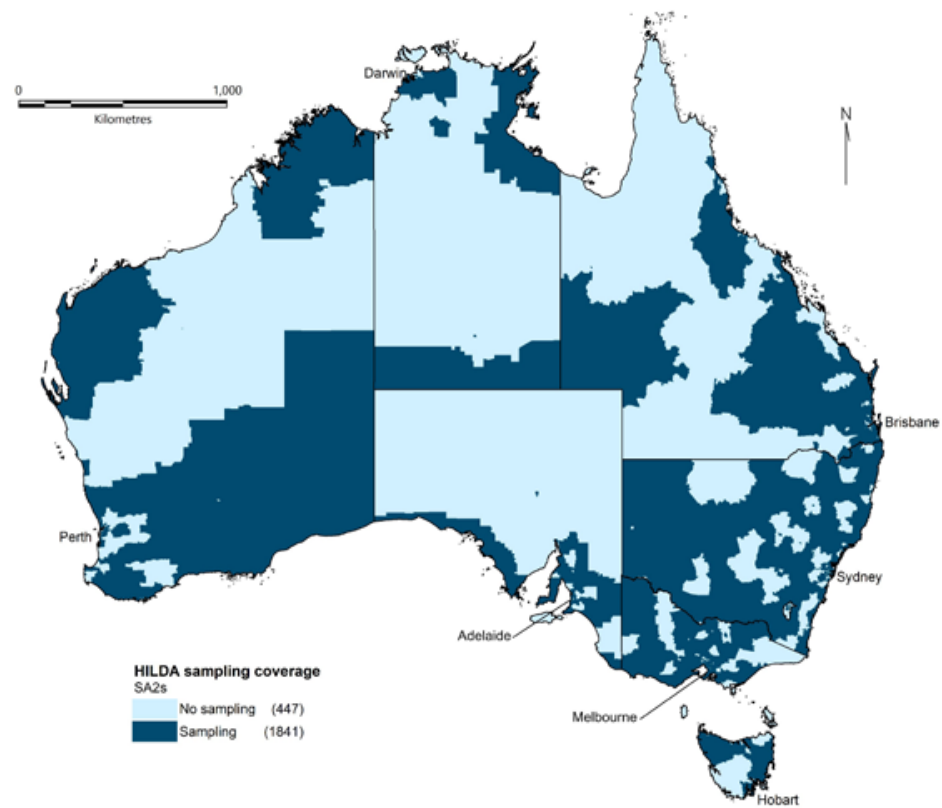

Source: HILDA survey wave 16, ABS SA2 digital Census boundaries, 2016. 


\section{Appendix 3: SAE data tables}

Small Area estimates are provided for each SA2 and SA3 in Table A4 and Table A5 respectively. Table A3 below lists the names and definitions of the variables in that excel sheet.

Please note, both area-level and unit-level approaches produced a proportion of people at-risk in each area. The rate of homelessness risk is calculated by multiplying this proportion by 10,000, while the number at-risk is calculated by multiplying the proportion by the relevant total population in that SA3.

Table A3: The variable names and definitions contained in Table A4 and Table A5

\begin{tabular}{|c|c|}
\hline Variable name & Definition \\
\hline SA2_5DIGITCODE_2016^ & The 5 Digit SA2 2016 code from the ASGS \\
\hline SA2_name & The name of that SA2 \\
\hline SA3_CODE_2016^ & The 5 Digit SA3 2016 code from the ASGS \\
\hline SA3_NAME_2016^ & The name of that SA3 \\
\hline Unit-level_Probit_totalpopulation & $\begin{array}{l}\text { The total population for each SA2/SA3 used to calculate the number of persons aged } 15 \text { years } \\
\text { and over at-risk for the unit-level (probit) estimates }\end{array}$ \\
\hline Unit-level_probit_RATE & $\begin{array}{l}\text { The rate of homelessness risk per } 10,000 \text { persons, aged } 15 \text { years and over, per SA2/SA3 from } \\
\text { the unit-level (probit) estimates }\end{array}$ \\
\hline Unit-level_probit_RATE_LowerCl & $\begin{array}{l}\text { The lower confidence interval for the rate of homelessness risk per 10,000 persons, aged } 15 \\
\text { years and over, per SA2/SA3 from the unit-level (probit) estimates }\end{array}$ \\
\hline Unit-level_probit_RATE_UpperCl & $\begin{array}{l}\text { The upper confidence interval for the rate of homelessness risk per 10,000 persons, aged } 15 \\
\text { years and over, per SA2/SA3 from the unit-level (probit) estimates }\end{array}$ \\
\hline Unit-level_probit_number & $\begin{array}{l}\text { The number of persons aged } 15 \text { years and over at-risk of homelessness per SA2/SA3 based on } \\
\text { the unit-level (probit) estimates }\end{array}$ \\
\hline Unit-level_probit_number_LowerCl & $\begin{array}{l}\text { Number of persons aged } 15 \text { years and over at-risk of homelessness per SA2/SA3 based on the } \\
\text { lower Cl unit-level (probit) estimates }\end{array}$ \\
\hline Unit-level_probit_number_UpperCl & $\begin{array}{l}\text { Number of persons aged } 15 \text { years and over at-risk of homelessness per SA2/SA3 based on the } \\
\text { upper Cl unit-level (probit) estimates }\end{array}$ \\
\hline Area-level_FH_totalpopulation & $\begin{array}{l}\text { The total population for each SA2/SA3 used to calculate the number of persons aged } 15 \text { years } \\
\text { and over at-risk for the area-level (FH) estimates }\end{array}$ \\
\hline Area-level_FH_RATE & $\begin{array}{l}\text { The rate of homelessness risk per 10,000 persons, aged } 15 \text { years and over, per SA2/SA3 from } \\
\text { the area-level }(\mathrm{FH}) \text { estimates }\end{array}$ \\
\hline Area-level_FH_RATE_LowerCl & $\begin{array}{l}\text { The lower confidence interval for the rate of homelessness risk per 10,000 persons, aged } 15 \\
\text { years and over, per SA2/SA3 from the area-level }(\mathrm{FH}) \text { estimates }\end{array}$ \\
\hline Area-level_FH_RATE_UpperCl & $\begin{array}{l}\text { The upper confidence interval for the rate of homelessness risk per } 10,000 \text { persons, aged } 15 \\
\text { years and over, per SA2/SA3 from the area-level }(\mathrm{FH}) \text { estimates }\end{array}$ \\
\hline Area-level_FH_number & $\begin{array}{l}\text { The number of persons aged } 15 \text { years and over at-risk of homelessness per SA2/SA3 based on } \\
\text { the area-level (FH) estimates }\end{array}$ \\
\hline Area-level_FH_number_LowerCl & $\begin{array}{l}\text { Number of persons aged } 15 \text { years and over at-risk of homelessness per SA2/SA3 based on the } \\
\text { lower CIT area-level (FH) estimates }\end{array}$ \\
\hline Area-level_FH_number_UpperCl & $\begin{array}{l}\text { Number of persons aged } 15 \text { years and over at-risk of homelessness per SA2/SA3 based on the } \\
\text { upper } \mathrm{Cl} \text { area-level (FH) estimates }\end{array}$ \\
\hline
\end{tabular}

Source: Authors' naming and calculation. Except ${ }^{\wedge}$ which are standard ASGS variable naming conventions. 
Table A4: SA2 level estimates

\begin{tabular}{|c|c|c|c|c|c|c|c|c|}
\hline \multirow[b]{2}{*}{$\begin{array}{l}\text { SA2_5DIGIT } \\
\text { CODE_2016 }\end{array}$} & \multirow[b]{2}{*}{ SA2_name } & \multicolumn{7}{|c|}{ Unit-level SAEs } \\
\hline & & $\begin{array}{l}\text { Unit-level_Probit_ } \\
\text { totalpopulation }\end{array}$ & $\begin{array}{r}\text { Unit-level_ } \\
\text { probit_ } \\
\text { RATE }\end{array}$ & $\begin{array}{c}\text { Unit-level_ } \\
\text { probit_ } \\
\text { RATE_- } \\
\text { LowerCl }\end{array}$ & $\begin{array}{r}\text { Unit-level_ } \\
\text { probit_ } \\
\text { RATE_ } \\
\text { UpperCl }\end{array}$ & $\begin{array}{r}\text { Unit-level_ } \\
\text { probit_ } \\
\text { number }\end{array}$ & $\begin{array}{r}\text { Unit-level_ } \\
\text { probit_ } \\
\text { number_ } \\
\text { LowerCl }\end{array}$ & $\begin{array}{r}\text { Unit-level_ } \\
\text { probit_ } \\
\text { number_- } \\
\text { UpperCl }\end{array}$ \\
\hline 11007 & Braidwood & 2922 & 508.6 & 420.2 & 626.5 & 149 & 123 & 183 \\
\hline 11008 & Karabar & 6285 & 888.2 & 722.6 & 1105.6 & 558 & 454 & 695 \\
\hline 11009 & Queanbeyan & 8678 & 1148.6 & 948.2 & 1440.2 & 997 & 823 & 1250 \\
\hline 11010 & Queanbeyan - East & 3749 & 1183.2 & 977.2 & 1487.0 & 444 & 366 & 557 \\
\hline 11011 & Queanbeyan Region & 12559 & 176.5 & 146.4 & 228.1 & 222 & 184 & 286 \\
\hline 11012 & Queanbeyan West - Jerrabomberra & 9213 & 399.5 & 329.5 & 519.4 & 368 & 304 & 478 \\
\hline 11013 & Bombala & 1818 & 586.3 & 481.5 & 734.2 & 107 & 88 & 133 \\
\hline 11014 & Cooma & 5264 & 1010.0 & 827.2 & 1242.8 & 532 & 435 & 654 \\
\hline 11015 & Cooma Region & 2526 & 314.7 & 258.4 & 393.9 & 79 & 65 & 100 \\
\hline 11016 & Jindabyne - Berridale & 5223 & 588.9 & 489.5 & 745.1 & 308 & 256 & 389 \\
\hline 11017 & Batemans Bay & 5941 & 1200.7 & 969.5 & 1492.9 & 713 & 576 & 887 \\
\hline 11018 & Batemans Bay - South & 6631 & 960.4 & 780.0 & 1194.6 & 637 & 517 & 792 \\
\hline 11019 & Bega - Tathra & 6282 & 928.6 & 761.2 & 1141.9 & 583 & 478 & 717 \\
\hline 11020 & Bega-Eden Hinterland & 6723 & 423.8 & 346.9 & 527.4 & 285 & 233 & 355 \\
\hline 11021 & Broulee - Tomakin & 2536 & 769.0 & 631.1 & 948.6 & 195 & 160 & 241 \\
\hline 11023 & Eden & 2480 & 1256.5 & 1022.0 & 1540.9 & 312 & 253 & 382 \\
\hline 11024 & Eurobodalla Hinterland & 2600 & 600.5 & 488.6 & 738.8 & 156 & 127 & 192 \\
\hline 11025 & Merimbula - Tura Beach & 8298 & 783.9 & 640.6 & 975.7 & 650 & 532 & 810 \\
\hline 11026 & Moruya - Tuross Head & 6290 & 898.1 & 731.9 & 1100.6 & 565 & 460 & 692 \\
\hline 11027 & Narooma - Bermagui & 7133 & 856.3 & 694.4 & 1055.7 & 611 & 495 & 753 \\
\hline 11028 & Avoca Beach - Copacabana & 5339 & 452.3 & 373.4 & 574.9 & 242 & 199 & 307 \\
\hline 11029 & Box Head - MacMasters Beach & 8318 & 396.0 & 323.4 & 498.0 & 329 & 269 & 414 \\
\hline 11030 & Calga - Kulnura & 3752 & 603.5 & 493.2 & 765.1 & 226 & 185 & 287 \\
\hline 11031 & Erina - Green Point & 11119 & 547.7 & 446.8 & 686.0 & 609 & 497 & 763 \\
\hline 11032 & Gosford - Springfield & 14909 & 1403.4 & 1151.3 & 1741.8 & 2092 & 1717 & 2597 \\
\hline 11033 & Kariong & 4739 & 548.8 & 446.7 & 692.3 & 260 & 212 & 328 \\
\hline 11034 & Kincumber - Picketts Valley & 5763 & 830.7 & 677.2 & 1030.7 & 479 & 390 & 594 \\
\hline 11035 & Narara & 5095 & 557.9 & 452.5 & 705.9 & 284 & 231 & 360 \\
\hline 11036 & Niagara Park - Lisarow & 6079 & 500.6 & 410.6 & 627.1 & 304 & 250 & 381 \\
\hline 11037 & Point Clare - Koolewong & 4848 & 624.9 & 510.6 & 784.8 & 303 & 248 & 380 \\
\hline 11038 & Saratoga - Davistown & 5291 & 489.2 & 398.3 & 620.9 & 259 & 211 & 329 \\
\hline 11039 & Terrigal - North Avoca & 10294 & 528.8 & 434.7 & 681.6 & 544 & 448 & 702 \\
\hline 11040 & Umina - Booker Bay - Patonga & 18631 & 1075.4 & 876.9 & 1338.9 & 2004 & 1634 & 2494 \\
\hline 11041 & Wamberal - Forresters Beach & 7151 & 444.0 & 364.6 & 564.2 & 317 & 261 & 403 \\
\hline 11042 & Woy Woy - Blackwall & 11236 & 1141.7 & 929.3 & 1415.0 & 1283 & 1044 & 1590 \\
\hline 11043 & Wyoming & 8898 & 877.1 & 710.9 & 1099.7 & 780 & 633 & 979 \\
\hline 11044 & Bateau Bay - Killarney Vale & 16920 & 817.4 & 664.7 & 1017.9 & 1383 & 1125 & 1722 \\
\hline 11045 & Blue Haven - San Remo & 8086 & 952.0 & 767.7 & 1201.0 & 770 & 621 & 971 \\
\hline 11046 & Budgewoi - Buff Point - Halekulani & 7298 & 859.6 & 698.4 & 1068.7 & 627 & 510 & 780 \\
\hline 11047 & Chittaway Bay - Tumbi Umbi & 11676 & 541.0 & 439.8 & 683.5 & 632 & 514 & 798 \\
\hline 11048 & Gorokan - Kanwal - Charmhaven & 17234 & 1006.6 & 815.6 & 1254.2 & 1735 & 1406 & 2161 \\
\hline 11049 & Jilliby - Yarramalong & 2578 & 278.7 & 229.9 & 347.0 & 72 & 59 & 89 \\
\hline 11050 & Lake Munmorah - Mannering Park & 8488 & 552.4 & 450.5 & 690.4 & 469 & 382 & 586 \\
\hline 11051 & Ourimbah - Fountaindale & 3723 & 545.8 & 448.1 & 686.5 & 203 & 167 & 256 \\
\hline 11052 & Summerland Point - Gwandalan & 4430 & 623.0 & 510.8 & 770.8 & 276 & 226 & 341 \\
\hline 11053 & The Entrance & 11863 & 1583.5 & 1289.7 & 1967.8 & 1879 & 1530 & 2334 \\
\hline 11054 & Toukley - Norah Head & 7840 & 1134.6 & 922.0 & 1404.0 & 889 & 723 & 1101 \\
\hline 11055 & Tuggerah - Kangy Angy & 3996 & 729.2 & 595.1 & 932.5 & 291 & 238 & 373 \\
\hline 11056 & Warnervale - Wadalba & 10946 & 720.5 & 582.0 & 924.0 & 789 & 637 & 1011 \\
\hline 11057 & Wyong & 6730 & 1361.6 & 1102.9 & 1691.0 & 916 & 742 & 1138 \\
\hline 11058 & Bathurst & 18295 & 1150.5 & 937.8 & 1429.7 & 2105 & 1716 & 2616 \\
\hline 11059 & Bathurst - East & 7969 & 817.9 & 660.2 & 1020.7 & 652 & 526 & 813 \\
\hline 11060 & Bathurst Region & 5296 & 330.6 & 271.6 & 412.5 & 175 & 144 & 218 \\
\hline 11061 & Oberon & 3625 & 653.2 & 534.3 & 816.3 & 237 & 194 & 296 \\
\hline 11062 & Condobolin & 4849 & 1007.2 & 804.5 & 1243.6 & 488 & 390 & 603 \\
\hline 11063 & Cowra & 7036 & 1093.1 & 885.4 & 1341.2 & 769 & 623 & 944 \\
\hline
\end{tabular}




\begin{tabular}{|c|c|c|c|c|c|c|c|c|}
\hline \multirow[b]{2}{*}{$\begin{array}{l}\text { SA2_5DIGIT } \\
\text { CODE_2016 }\end{array}$} & \multirow[b]{2}{*}{ SA2_name } & \multicolumn{7}{|c|}{ Unit-level SAES } \\
\hline & & $\begin{array}{r}\text { Unit-level_Probit_ } \\
\text { totalpopulation }\end{array}$ & $\begin{array}{r}\text { Unit-level_ } \\
\text { probit_ } \\
\text { RATE }\end{array}$ & $\begin{array}{r}\text { Unit-level_ } \\
\text { probit_ } \\
\text { RATE_ } \\
\text { LowerCl }\end{array}$ & $\begin{array}{r}\text { Unit-level_ } \\
\text { probit_ } \\
\text { RATE_ } \\
\text { UpperCl }\end{array}$ & $\begin{array}{r}\text { Unit-level_ } \\
\text { probit_ } \\
\text { number }\end{array}$ & $\begin{array}{c}\text { Unit-level_ } \\
\text { probit_ } \\
\text { number_- } \\
\text { LowerCl }\end{array}$ & $\begin{array}{r}\text { Unit-level_ } \\
\text { probit_ } \\
\text { number_ } \\
\text { UpperCl }\end{array}$ \\
\hline 11064 & Cowra Region & 4194 & 585.3 & 480.8 & 724.0 & 245 & 202 & 304 \\
\hline 11065 & Forbes & 7572 & 889.4 & 722.7 & 1095.3 & 673 & 547 & 829 \\
\hline 11066 & Grenfell & 2810 & 623.3 & 510.7 & 765.6 & 175 & 144 & 215 \\
\hline 11067 & Parkes (NSW) & 8046 & 1044.5 & 849.5 & 1286.3 & 840 & 684 & 1035 \\
\hline 11068 & Parkes Region & 2552 & 747.2 & 600.3 & 920.5 & 191 & 153 & 235 \\
\hline 11069 & West Wyalong & 4359 & 612.9 & 500.7 & 766.1 & 267 & 218 & 334 \\
\hline 11070 & Lithgow & 10062 & 1087.8 & 884.7 & 1338.3 & 1095 & 890 & 1347 \\
\hline 11071 & Lithgow Region & 6349 & 483.9 & 393.4 & 599.5 & 307 & 250 & 381 \\
\hline 11072 & Mudgee & 8576 & 1015.0 & 828.6 & 1267.0 & 870 & 711 & 1087 \\
\hline 11073 & Mudgee Region - East & 2717 & 879.4 & 714.7 & 1089.0 & 239 & 194 & 296 \\
\hline 11074 & Mudgee Region - West & 7741 & 555.1 & 451.4 & 694.2 & 430 & 349 & 537 \\
\hline 11076 & Blayney & 5389 & 673.1 & 551.2 & 835.3 & 363 & 297 & 450 \\
\hline 11077 & Orange & 14518 & 1216.1 & 988.3 & 1505.7 & 1766 & 1435 & 2186 \\
\hline 11078 & Orange - North & 14032 & 832.5 & 675.7 & 1048.2 & 1168 & 948 & 1471 \\
\hline 11079 & Orange Region & 8455 & 431.8 & 353.4 & 542.2 & 365 & 299 & 458 \\
\hline 11080 & Grafton & 14241 & 1255.6 & 1018.6 & 1540.4 & 1788 & 1451 & 2194 \\
\hline 11081 & Grafton Region & 11935 & 556.7 & 450.0 & 689.7 & 664 & 537 & 823 \\
\hline 11082 & Maclean - Yamba - Iluka & 13147 & 972.3 & 789.2 & 1202.5 & 1278 & 1038 & 1581 \\
\hline 11083 & Bellingen & 4315 & 813.0 & 664.0 & 1015.2 & 351 & 287 & 438 \\
\hline 11084 & Coffs Harbour - North & 13350 & 1359.4 & 1105.2 & 1681.5 & 1815 & 1475 & 2245 \\
\hline 11085 & Coffs Harbour - South & 8147 & 1380.5 & 1127.0 & 1702.5 & 1125 & 918 & 1387 \\
\hline 11086 & Coramba - Nana Glen - Bucca & 2878 & 519.1 & 421.8 & 656.2 & 149 & 121 & 189 \\
\hline 11087 & Dorrigo & 2526 & 752.9 & 614.3 & 932.2 & 190 & 155 & 235 \\
\hline 11088 & Korora - Emerald Beach & 6462 & 570.1 & 465.0 & 725.9 & 368 & 300 & 469 \\
\hline 11089 & Sawtell - Boambee & 14853 & 1068.3 & 868.3 & 1321.1 & 1587 & 1290 & 1962 \\
\hline 11090 & Urunga & 3752 & 846.8 & 694.9 & 1046.9 & 318 & 261 & 393 \\
\hline 11091 & Woolgoolga - Arrawarra & 9608 & 856.0 & 693.7 & 1074.7 & 822 & 667 & 1033 \\
\hline 11092 & Bourke - Brewarrina & 2782 & 1677.2 & 1299.4 & 2097.8 & 467 & 361 & 584 \\
\hline 11093 & Cobar & 3315 & 906.7 & 734.9 & 1138.6 & 301 & 244 & 377 \\
\hline 11094 & Coonamble & 3032 & 1118.2 & 880.3 & 1385.5 & 339 & 267 & 420 \\
\hline 11095 & Nyngan - Warren & 3615 & 926.9 & 745.9 & 1154.3 & 335 & 270 & 417 \\
\hline 11096 & Walgett - Lightning Ridge & 4653 & 1621.4 & 1269.1 & 2017.0 & 754 & 591 & 938 \\
\hline 11097 & Broken Hill & 13522 & 782.3 & 634.9 & 962.3 & 1058 & 859 & 1301 \\
\hline 11098 & Far West & 1806 & 1489.4 & 1146.4 & 1881.9 & 269 & 207 & 340 \\
\hline 11099 & Coonabarabran & 5980 & 917.4 & 741.0 & 1128.7 & 549 & 443 & 675 \\
\hline 11100 & Dubbo - East & 7585 & 1159.3 & 930.5 & 1438.0 & 879 & 706 & 1091 \\
\hline 11101 & Dubbo - South & 12575 & 1126.0 & 910.2 & 1406.8 & 1416 & 1145 & 1769 \\
\hline 11102 & Dubbo - West & 6251 & 1071.5 & 854.1 & 1338.4 & 670 & 534 & 837 \\
\hline 11103 & Dubbo Region & 4131 & 270.8 & 218.6 & 343.8 & 112 & 90 & 142 \\
\hline 11104 & Gilgandra & 3271 & 1054.3 & 849.3 & 1292.4 & 345 & 278 & 423 \\
\hline 11105 & Narromine & 4749 & 961.5 & 767.4 & 1190.2 & 457 & 364 & 565 \\
\hline 11106 & Wellington & 6739 & 979.5 & 777.2 & 1210.8 & 660 & 524 & 816 \\
\hline 11107 & Branxton - Greta - Pokolbin & 7363 & 542.0 & 442.6 & 685.5 & 399 & 326 & 505 \\
\hline 11108 & Cessnock & 16692 & 1156.2 & 939.4 & 1428.5 & 1930 & 1568 & 2384 \\
\hline 11109 & Cessnock Region & 5981 & 337.1 & 274.4 & 420.1 & 202 & 164 & 251 \\
\hline 11110 & Dungog & 6875 & 524.2 & 426.7 & 654.3 & 360 & 293 & 450 \\
\hline 11111 & Kurri Kurri - Abermain & 13307 & 973.1 & 787.3 & 1208.2 & 1295 & 1048 & 1608 \\
\hline 11112 & Singleton & 11894 & 857.4 & 698.0 & 1072.2 & 1020 & 830 & 1275 \\
\hline 11113 & Singleton Region & 3680 & 392.6 & 318.1 & 504.4 & 144 & 117 & 186 \\
\hline 11114 & Maitland & 4981 & 878.9 & 715.8 & 1112.1 & 438 & 357 & 554 \\
\hline 11115 & Maitland - East & 20569 & 1035.4 & 843.3 & 1285.8 & 2130 & 1735 & 2645 \\
\hline 11116 & Maitland - North & 5592 & 349.9 & 287.3 & 438.6 & 196 & 161 & 245 \\
\hline 11117 & Maitland-West & 16419 & 1057.1 & 858.8 & 1320.8 & 1736 & 1410 & 2169 \\
\hline 11118 & Thornton - Millers Forest & 7311 & 421.1 & 345.3 & 538.4 & 308 & 252 & 394 \\
\hline 11119 & Anna Bay & 4407 & 583.4 & 477.2 & 736.5 & 257 & 210 & 325 \\
\hline 11120 & Lemon Tree Passage - Tanilba Bay & 5137 & 885.5 & 722.5 & 1098.8 & 455 & 371 & 564 \\
\hline 11121 & Nelson Bay Peninsula & 16480 & 895.5 & 731.4 & 1120.2 & 1476 & 1205 & 1846 \\
\hline
\end{tabular}




\begin{tabular}{|c|c|c|c|c|c|c|c|c|}
\hline \multirow[b]{2}{*}{$\begin{array}{l}\text { SA2_5DIGIT } \\
\text { CODE_2016 }\end{array}$} & \multirow[b]{2}{*}{ SA2_name } & \multicolumn{7}{|c|}{ Unit-level SAEs } \\
\hline & & $\begin{array}{r}\text { Unit-level_Probit_ } \\
\text { totalpopulation }\end{array}$ & $\begin{array}{r}\text { Unit-level_ } \\
\text { probit_ } \\
\text { RATE }\end{array}$ & $\begin{array}{r}\text { Unit-level_ } \\
\text { probit_ } \\
\text { RATE_ } \\
\text { LowerCl }\end{array}$ & $\begin{array}{c}\text { Unit-level_ } \\
\text { probit_ } \\
\text { RATE_ } \\
\text { UpperCl }\end{array}$ & $\begin{array}{r}\text { Unit-level_ } \\
\text { probit_ } \\
\text { number }\end{array}$ & $\begin{array}{c}\text { Unit-level_ } \\
\text { probit_ } \\
\text { number } \\
\text { LowerCl }\end{array}$ & $\begin{array}{c}\text { Unit-level_ } \\
\text { probit_ } \\
\text { number_ } \\
\text { UpperCl }\end{array}$ \\
\hline 11122 & Raymond Terrace & 10336 & 1339.7 & 1086.0 & 1657.5 & 1385 & 1122 & 1713 \\
\hline 11123 & Seaham - Woodville & 4095 & 188.2 & 154.6 & 238.8 & 77 & 63 & 98 \\
\hline 11124 & Tea Gardens - Hawks Nest & 4165 & 906.8 & 736.3 & 1138.6 & 378 & 307 & 474 \\
\hline 11125 & Williamtown - Medowie - Karuah & 10088 & 500.8 & 405.6 & 639.1 & 505 & 409 & 645 \\
\hline 11126 & Muswellbrook & 8786 & 1345.0 & 1089.6 & 1671.0 & 1182 & 957 & 1468 \\
\hline 11127 & Muswellbrook Region & 3003 & 620.9 & 508.4 & 787.9 & 186 & 153 & 237 \\
\hline 11128 & Scone & 4356 & 819.1 & 671.9 & 1024.1 & 357 & 293 & 446 \\
\hline 11129 & Scone Region & 6185 & 744.9 & 606.9 & 935.8 & 461 & 375 & 579 \\
\hline 11131 & Dapto - Avondale & 18156 & 755.0 & 612.7 & 940.4 & 1371 & 1112 & 1707 \\
\hline 11132 & Horsley - Kembla Grange & 6311 & 352.9 & 287.9 & 448.5 & 223 & 182 & 283 \\
\hline 11134 & Unanderra - Mount Kembla & 11958 & 711.0 & 578.4 & 883.1 & 850 & 692 & 1056 \\
\hline 11136 & Albion Park - Macquarie Pass & 10662 & 433.9 & 352.9 & 551.3 & 463 & 376 & 588 \\
\hline 11137 & Albion Park Rail & 5366 & 806.7 & 656.9 & 1002.0 & 433 & 353 & 538 \\
\hline 11138 & Kiama & 6101 & 666.4 & 547.4 & 833.2 & 407 & 334 & 508 \\
\hline 11139 & Kiama Downs - Minnamurra & 4430 & 332.0 & 272.4 & 422.1 & 147 & 121 & 187 \\
\hline 11140 & Kiama Hinterland - Gerringong & 5951 & 430.0 & 351.7 & 548.9 & 256 & 209 & 327 \\
\hline 11141 & Shellharbour - Flinders & 12404 & 550.0 & 448.8 & 699.8 & 682 & 557 & 868 \\
\hline 11142 & Shellharbour-Oak Flats & 7909 & 712.8 & 582.4 & 889.2 & 564 & 461 & 703 \\
\hline 11143 & Warilla & 15911 & 1330.3 & 1077.0 & 1647.2 & 2117 & 1714 & 2621 \\
\hline 11144 & Balgownie - Fairy Meadow & 16777 & 1005.0 & 820.3 & 1250.7 & 1686 & 1376 & 2098 \\
\hline 11145 & Corrimal - Tarrawanna - Bellambi & 12104 & 1366.7 & 1116.4 & 1679.4 & 1654 & 1351 & 2033 \\
\hline 11146 & Figtree - Keiraville & 16290 & 791.5 & 644.8 & 994.0 & 1289 & 1050 & 1619 \\
\hline 11147 & Helensburgh & 6510 & 263.4 & 216.4 & 337.8 & 171 & 141 & 220 \\
\hline 11148 & Thirroul - Austinmer - Coalcliff & 8374 & 375.7 & 310.4 & 481.7 & 315 & 260 & 403 \\
\hline 11150 & Woonona - Bulli - Russell Vale & 14871 & 701.7 & 575.3 & 866.0 & 1043 & 856 & 1288 \\
\hline 11151 & Bulahdelah - Stroud & 3683 & 603.1 & 489.0 & 748.5 & 222 & 180 & 276 \\
\hline 11152 & Forster & 11382 & 1145.6 & 928.5 & 1413.6 & 1304 & 1057 & 1609 \\
\hline 11153 & Forster-Tuncurry Region & 4623 & 597.1 & 486.4 & 740.3 & 276 & 225 & 342 \\
\hline 11154 & Tuncurry & 5182 & 1112.1 & 909.1 & 1362.6 & 576 & 471 & 706 \\
\hline 11155 & Kempsey & 11255 & 1190.1 & 950.9 & 1460.3 & 1339 & 1070 & 1644 \\
\hline 11156 & Kempsey Region & 7122 & 712.5 & 574.5 & 881.0 & 507 & 409 & 627 \\
\hline 11157 & Macksville - Scotts Head & 3664 & 906.6 & 730.5 & 1129.1 & 332 & 268 & 414 \\
\hline 11158 & Nambucca Heads & 5484 & 1482.6 & 1197.4 & 1817.8 & 813 & 657 & 997 \\
\hline 11159 & Nambucca Heads Region & 5856 & 654.3 & 527.4 & 810.7 & 383 & 309 & 475 \\
\hline 11160 & South West Rocks & 4135 & 953.8 & 773.5 & 1177.6 & 394 & 320 & 487 \\
\hline 11162 & Laurieton - Bonny Hills & 13321 & 733.2 & 597.9 & 906.3 & 977 & 796 & 1207 \\
\hline 11163 & Port Macquarie - East & 21676 & 976.1 & 796.3 & 1218.3 & 2116 & 1726 & 2641 \\
\hline 11164 & Port Macquarie - West & 13777 & 1181.7 & 963.8 & 1461.9 & 1628 & 1328 & 2014 \\
\hline 11165 & Port Macquarie Region & 4087 & 508.3 & 412.7 & 636.1 & 208 & 169 & 260 \\
\hline 11166 & Wauchope & 8368 & 844.7 & 685.8 & 1044.9 & 707 & 574 & 874 \\
\hline 11167 & Gloucester & 3910 & 968.9 & 782.0 & 1196.4 & 379 & 306 & 468 \\
\hline 11168 & Old Bar - Manning Point - Red Head & 8118 & 774.9 & 629.3 & 969.2 & 629 & 511 & 787 \\
\hline 11169 & Taree & 15834 & 1435.8 & 1157.0 & 1760.0 & 2274 & 1832 & 2787 \\
\hline 11170 & Taree Region & 9872 & 648.4 & 526.5 & 803.5 & 640 & 520 & 793 \\
\hline 11171 & Wingham & 4170 & 892.5 & 725.3 & 1101.0 & 372 & 302 & 459 \\
\hline 11172 & Albury - East & 10929 & 859.4 & 703.2 & 1081.7 & 939 & 769 & 1182 \\
\hline 11173 & Albury - North & 7449 & 1145.4 & 935.1 & 1412.9 & 853 & 697 & 1052 \\
\hline 11174 & Albury - South & 8018 & 1166.5 & 959.3 & 1436.6 & 935 & 769 & 1152 \\
\hline 11175 & Albury Region & 8404 & 483.0 & 396.4 & 600.1 & 406 & 333 & 504 \\
\hline 11176 & Lavington & 11155 & 1440.1 & 1175.6 & 1769.4 & 1606 & 1311 & 1974 \\
\hline 11177 & Hay & 2203 & 888.4 & 728.8 & 1095.0 & 196 & 161 & 241 \\
\hline 11178 & Wentworth - Buronga & 4449 & 911.5 & 730.8 & 1123.0 & 406 & 325 & 500 \\
\hline 11179 & Wentworth-Balranald Region & 2688 & 734.4 & 594.7 & 928.9 & 197 & 160 & 250 \\
\hline 11180 & Corowa & 4238 & 801.1 & 654.8 & 992.4 & 339 & 278 & 421 \\
\hline 11181 & Corowa Region & 5079 & 610.8 & 500.0 & 763.3 & 310 & 254 & 388 \\
\hline 11182 & Deniliquin & 5688 & 960.3 & 781.9 & 1184.1 & 546 & 445 & 674 \\
\hline 11183 & Deniliquin Region & 5140 & 626.9 & 514.6 & 776.8 & 322 & 264 & 399 \\
\hline
\end{tabular}




\begin{tabular}{|c|c|c|c|c|c|c|c|c|}
\hline \multirow[b]{2}{*}{$\begin{array}{l}\text { SA2_5DIGIT } \\
\text { CODE_2016 }\end{array}$} & \multirow[b]{2}{*}{ SA2_name } & \multicolumn{7}{|c|}{ Unit-level SAES } \\
\hline & & $\begin{array}{r}\text { Unit-level_Probit_ } \\
\text { totalpopulation }\end{array}$ & $\begin{array}{r}\text { Unit-level_ } \\
\text { probit_ } \\
\text { RATE }\end{array}$ & $\begin{array}{r}\text { Unit-level_ } \\
\text { probit_ } \\
\text { RATE_ } \\
\text { LowerCl }\end{array}$ & $\begin{array}{r}\text { Unit-level_ } \\
\text { probit_ } \\
\text { RATE_ } \\
\text { UpperCl }\end{array}$ & $\begin{array}{r}\text { Unit-level_ } \\
\text { probit_ } \\
\text { number }\end{array}$ & $\begin{array}{c}\text { Unit-level_ } \\
\text { probit_ } \\
\text { number_- } \\
\text { LowerCl }\end{array}$ & $\begin{array}{r}\text { Unit-level_ } \\
\text { probit_ } \\
\text { number_ } \\
\text { UpperCl }\end{array}$ \\
\hline 11184 & Moama & 4362 & 656.7 & 540.6 & 821.7 & 286 & 236 & 358 \\
\hline 11185 & Tocumwal - Finley - Jerilderie & 7341 & 752.6 & 617.8 & 933.9 & 552 & 454 & 686 \\
\hline 11186 & Armidale & 17627 & 1243.3 & 1007.5 & 1546.0 & 2192 & 1776 & 2725 \\
\hline 11187 & Armidale Region - North & 3293 & 886.9 & 720.6 & 1110.2 & 292 & 237 & 366 \\
\hline 11188 & Armidale Region - South & 4517 & 585.2 & 473.7 & 735.6 & 264 & 214 & 332 \\
\hline 11189 & Walcha & 2496 & 750.7 & 605.2 & 942.6 & 187 & 151 & 235 \\
\hline 11190 & Glen Innes & 6775 & 912.7 & 742.5 & 1121.8 & 618 & 503 & 760 \\
\hline 11191 & Inverell & 8689 & 1282.0 & 1034.3 & 1580.9 & 1114 & 899 & 1374 \\
\hline 11192 & Inverell Region - East & 3947 & 720.4 & 575.2 & 913.3 & 284 & 227 & 360 \\
\hline 11193 & Inverell Region - West & 4500 & 684.7 & 559.3 & 848.3 & 308 & 252 & 382 \\
\hline 11194 & Tenterfield & 5177 & 882.5 & 713.0 & 1084.3 & 457 & 369 & 561 \\
\hline 11195 & Moree & 6005 & 1448.9 & 1146.1 & 1795.5 & 870 & 688 & 1078 \\
\hline 11196 & Moree Region & 3784 & 1149.8 & 907.0 & 1465.3 & 435 & 343 & 554 \\
\hline 11197 & Narrabri & 5303 & 970.0 & 782.9 & 1205.5 & 514 & 415 & 639 \\
\hline 11198 & Narrabri Region & 3477 & 951.7 & 767.5 & 1184.1 & 331 & 267 & 412 \\
\hline 11199 & Gunnedah & 6833 & 1065.5 & 859.4 & 1319.2 & 728 & 587 & 901 \\
\hline 11200 & Gunnedah Region & 3110 & 723.1 & 585.8 & 914.6 & 225 & 182 & 284 \\
\hline 11201 & Quirindi & 5826 & 959.1 & 771.8 & 1192.9 & 559 & 450 & 695 \\
\hline 11202 & Tamworth - East & 15253 & 1074.2 & 870.4 & 1338.0 & 1638 & 1328 & 2041 \\
\hline 11203 & Tamworth - North & 11415 & 1112.7 & 904.2 & 1387.2 & 1270 & 1032 & 1584 \\
\hline 11204 & Tamworth - West & 3781 & 1794.9 & 1428.3 & 2214.5 & 679 & 540 & 837 \\
\hline 11205 & Tamworth Region & 13859 & 550.7 & 446.3 & 689.1 & 763 & 619 & 955 \\
\hline 11206 & Belmont - Bennetts Green & 13723 & 744.1 & 606.5 & 923.5 & 1021 & 832 & 1267 \\
\hline 11207 & Belmont South - Blacksmiths & 4504 & 1152.2 & 941.4 & 1420.6 & 519 & 424 & 640 \\
\hline 11208 & Charlestown - Dudley & 18313 & 786.9 & 641.8 & 981.1 & 1441 & 1175 & 1797 \\
\hline 11209 & Glendale - Cardiff - Hillsborough & 17942 & 640.9 & 522.6 & 800.3 & 1150 & 938 & 1436 \\
\hline 11210 & Mount Hutton - Windale & 6784 & 1706.3 & 1384.9 & 2089.2 & 1158 & 940 & 1417 \\
\hline 11211 & Redhead & 2678 & 444.7 & 365.0 & 556.9 & 119 & 98 & 149 \\
\hline 11212 & Swansea - Caves Beach & 9088 & 764.4 & 623.0 & 946.6 & 695 & 566 & 860 \\
\hline 11213 & Valentine - Eleebana & 9170 & 248.5 & 204.0 & 316.1 & 228 & 187 & 290 \\
\hline 11214 & Warners Bay - Boolaroo & 10337 & 691.9 & 565.8 & 865.7 & 715 & 585 & 895 \\
\hline 11215 & Bolton Point - Teralba & 6663 & 1092.0 & 878.5 & 1353.9 & 728 & 585 & 902 \\
\hline 11216 & Bonnells Bay - Silverwater & 6620 & 749.4 & 607.8 & 940.6 & 496 & 402 & 623 \\
\hline 11217 & Edgeworth - Cameron Park & 10349 & 638.9 & 519.6 & 804.8 & 661 & 538 & 833 \\
\hline 11218 & Morisset - Cooranbong & 11867 & 732.5 & 595.5 & 916.7 & 869 & 707 & 1088 \\
\hline 11219 & Toronto - Awaba & 10578 & 929.6 & 752.6 & 1151.1 & 983 & 796 & 1218 \\
\hline 11220 & Wangi Wangi - Rathmines & 6862 & 547.8 & 449.2 & 682.2 & 376 & 308 & 468 \\
\hline 11221 & West Wallsend - Barnsley - Killingworth & 4917 & 464.1 & 379.1 & 580.6 & 228 & 186 & 285 \\
\hline 11222 & Adamstown - Kotara & 11824 & 700.2 & 574.5 & 880.8 & 828 & 679 & 1041 \\
\hline 11223 & Beresfield - Hexham & 6475 & 1034.6 & 837.5 & 1283.6 & 670 & 542 & 831 \\
\hline 11224 & Hamilton - Broadmeadow & 9427 & 1389.9 & 1137.0 & 1724.0 & 1310 & 1072 & 1625 \\
\hline 11225 & Lambton - New Lambton & 12568 & 924.6 & 757.9 & 1149.4 & 1162 & 952 & 1445 \\
\hline 11226 & Maryland - Fletcher - Minmi & 9752 & 535.4 & 433.2 & 681.8 & 522 & 422 & 665 \\
\hline 11227 & Mayfield - Warabrook & 11951 & 1285.3 & 1052.5 & 1594.9 & 1536 & 1258 & 1906 \\
\hline 11228 & Merewether - The Junction & 10459 & 833.4 & 686.7 & 1046.2 & 872 & 718 & 1094 \\
\hline 11229 & Newcastle - Cooks Hill & 8827 & 1369.3 & 1128.0 & 1715.1 & 1209 & 996 & 1514 \\
\hline 11231 & Shortland - Jesmond & 9436 & 1682.6 & 1361.9 & 2118.6 & 1588 & 1285 & 1999 \\
\hline 11232 & Stockton - Fullerton Cove & 6008 & 665.4 & 543.3 & 828.3 & 400 & 326 & 498 \\
\hline 11233 & Wallsend - Elermore Vale & 15490 & 1036.4 & 845.3 & 1285.1 & 1605 & 1309 & 1991 \\
\hline 11234 & Waratah - North Lambton & 9597 & 1373.2 & 1118.5 & 1711.8 & 1318 & 1073 & 1643 \\
\hline 11235 & Wickham - Carrington - Tighes Hill & 6311 & 1268.6 & 1040.2 & 1591.1 & 801 & 656 & 1004 \\
\hline 11236 & Ballina & 13925 & 1315.6 & 1075.3 & 1622.1 & 1832 & 1497 & 2259 \\
\hline 11237 & Ballina Region & 12991 & 644.7 & 524.7 & 810.7 & 838 & 682 & 1053 \\
\hline 11238 & Bangalow & 4273 & 677.2 & 557.3 & 854.3 & 289 & 238 & 365 \\
\hline 11239 & Brunswick Heads - Ocean Shores & 6416 & 1035.7 & 848.7 & 1289.2 & 664 & 545 & 827 \\
\hline 11240 & Byron Bay & 7473 & 913.0 & 745.3 & 1160.8 & 682 & 557 & 867 \\
\hline 11241 & Evans Head & 4071 & 1187.6 & 969.8 & 1461.9 & 483 & 395 & 595 \\
\hline
\end{tabular}




\begin{tabular}{|c|c|c|c|c|c|c|c|c|}
\hline \multirow[b]{2}{*}{$\begin{array}{l}\text { SA2_5DIGIT } \\
\text { CODE_2016 }\end{array}$} & \multirow[b]{2}{*}{ SA2_name } & \multicolumn{7}{|c|}{ Unit-level SAEs } \\
\hline & & $\begin{array}{r}\text { Unit-level_Probit_ } \\
\text { totalpopulation }\end{array}$ & $\begin{array}{r}\text { Unit-level_ } \\
\text { probit_ } \\
\text { RATE }\end{array}$ & $\begin{array}{r}\text { Unit-level_ } \\
\text { probit_ } \\
\text { RATE_- } \\
\text { LowerCl }\end{array}$ & $\begin{array}{r}\text { Unit-level_ } \\
\text { probit_ } \\
\text { RATE_- } \\
\text { UpperCl }\end{array}$ & $\begin{array}{r}\text { Unit-level_ } \\
\text { probit_ } \\
\text { number }\end{array}$ & $\begin{array}{r}\text { Unit-level_ } \\
\text { probit_ } \\
\text { number_ } \\
\text { LowerCl }\end{array}$ & $\begin{array}{r}\text { Unit-level } \\
\text { probit } \\
\text { number } \\
\text { UpperCl }\end{array}$ \\
\hline 11242 & Lennox Head - Skennars Head & 5813 & 549.7 & 452.1 & 700.6 & 320 & 263 & 407 \\
\hline 11243 & Mullumbimby & 6139 & 947.3 & 777.4 & 1172.0 & 582 & 477 & 719 \\
\hline 11244 & Casino & 9235 & 1267.6 & 1018.6 & 1569.5 & 1171 & 941 & 1449 \\
\hline 11245 & Casino Region & 5378 & 635.3 & 508.3 & 799.8 & 342 & 273 & 430 \\
\hline 11246 & Goonellabah & 10110 & 1064.4 & 863.8 & 1314.4 & 1076 & 873 & 1329 \\
\hline 11247 & Kyogle & 5755 & 890.2 & 724.2 & 1090.2 & 512 & 417 & 627 \\
\hline 11248 & Lismore & 11917 & 1406.5 & 1146.8 & 1724.7 & 1676 & 1367 & 2055 \\
\hline 11249 & Lismore Region & 11639 & 592.4 & 483.9 & 735.9 & 689 & 563 & 856 \\
\hline 11250 & Kingscliff - Fingal Head & 10037 & 833.9 & 678.5 & 1052.9 & 837 & 681 & 1057 \\
\hline 11251 & Murwillumbah & 6865 & 1105.4 & 899.5 & 1367.7 & 759 & 617 & 939 \\
\hline 11252 & Murwillumbah Region & 7501 & 614.6 & 501.2 & 766.1 & 461 & 376 & 575 \\
\hline 11253 & Pottsville & 9813 & 832.5 & 678.4 & 1043.8 & 817 & 666 & 1024 \\
\hline 11254 & Tweed Heads & 15894 & 1067.6 & 869.9 & 1326.6 & 1697 & 1383 & 2108 \\
\hline 11256 & Griffith (NSW) & 14262 & 934.7 & 761.5 & 1179.1 & 1333 & 1086 & 1682 \\
\hline 11257 & Griffith Region & 9417 & 745.5 & 605.3 & 939.7 & 702 & 570 & 885 \\
\hline 11258 & Leeton & 7589 & 807.0 & 659.5 & 1002.7 & 612 & 500 & 761 \\
\hline 11259 & Narrandera & 4488 & 890.1 & 722.9 & 1091.4 & 399 & 324 & 490 \\
\hline 11260 & Tumbarumba & 2601 & 579.7 & 477.3 & 726.8 & 151 & 124 & 189 \\
\hline 11261 & Tumut & 4732 & 970.7 & 792.9 & 1197.5 & 459 & 375 & 567 \\
\hline 11262 & Tumut Region & 3561 & 523.3 & 427.4 & 651.8 & 186 & 152 & 232 \\
\hline 11263 & Cootamundra & 5784 & 869.6 & 708.0 & 1070.9 & 503 & 410 & 619 \\
\hline 11264 & Gundagai & 2669 & 693.3 & 567.0 & 867.4 & 185 & 151 & 232 \\
\hline 11265 & Junee & 4836 & 649.3 & 526.5 & 813.7 & 314 & 255 & 394 \\
\hline 11266 & Temora & 5078 & 799.1 & 655.0 & 979.7 & 406 & 333 & 498 \\
\hline 11267 & Wagga Wagga - East & 12111 & 812.3 & 663.2 & 1015.3 & 984 & 803 & 1230 \\
\hline 11268 & Wagga Wagga - North & 3347 & 740.0 & 604.7 & 937.0 & 248 & 202 & 314 \\
\hline 11269 & Wagga Wagga - South & 15602 & 1067.9 & 868.8 & 1327.7 & 1666 & 1355 & 2071 \\
\hline 11270 & Wagga Wagga - West & 9394 & 1537.1 & 1256.0 & 1896.1 & 1444 & 1180 & 1781 \\
\hline 11271 & Wagga Wagga Region & 10876 & 519.8 & 425.3 & 652.4 & 565 & 463 & 710 \\
\hline 11272 & Berry - Kangaroo Valley & 6992 & 462.2 & 379.8 & 580.9 & 323 & 266 & 406 \\
\hline 11273 & Callala Bay - Currarong & 2800 & 737.1 & 598.3 & 925.0 & 206 & 168 & 259 \\
\hline 11274 & Culburra Beach & 3969 & 789.9 & 641.9 & 983.2 & 314 & 255 & 390 \\
\hline 11276 & Huskisson - Vincentia & 3282 & 763.5 & 627.1 & 950.7 & 251 & 206 & 312 \\
\hline 11277 & North Nowra - Bomaderry & 11981 & 921.1 & 749.5 & 1138.5 & 1104 & 898 & 1364 \\
\hline 11278 & Nowra & 15044 & 1253.6 & 1014.6 & 1549.2 & 1886 & 1526 & 2331 \\
\hline 11279 & St Georges Basin - Erowal Bay & 10809 & 886.8 & 717.5 & 1104.5 & 959 & 776 & 1194 \\
\hline 11280 & Sussex Inlet - Berrara & 3532 & 762.7 & 622.3 & 933.9 & 269 & 220 & 330 \\
\hline 11281 & Tomerong - Wandandian - Woollamia & 2612 & 318.6 & 261.9 & 391.8 & 83 & 68 & 102 \\
\hline 11282 & Ulladulla & 11942 & 856.0 & 698.9 & 1060.6 & 1022 & 835 & 1267 \\
\hline 11283 & Ulladulla Region & 3924 & 513.9 & 422.2 & 634.8 & 202 & 166 & 249 \\
\hline 11284 & Bowral & 10242 & 488.3 & 399.2 & 618.3 & 500 & 409 & 633 \\
\hline 11285 & Hill Top - Colo Vale & 4447 & 355.3 & 291.1 & 447.4 & 158 & 129 & 199 \\
\hline 11286 & Mittagong & 7051 & 672.2 & 550.6 & 843.7 & 474 & 388 & 595 \\
\hline 11287 & Moss Vale - Berrima & 7523 & 774.0 & 633.7 & 961.9 & 582 & 477 & 724 \\
\hline 11288 & Robertson - Fitzroy Falls & 2630 & 380.0 & 314.5 & 478.1 & 100 & 83 & 126 \\
\hline 11289 & Southern Highlands & 5147 & 380.4 & 314.4 & 475.4 & 196 & 162 & 245 \\
\hline 11290 & Baulkham Hills (East) & 17330 & 404.8 & 335.5 & 520.5 & 702 & 582 & 902 \\
\hline 11291 & Baulkham Hills (West) - Bella Vista & 15694 & 309.2 & 253.3 & 402.0 & 485 & 397 & 631 \\
\hline 11294 & Glenhaven & 4922 & 338.7 & 275.6 & 434.6 & 167 & 136 & 214 \\
\hline 11296 & West Pennant Hills & 10114 & 174.6 & 144.3 & 226.1 & 177 & 146 & 229 \\
\hline 11297 & Dural - Kenthurst - Wisemans Ferry & 16312 & 283.9 & 232.7 & 365.3 & 463 & 380 & 596 \\
\hline 11298 & Galston - Laughtondale & 4062 & 323.6 & 265.9 & 413.5 & 131 & 108 & 168 \\
\hline 11299 & Bilpin - Colo - St Albans & 2089 & 333.2 & 276.3 & 412.9 & 70 & 58 & 86 \\
\hline 11300 & Kurrajong Heights - Ebenezer & 16707 & 246.2 & 201.2 & 313.8 & 411 & 336 & 524 \\
\hline 11301 & Pitt Town - McGraths Hill & 7934 & 292.4 & 239.6 & 376.9 & 232 & 190 & 299 \\
\hline 11302 & Rouse Hill - Beaumont Hills & 16260 & 283.7 & 233.1 & 376.6 & 461 & 379 & 612 \\
\hline 11303 & Blacktown (East) - Kings Park & 13012 & 1186.2 & 970.1 & 1519.4 & 1543 & 1262 & 1977 \\
\hline
\end{tabular}




\begin{tabular}{|c|c|c|c|c|c|c|c|c|}
\hline \multirow[b]{2}{*}{$\begin{array}{l}\text { SA2_5DIGIT } \\
\text { CODE_2016 }\end{array}$} & \multirow[b]{2}{*}{ SA2_name } & \multicolumn{7}{|c|}{ Unit-level SAEs } \\
\hline & & $\begin{array}{r}\text { Unit-level_Probit_ } \\
\text { totalpopulation }\end{array}$ & $\begin{array}{r}\text { Unit-level_ } \\
\text { probit_ } \\
\text { RATE }\end{array}$ & $\begin{array}{r}\text { Unit-level_ } \\
\text { probit_ } \\
\text { RATE_ } \\
\text { LowerCl }\end{array}$ & $\begin{array}{c}\text { Unit-level_ } \\
\text { probit_ } \\
\text { RATE_ } \\
\text { UpperCl }\end{array}$ & $\begin{array}{r}\text { Unit-level_ } \\
\text { probit_ } \\
\text { number }\end{array}$ & $\begin{array}{r}\text { Unit-level_ } \\
\text { probit_ } \\
\text { number_- } \\
\text { LowerCl }\end{array}$ & $\begin{array}{r}\text { Unit-level__ } \\
\text { probit_ } \\
\text { number_- } \\
\text { UpperCl }\end{array}$ \\
\hline 11304 & Blacktown (North) - Marayong & 13909 & 1023.1 & 829.9 & 1294.1 & 1423 & 1154 & 1800 \\
\hline 11306 & Doonside - Woodcroft & 17319 & 936.0 & 754.2 & 1180.9 & 1621 & 1306 & 2045 \\
\hline 11307 & Lalor Park - Kings Langley & 19316 & 754.9 & 617.2 & 944.1 & 1458 & 1192 & 1824 \\
\hline 11308 & Seven Hills - Toongabbie & 18589 & 703.6 & 574.3 & 894.8 & 1308 & 1068 & 1663 \\
\hline 11309 & Glenwood & 12097 & 386.4 & 314.3 & 508.4 & 467 & 380 & 615 \\
\hline 11310 & Parklea - Kellyville Ridge & 23243 & 330.1 & 271.1 & 435.2 & 767 & 630 & 1011 \\
\hline 11312 & Riverstone - Marsden Park & 12975 & 591.8 & 481.9 & 762.0 & 768 & 625 & 989 \\
\hline 11313 & Bidwill - Hebersham - Emerton & 13243 & 1767.8 & 1415.9 & 2206.6 & 2341 & 1875 & 2922 \\
\hline 11314 & Glendenning - Dean Park & 6149 & 594.7 & 479.8 & 766.5 & 366 & 295 & 471 \\
\hline 11315 & Hassall Grove - Plumpton & 15526 & 557.2 & 450.0 & 717.8 & 865 & 699 & 1114 \\
\hline 11316 & Lethbridge Park - Tregear & 14685 & 1616.1 & 1291.7 & 2028.2 & 2373 & 1897 & 2978 \\
\hline 11317 & Mount Druitt - Whalan & 16482 & 1484.9 & 1196.7 & 1883.6 & 2447 & 1972 & 3105 \\
\hline 11319 & Rooty Hill - Minchinbury & 16382 & 585.8 & 473.4 & 761.3 & 960 & 775 & 1247 \\
\hline 11321 & Botany & 8294 & 647.1 & 532.3 & 828.9 & 537 & 441 & 688 \\
\hline 11322 & Mascot - Eastlakes & 20019 & 1076.8 & 884.1 & 1379.9 & 2156 & 1770 & 2762 \\
\hline 11323 & Pagewood - Hillsdale - Daceyville & 9035 & 1275.9 & 1044.4 & 1595.5 & 1153 & 944 & 1442 \\
\hline 11326 & Marrickville & 21752 & 1010.7 & 830.1 & 1289.6 & 2199 & 1806 & 2805 \\
\hline 11327 & Petersham - Stanmore & 16735 & 950.5 & 785.3 & 1222.3 & 1591 & 1314 & 2045 \\
\hline 11328 & Sydenham - Tempe - St Peters & 6427 & 656.0 & 539.2 & 856.1 & 422 & 347 & 550 \\
\hline 11329 & Darlinghurst & 10261 & 1015.3 & 847.9 & 1300.9 & 1042 & 870 & 1335 \\
\hline 11330 & Erskineville - Alexandria & 13806 & 819.9 & 684.9 & 1066.0 & 1132 & 946 & 1472 \\
\hline 11331 & Glebe - Forest Lodge & 16955 & 1502.7 & 1234.2 & 1897.7 & 2548 & 2093 & 3218 \\
\hline 11332 & Newtown - Camperdown - Darlington & 21576 & 1233.9 & 1013.4 & 1589.0 & 2662 & 2186 & 3428 \\
\hline 11333 & Potts Point - Woolloomooloo & 19321 & 1148.0 & 956.6 & 1453.4 & 2218 & 1848 & 2808 \\
\hline 11334 & Pyrmont - Ultimo & 19242 & 1412.7 & 1154.3 & 1827.3 & 2718 & 2221 & 3516 \\
\hline 11335 & Redfern - Chippendale & 20297 & 1621.5 & 1326.9 & 2060.1 & 3291 & 2693 & 4181 \\
\hline 11336 & Surry Hills & 14815 & 1304.1 & 1080.0 & 1660.2 & 1932 & 1600 & 2460 \\
\hline 11337 & Sydney - Haymarket - The Rocks & 24911 & 1361.9 & 1106.0 & 1797.2 & 3393 & 2755 & 4477 \\
\hline 11338 & Waterloo - Beaconsfield & 29147 & 1481.7 & 1213.7 & 1886.8 & 4319 & 3538 & 5500 \\
\hline 11339 & Bondi - Tamarama - Bronte & 14829 & 792.1 & 661.3 & 1026.5 & 1175 & 981 & 1522 \\
\hline 11340 & Bondi Beach - North Bondi & 16668 & 872.7 & 728.7 & 1131.1 & 1455 & 1215 & 1885 \\
\hline 11341 & Bondi Junction - Waverly & 13714 & 805.7 & 669.3 & 1036.1 & 1105 & 918 & 1421 \\
\hline 11343 & Double Bay - Bellevue Hill & 20196 & 608.7 & 507.6 & 792.8 & 1229 & 1025 & 1601 \\
\hline 11344 & Dover Heights & 8331 & 636.3 & 530.2 & 816.5 & 530 & 442 & 680 \\
\hline 11345 & Paddington - Moore Park & 12465 & 801.4 & 671.5 & 1032.3 & 999 & 837 & 1287 \\
\hline 11346 & Rose Bay - Vaucluse - Watsons Bay & 9019 & 448.8 & 373.5 & 578.2 & 405 & 337 & 521 \\
\hline 11347 & Woollahra & 6172 & 568.5 & 475.6 & 736.5 & 351 & 294 & 455 \\
\hline 11348 & Coogee - Clovelly & 20240 & 916.1 & 763.1 & 1166.8 & 1854 & 1544 & 2362 \\
\hline 11350 & Malabar - La Perouse - Chifley & 19405 & 776.6 & 633.9 & 966.8 & 1507 & 1230 & 1876 \\
\hline 11354 & Bass Hill - Georges Hall & 16429 & 1049.3 & 847.3 & 1312.9 & 1724 & 1392 & 2157 \\
\hline 11355 & Chullora & 694 & 630.8 & 517.8 & 812.5 & 44 & 36 & 56 \\
\hline 11356 & Condell Park & 8384 & 753.0 & 607.7 & 961.7 & 631 & 509 & 806 \\
\hline 11357 & Greenacre - Mount Lewis & 19114 & 991.0 & 801.4 & 1242.2 & 1894 & 1532 & 2374 \\
\hline 11358 & Padstow & 13257 & 713.2 & 582.2 & 898.3 & 945 & 772 & 1191 \\
\hline 11359 & Panania - Milperra - Picnic Point & 19883 & 589.9 & 480.8 & 741.8 & 1173 & 956 & 1475 \\
\hline 11360 & Revesby & 12736 & 864.4 & 705.7 & 1086.0 & 1101 & 899 & 1383 \\
\hline 11361 & Yagoona - Birrong & 15656 & 1034.9 & 838.3 & 1301.6 & 1620 & 1312 & 2038 \\
\hline 11362 & Belmore - Belfield & 15015 & 1099.7 & 896.4 & 1393.3 & 1651 & 1346 & 2092 \\
\hline 11363 & Canterbury (South) - Campsie & 25135 & 1260.8 & 1031.6 & 1614.6 & 3169 & 2593 & 4058 \\
\hline 11364 & Kingsgrove (North) - Earlwood & 18688 & 477.6 & 390.9 & 609.8 & 893 & 731 & 1140 \\
\hline 11366 & Punchbowl & 15627 & 1075.7 & 869.1 & 1366.6 & 1681 & 1358 & 2136 \\
\hline 11367 & Roselands & 10502 & 737.9 & 599.8 & 936.7 & 775 & 630 & 984 \\
\hline 11368 & Hurstville & 19602 & 1082.1 & 881.2 & 1398.2 & 2121 & 1727 & 2741 \\
\hline 11369 & Mortdale - Penshurst & 19167 & 760.4 & 625.4 & 976.5 & 1457 & 1199 & 1872 \\
\hline 11370 & Narwee - Beverly Hills & 11119 & 941.1 & 768.4 & 1186.0 & 1046 & 854 & 1319 \\
\hline 11371 & Oatley - Hurstville Grove & 9983 & 371.7 & 306.4 & 482.6 & 371 & 306 & 482 \\
\hline 11372 & Peakhurst - Lugarno & 14214 & 463.4 & 378.1 & 583.2 & 659 & 537 & 829 \\
\hline
\end{tabular}




\begin{tabular}{|c|c|c|c|c|c|c|c|c|}
\hline \multirow[b]{2}{*}{$\begin{array}{l}\text { SA2_5DIGIT } \\
\text { CODE_2016 }\end{array}$} & \multirow[b]{2}{*}{ SA2_name } & \multicolumn{7}{|c|}{ Unit-level SAEs } \\
\hline & & $\begin{array}{r}\text { Unit-level_Probit_ } \\
\text { totalpopulation }\end{array}$ & $\begin{array}{r}\text { Unit-level_ } \\
\text { probit_ } \\
\text { RATE }\end{array}$ & $\begin{array}{r}\text { Unit-level_ } \\
\text { probit_ } \\
\text { RATE_ } \\
\text { LowerCl }\end{array}$ & $\begin{array}{r}\text { Unit-level_ } \\
\text { probit_ } \\
\text { RATE_ } \\
\text { UpperCl }\end{array}$ & $\begin{array}{r}\text { Unit-level_ } \\
\text { probit_ } \\
\text { number }\end{array}$ & $\begin{array}{c}\text { Unit-level_ } \\
\text { probit_ } \\
\text { number_- } \\
\text { LowerCl }\end{array}$ & $\begin{array}{r}\text { Unit-level_ } \\
\text { probit_ } \\
\text { number_ } \\
\text { UpperCl }\end{array}$ \\
\hline 11373 & Riverwood & 9229 & 1756.0 & 1432.8 & 2174.5 & 1621 & 1322 & 2007 \\
\hline 11374 & South Hurstville - Blakehurst & 19490 & 724.9 & 591.4 & 936.5 & 1413 & 1153 & 1825 \\
\hline 11375 & Arncliffe - Bardwell Valley & 17883 & 976.3 & 799.0 & 1267.8 & 1746 & 1429 & 2267 \\
\hline 11376 & Bexley & 21144 & 749.6 & 613.4 & 965.7 & 1585 & 1297 & 2042 \\
\hline 11377 & Kingsgrove (South) - Bardwell Park & 10032 & 640.6 & 523.4 & 815.1 & 643 & 525 & 818 \\
\hline 11378 & Kogarah & 9225 & 947.4 & 780.8 & 1228.9 & 874 & 720 & 1134 \\
\hline 11379 & Kogarah Bay - Carlton - Allawah & 12889 & 875.7 & 719.1 & 1126.2 & 1129 & 927 & 1452 \\
\hline 11380 & Monterey - Brighton-le-Sands - Kyeemagh & 11297 & 894.3 & 737.4 & 1133.2 & 1010 & 833 & 1280 \\
\hline 11381 & Rockdale - Banksia & 16685 & 950.9 & 778.9 & 1237.8 & 1587 & 1300 & 2065 \\
\hline 11382 & Sans Souci - Ramsgate & 12814 & 690.6 & 567.5 & 876.7 & 885 & 727 & 1123 \\
\hline 11383 & Concord - Mortlake - Cabarita & 17294 & 457.4 & 380.1 & 587.3 & 791 & 657 & 1016 \\
\hline 11384 & Concord West - North Strathfield & 20414 & 962.5 & 791.1 & 1253.3 & 1965 & 1615 & 2559 \\
\hline 11385 & Drummoyne - Rodd Point & 14415 & 548.5 & 456.8 & 704.3 & 791 & 658 & 1015 \\
\hline 11386 & Five Dock - Abbotsford & 16249 & 705.0 & 584.3 & 896.1 & 1145 & 949 & 1456 \\
\hline 11387 & Balmain & 12217 & 698.5 & 584.4 & 883.0 & 853 & 714 & 1079 \\
\hline 11388 & Leichhardt - Annandale & 20389 & 793.4 & 658.0 & 1012.1 & 1618 & 1342 & 2064 \\
\hline 11389 & Lilyfield - Rozelle & 10823 & 686.3 & 573.4 & 871.7 & 743 & 621 & 943 \\
\hline 11390 & Ashfield & 20738 & 1090.3 & 897.6 & 1403.7 & 2261 & 1861 & 2911 \\
\hline 11391 & Burwood - Croydon & 20969 & 1165.3 & 948.6 & 1505.6 & 2444 & 1989 & 3157 \\
\hline 11392 & Canterbury (North) - Ashbury & 8367 & 629.1 & 518.2 & 807.1 & 526 & 434 & 675 \\
\hline 11393 & Croydon Park - Enfield & 13805 & 731.8 & 601.7 & 927.6 & 1010 & 831 & 1281 \\
\hline 11394 & Dulwich Hill - Lewisham & 13687 & 962.2 & 794.5 & 1227.4 & 1317 & 1087 & 1680 \\
\hline 11395 & Haberfield - Summer Hill & 10786 & 695.5 & 577.5 & 890.6 & 750 & 623 & 961 \\
\hline 11396 & Homebush & 13135 & 1152.9 & 948.4 & 1494.7 & 1514 & 1246 & 1963 \\
\hline 11398 & Chatswood (East) - Artarmon & 22893 & 979.8 & 808.9 & 1266.4 & 2243 & 1852 & 2899 \\
\hline 11399 & Chatswood (West) - Lane Cove North & 16660 & 705.4 & 586.5 & 912.0 & 1175 & 977 & 1519 \\
\hline 11400 & Lane Cove - Greenwich & 20658 & 462.7 & 387.5 & 596.0 & 956 & 801 & 1231 \\
\hline 11401 & St Leonards - Naremburn & 8482 & 734.8 & 617.7 & 958.2 & 623 & 524 & 813 \\
\hline 11402 & Willoughby - Castle Cove - Northbridge & 18766 & 341.8 & 284.7 & 443.2 & 641 & 534 & 832 \\
\hline 11403 & Asquith - Mount Colah & 13845 & 267.4 & 220.9 & 344.4 & 370 & 306 & 477 \\
\hline 11404 & Berowra - Brooklyn - Cowan & 8730 & 215.8 & 179.0 & 278.6 & 188 & 156 & 243 \\
\hline 11406 & Normanhurst - Thornleigh - Westleigh & 14075 & 343.9 & 283.9 & 436.1 & 484 & 400 & 614 \\
\hline 11407 & Gordon - Killara & 16759 & 416.0 & 345.2 & 542.3 & 697 & 578 & 909 \\
\hline 11408 & Lindfield - Roseville & 17500 & 371.8 & 308.4 & 481.9 & 651 & 540 & 843 \\
\hline 11409 & Pymble & 12172 & 232.6 & 193.8 & 304.2 & 283 & 236 & 370 \\
\hline 11410 & St Ives & 15597 & 213.0 & 177.2 & 281.4 & 332 & 276 & 439 \\
\hline 11411 & Turramurra & 14824 & 287.2 & 237.0 & 370.0 & 426 & 351 & 548 \\
\hline 11412 & Wahroonga (East) - Warrawee & 13837 & 231.8 & 191.1 & 304.3 & 321 & 264 & 421 \\
\hline 11413 & Cremorne - Cammeray & 15270 & 674.2 & 566.3 & 874.3 & 1030 & 865 & 1335 \\
\hline 11414 & Crows Nest - Waverton & 14929 & 777.0 & 653.6 & 1008.5 & 1160 & 976 & 1506 \\
\hline 11415 & Mosman & 22197 & 543.4 & 454.5 & 699.6 & 1206 & 1009 & 1553 \\
\hline 11416 & Neutral Bay - Kirribilli & 15087 & 906.3 & 760.3 & 1165.1 & 1367 & 1147 & 1758 \\
\hline 11417 & North Sydney - Lavender Bay & 9096 & 777.2 & 655.0 & 1015.1 & 707 & 596 & 923 \\
\hline 11418 & Balgowlah - Clontarf - Seaforth & 14672 & 347.7 & 289.5 & 451.1 & 510 & 425 & 662 \\
\hline 11419 & Manly - Fairlight & 17642 & 709.0 & 595.2 & 919.1 & 1251 & 1050 & 1621 \\
\hline 11420 & Avalon - Palm Beach & 9327 & 309.5 & 256.8 & 398.4 & 289 & 240 & 372 \\
\hline 11421 & Bayview - Elanora Heights & 8305 & 297.5 & 244.6 & 379.0 & 247 & 203 & 315 \\
\hline 11422 & Newport - Bilgola & 9947 & 310.4 & 259.1 & 400.9 & 309 & 258 & 399 \\
\hline 11423 & Warriewood - Mona Vale & 18236 & 371.1 & 307.5 & 481.2 & 677 & 561 & 878 \\
\hline 11424 & Beacon Hill - Narraweena & 10625 & 567.8 & 467.2 & 707.7 & 603 & 496 & 752 \\
\hline 11425 & Cromer & 5713 & 369.0 & 303.6 & 470.6 & 211 & 173 & 269 \\
\hline 11426 & Dee Why - North Curl Curl & 19762 & 870.1 & 722.3 & 1117.0 & 1720 & 1427 & 2208 \\
\hline 11427 & Forestville - Killarney Heights & 9479 & 353.7 & 291.4 & 451.5 & 335 & 276 & 428 \\
\hline 11428 & Frenchs Forest - Belrose & 18990 & 206.7 & 170.4 & 270.8 & 393 & 324 & 514 \\
\hline 11429 & Freshwater-Brookvale & 16013 & 569.9 & 477.6 & 733.1 & 913 & 765 & 1174 \\
\hline 11430 & Manly Vale - Allambie Heights & 12467 & 521.0 & 432.6 & 657.1 & 650 & 539 & 819 \\
\hline 11431 & Narrabeen - Collaroy & 19439 & 534.7 & 445.3 & 679.9 & 1039 & 866 & 1322 \\
\hline
\end{tabular}




\begin{tabular}{|c|c|c|c|c|c|c|c|c|}
\hline \multirow[b]{2}{*}{$\begin{array}{l}\text { SA2_5DIGIT } \\
\text { CODE_2016 }\end{array}$} & \multirow[b]{2}{*}{ SA2_name } & \multicolumn{7}{|c|}{ Unit-level SAEs } \\
\hline & & $\begin{array}{r}\text { Unit-level_Probit_ } \\
\text { totalpopulation }\end{array}$ & $\begin{array}{r}\text { Unit-level_ } \\
\text { probit_ } \\
\text { RATE }\end{array}$ & $\begin{array}{r}\text { Unit-level_ } \\
\text { probit_ } \\
\text { RATE_ } \\
\text { LowerCl }\end{array}$ & $\begin{array}{r}\text { Unit-level_ } \\
\text { probit_ } \\
\text { RATE_ } \\
\text { UpperCl }\end{array}$ & $\begin{array}{r}\text { Unit-level_ } \\
\text { probit_ } \\
\text { number }\end{array}$ & $\begin{array}{c}\text { Unit-level_ } \\
\text { probit_ } \\
\text { number_ } \\
\text { LowerCl }\end{array}$ & $\begin{array}{r}\text { Unit-level_ } \\
\text { probit_ } \\
\text { number_ } \\
\text { UpperCl }\end{array}$ \\
\hline 11432 & Terrey Hills - Duffys Forest & 2814 & 215.3 & 180.6 & 277.5 & 61 & 51 & 78 \\
\hline 11433 & Camden - Ellis Lane & 9917 & 401.0 & 328.1 & 504.5 & 398 & 325 & 500 \\
\hline 11434 & Elderslie - Harrington Park & 15313 & 440.0 & 359.6 & 561.1 & 674 & 551 & 859 \\
\hline 11435 & Mount Annan - Currans Hill & 20623 & 454.3 & 370.6 & 586.2 & 937 & 764 & 1209 \\
\hline 11436 & Bradbury - Wedderburn & 13927 & 1252.6 & 1006.0 & 1571.1 & 1744 & 1401 & 2188 \\
\hline 11437 & Campbelltown - Woodbine & 14147 & 1088.3 & 885.1 & 1372.4 & 1540 & 1252 & 1942 \\
\hline 11438 & Claymore - Eagle Vale - Raby & 15283 & 800.9 & 645.0 & 1014.7 & 1224 & 986 & 1551 \\
\hline 11440 & Ingleburn - Denham Court & 15391 & 739.7 & 601.2 & 943.7 & 1138 & 925 & 1452 \\
\hline 11441 & Leumeah - Minto Heights & 12734 & 823.7 & 671.2 & 1035.3 & 1049 & 855 & 1318 \\
\hline 11442 & Macquarie Fields - Glenfield & 17795 & 1087.9 & 880.9 & 1365.5 & 1936 & 1568 & 2430 \\
\hline 11443 & Minto - St Andrews & 14976 & 884.3 & 716.5 & 1110.9 & 1324 & 1073 & 1664 \\
\hline 11444 & Rosemeadow - Glen Alpine & 15764 & 910.1 & 735.7 & 1144.4 & 1435 & 1160 & 1804 \\
\hline 11445 & Bargo & 4335 & 411.3 & 333.7 & 521.4 & 178 & 145 & 226 \\
\hline 11446 & Douglas Park - Appin & 7068 & 260.3 & 211.9 & 333.5 & 184 & 150 & 236 \\
\hline 11447 & Picton - Tahmoor - Buxton & 12599 & 569.8 & 463.8 & 717.8 & 718 & 584 & 904 \\
\hline 11448 & The Oaks - Oakdale & 6745 & 266.3 & 217.8 & 339.9 & 180 & 147 & 229 \\
\hline 11449 & Blackheath - Megalong Valley & 4325 & 826.0 & 676.6 & 1019.9 & 357 & 293 & 441 \\
\hline 11450 & Blaxland - Warrimoo - Lapstone & 14381 & 329.6 & 270.3 & 419.1 & 474 & 389 & 603 \\
\hline 11452 & Katoomba - Leura & 10552 & 1013.2 & 827.4 & 1251.2 & 1069 & 873 & 1320 \\
\hline 11453 & Lawson - Hazelbrook - Linden & 8558 & 450.9 & 368.9 & 563.7 & 386 & 316 & 482 \\
\hline 11454 & Springwood - Winmalee & 16626 & 395.3 & 324.0 & 495.5 & 657 & 539 & 824 \\
\hline 11455 & Wentworth Falls & 4785 & 588.9 & 479.8 & 739.1 & 282 & 230 & 354 \\
\hline 11457 & Cambridge Park & 11928 & 566.3 & 457.9 & 722.5 & 675 & 546 & 862 \\
\hline 11458 & Castlereagh - Cranebrook & 17466 & 654.4 & 530.9 & 835.4 & 1143 & 927 & 1459 \\
\hline 11459 & Emu Plains - Leonay & 10947 & 407.6 & 332.1 & 518.6 & 446 & 364 & 568 \\
\hline 11460 & Glenmore Park - Regentville & 15673 & 390.6 & 321.5 & 504.3 & 612 & 504 & 790 \\
\hline 11461 & Jamisontown - South Penrith & 13223 & 757.0 & 619.5 & 953.6 & 1001 & 819 & 1261 \\
\hline 11462 & Kingswood - Werrington & 14726 & 1168.8 & 954.1 & 1462.6 & 1721 & 1405 & 2154 \\
\hline 11463 & Mulgoa - Luddenham - Orchard Hills & 7124 & 331.4 & 269.5 & 434.5 & 236 & 192 & 310 \\
\hline 11464 & Penrith & 10649 & 1640.4 & 1342.0 & 2038.0 & 1747 & 1429 & 2170 \\
\hline 11465 & Warragamba - Silverdale & 3905 & 265.0 & 218.0 & 332.8 & 103 & 85 & 130 \\
\hline 11466 & Richmond - Clarendon & 10898 & 965.1 & 787.4 & 1214.3 & 1052 & 858 & 1323 \\
\hline 11467 & Windsor - Bligh Park & 11692 & 1063.5 & 867.5 & 1328.1 & 1243 & 1014 & 1553 \\
\hline 11468 & Yarramundi - Londonderry & 5867 & 283.1 & 230.7 & 362.7 & 166 & 135 & 213 \\
\hline 11469 & Erskine Park & 5048 & 309.9 & 253.8 & 400.9 & 156 & 128 & 202 \\
\hline 11470 & St Clair & 15275 & 407.8 & 330.3 & 526.7 & 623 & 505 & 805 \\
\hline 11473 & Homebush Bay - Silverwater & 15301 & 752.4 & 626.0 & 979.2 & 1151 & 958 & 1498 \\
\hline 11476 & Carlingford & 21564 & 534.0 & 437.8 & 690.2 & 1152 & 944 & 1488 \\
\hline 11477 & Ermington - Rydalmere & 16536 & 963.8 & 788.5 & 1211.6 & 1594 & 1304 & 2004 \\
\hline 11478 & Oatlands - Dundas Valley & 13953 & 1037.8 & 848.5 & 1298.7 & 1448 & 1184 & 1812 \\
\hline 11479 & Chester Hill - Sefton & 14068 & 1079.6 & 873.9 & 1353.7 & 1519 & 1229 & 1904 \\
\hline 11480 & Fairfield - East & 11872 & 1259.0 & 1017.9 & 1579.0 & 1495 & 1208 & 1875 \\
\hline 11481 & Granville - Clyde & 16158 & 1135.4 & 920.9 & 1454.7 & 1835 & 1488 & 2350 \\
\hline 11482 & Greystanes - Pemulwuy & 19923 & 439.0 & 357.5 & 561.9 & 875 & 712 & 1119 \\
\hline 11483 & Guildford - South Granville & 15316 & 1312.7 & 1058.4 & 1654.7 & 2010 & 1621 & 2534 \\
\hline 11484 & Guildford West - Merrylands West & 15695 & 1180.9 & 958.8 & 1492.4 & 1853 & 1505 & 2342 \\
\hline 11485 & Merrylands - Holroyd & 21736 & 1291.8 & 1047.1 & 1645.4 & 2808 & 2276 & 3576 \\
\hline 11489 & North Parramatta & 17933 & 1284.9 & 1057.9 & 1637.6 & 2304 & 1897 & 2937 \\
\hline 11490 & North Rocks & 6075 & 223.2 & 184.5 & 293.4 & 136 & 112 & 178 \\
\hline 11491 & Northmead & 15614 & 979.5 & 811.7 & 1255.9 & 1529 & 1267 & 1961 \\
\hline 11492 & Parramatta - Rosehill & 23562 & 1393.1 & 1150.3 & 1799.0 & 3282 & 2710 & 4239 \\
\hline 11493 & Toongabbie - Constitution Hill & 17203 & 760.7 & 618.5 & 970.4 & 1309 & 1064 & 1669 \\
\hline 11494 & Winston Hills & 8145 & 220.8 & 182.0 & 286.4 & 180 & 148 & 233 \\
\hline 11495 & Epping - North Epping & 21677 & 620.2 & 511.2 & 804.7 & 1344 & 1108 & 1744 \\
\hline 11496 & Pennant Hills - Cheltenham & 15933 & 311.3 & 256.0 & 401.7 & 496 & 408 & 640 \\
\hline 11497 & Eastwood - Denistone & 20277 & 733.2 & 600.5 & 938.8 & 1487 & 1218 & 1904 \\
\hline 11498 & Gladesville - Huntleys Point & 11364 & 712.1 & 591.0 & 895.1 & 809 & 672 & 1017 \\
\hline
\end{tabular}




\begin{tabular}{|c|c|c|c|c|c|c|c|c|}
\hline \multirow[b]{2}{*}{$\begin{array}{l}\text { SA2_5DIGIT } \\
\text { CODE_2016 }\end{array}$} & \multirow[b]{2}{*}{ SA2_name } & \multicolumn{7}{|c|}{ Unit-level SAEs } \\
\hline & & $\begin{array}{r}\text { Unit-level_Probit_ } \\
\text { totalpopulation }\end{array}$ & $\begin{array}{r}\text { Unit-level_ } \\
\text { probit_ } \\
\text { RATE }\end{array}$ & $\begin{array}{r}\text { Unit-level_ } \\
\text { probit_ } \\
\text { RATE_ } \\
\text { LowerCl }\end{array}$ & $\begin{array}{r}\text { Unit-level_ } \\
\text { probit_ } \\
\text { RATE_ } \\
\text { UpperCl }\end{array}$ & $\begin{array}{r}\text { Unit-level_ } \\
\text { probit_ } \\
\text { number }\end{array}$ & $\begin{array}{c}\text { Unit-level_ } \\
\text { probit_ } \\
\text { number_ } \\
\text { LowerCl }\end{array}$ & $\begin{array}{r}\text { Unit-level_ } \\
\text { probit_ } \\
\text { number_ } \\
\text { UpperCl }\end{array}$ \\
\hline 11499 & Hunters Hill - Woolwich & 7929 & 378.8 & 313.6 & 478.1 & 300 & 249 & 379 \\
\hline 11500 & Macquarie Park - Marsfield & 18374 & 1112.2 & 914.3 & 1421.1 & 2044 & 1680 & 2611 \\
\hline 11501 & North Ryde - East Ryde & 9692 & 497.1 & 409.3 & 626.2 & 482 & 397 & 607 \\
\hline 11503 & West Ryde - Meadowbank & 15710 & 1043.8 & 863.7 & 1332.5 & 1640 & 1357 & 2093 \\
\hline 11504 & Ashcroft - Busby - Miller & 12709 & 1822.2 & 1464.6 & 2262.3 & 2316 & 1861 & 2875 \\
\hline 11505 & Austral - Greendale & 6981 & 618.9 & 500.4 & 798.2 & 432 & 349 & 557 \\
\hline 11506 & Cobbitty - Leppington & 13152 & 467.7 & 381.7 & 611.1 & 615 & 502 & 804 \\
\hline 11509 & Bonnyrigg Heights - Bonnyrigg & 12501 & 1020.4 & 820.1 & 1283.3 & 1276 & 1025 & 1604 \\
\hline 11510 & Bossley Park - Abbotsbury & 15093 & 654.7 & 521.8 & 842.4 & 988 & 788 & 1271 \\
\hline 11511 & Cabramatta - Lansvale & 19514 & 1380.4 & 1118.9 & 1748.7 & 2694 & 2183 & 3412 \\
\hline 11512 & Cabramatta West - Mount Pritchard & 13160 & 1051.2 & 849.2 & 1320.9 & 1383 & 1118 & 1738 \\
\hline 11513 & Canley Vale - Canley Heights & 16290 & 1187.4 & 959.5 & 1495.5 & 1934 & 1563 & 2436 \\
\hline 11514 & Edensor Park & 7800 & 694.5 & 553.8 & 895.7 & 542 & 432 & 699 \\
\hline 11515 & Fairfield & 13890 & 2002.6 & 1610.1 & 2523.0 & 2782 & 2236 & 3504 \\
\hline 11516 & Fairfield - West & 14773 & 1159.0 & 927.2 & 1480.9 & 1712 & 1370 & 2188 \\
\hline 11517 & Greenfield Park - Prairiewood & 6574 & 827.1 & 659.8 & 1058.8 & 544 & 434 & 696 \\
\hline 11518 & Horsley Park - Kemps Creek & 3559 & 304.0 & 244.2 & 399.4 & 108 & 87 & 142 \\
\hline 11519 & Smithfield - Wetherill Park & 14130 & 1025.7 & 824.5 & 1297.3 & 1449 & 1165 & 1833 \\
\hline 11520 & St Johns Park - Wakeley & 8781 & 556.8 & 444.5 & 716.3 & 489 & 390 & 629 \\
\hline 11522 & Casula & 11946 & 754.0 & 610.9 & 956.2 & 901 & 730 & 1142 \\
\hline 11523 & Chipping Norton - Moorebank & 14082 & 418.4 & 340.4 & 537.3 & 589 & 479 & 757 \\
\hline 11524 & Holsworthy - Wattle Grove & 15476 & 428.0 & 352.0 & 555.9 & 662 & 545 & 860 \\
\hline 11529 & Gymea - Grays Point & 13399 & 339.4 & 281.9 & 433.9 & 455 & 378 & 581 \\
\hline 11530 & Miranda - Yowie Bay & 14259 & 690.0 & 568.2 & 870.5 & 984 & 810 & 1241 \\
\hline 11531 & Sylvania - Taren Point & 12670 & 435.2 & 358.0 & 549.3 & 551 & 454 & 696 \\
\hline 11533 & Heathcote - Waterfall & 5020 & 312.1 & 257.3 & 388.6 & 157 & 129 & 195 \\
\hline 11534 & Illawong - Alfords Point & 8382 & 129.3 & 105.5 & 170.1 & 108 & 88 & 143 \\
\hline 11535 & Menai - Lucas Heights - Woronora & 16417 & 257.7 & 210.5 & 330.3 & 423 & 346 & 542 \\
\hline 11536 & Oyster Bay - Como - Jannali & 15874 & 298.1 & 245.5 & 374.6 & 473 & 390 & 595 \\
\hline 11538 & Sutherland - Kirrawee & 16453 & 778.1 & 644.5 & 977.6 & 1280 & 1060 & 1608 \\
\hline 11539 & Goulburn & 17653 & 1033.1 & 842.5 & 1279.9 & 1824 & 1487 & 2259 \\
\hline 11540 & Goulburn Region & 9755 & 462.2 & 377.9 & 577.4 & 451 & 369 & 563 \\
\hline 11541 & Yass & 4875 & 684.0 & 558.5 & 854.4 & 333 & 272 & 417 \\
\hline 11542 & Yass Region & 8503 & 304.7 & 252.6 & 383.1 & 259 & 215 & 326 \\
\hline 11543 & Young & 7742 & 1042.6 & 849.8 & 1287.4 & 807 & 658 & 997 \\
\hline 11544 & Young Region & 5667 & 669.6 & 550.5 & 824.8 & 379 & 312 & 467 \\
\hline 11545 & Berkeley - Lake Heights - Cringila & 10637 & 1118.5 & 905.3 & 1389.1 & 1190 & 963 & 1478 \\
\hline 11546 & Port Kembla - Warrawong & 7645 & 1496.6 & 1213.3 & 1846.4 & 1144 & 928 & 1412 \\
\hline 11547 & Windang - Primbee & 3513 & 830.6 & 680.2 & 1022.2 & 292 & 239 & 359 \\
\hline 11548 & Wollongong - East & 12155 & 1600.0 & 1310.8 & 2014.3 & 1945 & 1593 & 2448 \\
\hline 11549 & Wollongong - West & 13445 & 1546.2 & 1260.0 & 1942.4 & 2079 & 1694 & 2612 \\
\hline 11550 & Banora Point & 12462 & 723.8 & 586.5 & 909.2 & 902 & 731 & 1133 \\
\hline 11551 & Terranora - North Tumblegum & 2428 & 311.4 & 250.1 & 408.9 & 76 & 61 & 99 \\
\hline 11552 & Tweed Heads South & 6745 & 1249.4 & 1017.5 & 1540.3 & 843 & 686 & 1039 \\
\hline 11553 & Castle Hill - Central & 5856 & 504.5 & 418.8 & 655.6 & 295 & 245 & 384 \\
\hline 11554 & Castle Hill - East & 4668 & 765.3 & 625.1 & 946.4 & 357 & 292 & 442 \\
\hline 11555 & Castle Hill - North & 9228 & 317.9 & 262.4 & 412.6 & 293 & 242 & 381 \\
\hline 11556 & Castle Hill - South & 7273 & 393.5 & 325.4 & 512.9 & 286 & 237 & 373 \\
\hline 11557 & Castle Hill - West & 3999 & 218.0 & 180.5 & 288.8 & 87 & 72 & 115 \\
\hline 11558 & Cherrybrook & 14943 & 246.7 & 203.4 & 324.4 & 369 & 304 & 485 \\
\hline 11559 & Kellyville & 17175 & 295.6 & 242.8 & 389.5 & 508 & 417 & 669 \\
\hline 11560 & Blacktown (South) & 9445 & 822.9 & 669.6 & 1047.6 & 777 & 632 & 989 \\
\hline 11561 & Blacktown (West) & 12447 & 797.5 & 648.4 & 1027.2 & 993 & 807 & 1279 \\
\hline 11562 & Acacia Gardens & 2849 & 267.4 & 221.3 & 349.2 & 76 & 63 & 99 \\
\hline 11563 & Quakers Hill & 17060 & 559.9 & 457.2 & 725.5 & 955 & 780 & 1238 \\
\hline 11564 & Kensington (NSW) & 12923 & 1122.3 & 916.1 & 1446.5 & 1450 & 1184 & 1869 \\
\hline 11565 & Kingsford & 13354 & 1613.0 & 1301.3 & 2086.1 & 2154 & 1738 & 2786 \\
\hline
\end{tabular}




\begin{tabular}{|c|c|c|c|c|c|c|c|c|}
\hline \multirow[b]{2}{*}{$\begin{array}{l}\text { SA2_5DIGIT } \\
\text { CODE_2016 }\end{array}$} & \multirow[b]{2}{*}{ SA2_name } & \multicolumn{7}{|c|}{ Unit-level SAEs } \\
\hline & & $\begin{array}{r}\text { Unit-level_Probit_ } \\
\text { totalpopulation }\end{array}$ & $\begin{array}{r}\text { Unit-level_ } \\
\text { probit_ } \\
\text { RATE }\end{array}$ & $\begin{array}{r}\text { Unit-level_ } \\
\text { probit_ } \\
\text { RATE_ } \\
\text { LowerCl }\end{array}$ & $\begin{array}{r}\text { Unit-level_ } \\
\text { probit_ } \\
\text { RATE_ } \\
\text { UpperCl }\end{array}$ & $\begin{array}{r}\text { Unit-level_ } \\
\text { probit_ } \\
\text { number }\end{array}$ & $\begin{array}{c}\text { Unit-level_ } \\
\text { probit_ } \\
\text { number_- } \\
\text { LowerCl }\end{array}$ & $\begin{array}{r}\text { Unit-level_ } \\
\text { probit_ } \\
\text { number_ } \\
\text { UpperCl }\end{array}$ \\
\hline 11566 & Maroubra - North & 7885 & 641.3 & 532.2 & 819.9 & 506 & 420 & 647 \\
\hline 11567 & Maroubra - South & 8533 & 1418.8 & 1166.2 & 1764.0 & 1211 & 995 & 1505 \\
\hline 11568 & Maroubra - West & 8301 & 983.2 & 803.2 & 1269.4 & 816 & 667 & 1054 \\
\hline 11569 & Randwick - North & 13658 & 863.6 & 719.7 & 1115.4 & 1180 & 983 & 1523 \\
\hline 11570 & Randwick - South & 10692 & 984.6 & 813.0 & 1272.8 & 1053 & 869 & 1361 \\
\hline 11571 & Bankstown - North & 12187 & 1468.3 & 1195.7 & 1861.8 & 1789 & 1457 & 2269 \\
\hline 11572 & Bankstown - South & 12188 & 1288.9 & 1045.5 & 1633.2 & 1571 & 1274 & 1991 \\
\hline 11573 & Lakemba & 12426 & 1674.8 & 1363.5 & 2150.2 & 2081 & 1694 & 2672 \\
\hline 11574 & Wiley Park & 7560 & 1567.7 & 1277.7 & 2011.5 & 1185 & 966 & 1521 \\
\hline 11575 & Strathfield & 21214 & 966.0 & 789.9 & 1255.2 & 2049 & 1676 & 2663 \\
\hline 11576 & Strathfield South & 2818 & 675.1 & 556.7 & 862.0 & 190 & 157 & 243 \\
\hline 11577 & Hornsby - East & 9382 & 1254.2 & 1037.7 & 1599.3 & 1177 & 974 & 1501 \\
\hline 11578 & Hornsby - West & 8335 & 651.9 & 537.2 & 825.2 & 543 & 448 & 688 \\
\hline 11579 & Waitara - Wahroonga (West) & 7401 & 787.1 & 652.5 & 1007.1 & 582 & 483 & 745 \\
\hline 11580 & Colyton - Oxley Park & 8766 & 890.9 & 721.1 & 1131.8 & 781 & 632 & 992 \\
\hline 11581 & St Marys - North St Marys & 12241 & 1488.4 & 1209.6 & 1866.3 & 1822 & 1481 & 2284 \\
\hline 11582 & Auburn - Central & 13408 & 1240.1 & 998.8 & 1613.7 & 1663 & 1339 & 2164 \\
\hline 11583 & Auburn - North & 9081 & 1674.6 & 1359.9 & 2171.8 & 1521 & 1235 & 1972 \\
\hline 11584 & Auburn - South & 6459 & 881.4 & 711.4 & 1130.0 & 569 & 459 & 730 \\
\hline 11585 & Berala & 7106 & 1088.8 & 883.9 & 1407.4 & 774 & 628 & 1000 \\
\hline 11586 & Lidcombe & 16547 & 981.3 & 799.3 & 1272.2 & 1624 & 1323 & 2105 \\
\hline 11587 & Regents Park & 3956 & 1286.3 & 1042.9 & 1634.7 & 509 & 413 & 647 \\
\hline 11588 & Pendle Hill - Girraween & 9692 & 924.1 & 755.6 & 1178.5 & 896 & 732 & 1142 \\
\hline 11589 & Wentworthville - Westmead & 12014 & 1244.1 & 1022.0 & 1580.3 & 1495 & 1228 & 1899 \\
\hline 11590 & Putney & 3193 & 222.2 & 185.0 & 288.6 & 71 & 59 & 92 \\
\hline 11591 & Ryde & 21895 & 857.6 & 708.5 & 1093.7 & 1878 & 1551 & 2395 \\
\hline 11593 & Cecil Hills & 5408 & 295.7 & 238.2 & 387.2 & 160 & 129 & 209 \\
\hline 11594 & Green Valley & 9635 & 700.7 & 562.9 & 899.8 & 675 & 542 & 867 \\
\hline 11595 & Hinchinbrook & 9305 & 481.9 & 386.6 & 623.1 & 448 & 360 & 580 \\
\hline 11596 & Hoxton Park - Carnes Hill - Horningsea Park & 8369 & 487.8 & 391.3 & 635.3 & 408 & 327 & 532 \\
\hline 11597 & West Hoxton - Middleton Grange & 10851 & 386.2 & 312.0 & 506.9 & 419 & 339 & 550 \\
\hline 11598 & Liverpool & 20850 & 1653.0 & 1341.1 & 2079.6 & 3447 & 2796 & 4336 \\
\hline 11599 & Lurnea - Cartwright & 8659 & 1424.5 & 1148.5 & 1773.9 & 1233 & 995 & 1536 \\
\hline 11600 & Prestons - Edmondson Park & 12728 & 388.2 & 313.6 & 506.1 & 494 & 399 & 644 \\
\hline 11601 & Warwick Farm & 4599 & 2108.4 & 1720.9 & 2617.5 & 970 & 791 & 1204 \\
\hline 11602 & Caringbah & 9140 & 866.7 & 716.1 & 1090.8 & 792 & 654 & 997 \\
\hline 11603 & Caringbah South & 9231 & 215.3 & 178.0 & 277.2 & 199 & 164 & 256 \\
\hline 11604 & Cronulla - Kurnell - Bundeena & 18935 & 691.8 & 575.6 & 880.5 & 1310 & 1090 & 1667 \\
\hline 11605 & Lilli Pilli - Port Hacking - Dolans Bay & 2411 & 93.5 & 78.5 & 123.8 & 23 & 19 & 30 \\
\hline 11606 & Woolaware - Burraneer & 5915 & 287.9 & 240.0 & 364.7 & 170 & 142 & 216 \\
\hline 11607 & Engadine & 12521 & 263.9 & 218.2 & 336.4 & 330 & 273 & 421 \\
\hline 11608 & Loftus - Yarrawarrah & 5495 & 164.8 & 136.3 & 211.9 & 91 & 75 & 116 \\
\hline 11609 & Woronora Heights & 2875 & 90.6 & 75.9 & 115.9 & 26 & 22 & 33 \\
\hline 21001 & Alfredton & 8383 & 710.4 & 582.6 & 898.4 & 596 & 488 & 753 \\
\hline 21002 & Ballarat & 9300 & 1053.2 & 866.1 & 1307.7 & 980 & 805 & 1216 \\
\hline 21003 & Ballarat - North & 17615 & 1029.5 & 844.2 & 1271.7 & 1813 & 1487 & 2240 \\
\hline 21004 & Ballarat - South & 18695 & 1491.2 & 1220.4 & 1835.9 & 2788 & 2282 & 3432 \\
\hline 21005 & Buninyong & 5276 & 464.4 & 379.5 & 584.9 & 245 & 200 & 309 \\
\hline 21006 & Delacombe & 5299 & 753.7 & 610.8 & 946.1 & 399 & 324 & 501 \\
\hline 21007 & Smythes Creek & 2891 & 120.0 & 97.4 & 149.8 & 35 & 28 & 43 \\
\hline 21008 & Wendouree - Miners Rest & 11042 & 1276.9 & 1040.2 & 1574.6 & 1410 & 1149 & 1739 \\
\hline 21009 & Bacchus Marsh Region & 4500 & 382.6 & 314.9 & 471.9 & 172 & 142 & 212 \\
\hline 21010 & Creswick-Clunes & 6034 & 540.5 & 441.9 & 667.7 & 326 & 267 & 403 \\
\hline 21011 & Daylesford & 6961 & 566.9 & 467.1 & 699.6 & 395 & 325 & 487 \\
\hline 21012 & Gordon (Vic.) & 4309 & 276.7 & 228.2 & 340.9 & 119 & 98 & 147 \\
\hline 21013 & Avoca & 2593 & 481.5 & 393.6 & 594.8 & 125 & 102 & 154 \\
\hline 21014 & Beaufort & 3468 & 407.5 & 333.4 & 504.5 & 141 & 116 & 175 \\
\hline
\end{tabular}




\begin{tabular}{|c|c|c|c|c|c|c|c|c|}
\hline \multirow[b]{2}{*}{$\begin{array}{l}\text { SA2_5DIGIT } \\
\text { CODE_2016 }\end{array}$} & \multirow[b]{2}{*}{ SA2_name } & \multicolumn{7}{|c|}{ Unit-level SAEs } \\
\hline & & $\begin{array}{r}\text { Unit-level_Probit_ } \\
\text { totalpopulation }\end{array}$ & $\begin{array}{r}\text { Unit-level_ } \\
\text { probit_ } \\
\text { RATE }\end{array}$ & $\begin{array}{r}\text { Unit-level_ } \\
\text { probit_ } \\
\text { RATE_ } \\
\text { LowerCl }\end{array}$ & $\begin{array}{r}\text { Unit-level_ } \\
\text { probit_ } \\
\text { RATE_ } \\
\text { UpperCl }\end{array}$ & $\begin{array}{r}\text { Unit-level_ } \\
\text { probit_ } \\
\text { number }\end{array}$ & $\begin{array}{c}\text { Unit-level_ } \\
\text { probit_ } \\
\text { number_ } \\
\text { LowerCl }\end{array}$ & $\begin{array}{r}\text { Unit-level_ } \\
\text { probit_ } \\
\text { number_ } \\
\text { UpperCl }\end{array}$ \\
\hline 21015 & Golden Plains - North & 3407 & 217.6 & 179.6 & 269.5 & 74 & 61 & 92 \\
\hline 21016 & Maryborough (Vic.) & 6276 & 1139.4 & 931.6 & 1392.1 & 715 & 585 & 874 \\
\hline 21017 & Maryborough Region & 4191 & 490.1 & 401.3 & 601.6 & 205 & 168 & 252 \\
\hline 21018 & Bendigo & 11379 & 1486.8 & 1213.7 & 1843.6 & 1692 & 1381 & 2098 \\
\hline 21019 & California Gully - Eaglehawk & 9000 & 1226.4 & 999.1 & 1516.0 & 1104 & 899 & 1364 \\
\hline 21020 & East Bendigo - Kennington & 10581 & 1092.1 & 892.6 & 1357.6 & 1156 & 944 & 1437 \\
\hline 21021 & Flora Hill - Spring Gully & 7211 & 1394.0 & 1142.5 & 1728.2 & 1005 & 824 & 1246 \\
\hline 21022 & Kangaroo Flat - Golden Square & 15237 & 1043.6 & 852.8 & 1290.1 & 1590 & 1299 & 1966 \\
\hline 21023 & Maiden Gully & 3550 & 182.0 & 150.1 & 231.3 & 65 & 53 & 82 \\
\hline 21024 & Strathfieldsaye & 6083 & 258.8 & 212.0 & 329.7 & 157 & 129 & 201 \\
\hline 21025 & White Hills - Ascot & 8550 & 766.9 & 626.0 & 958.6 & 656 & 535 & 820 \\
\hline 21026 & Bendigo Region - South & 5283 & 188.0 & 154.6 & 239.2 & 99 & 82 & 126 \\
\hline 21027 & Castlemaine & 8432 & 702.4 & 578.0 & 863.6 & 592 & 487 & 728 \\
\hline 21028 & Castlemaine Region & 6674 & 381.3 & 313.2 & 471.0 & 255 & 209 & 314 \\
\hline 21029 & Heathcote & 3607 & 481.0 & 394.0 & 588.4 & 173 & 142 & 212 \\
\hline 21030 & Kyneton & 7451 & 582.2 & 475.8 & 726.0 & 434 & 354 & 541 \\
\hline 21031 & Woodend & 5170 & 385.0 & 317.0 & 480.2 & 199 & 164 & 248 \\
\hline 21032 & Bendigo Region - North & 3326 & 353.2 & 288.9 & 440.4 & 117 & 96 & 146 \\
\hline 21033 & Loddon & 5492 & 516.3 & 422.1 & 640.8 & 284 & 232 & 352 \\
\hline 21034 & Bannockburn & 4531 & 314.0 & 258.2 & 396.1 & 142 & 117 & 179 \\
\hline 21035 & Golden Plains - South & 5067 & 237.3 & 195.5 & 297.4 & 120 & 99 & 151 \\
\hline 21036 & Winchelsea & 4342 & 394.8 & 326.1 & 490.9 & 171 & 142 & 213 \\
\hline 21037 & Belmont & 11029 & 1080.2 & 887.0 & 1346.9 & 1191 & 978 & 1485 \\
\hline 21038 & Corio - Norlane & 20313 & 1523.6 & 1241.5 & 1878.5 & 3095 & 2522 & 3816 \\
\hline 21039 & Geelong & 10213 & 1149.5 & 945.2 & 1430.6 & 1174 & 965 & 1461 \\
\hline 21040 & Geelong West - Hamlyn Heights & 15240 & 1035.0 & 852.8 & 1289.8 & 1577 & 1300 & 1966 \\
\hline 21041 & Grovedale & 17943 & 764.7 & 625.1 & 959.6 & 1372 & 1122 & 1722 \\
\hline 21042 & Highton & 16889 & 588.3 & 480.6 & 745.5 & 994 & 812 & 1259 \\
\hline 21043 & Lara & 13780 & 501.8 & 410.9 & 634.4 & 692 & 566 & 874 \\
\hline 21044 & Leopold & 9640 & 510.3 & 419.2 & 640.8 & 492 & 404 & 618 \\
\hline 21045 & Newcomb - Moolap & 11679 & 1116.0 & 911.9 & 1376.3 & 1303 & 1065 & 1607 \\
\hline 21046 & Newtown (Vic.) & 7662 & 714.3 & 588.5 & 894.3 & 547 & 451 & 685 \\
\hline 21047 & North Geelong - Bell Park & 11689 & 885.9 & 726.7 & 1104.4 & 1035 & 849 & 1291 \\
\hline 21048 & Clifton Springs & 10267 & 545.2 & 445.9 & 683.4 & 560 & 458 & 702 \\
\hline 21049 & Lorne - Anglesea & 3710 & 585.0 & 484.9 & 733.6 & 217 & 180 & 272 \\
\hline 21050 & Ocean Grove - Barwon Heads & 16797 & 533.7 & 440.2 & 668.9 & 896 & 739 & 1123 \\
\hline 21051 & Portarlington & 5898 & 890.0 & 726.8 & 1105.3 & 525 & 429 & 652 \\
\hline 21052 & Point Lonsdale - Queenscliff & 3149 & 481.9 & 399.3 & 599.0 & 152 & 126 & 189 \\
\hline 21053 & Torquay & 12993 & 489.9 & 404.5 & 627.2 & 636 & 526 & 815 \\
\hline 21054 & Alexandra & 4915 & 610.7 & 501.3 & 755.9 & 300 & 246 & 372 \\
\hline 21055 & Euroa & 4940 & 644.8 & 528.0 & 795.4 & 319 & 261 & 393 \\
\hline 21056 & Kilmore - Broadford & 10506 & 617.8 & 505.4 & 774.3 & 649 & 531 & 813 \\
\hline 21057 & Mansfield (Vic.) & 6443 & 554.5 & 458.2 & 688.0 & 357 & 295 & 443 \\
\hline 21058 & Nagambie & 3132 & 596.1 & 490.1 & 745.9 & 187 & 154 & 234 \\
\hline 21059 & Seymour & 5034 & 1193.0 & 975.5 & 1460.7 & 601 & 491 & 735 \\
\hline 21060 & Seymour Region & 3327 & 380.5 & 317.1 & 493.8 & 127 & 106 & 164 \\
\hline 21062 & Yea & 2739 & 516.3 & 424.5 & 641.7 & 141 & 116 & 176 \\
\hline 21063 & Benalla & 8080 & 1065.6 & 871.7 & 1301.3 & 861 & 704 & 1051 \\
\hline 21064 & Benalla Region & 2764 & 311.0 & 256.2 & 390.2 & 86 & 71 & 108 \\
\hline 21065 & Rutherglen & 2967 & 692.1 & 570.7 & 855.2 & 205 & 169 & 254 \\
\hline 21066 & Wangaratta & 14314 & 1007.8 & 825.9 & 1238.6 & 1443 & 1182 & 1773 \\
\hline 21067 & Wangaratta Region & 7272 & 358.7 & 294.0 & 444.8 & 261 & 214 & 323 \\
\hline 21068 & Beechworth & 3484 & 603.9 & 498.3 & 743.3 & 210 & 174 & 259 \\
\hline 21069 & Bright - Mount Beauty & 6111 & 655.2 & 540.3 & 813.9 & 400 & 330 & 497 \\
\hline 21070 & Chiltern - Indigo Valley & 2355 & 363.8 & 295.5 & 456.6 & 86 & 70 & 108 \\
\hline 21071 & Myrtleford & 3630 & 745.7 & 612.6 & 917.3 & 271 & 222 & 333 \\
\hline 21072 & Towong & 4543 & 602.1 & 495.4 & 741.2 & 274 & 225 & 337 \\
\hline
\end{tabular}




\begin{tabular}{|c|c|c|c|c|c|c|c|c|}
\hline \multirow[b]{2}{*}{$\begin{array}{l}\text { SA2_5DIGIT } \\
\text { CODE_2016 }\end{array}$} & \multirow[b]{2}{*}{ SA2_name } & \multicolumn{7}{|c|}{ Unit-level SAEs } \\
\hline & & $\begin{array}{r}\text { Unit-level_Probit_ } \\
\text { totalpopulation }\end{array}$ & $\begin{array}{r}\text { Unit-level_ } \\
\text { probit_ } \\
\text { RATE }\end{array}$ & $\begin{array}{r}\text { Unit-level_ } \\
\text { probit_ } \\
\text { RATE_ } \\
\text { LowerCl }\end{array}$ & $\begin{array}{r}\text { Unit-level_ } \\
\text { probit_ } \\
\text { RATE_ } \\
\text { UpperCl }\end{array}$ & $\begin{array}{r}\text { Unit-level_ } \\
\text { probit_ } \\
\text { number }\end{array}$ & $\begin{array}{c}\text { Unit-level_ } \\
\text { probit_ } \\
\text { number_- } \\
\text { LowerCl }\end{array}$ & $\begin{array}{r}\text { Unit-level_ } \\
\text { probit_ } \\
\text { number_ } \\
\text { UpperCl }\end{array}$ \\
\hline 21073 & West Wodonga & 10932 & 1112.0 & 906.1 & 1389.3 & 1216 & 991 & 1519 \\
\hline 21074 & Wodonga & 18042 & 1060.8 & 868.6 & 1317.4 & 1914 & 1567 & 2377 \\
\hline 21075 & Yackandandah & 3325 & 421.5 & 347.7 & 524.4 & 140 & 116 & 174 \\
\hline 21076 & Drouin & 12152 & 704.4 & 577.6 & 873.7 & 856 & 702 & 1062 \\
\hline 21077 & Mount Baw Baw Region & 4619 & 349.8 & 287.3 & 436.8 & 162 & 133 & 202 \\
\hline 21078 & Trafalgar (Vic.) & 5765 & 568.7 & 465.9 & 706.2 & 328 & 269 & 407 \\
\hline 21079 & Warragul & 14193 & 707.4 & 579.2 & 878.5 & 1004 & 822 & 1247 \\
\hline 21081 & Bairnsdale & 11162 & 1051.7 & 856.6 & 1297.9 & 1174 & 956 & 1449 \\
\hline 21082 & Bruthen - Omeo & 5884 & 398.6 & 327.6 & 497.5 & 235 & 193 & 293 \\
\hline 21084 & Lakes Entrance & 7571 & 865.5 & 708.2 & 1059.7 & 655 & 536 & 802 \\
\hline 21085 & Orbost & 4866 & 748.6 & 609.4 & 920.6 & 364 & 297 & 448 \\
\hline 21086 & Paynesville & 4958 & 671.2 & 548.8 & 830.0 & 333 & 272 & 412 \\
\hline 21087 & Foster & 6737 & 592.3 & 485.2 & 735.4 & 399 & 327 & 495 \\
\hline 21089 & Korumburra & 6875 & 612.5 & 501.5 & 756.6 & 421 & 345 & 520 \\
\hline 21090 & Leongatha & 8234 & 614.5 & 505.3 & 760.4 & 506 & 416 & 626 \\
\hline 21091 & Phillip Island & 7717 & 860.1 & 706.1 & 1063.3 & 664 & 545 & 821 \\
\hline 21093 & Wonthaggi - Inverloch & 17053 & 913.8 & 749.0 & 1125.3 & 1558 & 1277 & 1919 \\
\hline 21094 & Churchill & 8712 & 631.2 & 515.6 & 775.8 & 550 & 449 & 676 \\
\hline 21095 & Moe - Newborough & 12939 & 1157.7 & 942.2 & 1417.1 & 1498 & 1219 & 1834 \\
\hline 21096 & Morwell & 10794 & 1318.5 & 1071.4 & 1618.3 & 1423 & 1156 & 1747 \\
\hline 21097 & Traralgon & 20033 & 808.2 & 662.4 & 1002.3 & 1619 & 1327 & 2008 \\
\hline 21098 & Yallourn North - Glengarry & 3405 & 327.1 & 269.6 & 402.5 & 111 & 92 & 137 \\
\hline 21100 & Longford - Loch Sport & 3280 & 378.0 & 310.3 & 463.6 & 124 & 102 & 152 \\
\hline 21101 & Maffra & 10364 & 615.0 & 503.7 & 760.2 & 637 & 522 & 788 \\
\hline 21102 & Rosedale & 3789 & 347.1 & 286.4 & 438.9 & 132 & 109 & 166 \\
\hline 21103 & Sale & 10862 & 1052.4 & 864.4 & 1297.7 & 1143 & 939 & 1410 \\
\hline 21104 & Yarram & 4208 & 750.1 & 614.7 & 922.1 & 316 & 259 & 388 \\
\hline 21105 & Brunswick & 21626 & 1228.0 & 1010.4 & 1574.1 & 2656 & 2185 & 3404 \\
\hline 21106 & Brunswick East & 9399 & 1281.3 & 1058.5 & 1639.5 & 1204 & 995 & 1541 \\
\hline 21107 & Brunswick West & 11319 & 1348.9 & 1111.7 & 1697.6 & 1527 & 1258 & 1921 \\
\hline 21108 & Coburg & 20990 & 863.5 & 707.6 & 1106.1 & 1813 & 1485 & 2322 \\
\hline 21109 & Pascoe Vale South & 7697 & 439.4 & 361.6 & 565.6 & 338 & 278 & 435 \\
\hline 21110 & Alphington - Fairfield & 7124 & 897.6 & 744.3 & 1132.9 & 639 & 530 & 807 \\
\hline 21111 & Northcote & 19668 & 882.6 & 728.8 & 1123.7 & 1736 & 1433 & 2210 \\
\hline 21112 & Thornbury & 14816 & 1121.1 & 924.1 & 1416.1 & 1661 & 1369 & 2098 \\
\hline 21113 & Ascot Vale & 11579 & 1087.1 & 894.4 & 1367.0 & 1259 & 1036 & 1583 \\
\hline 21114 & Essendon - Aberfeldie & 22072 & 739.9 & 612.8 & 940.8 & 1633 & 1353 & 2077 \\
\hline 21115 & Flemington & 8116 & 1969.8 & 1614.3 & 2458.5 & 1599 & 1310 & 1995 \\
\hline 21116 & Moonee Ponds & 11437 & 781.4 & 647.6 & 990.1 & 894 & 741 & 1132 \\
\hline 21117 & Carlton & 17101 & 2258.5 & 1822.1 & 2891.8 & 3862 & 3116 & 4945 \\
\hline 21118 & Docklands & 9839 & 1189.3 & 980.1 & 1550.6 & 1170 & 964 & 1526 \\
\hline 21119 & East Melbourne & 4385 & 862.1 & 720.9 & 1115.9 & 378 & 316 & 489 \\
\hline 21121 & Kensington (Vic.) & 8823 & 1271.4 & 1049.3 & 1605.6 & 1122 & 926 & 1417 \\
\hline 21122 & Melbourne & 34944 & 1975.8 & 1600.2 & 2550.2 & 6904 & 5592 & 8911 \\
\hline 21123 & North Melbourne & 17906 & 1736.2 & 1417.3 & 2212.0 & 3109 & 2538 & 3961 \\
\hline 21124 & Parkville & 6683 & 1091.9 & 894.8 & 1391.8 & 730 & 598 & 930 \\
\hline 21125 & South Yarra - West & 5286 & 908.9 & 758.0 & 1175.1 & 480 & 401 & 621 \\
\hline 21126 & Southbank & 16980 & 1243.0 & 1021.9 & 1619.5 & 2111 & 1735 & 2750 \\
\hline 21128 & Albert Park & 12432 & 755.6 & 629.7 & 972.2 & 939 & 783 & 1209 \\
\hline 21129 & Elwood & 12422 & 1113.1 & 929.8 & 1411.2 & 1383 & 1155 & 1753 \\
\hline 21130 & Port Melbourne & 13197 & 898.1 & 748.4 & 1135.0 & 1185 & 988 & 1498 \\
\hline 21132 & South Melbourne & 9659 & 1314.4 & 1087.8 & 1650.3 & 1270 & 1051 & 1594 \\
\hline 21133 & St Kilda & 22941 & 1333.0 & 1109.0 & 1680.2 & 3058 & 2544 & 3854 \\
\hline 21134 & St Kilda East & 13620 & 1314.6 & 1090.4 & 1663.3 & 1790 & 1485 & 2265 \\
\hline 21135 & Armadale & 7271 & 959.2 & 795.7 & 1220.7 & 697 & 579 & 888 \\
\hline 21136 & Prahran - Windsor & 17038 & 1169.9 & 974.0 & 1488.7 & 1993 & 1660 & 2536 \\
\hline 21137 & South Yarra - East & 18207 & 1439.9 & 1194.3 & 1832.1 & 2622 & 2175 & 3336 \\
\hline
\end{tabular}




\begin{tabular}{|c|c|c|c|c|c|c|c|c|}
\hline \multirow[b]{2}{*}{$\begin{array}{l}\text { SA2_5DIGIT } \\
\text { CODE_2016 }\end{array}$} & \multirow[b]{2}{*}{ SA2_name } & \multicolumn{7}{|c|}{ Unit-level SAEs } \\
\hline & & $\begin{array}{r}\text { Unit-level_Probit_ } \\
\text { totalpopulation }\end{array}$ & $\begin{array}{r}\text { Unit-level_ } \\
\text { probit_ } \\
\text { RATE }\end{array}$ & $\begin{array}{r}\text { Unit-level_ } \\
\text { probit_ } \\
\text { RATE_ } \\
\text { LowerCl }\end{array}$ & $\begin{array}{r}\text { Unit-level_ } \\
\text { probit_ } \\
\text { RATE_ } \\
\text { UpperCl }\end{array}$ & $\begin{array}{r}\text { Unit-level_ } \\
\text { probit_ } \\
\text { number }\end{array}$ & $\begin{array}{c}\text { Unit-level_ } \\
\text { probit_ } \\
\text { number_- } \\
\text { LowerCl }\end{array}$ & $\begin{array}{r}\text { Unit-level_ } \\
\text { probit_ } \\
\text { number_ } \\
\text { UpperCl }\end{array}$ \\
\hline 21138 & Toorak & 10775 & 684.0 & 568.5 & 876.3 & 737 & 613 & 944 \\
\hline 21139 & Abbotsford & 7142 & 1100.4 & 916.5 & 1411.8 & 786 & 655 & 1008 \\
\hline 21140 & Carlton North - Princes Hill & 7054 & 1186.6 & 976.8 & 1530.7 & 837 & 689 & 1080 \\
\hline 21141 & Collingwood & 7210 & 1675.4 & 1379.7 & 2110.6 & 1208 & 995 & 1522 \\
\hline 21142 & Fitzroy & 8726 & 1542.7 & 1268.4 & 1950.7 & 1346 & 1107 & 1702 \\
\hline 21143 & Fitzroy North & 10097 & 1231.0 & 1015.2 & 1557.6 & 1243 & 1025 & 1573 \\
\hline 21144 & Richmond (Vic.) & 25920 & 1219.4 & 1010.4 & 1549.4 & 3161 & 2619 & 4016 \\
\hline 21145 & Yarra - North & 7252 & 762.4 & 632.3 & 976.2 & 553 & 459 & 708 \\
\hline 21146 & Ashburton (Vic.) & 5798 & 596.1 & 488.9 & 751.5 & 346 & 283 & 436 \\
\hline 21147 & Balwyn & 12700 & 570.4 & 469.6 & 729.8 & 724 & 596 & 927 \\
\hline 21148 & Balwyn North & 15792 & 399.6 & 329.0 & 516.6 & 631 & 520 & 816 \\
\hline 21149 & Camberwell & 16809 & 481.3 & 398.8 & 619.9 & 809 & 670 & 1042 \\
\hline 21150 & Glen Iris - East & 12404 & 356.0 & 295.5 & 461.6 & 442 & 367 & 573 \\
\hline 21151 & Hawthorn & 18882 & 1109.4 & 917.6 & 1416.2 & 2095 & 1733 & 2674 \\
\hline 21152 & Hawthorn East & 12182 & 948.4 & 785.2 & 1210.4 & 1155 & 956 & 1475 \\
\hline 21153 & Kew & 19685 & 572.0 & 473.3 & 738.6 & 1126 & 932 & 1454 \\
\hline 21154 & Kew East & 4968 & 459.1 & 379.7 & 591.0 & 228 & 189 & 294 \\
\hline 21155 & Surrey Hills (West) - Canterbury & 12697 & 389.4 & 322.7 & 499.8 & 494 & 410 & 635 \\
\hline 21156 & Bulleen & 9037 & 418.2 & 343.5 & 541.0 & 378 & 310 & 489 \\
\hline 21157 & Doncaster & 17104 & 719.1 & 589.4 & 925.8 & 1230 & 1008 & 1584 \\
\hline 21159 & Templestowe & 13480 & 262.9 & 216.9 & 339.0 & 354 & 292 & 457 \\
\hline 21160 & Templestowe Lower & 10895 & 366.8 & 303.0 & 470.5 & 400 & 330 & 513 \\
\hline 21161 & Blackburn & 16694 & 546.3 & 449.8 & 700.2 & 912 & 751 & 1169 \\
\hline 21162 & Blackburn South & 8439 & 643.3 & 527.1 & 804.1 & 543 & 445 & 679 \\
\hline 21163 & Box Hill & 16412 & 1323.0 & 1079.7 & 1683.9 & 2171 & 1772 & 2764 \\
\hline 21164 & Box Hill North & 13852 & 728.6 & 596.0 & 935.3 & 1009 & 826 & 1296 \\
\hline 21165 & Burwood & 10465 & 1306.2 & 1056.9 & 1670.7 & 1367 & 1106 & 1748 \\
\hline 21166 & Burwood East & 8467 & 737.7 & 600.2 & 952.7 & 625 & 508 & 807 \\
\hline 21167 & Surrey Hills (East) - Mont Albert & 7821 & 531.8 & 440.7 & 678.9 & 416 & 345 & 531 \\
\hline 21168 & Beaumaris & 10387 & 228.1 & 190.0 & 292.1 & 237 & 197 & 303 \\
\hline 21169 & Brighton (Vic.) & 17603 & 436.1 & 362.4 & 558.1 & 768 & 638 & 982 \\
\hline 21170 & Brighton East & 12034 & 412.7 & 342.7 & 523.1 & 497 & 412 & 630 \\
\hline 21171 & Cheltenham - Highett (West) & 8294 & 656.0 & 542.7 & 823.1 & 544 & 450 & 683 \\
\hline 21172 & Hampton & 13408 & 652.1 & 538.0 & 815.7 & 874 & 721 & 1094 \\
\hline 21173 & Sandringham - Black Rock & 12786 & 448.6 & 373.8 & 567.7 & 574 & 478 & 726 \\
\hline 21174 & Bentleigh - McKinnon & 17261 & 620.2 & 511.9 & 789.1 & 1071 & 884 & 1362 \\
\hline 21176 & Carnegie & 14814 & 1145.5 & 943.7 & 1456.7 & 1697 & 1398 & 2158 \\
\hline 21177 & Caulfield - North & 16327 & 890.0 & 731.8 & 1137.5 & 1453 & 1195 & 1857 \\
\hline 21178 & Caulfield - South & 13765 & 635.0 & 524.7 & 810.6 & 874 & 722 & 1116 \\
\hline 21179 & Elsternwick & 8819 & 733.8 & 610.4 & 934.9 & 647 & 538 & 824 \\
\hline 21180 & Hughesdale & 6036 & 885.9 & 730.4 & 1125.6 & 535 & 441 & 679 \\
\hline 21181 & Murrumbeena & 7398 & 874.0 & 723.1 & 1112.1 & 647 & 535 & 823 \\
\hline 21182 & Ormond - Glen Huntly & 10665 & 1088.9 & 897.6 & 1392.8 & 1161 & 957 & 1485 \\
\hline 21183 & Aspendale Gardens - Waterways & 6924 & 218.4 & 179.8 & 278.5 & 151 & 124 & 193 \\
\hline 21185 & Carrum - Patterson Lakes & 9088 & 591.3 & 487.5 & 739.3 & 537 & 443 & 672 \\
\hline 21186 & Chelsea - Bonbeach & 11228 & 875.5 & 724.0 & 1090.4 & 983 & 813 & 1224 \\
\hline 21187 & Chelsea Heights & 4119 & 421.7 & 347.7 & 525.5 & 174 & 143 & 216 \\
\hline 21188 & Cheltenham - Highett (East) & 17548 & 656.2 & 541.0 & 829.6 & 1152 & 949 & 1456 \\
\hline 21189 & Edithvale - Aspendale & 9682 & 450.8 & 373.8 & 569.8 & 436 & 362 & 552 \\
\hline 21190 & Mentone & 10321 & 794.6 & 660.2 & 996.8 & 820 & 681 & 1029 \\
\hline 21191 & Moorabbin - Heatherton & 6798 & 631.7 & 521.8 & 799.4 & 429 & 355 & 543 \\
\hline 21193 & Mordialloc - Parkdale & 15345 & 605.6 & 501.3 & 759.7 & 929 & 769 & 1166 \\
\hline 21194 & Malvern - Glen Iris & 15830 & 716.9 & 595.2 & 915.0 & 1135 & 942 & 1448 \\
\hline 21195 & Malvern East & 16851 & 770.0 & 629.3 & 990.9 & 1298 & 1060 & 1670 \\
\hline 21196 & Bundoora - East & 7938 & 636.3 & 518.0 & 811.2 & 505 & 411 & 644 \\
\hline 21197 & Greensborough & 15919 & 444.6 & 365.4 & 558.4 & 708 & 582 & 889 \\
\hline 21198 & Heidelberg - Rosanna & 11475 & 668.8 & 554.1 & 846.8 & 767 & 636 & 972 \\
\hline
\end{tabular}




\begin{tabular}{|c|c|c|c|c|c|c|c|c|}
\hline \multirow[b]{2}{*}{$\begin{array}{l}\text { SA2_5DIGIT } \\
\text { CODE_2016 }\end{array}$} & \multirow[b]{2}{*}{ SA2_name } & \multicolumn{7}{|c|}{ Unit-level SAEs } \\
\hline & & $\begin{array}{r}\text { Unit-level_Probit_ } \\
\text { totalpopulation }\end{array}$ & $\begin{array}{r}\text { Unit-level_ } \\
\text { probit_ } \\
\text { RATE }\end{array}$ & $\begin{array}{r}\text { Unit-level_ } \\
\text { probit_ } \\
\text { RATE_ } \\
\text { LowerCl }\end{array}$ & $\begin{array}{r}\text { Unit-level_ } \\
\text { probit_ } \\
\text { RATE_ } \\
\text { UpperCl }\end{array}$ & $\begin{array}{r}\text { Unit-level_ } \\
\text { probit_ } \\
\text { number }\end{array}$ & $\begin{array}{c}\text { Unit-level_ } \\
\text { probit_ } \\
\text { number_ } \\
\text { LowerCl }\end{array}$ & $\begin{array}{r}\text { Unit-level__ } \\
\text { probit_ } \\
\text { number_- } \\
\text { UpperCl }\end{array}$ \\
\hline 21199 & Heidelberg West & 11204 & 1484.9 & 1211.6 & 1850.4 & 1664 & 1357 & 2073 \\
\hline 21200 & Ivanhoe & 9085 & 654.9 & 541.1 & 832.1 & 595 & 492 & 756 \\
\hline 21201 & Ivanhoe East - Eaglemont & 6026 & 357.5 & 297.7 & 453.5 & 215 & 179 & 273 \\
\hline 21202 & Montmorency - Briar Hill & 12420 & 402.1 & 333.1 & 506.1 & 499 & 414 & 629 \\
\hline 21203 & Viewbank - Yallambie & 14151 & 477.5 & 392.9 & 606.1 & 676 & 556 & 858 \\
\hline 21204 & Watsonia & 7122 & 617.4 & 506.2 & 774.9 & 440 & 360 & 552 \\
\hline 21205 & Kingsbury & 9431 & 929.6 & 756.9 & 1185.0 & 877 & 714 & 1118 \\
\hline 21207 & Reservoir - East & 22029 & 1252.1 & 1023.0 & 1571.2 & 2758 & 2254 & 3461 \\
\hline 21208 & Reservoir - West & 19241 & 875.9 & 718.5 & 1110.8 & 1685 & 1382 & 2137 \\
\hline 21209 & Eltham & 17471 & 224.0 & 185.1 & 283.4 & 391 & 323 & 495 \\
\hline 21210 & Hurstbridge & 2613 & 268.2 & 219.2 & 331.9 & 70 & 57 & 87 \\
\hline 21211 & Kinglake & 2870 & 211.7 & 174.9 & 264.9 & 61 & 50 & 76 \\
\hline 21212 & Panton Hill - St Andrews & 3962 & 163.2 & 135.3 & 206.3 & 65 & 54 & 82 \\
\hline 21213 & Plenty - Yarrambat & 7237 & 153.7 & 125.4 & 197.7 & 111 & 91 & 143 \\
\hline 21214 & Research - North Warrandyte & 5053 & 163.2 & 134.2 & 207.0 & 82 & 68 & 105 \\
\hline 21215 & Wattle Glen - Diamond Creek & 10482 & 212.3 & 174.6 & 270.2 & 223 & 183 & 283 \\
\hline 21216 & Bundoora - North & 5971 & 1012.7 & 825.2 & 1284.6 & 605 & 493 & 767 \\
\hline 21217 & Bundoora-West & 5191 & 855.2 & 695.9 & 1091.2 & 444 & 361 & 566 \\
\hline 21219 & Lalor & 18007 & 753.4 & 611.2 & 962.3 & 1357 & 1101 & 1733 \\
\hline 21220 & Mill Park - North & 14358 & 464.1 & 379.3 & 592.8 & 666 & 545 & 851 \\
\hline 21221 & Mill Park - South & 9512 & 649.2 & 526.9 & 825.3 & 617 & 501 & 785 \\
\hline 21223 & Thomastown & 16455 & 812.8 & 659.7 & 1037.2 & 1337 & 1085 & 1707 \\
\hline 21224 & Wallan & 11893 & 427.6 & 349.4 & 539.4 & 509 & 416 & 642 \\
\hline 21225 & Whittlesea & 6225 & 409.2 & 336.5 & 510.4 & 255 & 209 & 318 \\
\hline 21226 & Airport West & 6100 & 605.2 & 498.2 & 771.1 & 369 & 304 & 470 \\
\hline 21228 & Keilor & 6692 & 311.1 & 255.1 & 395.6 & 208 & 171 & 265 \\
\hline 21229 & Keilor East & 21047 & 450.0 & 369.5 & 570.7 & 947 & 778 & 1201 \\
\hline 21230 & Niddrie - Essendon West & 5389 & 531.4 & 439.0 & 679.2 & 286 & 237 & 366 \\
\hline 21231 & Strathmore & 7221 & 299.6 & 248.0 & 383.5 & 216 & 179 & 277 \\
\hline 21232 & Gisborne & 9379 & 316.9 & 261.0 & 400.7 & 297 & 245 & 376 \\
\hline 21233 & Macedon & 2486 & 202.8 & 168.0 & 257.3 & 50 & 42 & 64 \\
\hline 21234 & Riddells Creek & 2984 & 197.1 & 162.6 & 248.8 & 59 & 49 & 74 \\
\hline 21235 & Romsey & 7039 & 324.7 & 268.3 & 406.1 & 229 & 189 & 286 \\
\hline 21236 & Coburg North & 6081 & 799.4 & 656.0 & 1009.2 & 486 & 399 & 614 \\
\hline 21237 & Fawkner & 10467 & 838.0 & 681.3 & 1077.3 & 877 & 713 & 1128 \\
\hline 21239 & Pascoe Vale & 18582 & 743.5 & 613.6 & 947.8 & 1382 & 1140 & 1761 \\
\hline 21240 & Sunbury & 9711 & 353.3 & 289.5 & 444.9 & 343 & 281 & 432 \\
\hline 21241 & Sunbury - South & 20538 & 614.7 & 504.5 & 772.5 & 1262 & 1036 & 1587 \\
\hline 21242 & Broadmeadows & 10070 & 1595.2 & 1293.1 & 1999.6 & 1606 & 1302 & 2014 \\
\hline 21243 & Campbellfield - Coolaroo & 12154 & 1016.8 & 817.5 & 1288.3 & 1236 & 994 & 1566 \\
\hline 21245 & Gladstone Park - Westmeadows & 14119 & 547.7 & 445.6 & 695.5 & 773 & 629 & 982 \\
\hline 21246 & Greenvale - Bulla & 12693 & 177.3 & 144.6 & 231.2 & 225 & 183 & 294 \\
\hline 21247 & Meadow Heights & 11043 & 1069.9 & 859.6 & 1349.5 & 1182 & 949 & 1490 \\
\hline 21249 & Roxburgh Park - Somerton & 15779 & 662.8 & 530.1 & 852.0 & 1046 & 836 & 1344 \\
\hline 21250 & Tullamarine & 5290 & 1011.4 & 828.8 & 1270.3 & 535 & 438 & 672 \\
\hline 21251 & Bayswater & 9625 & 874.2 & 717.6 & 1095.2 & 841 & 691 & 1054 \\
\hline 21254 & Knoxfield - Scoresby & 11762 & 464.3 & 381.1 & 597.0 & 546 & 448 & 702 \\
\hline 21255 & Lysterfield & 5107 & 136.4 & 113.2 & 173.0 & 70 & 58 & 88 \\
\hline 21256 & Rowville - Central & 12148 & 359.5 & 296.7 & 460.6 & 437 & 360 & 560 \\
\hline 21257 & Rowville - North & 6092 & 363.0 & 296.6 & 461.3 & 221 & 181 & 281 \\
\hline 21258 & Rowville - South & 8297 & 202.9 & 166.6 & 264.5 & 168 & 138 & 219 \\
\hline 21259 & Wantirna & 11151 & 513.6 & 419.5 & 655.0 & 573 & 468 & 730 \\
\hline 21260 & Wantirna South & 14632 & 503.2 & 411.2 & 640.0 & 736 & 602 & 936 \\
\hline 21261 & Donvale - Park Orchards & 12469 & 271.6 & 223.9 & 347.4 & 339 & 279 & 433 \\
\hline 21262 & Warrandyte - Wonga Park & 7745 & 151.0 & 125.0 & 190.6 & 117 & 97 & 148 \\
\hline 21263 & Bayswater North & 9176 & 527.2 & 433.0 & 662.1 & 484 & 397 & 608 \\
\hline 21265 & Croydon Hills - Warranwood & 13805 & 286.6 & 236.3 & 364.0 & 396 & 326 & 503 \\
\hline
\end{tabular}




\begin{tabular}{|c|c|c|c|c|c|c|c|c|}
\hline \multirow[b]{2}{*}{$\begin{array}{l}\text { SA2_5DIGIT } \\
\text { CODE_2016 }\end{array}$} & \multirow[b]{2}{*}{ SA2_name } & \multicolumn{7}{|c|}{ Unit-level SAEs } \\
\hline & & $\begin{array}{r}\text { Unit-level_Probit_ } \\
\text { totalpopulation }\end{array}$ & $\begin{array}{r}\text { Unit-level_ } \\
\text { probit_ } \\
\text { RATE }\end{array}$ & $\begin{array}{r}\text { Unit-level_ } \\
\text { probit_ } \\
\text { RATE_ } \\
\text { LowerCl }\end{array}$ & $\begin{array}{r}\text { Unit-level_ } \\
\text { probit_ } \\
\text { RATE_- } \\
\text { UpperCl }\end{array}$ & $\begin{array}{r}\text { Unit-level_ } \\
\text { probit_ } \\
\text { number }\end{array}$ & $\begin{array}{c}\text { Unit-level_ } \\
\text { probit_ } \\
\text { number- } \\
\text { LowerCl }\end{array}$ & $\begin{array}{r}\text { Unit-level_ } \\
\text { probit_ } \\
\text { number_ } \\
\text { UpperCl }\end{array}$ \\
\hline 21266 & Ringwood & 13482 & 1008.2 & 830.8 & 1269.6 & 1359 & 1120 & 1712 \\
\hline 21267 & Ringwood East & 15732 & 651.9 & 535.3 & 825.9 & 1026 & 842 & 1299 \\
\hline 21268 & Ringwood North & 7347 & 266.1 & 219.9 & 336.1 & 195 & 162 & 247 \\
\hline 21269 & Forest Hill & 8497 & 744.3 & 610.8 & 938.1 & 632 & 519 & 797 \\
\hline 21270 & Mitcham (Vic.) & 12567 & 627.9 & 518.8 & 799.8 & 789 & 652 & 1005 \\
\hline 21271 & Nunawading & 9323 & 733.2 & 604.0 & 928.0 & 684 & 563 & 865 \\
\hline 21272 & Vermont & 7900 & 412.4 & 338.9 & 528.3 & 326 & 268 & 417 \\
\hline 21273 & Vermont South & 9510 & 303.5 & 249.5 & 391.8 & 289 & 237 & 373 \\
\hline 21274 & Belgrave - Selby & 7652 & 209.5 & 172.4 & 264.7 & 160 & 132 & 203 \\
\hline 21275 & Chirnside Park & 7663 & 330.6 & 271.0 & 421.4 & 253 & 208 & 323 \\
\hline 21276 & Healesville - Yarra Glen & 10506 & 495.6 & 404.7 & 618.2 & 521 & 425 & 649 \\
\hline 21277 & Kilsyth & 7161 & 552.3 & 453.1 & 691.5 & 396 & 324 & 495 \\
\hline 21278 & Lilydale - Coldstream & 14391 & 555.7 & 454.1 & 697.7 & 800 & 653 & 1004 \\
\hline 21279 & Monbulk - Silvan & 4259 & 363.7 & 299.4 & 457.0 & 155 & 127 & 195 \\
\hline 21280 & Montrose & 5241 & 275.6 & 226.4 & 344.8 & 144 & 119 & 181 \\
\hline 21281 & Mooroolbark & 16906 & 483.5 & 396.0 & 614.1 & 817 & 669 & 1038 \\
\hline 21282 & Mount Dandenong - Olinda & 7437 & 240.5 & 198.5 & 302.6 & 179 & 148 & 225 \\
\hline 21283 & Mount Evelyn & 7341 & 304.7 & 249.6 & 380.7 & 224 & 183 & 279 \\
\hline 21284 & Upwey - Tecoma & 7398 & 322.8 & 265.2 & 404.2 & 239 & 196 & 299 \\
\hline 21285 & Wandin - Seville & 5725 & 221.8 & 183.6 & 279.8 & 127 & 105 & 160 \\
\hline 21286 & Yarra Valley & 12367 & 501.6 & 410.3 & 621.7 & 620 & 507 & 769 \\
\hline 21287 & Beaconsfield - Officer & 9724 & 424.6 & 349.3 & 545.7 & 413 & 340 & 531 \\
\hline 21288 & Bunyip - Garfield & 6585 & 327.8 & 268.6 & 414.7 & 216 & 177 & 273 \\
\hline 21289 & Emerald - Cockatoo & 13534 & 227.7 & 187.2 & 285.4 & 308 & 253 & 386 \\
\hline 21290 & Koo Wee Rup & 5658 & 488.8 & 402.0 & 610.7 & 277 & 227 & 346 \\
\hline 21291 & Pakenham - North & 13346 & 945.2 & 774.8 & 1190.3 & 1261 & 1034 & 1589 \\
\hline 21292 & Pakenham - South & 20408 & 812.8 & 665.2 & 1027.0 & 1659 & 1358 & 2096 \\
\hline 21293 & Berwick - North & 18015 & 500.4 & 411.3 & 631.4 & 901 & 741 & 1137 \\
\hline 21294 & Berwick - South & 18249 & 509.9 & 419.1 & 656.6 & 931 & 765 & 1198 \\
\hline 21295 & Doveton & 8799 & 1323.9 & 1073.3 & 1671.0 & 1165 & 944 & 1470 \\
\hline 21297 & Hallam & 8364 & 691.0 & 559.4 & 884.9 & 578 & 468 & 740 \\
\hline 21299 & Narre Warren North & 6145 & 101.6 & 83.2 & 129.3 & 62 & 51 & 79 \\
\hline 21300 & Cranbourne & 15138 & 891.4 & 726.8 & 1119.3 & 1349 & 1100 & 1694 \\
\hline 21301 & Cranbourne East & 17955 & 495.9 & 406.5 & 636.1 & 890 & 730 & 1142 \\
\hline 21302 & Cranbourne North & 14472 & 590.2 & 481.6 & 751.9 & 854 & 697 & 1088 \\
\hline 21303 & Cranbourne South & 6722 & 208.8 & 171.7 & 267.1 & 140 & 115 & 180 \\
\hline 21304 & Cranbourne West & 10838 & 536.4 & 438.8 & 681.2 & 581 & 476 & 738 \\
\hline 21305 & Hampton Park - Lynbrook & 19197 & 721.6 & 586.8 & 920.1 & 1385 & 1127 & 1766 \\
\hline 21306 & Lynbrook - Lyndhurst & 10867 & 317.3 & 260.6 & 411.4 & 345 & 283 & 447 \\
\hline 21308 & Pearcedale - Tooradin & 5877 & 299.0 & 245.2 & 374.9 & 176 & 144 & 220 \\
\hline 21309 & Clarinda - Oakleigh South & 9676 & 504.7 & 413.7 & 642.4 & 488 & 400 & 622 \\
\hline 21310 & Clayton South & 10322 & 1065.2 & 869.0 & 1373.4 & 1100 & 897 & 1418 \\
\hline 21311 & Dandenong & 24048 & 1592.9 & 1294.9 & 2030.2 & 3831 & 3114 & 4882 \\
\hline 21312 & Dandenong North & 17776 & 834.4 & 677.3 & 1059.5 & 1483 & 1204 & 1883 \\
\hline 21313 & Dingley Village & 8075 & 251.4 & 207.4 & 319.1 & 203 & 167 & 258 \\
\hline 21314 & Keysborough & 20226 & 424.5 & 346.3 & 544.6 & 859 & 700 & 1101 \\
\hline 21316 & Noble Park North & 5986 & 806.6 & 657.2 & 1021.0 & 483 & 393 & 611 \\
\hline 21317 & Springvale & 17694 & 1140.7 & 924.0 & 1462.8 & 2018 & 1635 & 2588 \\
\hline 21318 & Springvale South & 10015 & 701.0 & 569.8 & 897.0 & 702 & 571 & 898 \\
\hline 21319 & Ashwood - Chadstone & 14559 & 1021.1 & 836.0 & 1290.4 & 1487 & 1217 & 1879 \\
\hline 21320 & Clayton & 19784 & 1680.1 & 1358.5 & 2163.1 & 3324 & 2688 & 4279 \\
\hline 21321 & Glen Waverley - East & 16813 & 481.2 & 396.5 & 621.8 & 809 & 667 & 1045 \\
\hline 21322 & Glen Waverley - West & 15531 & 682.3 & 558.3 & 883.8 & 1060 & 867 & 1373 \\
\hline 21323 & Mount Waverley - North & 12230 & 520.3 & 428.2 & 672.3 & 636 & 524 & 822 \\
\hline 21324 & Mount Waverley - South & 14553 & 529.8 & 435.6 & 682.7 & 771 & 634 & 994 \\
\hline 21325 & Mulgrave & 15450 & 517.9 & 423.7 & 665.1 & 800 & 655 & 1028 \\
\hline 21326 & Oakleigh - Huntingdale & 17154 & 829.1 & 680.0 & 1061.5 & 1422 & 1166 & 1821 \\
\hline
\end{tabular}




\begin{tabular}{|c|c|c|c|c|c|c|c|c|}
\hline \multirow[b]{2}{*}{$\begin{array}{l}\text { SA2_5DIGIT } \\
\text { CODE_2016 }\end{array}$} & \multirow[b]{2}{*}{ SA2_name } & \multicolumn{7}{|c|}{ Unit-level SAES } \\
\hline & & $\begin{array}{r}\text { Unit-level_Probit_ } \\
\text { totalpopulation }\end{array}$ & $\begin{array}{r}\text { Unit-level_ } \\
\text { probit_ } \\
\text { RATE }\end{array}$ & $\begin{array}{r}\text { Unit-level_ } \\
\text { probit_ } \\
\text { RATE_ } \\
\text { LowerCl }\end{array}$ & $\begin{array}{r}\text { Unit-level_ } \\
\text { probit_ } \\
\text { RATE_ } \\
\text { UpperCl }\end{array}$ & $\begin{array}{r}\text { Unit-level_ } \\
\text { probit_ } \\
\text { number }\end{array}$ & $\begin{array}{c}\text { Unit-level_ } \\
\text { probit_ } \\
\text { number_- } \\
\text { LowerCl }\end{array}$ & $\begin{array}{r}\text { Unit-level_ } \\
\text { probit_ } \\
\text { number_ } \\
\text { UpperCl }\end{array}$ \\
\hline 21327 & Wheelers Hill & 15985 & 352.8 & 289.6 & 451.0 & 564 & 463 & 721 \\
\hline 21328 & Ardeer-Albion & 6348 & 1227.2 & 1000.8 & 1560.1 & 779 & 635 & 990 \\
\hline 21329 & Cairnlea & 7293 & 354.6 & 286.5 & 455.3 & 259 & 209 & 332 \\
\hline 21330 & Deer Park - Derrimut & 19300 & 749.4 & 608.8 & 958.8 & 1446 & 1175 & 1850 \\
\hline 21331 & Delahey & 6696 & 640.8 & 521.5 & 804.4 & 429 & 349 & 539 \\
\hline 21332 & Keilor Downs & 10617 & 544.5 & 441.9 & 689.4 & 578 & 469 & 732 \\
\hline 21333 & Kings Park (Vic.) & 10834 & 696.5 & 562.7 & 883.9 & 755 & 610 & 958 \\
\hline 21334 & St Albans - North & 16027 & 1112.2 & 903.9 & 1416.1 & 1783 & 1449 & 2270 \\
\hline 21335 & St Albans - South & 13880 & 980.6 & 796.3 & 1245.1 & 1361 & 1105 & 1728 \\
\hline 21336 & Sunshine & 7722 & 1225.4 & 998.0 & 1566.9 & 946 & 771 & 1210 \\
\hline 21337 & Sunshine North & 9272 & 828.5 & 672.7 & 1062.0 & 768 & 624 & 985 \\
\hline 21338 & Sunshine West & 14853 & 821.5 & 667.6 & 1047.1 & 1220 & 992 & 1555 \\
\hline 21339 & Sydenham & 9382 & 719.8 & 590.9 & 921.9 & 675 & 554 & 865 \\
\hline 21340 & Taylors Lakes & 14141 & 238.4 & 194.5 & 305.1 & 337 & 275 & 431 \\
\hline 21341 & Altona & 10116 & 730.0 & 603.4 & 918.2 & 738 & 610 & 929 \\
\hline 21342 & Altona Meadows & 15362 & 730.7 & 598.2 & 922.7 & 1122 & 919 & 1417 \\
\hline 21343 & Altona North & 11086 & 800.7 & 655.8 & 1015.2 & 888 & 727 & 1125 \\
\hline 21344 & Newport & 13341 & 626.8 & 519.4 & 799.1 & 836 & 693 & 1066 \\
\hline 21345 & Seabrook & 3860 & 376.2 & 304.8 & 490.1 & 145 & 118 & 189 \\
\hline 21346 & Williamstown & 11890 & 586.2 & 485.0 & 734.3 & 697 & 577 & 873 \\
\hline 21347 & Braybrook & 14571 & 1437.5 & 1172.0 & 1810.1 & 2095 & 1708 & 2637 \\
\hline 21348 & Footscray & 13916 & 1673.7 & 1371.2 & 2117.4 & 2329 & 1908 & 2947 \\
\hline 21349 & Maribyrnong & 10012 & 856.2 & 705.8 & 1100.8 & 857 & 707 & 1102 \\
\hline 21350 & Seddon - Kingsville & 7206 & 998.1 & 826.1 & 1257.6 & 719 & 595 & 906 \\
\hline 21351 & West Footscray - Tottenham & 9162 & 1181.3 & 968.2 & 1501.7 & 1082 & 887 & 1376 \\
\hline 21352 & Yarraville & 11504 & 688.1 & 571.0 & 874.5 & 792 & 657 & 1006 \\
\hline 21353 & Bacchus Marsh & 15363 & 650.4 & 531.1 & 810.8 & 999 & 816 & 1246 \\
\hline 21355 & Hillside & 14983 & 284.0 & 231.9 & 366.4 & 425 & 347 & 549 \\
\hline 21356 & Melton & 14272 & 878.9 & 714.9 & 1095.2 & 1254 & 1020 & 1563 \\
\hline 21357 & Melton South & 17152 & 860.4 & 700.8 & 1078.2 & 1476 & 1202 & 1849 \\
\hline 21358 & Melton West & 12655 & 710.5 & 578.3 & 895.6 & 899 & 732 & 1133 \\
\hline 21359 & Rockbank - Mount Cottrell & 2672 & 392.7 & 321.6 & 491.1 & 105 & 86 & 131 \\
\hline 21360 & Taylors Hill & 13253 & 324.2 & 264.7 & 418.2 & 430 & 351 & 554 \\
\hline 21361 & Hoppers Crossing - North & 14866 & 557.8 & 454.6 & 710.8 & 829 & 676 & 1057 \\
\hline 21362 & Hoppers Crossing - South & 15094 & 769.7 & 626.2 & 980.3 & 1162 & 945 & 1480 \\
\hline 21363 & Laverton & 6928 & 1072.1 & 870.6 & 1383.6 & 743 & 603 & 959 \\
\hline 21365 & Tarneit & 23965 & 686.0 & 558.8 & 889.5 & 1644 & 1339 & 2132 \\
\hline 21366 & Truganina & 16482 & 645.1 & 527.3 & 838.3 & 1063 & 869 & 1382 \\
\hline 21368 & Werribee - South & 9021 & 868.2 & 711.3 & 1091.4 & 783 & 642 & 985 \\
\hline 21369 & Wyndham Vale & 16303 & 735.8 & 601.3 & 932.7 & 1200 & 980 & 1521 \\
\hline 21370 & Carrum Downs & 15873 & 748.3 & 613.9 & 944.6 & 1188 & 974 & 1499 \\
\hline 21371 & Frankston & 18031 & 1385.9 & 1138.3 & 1717.1 & 2499 & 2052 & 3096 \\
\hline 21372 & Frankston North & 15134 & 1263.9 & 1031.7 & 1570.6 & 1913 & 1561 & 2377 \\
\hline 21373 & Frankston South & 14101 & 533.6 & 438.3 & 665.9 & 752 & 618 & 939 \\
\hline 21374 & Langwarrin & 18279 & 471.3 & 388.3 & 589.3 & 861 & 710 & 1077 \\
\hline 21375 & Seaford (Vic.) & 13066 & 1042.8 & 856.1 & 1297.4 & 1362 & 1119 & 1695 \\
\hline 21376 & Skye - Sandhurst & 9582 & 368.9 & 303.5 & 474.8 & 353 & 291 & 455 \\
\hline 21377 & Dromana & 8633 & 790.4 & 648.8 & 991.0 & 682 & 560 & 856 \\
\hline 21378 & Flinders & 4022 & 322.3 & 267.6 & 408.0 & 130 & 108 & 164 \\
\hline 21379 & Hastings - Somers & 16835 & 795.8 & 652.0 & 988.9 & 1340 & 1098 & 1665 \\
\hline 21380 & Mornington & 18670 & 728.9 & 599.1 & 907.6 & 1361 & 1118 & 1694 \\
\hline 21381 & Mount Eliza & 13267 & 205.1 & 168.8 & 261.0 & 272 & 224 & 346 \\
\hline 21382 & Mount Martha & 13548 & 336.6 & 277.0 & 428.9 & 456 & 375 & 581 \\
\hline 21383 & Point Nepean & 12828 & 689.4 & 565.9 & 857.9 & 884 & 726 & 1100 \\
\hline 21384 & Rosebud - McCrae & 16649 & 985.0 & 804.7 & 1219.6 & 1640 & 1340 & 2031 \\
\hline 21385 & Somerville & 14070 & 462.8 & 379.9 & 579.8 & 651 & 534 & 816 \\
\hline 21386 & Ararat & 6622 & 824.6 & 669.5 & 1026.4 & 546 & 443 & 680 \\
\hline
\end{tabular}




\begin{tabular}{|c|c|c|c|c|c|c|c|c|}
\hline \multirow[b]{2}{*}{$\begin{array}{l}\text { SA2_5DIGIT } \\
\text { CODE_2016 }\end{array}$} & \multirow[b]{2}{*}{ SA2_name } & \multicolumn{7}{|c|}{ Unit-level SAES } \\
\hline & & $\begin{array}{r}\text { Unit-level_Probit_ } \\
\text { totalpopulation }\end{array}$ & $\begin{array}{r}\text { Unit-level_ } \\
\text { probit_ } \\
\text { RATE }\end{array}$ & $\begin{array}{r}\text { Unit-level_ } \\
\text { probit_ } \\
\text { RATE_ } \\
\text { LowerCl }\end{array}$ & $\begin{array}{r}\text { Unit-level_ } \\
\text { probit_ } \\
\text { RATE_ } \\
\text { UpperCl }\end{array}$ & $\begin{array}{r}\text { Unit-level_ } \\
\text { probit_ } \\
\text { number }\end{array}$ & $\begin{array}{c}\text { Unit-level_ } \\
\text { probit_ } \\
\text { number_- } \\
\text { LowerCl }\end{array}$ & $\begin{array}{r}\text { Unit-level_ } \\
\text { probit_ } \\
\text { number_ } \\
\text { UpperCl }\end{array}$ \\
\hline 21387 & Ararat Region & 2339 & 453.6 & 373.6 & 571.5 & 106 & 87 & 134 \\
\hline 21388 & Horsham & 12142 & 948.8 & 778.1 & 1165.9 & 1152 & 945 & 1416 \\
\hline 21389 & Horsham Region & 2542 & 358.2 & 298.1 & 441.7 & 91 & 76 & 112 \\
\hline 21390 & Nhill Region & 5370 & 574.3 & 470.5 & 711.0 & 308 & 253 & 382 \\
\hline 21391 & St Arnaud & 2698 & 639.6 & 527.7 & 777.5 & 173 & 142 & 210 \\
\hline 21392 & Stawell & 6402 & 820.9 & 666.9 & 1018.8 & 526 & 427 & 652 \\
\hline 21393 & West Wimmera & 2097 & 587.0 & 485.7 & 726.3 & 123 & 102 & 152 \\
\hline 21394 & Yarriambiack & 5150 & 549.8 & 451.5 & 673.7 & 283 & 233 & 347 \\
\hline 21395 & Irymple & 5149 & 470.2 & 383.8 & 585.3 & 242 & 198 & 301 \\
\hline 21396 & Merbein & 3573 & 597.0 & 486.4 & 736.2 & 213 & 174 & 263 \\
\hline 21398 & Mildura Region & 2877 & 653.0 & 537.1 & 815.2 & 188 & 155 & 235 \\
\hline 21399 & Red Cliffs & 4432 & 706.5 & 576.2 & 877.8 & 313 & 255 & 389 \\
\hline 21400 & Buloke & 4824 & 554.3 & 455.7 & 679.4 & 267 & 220 & 328 \\
\hline 21401 & Gannawarra & 5178 & 624.5 & 510.7 & 776.9 & 323 & 264 & 402 \\
\hline 21402 & Kerang & 3043 & 807.5 & 661.4 & 993.3 & 246 & 201 & 302 \\
\hline 21403 & Robinvale & 2494 & 1000.9 & 807.7 & 1256.5 & 250 & 201 & 313 \\
\hline 21404 & Swan Hill & 8198 & 1079.3 & 880.3 & 1336.6 & 885 & 722 & 1096 \\
\hline 21405 & Swan Hill Region & 4821 & 464.8 & 380.2 & 579.8 & 224 & 183 & 280 \\
\hline 21406 & Echuca & 11026 & 908.7 & 742.7 & 1124.7 & 1002 & 819 & 1240 \\
\hline 21407 & Kyabram & 8272 & 748.4 & 610.6 & 929.9 & 619 & 505 & 769 \\
\hline 21408 & Lockington - Gunbower & 2826 & 436.6 & 359.5 & 548.5 & 123 & 102 & 155 \\
\hline 21409 & Rochester & 2954 & 655.8 & 535.7 & 808.3 & 194 & 158 & 239 \\
\hline 21410 & Rushworth & 3241 & 516.2 & 423.6 & 635.5 & 167 & 137 & 206 \\
\hline 21411 & Cobram & 4781 & 965.0 & 787.6 & 1197.3 & 461 & 377 & 572 \\
\hline 21412 & Moira & 1969 & 426.0 & 352.3 & 524.6 & 84 & 69 & 103 \\
\hline 21413 & Numurkah & 9327 & 665.2 & 545.5 & 821.7 & 620 & 509 & 766 \\
\hline 21414 & Yarrawonga & 5873 & 820.9 & 674.0 & 1013.5 & 482 & 396 & 595 \\
\hline 21415 & Mooroopna & 6067 & 1195.7 & 968.8 & 1470.8 & 725 & 588 & 892 \\
\hline 21416 & Shepparton - North & 13888 & 1098.6 & 896.4 & 1365.9 & 1526 & 1245 & 1897 \\
\hline 21417 & Shepparton - South & 17193 & 942.4 & 765.8 & 1177.6 & 1620 & 1317 & 2025 \\
\hline 21418 & Shepparton Region - East & 2842 & 344.3 & 282.2 & 431.7 & 98 & 80 & 123 \\
\hline 21419 & Shepparton Region - West & 7709 & 586.2 & 477.2 & 735.8 & 452 & 368 & 567 \\
\hline 21420 & Glenelg (Vic.) & 6767 & 520.0 & 426.2 & 639.4 & 352 & 288 & 433 \\
\hline 21421 & Hamilton (Vic.) & 7669 & 816.5 & 670.5 & 1008.7 & 626 & 514 & 774 \\
\hline 21422 & Portland & 8240 & 986.8 & 806.8 & 1215.4 & 813 & 665 & 1001 \\
\hline 21423 & Southern Grampians & 4528 & 484.4 & 398.3 & 605.8 & 219 & 180 & 274 \\
\hline 21424 & Doncaster East (North) & 11785 & 302.8 & 248.5 & 392.3 & 357 & 293 & 462 \\
\hline 21425 & Doncaster East (South) & 11129 & 739.7 & 607.7 & 945.7 & 823 & 676 & 1052 \\
\hline 21426 & Bentleigh East (North) & 11146 & 522.1 & 431.3 & 665.8 & 582 & 481 & 742 \\
\hline 21427 & Bentleigh East (South) & 10179 & 459.8 & 379.3 & 588.9 & 468 & 386 & 599 \\
\hline 21428 & Preston - East & 16282 & 1201.5 & 982.4 & 1514.9 & 1956 & 1599 & 2467 \\
\hline 21429 & Preston - West & 9624 & 863.8 & 710.4 & 1099.8 & 831 & 684 & 1058 \\
\hline 21430 & Doreen & 14249 & 512.2 & 421.6 & 652.2 & 730 & 601 & 929 \\
\hline 21431 & Epping - East & 10251 & 700.8 & 570.2 & 891.0 & 718 & 585 & 913 \\
\hline 21432 & Epping - South & 6625 & 958.0 & 783.8 & 1209.7 & 635 & 519 & 801 \\
\hline 21433 & Epping - West & 7659 & 682.9 & 560.5 & 870.9 & 523 & 429 & 667 \\
\hline 21434 & Mernda & 11649 & 702.8 & 575.5 & 894.2 & 819 & 670 & 1042 \\
\hline 21435 & South Morang (North) & 8608 & 404.9 & 330.1 & 523.8 & 349 & 284 & 451 \\
\hline 21436 & South Morang (South) & 9195 & 530.7 & 435.6 & 675.5 & 488 & 401 & 621 \\
\hline 21437 & Wollert & 6428 & 517.3 & 421.7 & 667.3 & 333 & 271 & 429 \\
\hline 21438 & Glenroy & 17628 & 992.5 & 810.5 & 1266.0 & 1750 & 1429 & 2232 \\
\hline 21439 & Gowanbrae & 2179 & 347.3 & 288.4 & 438.1 & 76 & 63 & 95 \\
\hline 21440 & Hadfield & 4449 & 736.8 & 600.3 & 931.9 & 328 & 267 & 415 \\
\hline 21441 & Craigieburn - Central & 6316 & 738.9 & 597.3 & 944.5 & 467 & 377 & 597 \\
\hline 21442 & Craigieburn - North & 7945 & 570.3 & 465.4 & 736.1 & 453 & 370 & 585 \\
\hline 21443 & Craigieburn - South & 12062 & 753.4 & 610.2 & 962.8 & 909 & 736 & 1161 \\
\hline 21444 & Craigieburn - West & 9816 & 884.1 & 720.4 & 1135.1 & 868 & 707 & 1114 \\
\hline
\end{tabular}




\begin{tabular}{|c|c|c|c|c|c|c|c|c|}
\hline \multirow[b]{2}{*}{$\begin{array}{l}\text { SA2_5DIGIT } \\
\text { CODE_2016 }\end{array}$} & \multirow[b]{2}{*}{ SA2_name } & \multicolumn{7}{|c|}{ Unit-level SAEs } \\
\hline & & $\begin{array}{r}\text { Unit-level_Probit_ } \\
\text { totalpopulation }\end{array}$ & $\begin{array}{r}\text { Unit-level_ } \\
\text { probit_ } \\
\text { RATE }\end{array}$ & $\begin{array}{c}\text { Unit-level_ } \\
\text { probit_ } \\
\text { RATE_ } \\
\text { LowerCl }\end{array}$ & $\begin{array}{r}\text { Unit-level_ } \\
\text { probit_ } \\
\text { RATE_ } \\
\text { UpperCl }\end{array}$ & $\begin{array}{r}\text { Unit-level_ } \\
\text { probit_ } \\
\text { number }\end{array}$ & $\begin{array}{c}\text { Unit-level_ } \\
\text { probit_ } \\
\text { number_ } \\
\text { LowerCl }\end{array}$ & $\begin{array}{r}\text { Unit-level_ } \\
\text { probit_ } \\
\text { number_ } \\
\text { UpperCl }\end{array}$ \\
\hline 21445 & Mickleham - Yuroke & 2574 & 152.5 & 124.7 & 196.4 & 39 & 32 & 51 \\
\hline 21446 & Boronia & 17548 & 735.7 & 603.1 & 925.2 & 1291 & 1058 & 1623 \\
\hline 21447 & Ferntree Gully (North) & 11019 & 616.5 & 509.2 & 766.9 & 679 & 561 & 845 \\
\hline 21448 & Ferntree Gully (South) - Upper Ferntree Gully & 11412 & 422.2 & 347.6 & 531.9 & 482 & 397 & 607 \\
\hline 21449 & The Basin & 3217 & 267.1 & 220.7 & 334.6 & 86 & 71 & 108 \\
\hline 21450 & Croydon - East & 11862 & 862.1 & 709.2 & 1082.2 & 1023 & 841 & 1284 \\
\hline 21451 & Croydon-West & 10495 & 664.0 & 543.9 & 835.6 & 697 & 571 & 877 \\
\hline 21452 & Croydon South & 3621 & 488.3 & 402.0 & 613.8 & 177 & 146 & 222 \\
\hline 21453 & Endeavour Hills - North & 9423 & 487.9 & 395.9 & 624.3 & 460 & 373 & 588 \\
\hline 21454 & Endeavour Hills - South & 10605 & 473.2 & 382.1 & 605.1 & 502 & 405 & 642 \\
\hline 21455 & Narre Warren - North East & 10312 & 494.1 & 403.1 & 629.8 & 509 & 416 & 649 \\
\hline 21456 & Narre Warren - South West & 10836 & 799.6 & 652.6 & 1012.8 & 866 & 707 & 1097 \\
\hline 21457 & Narre Warren South (East) & 9681 & 197.8 & 160.9 & 259.5 & 191 & 156 & 251 \\
\hline 21458 & Narre Warren South (West) & 12203 & 482.1 & 389.0 & 623.9 & 588 & 475 & 761 \\
\hline 21459 & Noble Park - East & 10006 & 1322.8 & 1085.9 & 1675.4 & 1324 & 1087 & 1676 \\
\hline 21460 & Noble Park - West & 14867 & 1060.2 & 863.5 & 1346.2 & 1576 & 1284 & 2001 \\
\hline 21461 & Burnside & 3647 & 332.2 & 272.0 & 414.0 & 121 & 99 & 151 \\
\hline 21462 & Burnside Heights & 4144 & 425.9 & 346.6 & 555.5 & 177 & 144 & 230 \\
\hline 21463 & Caroline Springs & 14268 & 497.8 & 408.0 & 639.9 & 710 & 582 & 913 \\
\hline 21464 & Point Cook - East & 8696 & 630.7 & 518.9 & 823.7 & 548 & 451 & 716 \\
\hline 21465 & Point Cook - North & 16236 & 536.7 & 441.2 & 697.8 & 871 & 716 & 1133 \\
\hline 21466 & Point Cook - South & 9825 & 586.5 & 483.1 & 766.3 & 576 & 475 & 753 \\
\hline 21467 & Werribee - East & 15193 & 1086.3 & 884.0 & 1367.7 & 1650 & 1343 & 2078 \\
\hline 21468 & Werribee - West & 9248 & 627.4 & 512.2 & 791.6 & 580 & 474 & 732 \\
\hline 21469 & Mildura - North & 13711 & 1487.0 & 1209.7 & 1836.2 & 2039 & 1659 & 2518 \\
\hline 21470 & Mildura - South & 11073 & 1063.6 & 866.0 & 1321.3 & 1178 & 959 & 1463 \\
\hline 21471 & Camperdown & 2666 & 771.4 & 632.9 & 944.6 & 206 & 169 & 252 \\
\hline 21472 & Colac & 9291 & 901.5 & 737.3 & 1106.6 & 838 & 685 & 1028 \\
\hline 21473 & Colac Region & 3982 & 425.8 & 350.4 & 530.9 & 170 & 140 & 211 \\
\hline 21474 & Corangamite - North & 4085 & 672.4 & 551.1 & 831.6 & 275 & 225 & 340 \\
\hline 21475 & Corangamite - South & 5342 & 630.9 & 518.6 & 788.5 & 337 & 277 & 421 \\
\hline 21476 & Otway & 2567 & 719.6 & 595.5 & 890.1 & 185 & 153 & 228 \\
\hline 21477 & Moyne - East & 4884 & 540.8 & 444.6 & 682.0 & 264 & 217 & 333 \\
\hline 21478 & Moyne - West & 7005 & 547.7 & 451.6 & 680.2 & 384 & 316 & 476 \\
\hline 21479 & Warrnambool - North & 15780 & 944.3 & 773.9 & 1170.5 & 1490 & 1221 & 1847 \\
\hline 21480 & Warrnambool - South & 10086 & 1055.7 & 866.0 & 1306.8 & 1065 & 873 & 1318 \\
\hline 31001 & Alexandra Hills & 12502 & 662.4 & 540.0 & 829.3 & 828 & 675 & 1037 \\
\hline 31002 & Belmont - Gumdale & 5591 & 323.7 & 264.6 & 420.0 & 181 & 148 & 235 \\
\hline 31003 & Birkdale & 11509 & 526.5 & 431.4 & 666.9 & 606 & 496 & 768 \\
\hline 31004 & Capalaba & 13662 & 765.6 & 624.6 & 958.0 & 1046 & 853 & 1309 \\
\hline 31005 & Thorneside & 2915 & 945.3 & 776.7 & 1186.1 & 276 & 226 & 346 \\
\hline 31006 & Wellington Point & 8843 & 542.1 & 445.4 & 685.9 & 479 & 394 & 607 \\
\hline 31007 & Cleveland & 11965 & 1001.5 & 820.6 & 1247.8 & 1198 & 982 & 1493 \\
\hline 31008 & Ormiston & 4563 & 522.1 & 429.9 & 658.7 & 238 & 196 & 301 \\
\hline 31009 & Redland Bay & 11504 & 576.4 & 469.9 & 736.6 & 663 & 541 & 847 \\
\hline 31011 & Sheldon - Mount Cotton & 5685 & 238.9 & 196.9 & 309.2 & 136 & 112 & 176 \\
\hline 31012 & Thornlands & 11099 & 552.0 & 452.4 & 703.0 & 613 & 502 & 780 \\
\hline 31013 & Victoria Point & 11725 & 769.1 & 626.1 & 975.0 & 902 & 734 & 1143 \\
\hline 31015 & Manly - Lota & 5674 & 728.3 & 597.1 & 916.0 & 413 & 339 & 520 \\
\hline 31016 & Manly West & 8572 & 678.3 & 555.2 & 852.9 & 581 & 476 & 731 \\
\hline 31017 & Murarrie & 3086 & 704.8 & 577.9 & 904.8 & 218 & 178 & 279 \\
\hline 31018 & Tingalpa & 6642 & 616.6 & 508.2 & 784.0 & 410 & 338 & 521 \\
\hline 31019 & Wakerley & 6062 & 438.6 & 365.1 & 567.1 & 266 & 221 & 344 \\
\hline 31020 & Wynnum & 10221 & 1020.9 & 836.7 & 1273.8 & 1043 & 855 & 1302 \\
\hline 31021 & Wynnum West - Hemmant & 11264 & 793.2 & 649.5 & 1005.3 & 893 & 732 & 1132 \\
\hline 31022 & Bald Hills & 5520 & 596.6 & 489.6 & 762.0 & 329 & 270 & 421 \\
\hline 31023 & Bridgeman Downs & 6320 & 259.0 & 213.2 & 333.9 & 164 & 135 & 211 \\
\hline
\end{tabular}




\begin{tabular}{|c|c|c|c|c|c|c|c|c|}
\hline \multirow[b]{2}{*}{$\begin{array}{l}\text { SA2_5DIGIT } \\
\text { CODE_2016 }\end{array}$} & \multirow[b]{2}{*}{ SA2_name } & \multicolumn{7}{|c|}{ Unit-level SAEs } \\
\hline & & $\begin{array}{r}\text { Unit-level_Probit_ } \\
\text { totalpopulation }\end{array}$ & $\begin{array}{r}\text { Unit-level_ } \\
\text { probit_ } \\
\text { RATE }\end{array}$ & $\begin{array}{r}\text { Unit-level_ } \\
\text { probit_ } \\
\text { RATE_- } \\
\text { LowerCl }\end{array}$ & $\begin{array}{c}\text { Unit-level_ } \\
\text { probit_ } \\
\text { RATE_ } \\
\text { UpperCl }\end{array}$ & $\begin{array}{r}\text { Unit-level_ } \\
\text { probit_ } \\
\text { number }\end{array}$ & $\begin{array}{r}\text { Unit-level_ } \\
\text { probit_ } \\
\text { number_ } \\
\text { LowerCl }\end{array}$ & $\begin{array}{c}\text { Unit-level_ } \\
\text { probit_ } \\
\text { number } \\
\text { UpperCl }\end{array}$ \\
\hline 31024 & Carseldine & 7253 & 669.5 & 546.8 & 857.6 & 486 & 397 & 622 \\
\hline 31025 & Everton Park & 6919 & 871.3 & 717.7 & 1104.8 & 603 & 497 & 764 \\
\hline 31026 & McDowall & 5711 & 355.1 & 293.9 & 464.0 & 203 & 168 & 265 \\
\hline 31027 & Aspley & 9828 & 708.5 & 579.4 & 895.3 & 696 & 569 & 880 \\
\hline 31028 & Chermside & 7767 & 1885.2 & 1544.6 & 2363.6 & 1464 & 1200 & 1836 \\
\hline 31029 & Chermside West & 4923 & 440.8 & 361.6 & 573.3 & 217 & 178 & 282 \\
\hline 31030 & Geebung & 3286 & 645.7 & 529.4 & 830.9 & 212 & 174 & 273 \\
\hline 31031 & Kedron - Gordon Park & 10534 & 1026.6 & 847.5 & 1302.2 & 1081 & 893 & 1372 \\
\hline 31032 & Stafford & 5131 & 1426.1 & 1171.9 & 1779.8 & 732 & 601 & 913 \\
\hline 31033 & Stafford Heights & 5374 & 859.8 & 699.3 & 1075.6 & 462 & 376 & 578 \\
\hline 31034 & Wavell Heights & 7287 & 584.3 & 481.3 & 745.0 & 426 & 351 & 543 \\
\hline 31035 & Boondall & 7273 & 720.7 & 585.6 & 922.5 & 524 & 426 & 671 \\
\hline 31037 & Eagle Farm - Pinkenba & 705 & 844.6 & 709.0 & 1075.1 & 60 & 50 & 76 \\
\hline 31038 & Northgate - Virginia & 5129 & 929.5 & 766.0 & 1173.9 & 477 & 393 & 602 \\
\hline 31039 & Nudgee - Banyo & 7393 & 674.2 & 553.5 & 858.2 & 498 & 409 & 634 \\
\hline 31040 & Nundah & 10064 & 1437.7 & 1191.2 & 1812.1 & 1447 & 1199 & 1824 \\
\hline 31041 & Bracken Ridge & 12955 & 630.6 & 514.0 & 806.1 & 817 & 666 & 1044 \\
\hline 31042 & Brighton (QId) & 7189 & 632.3 & 517.6 & 793.4 & 455 & 372 & 570 \\
\hline 31043 & Deagon & 2843 & 1034.1 & 842.6 & 1291.3 & 294 & 240 & 367 \\
\hline 31044 & Sandgate - Shorncliffe & 5326 & 865.4 & 710.6 & 1065.3 & 461 & 378 & 567 \\
\hline 31045 & Taigum - Fitzgibbon & 9550 & 1001.7 & 819.4 & 1270.4 & 957 & 783 & 1213 \\
\hline 31046 & Zillmere & 7093 & 1778.8 & 1449.8 & 2235.6 & 1262 & 1028 & 1586 \\
\hline 31047 & Camp Hill & 8177 & 596.3 & 492.7 & 763.6 & 488 & 403 & 624 \\
\hline 31048 & Cannon Hill & 4436 & 687.6 & 567.4 & 885.2 & 305 & 252 & 393 \\
\hline 31049 & Carina & 8703 & 787.0 & 646.3 & 1007.7 & 685 & 563 & 877 \\
\hline 31050 & Carina Heights & 5217 & 1221.0 & 1002.5 & 1533.1 & 637 & 523 & 800 \\
\hline 31051 & Carindale & 12449 & 302.4 & 248.7 & 392.9 & 376 & 310 & 489 \\
\hline 31052 & Annerley & 9464 & 1511.6 & 1241.0 & 1908.7 & 1431 & 1174 & 1806 \\
\hline 31053 & Coorparoo & 12853 & 1060.0 & 875.4 & 1348.3 & 1362 & 1125 & 1733 \\
\hline 31054 & Fairfield - Dutton Park & 3922 & 1451.9 & 1187.9 & 1839.6 & 569 & 466 & 721 \\
\hline 31055 & Greenslopes & 7522 & 1399.0 & 1153.8 & 1774.6 & 1052 & 868 & 1335 \\
\hline 31056 & Holland Park & 6177 & 992.7 & 817.4 & 1230.3 & 613 & 505 & 760 \\
\hline 31057 & Holland Park West & 4971 & 804.7 & 662.9 & 1025.1 & 400 & 330 & 510 \\
\hline 31058 & Woolloongabba & 4729 & 1555.4 & 1274.8 & 1975.7 & 736 & 603 & 934 \\
\hline 31059 & Yeronga & 7648 & 1013.4 & 836.5 & 1272.7 & 775 & 640 & 973 \\
\hline 31060 & Eight Mile Plains & 12154 & 837.0 & 684.0 & 1083.5 & 1017 & 831 & 1317 \\
\hline 31061 & Macgregor (QId) & 4918 & 995.7 & 803.1 & 1294.7 & 490 & 395 & 637 \\
\hline 31062 & Mansfield (QId) & 6655 & 696.4 & 568.7 & 884.3 & 463 & 378 & 588 \\
\hline 31063 & Mount Gravatt & 11669 & 1065.2 & 872.6 & 1337.8 & 1243 & 1018 & 1561 \\
\hline 31064 & Rochedale - Burbank & 4716 & 313.8 & 255.8 & 407.7 & 148 & 121 & 192 \\
\hline 31065 & Upper Mount Gravatt & 7673 & 1200.9 & 974.7 & 1535.0 & 921 & 748 & 1178 \\
\hline 31066 & Wishart & 8292 & 521.6 & 427.8 & 674.0 & 432 & 355 & 559 \\
\hline 31067 & Coopers Plains & 4439 & 1433.0 & 1163.0 & 1813.5 & 636 & 516 & 805 \\
\hline 31068 & Moorooka & 8238 & 1162.1 & 956.8 & 1458.3 & 957 & 788 & 1201 \\
\hline 31069 & Robertson & 4219 & 892.7 & 721.8 & 1168.0 & 377 & 305 & 493 \\
\hline 31070 & Salisbury - Nathan & 5608 & 765.1 & 623.8 & 974.2 & 429 & 350 & 546 \\
\hline 31071 & Tarragindi & 7874 & 439.2 & 361.0 & 563.8 & 346 & 284 & 444 \\
\hline 31072 & Algester & 6484 & 687.3 & 565.0 & 876.4 & 446 & 366 & 568 \\
\hline 31073 & Calamvale - Stretton & 16412 & 636.1 & 519.6 & 824.5 & 1044 & 853 & 1353 \\
\hline 31074 & Pallara - Willawong & 3460 & 497.1 & 409.9 & 652.1 & 172 & 142 & 226 \\
\hline 31075 & Parkinson - Drewvale & 11438 & 458.6 & 373.0 & 601.6 & 525 & 427 & 688 \\
\hline 31076 & Rocklea - Acacia Ridge & 7382 & 1520.6 & 1230.3 & 1911.9 & 1122 & 908 & 1411 \\
\hline 31077 & Kuraby & 6214 & 678.4 & 549.2 & 876.7 & 422 & 341 & 545 \\
\hline 31078 & Runcorn & 11309 & 996.4 & 808.8 & 1294.4 & 1127 & 915 & 1464 \\
\hline 31079 & Sunnybank & 7355 & 1118.9 & 905.3 & 1441.8 & 823 & 666 & 1060 \\
\hline 31080 & Sunnybank Hills & 14438 & 754.2 & 612.2 & 972.3 & 1089 & 884 & 1404 \\
\hline 31081 & Jindalee - Mount Ommaney & 5844 & 376.8 & 309.0 & 489.3 & 220 & 181 & 286 \\
\hline
\end{tabular}




\begin{tabular}{|c|c|c|c|c|c|c|c|c|}
\hline \multirow[b]{2}{*}{$\begin{array}{l}\text { SA2_5DIGIT } \\
\text { CODE_2016 }\end{array}$} & \multirow[b]{2}{*}{ SA2_name } & \multicolumn{7}{|c|}{ Unit-level SAEs } \\
\hline & & $\begin{array}{r}\text { Unit-level_Probit_ } \\
\text { totalpopulation }\end{array}$ & $\begin{array}{r}\text { Unit-level_ } \\
\text { probit_ } \\
\text { RATE }\end{array}$ & $\begin{array}{r}\text { Unit-level_ } \\
\text { probit_ } \\
\text { RATE_ } \\
\text { LowerCl }\end{array}$ & $\begin{array}{r}\text { Unit-level_ } \\
\text { probit_ } \\
\text { RATE_ } \\
\text { UpperCl }\end{array}$ & $\begin{array}{r}\text { Unit-level_ } \\
\text { probit_ } \\
\text { number }\end{array}$ & $\begin{array}{c}\text { Unit-level_ } \\
\text { probit_ } \\
\text { number_- } \\
\text { LowerCl }\end{array}$ & $\begin{array}{r}\text { Unit-level_ } \\
\text { probit_ } \\
\text { number_ } \\
\text { UpperCl }\end{array}$ \\
\hline 31082 & Middle Park - Jamboree Heights & 5440 & 470.6 & 385.0 & 610.1 & 256 & 209 & 332 \\
\hline 31083 & Riverhills & 3017 & 536.7 & 443.3 & 693.4 & 162 & 134 & 209 \\
\hline 31084 & Seventeen Mile Rocks - Sinnamon Park & 7217 & 359.2 & 296.5 & 463.8 & 259 & 214 & 335 \\
\hline 31085 & Westlake & 3372 & 201.1 & 167.0 & 262.3 & 68 & 56 & 88 \\
\hline 31086 & Bellbowrie - Moggill & 7446 & 393.6 & 323.0 & 509.6 & 293 & 241 & 379 \\
\hline 31087 & Brookfield - Kenmore Hills & 5247 & 221.0 & 181.5 & 284.6 & 116 & 95 & 149 \\
\hline 31088 & Chapel Hill & 7849 & 323.4 & 266.6 & 417.3 & 254 & 209 & 328 \\
\hline 31089 & Fig Tree Pocket & 2933 & 204.9 & 170.1 & 269.1 & 60 & 50 & 79 \\
\hline 31090 & Kenmore & 6602 & 370.3 & 304.1 & 482.5 & 244 & 201 & 319 \\
\hline 31091 & Pinjarra Hills - Pullenvale & 4006 & 192.9 & 158.0 & 248.7 & 77 & 63 & 100 \\
\hline 31092 & Chelmer - Graceville & 5388 & 407.8 & 337.7 & 527.9 & 220 & 182 & 284 \\
\hline 31093 & Corinda & 3619 & 815.5 & 673.4 & 1019.7 & 295 & 244 & 369 \\
\hline 31094 & Indooroopilly & 9829 & 1239.9 & 1013.0 & 1593.2 & 1219 & 996 & 1566 \\
\hline 31095 & Sherwood & 4325 & 872.4 & 723.3 & 1100.6 & 377 & 313 & 476 \\
\hline 31096 & St Lucia & 10966 & 1560.0 & 1259.5 & 2002.5 & 1711 & 1381 & 2196 \\
\hline 31097 & Taringa & 7072 & 1554.2 & 1273.1 & 1982.9 & 1099 & 900 & 1402 \\
\hline 31098 & Enoggera & 6378 & 1182.4 & 973.4 & 1482.7 & 754 & 621 & 946 \\
\hline 31100 & Keperra & 5457 & 1125.9 & 917.6 & 1400.3 & 614 & 501 & 764 \\
\hline 31101 & Mitchelton & 6218 & 920.3 & 755.0 & 1161.2 & 572 & 469 & 722 \\
\hline 31103 & The Gap & 12338 & 334.8 & 275.3 & 430.5 & 413 & 340 & 531 \\
\hline 31104 & Upper Kedron - Ferny Grove & 7202 & 450.9 & 370.9 & 584.9 & 325 & 267 & 421 \\
\hline 31105 & Brisbane City & 9148 & 1322.0 & 1078.8 & 1717.3 & 1209 & 987 & 1571 \\
\hline 31106 & Fortitude Valley & 6437 & 1666.2 & 1379.5 & 2110.9 & 1073 & 888 & 1359 \\
\hline 31107 & Highgate Hill & 5200 & 1376.3 & 1127.7 & 1747.3 & 716 & 586 & 909 \\
\hline 31108 & Kangaroo Point & 7264 & 1296.1 & 1070.5 & 1654.1 & 941 & 778 & 1202 \\
\hline 31109 & New Farm & 10912 & 1183.0 & 980.4 & 1497.8 & 1291 & 1070 & 1634 \\
\hline 31110 & South Brisbane & 6194 & 1289.6 & 1064.7 & 1657.8 & 799 & 659 & 1027 \\
\hline 31111 & Spring Hill & 5363 & 1628.1 & 1331.0 & 2087.7 & 873 & 714 & 1120 \\
\hline 31112 & West End & 7899 & 1293.6 & 1067.4 & 1645.1 & 1022 & 843 & 1299 \\
\hline 31113 & Balmoral & 3157 & 685.9 & 568.8 & 878.9 & 217 & 180 & 277 \\
\hline 31114 & Bulimba & 5100 & 646.4 & 539.8 & 831.2 & 330 & 275 & 424 \\
\hline 31115 & East Brisbane & 4697 & 1387.5 & 1143.2 & 1758.9 & 652 & 537 & 826 \\
\hline 31116 & Hawthorne & 3675 & 738.6 & 614.5 & 941.7 & 271 & 226 & 346 \\
\hline 31117 & Morningside - Seven Hills & 9794 & 1053.6 & 870.1 & 1344.0 & 1032 & 852 & 1316 \\
\hline 31118 & Norman Park & 4686 & 693.2 & 573.9 & 890.3 & 325 & 269 & 417 \\
\hline 31119 & Albion & 2297 & 1076.6 & 894.3 & 1379.8 & 247 & 205 & 317 \\
\hline 31120 & Alderley & 4592 & 1010.8 & 834.7 & 1278.1 & 464 & 383 & 587 \\
\hline 31121 & Ascot & 4109 & 1012.6 & 837.2 & 1278.0 & 416 & 344 & 525 \\
\hline 31122 & Clayfield & 8361 & 1019.2 & 844.7 & 1297.7 & 852 & 706 & 1085 \\
\hline 31123 & Grange & 3024 & 472.4 & 392.4 & 602.0 & 143 & 119 & 182 \\
\hline 31124 & Hamilton (QId) & 5207 & 972.5 & 809.2 & 1239.1 & 506 & 421 & 645 \\
\hline 31125 & Hendra & 3512 & 486.7 & 402.8 & 631.3 & 171 & 141 & 222 \\
\hline 31126 & Kelvin Grove - Herston & 8412 & 1704.2 & 1384.2 & 2188.6 & 1434 & 1164 & 1841 \\
\hline 31127 & Newmarket & 3980 & 1230.6 & 1012.0 & 1558.0 & 490 & 403 & 620 \\
\hline 31128 & Newstead - Bowen Hills & 9302 & 1176.8 & 981.4 & 1503.0 & 1095 & 913 & 1398 \\
\hline 31129 & Wilston & 2923 & 673.0 & 557.7 & 861.7 & 197 & 163 & 252 \\
\hline 31130 & Windsor & 5841 & 1275.4 & 1053.2 & 1620.8 & 745 & 615 & 947 \\
\hline 31131 & Wooloowin - Lutwyche & 7742 & 1191.1 & 982.0 & 1513.3 & 922 & 760 & 1172 \\
\hline 31132 & Ashgrove & 9729 & 583.9 & 483.2 & 744.5 & 568 & 470 & 724 \\
\hline 31133 & Auchenflower & 4508 & 1105.0 & 910.3 & 1425.7 & 498 & 410 & 643 \\
\hline 31134 & Bardon & 7058 & 489.9 & 405.2 & 630.0 & 346 & 286 & 445 \\
\hline 31135 & Paddington - Milton & 8622 & 1037.1 & 855.3 & 1340.3 & 894 & 737 & 1156 \\
\hline 31136 & Red Hill (QId) & 4599 & 1058.8 & 871.3 & 1356.2 & 487 & 401 & 624 \\
\hline 31137 & Toowong & 9086 & 1353.2 & 1107.5 & 1737.2 & 1230 & 1006 & 1578 \\
\hline 31138 & Brinsmead & 3880 & 488.1 & 394.2 & 640.0 & 189 & 153 & 248 \\
\hline 31139 & Clifton Beach - Kewarra Beach & 8245 & 907.0 & 745.9 & 1145.5 & 748 & 615 & 944 \\
\hline 31140 & Freshwater - Stratford & 2666 & 820.2 & 677.2 & 1024.7 & 219 & 181 & 273 \\
\hline
\end{tabular}




\begin{tabular}{|c|c|c|c|c|c|c|c|c|}
\hline \multirow[b]{2}{*}{$\begin{array}{l}\text { SA2_5DIGIT } \\
\text { CODE_2016 }\end{array}$} & \multirow[b]{2}{*}{ SA2_name } & \multicolumn{7}{|c|}{ Unit-level SAEs } \\
\hline & & $\begin{array}{r}\text { Unit-level_Probit_ } \\
\text { totalpopulation }\end{array}$ & $\begin{array}{r}\text { Unit-level_ } \\
\text { probit_ } \\
\text { RATE }\end{array}$ & $\begin{array}{r}\text { Unit-level_ } \\
\text { probit_ } \\
\text { RATE_ } \\
\text { LowerCl }\end{array}$ & $\begin{array}{c}\text { Unit-level_ } \\
\text { probit_ } \\
\text { RATE_ } \\
\text { UpperCl }\end{array}$ & $\begin{array}{r}\text { Unit-level_ } \\
\text { probit_ } \\
\text { number }\end{array}$ & $\begin{array}{r}\text { Unit-level_ } \\
\text { probit_ } \\
\text { number_- } \\
\text { LowerCl }\end{array}$ & $\begin{array}{r}\text { Unit-level__ } \\
\text { probit_ } \\
\text { number_- } \\
\text { UpperCl }\end{array}$ \\
\hline 31141 & Redlynch & 9024 & 585.4 & 477.5 & 748.9 & 528 & 431 & 676 \\
\hline 31142 & Trinity Beach - Smithfield & 10386 & 951.8 & 779.5 & 1201.4 & 989 & 810 & 1248 \\
\hline 31143 & Yorkeys Knob - Machans Beach & 4870 & 1381.8 & 1131.5 & 1713.7 & 673 & 551 & 835 \\
\hline 31144 & Bentley Park & 5430 & 1081.1 & 866.1 & 1371.9 & 587 & 470 & 745 \\
\hline 31145 & Cairns City & 9451 & 1500.8 & 1230.0 & 1877.6 & 1418 & 1162 & 1774 \\
\hline 31146 & Earlville - Bayview Heights & 6308 & 998.9 & 812.2 & 1231.5 & 630 & 512 & 777 \\
\hline 31147 & Edmonton & 7437 & 1215.8 & 973.7 & 1517.9 & 904 & 724 & 1129 \\
\hline 31148 & Gordonvale - Trinity & 6310 & 858.6 & 685.9 & 1069.0 & 542 & 433 & 675 \\
\hline 31149 & Kanimbla-Mooroobool & 7326 & 1008.2 & 803.6 & 1280.4 & 739 & 589 & 938 \\
\hline 31151 & Manoora & 4454 & 2496.8 & 2001.6 & 3075.2 & 1112 & 892 & 1370 \\
\hline 31152 & Manunda & 4190 & 2141.5 & 1728.4 & 2641.0 & 897 & 724 & 1107 \\
\hline 31153 & Mount Sheridan & 5986 & 835.3 & 668.4 & 1072.8 & 500 & 400 & 642 \\
\hline 31154 & Westcourt - Bungalow & 5178 & 1983.4 & 1603.4 & 2468.4 & 1027 & 830 & 1278 \\
\hline 31155 & White Rock & 3421 & 1252.5 & 1000.1 & 1575.8 & 428 & 342 & 539 \\
\hline 31156 & Whitfield - Edge Hill & 6149 & 1092.0 & 889.5 & 1365.8 & 671 & 547 & 840 \\
\hline 31157 & Woree & 3628 & 1839.0 & 1486.2 & 2270.4 & 667 & 539 & 824 \\
\hline 31158 & Babinda & 3257 & 787.1 & 634.4 & 980.1 & 256 & 207 & 319 \\
\hline 31159 & Innisfail & 7139 & 1504.7 & 1200.9 & 1878.6 & 1074 & 857 & 1341 \\
\hline 31160 & Johnstone & 5983 & 713.8 & 579.2 & 889.9 & 427 & 347 & 532 \\
\hline 31161 & Tully & 8281 & 997.2 & 805.0 & 1251.9 & 826 & 667 & 1037 \\
\hline 31163 & Yarrabah & 1620 & 4248.1 & 3041.4 & 5659.6 & 688 & 493 & 917 \\
\hline 31164 & Daintree & 4800 & 1078.3 & 863.3 & 1347.7 & 518 & 414 & 647 \\
\hline 31165 & Port Douglas & 4337 & 836.6 & 693.0 & 1055.2 & 363 & 301 & 458 \\
\hline 31166 & Atherton & 8193 & 1124.2 & 905.6 & 1397.3 & 921 & 742 & 1145 \\
\hline 31167 & Herberton & 4248 & 915.3 & 736.0 & 1133.6 & 389 & 313 & 482 \\
\hline 31168 & Kuranda & 3410 & 874.9 & 686.4 & 1102.5 & 298 & 234 & 376 \\
\hline 31169 & Malanda - Yungaburra & 6434 & 708.8 & 577.3 & 876.9 & 456 & 371 & 564 \\
\hline 31170 & Mareeba & 8378 & 1121.4 & 896.2 & 1400.4 & 940 & 751 & 1173 \\
\hline 31171 & Balonne & 3096 & 1021.5 & 818.7 & 1293.4 & 316 & 253 & 400 \\
\hline 31172 & Chinchilla & 5796 & 1021.9 & 838.2 & 1272.0 & 592 & 486 & 737 \\
\hline 31173 & Goondiwindi & 4594 & 954.7 & 779.6 & 1199.8 & 439 & 358 & 551 \\
\hline 31174 & Inglewood - Waggamba & 3102 & 949.9 & 773.1 & 1191.0 & 295 & 240 & 369 \\
\hline 31175 & Miles - Wandoan & 2967 & 867.7 & 712.3 & 1093.6 & 257 & 211 & 324 \\
\hline 31176 & Roma & 4884 & 940.3 & 769.7 & 1184.5 & 459 & 376 & 578 \\
\hline 31177 & Roma Region & 4176 & 599.8 & 487.1 & 757.5 & 250 & 203 & 316 \\
\hline 31178 & Tara & 3132 & 797.6 & 646.7 & 990.5 & 250 & 203 & 310 \\
\hline 31179 & Crows Nest - Rosalie & 6427 & 683.7 & 556.0 & 850.0 & 439 & 357 & 546 \\
\hline 31180 & Jondaryan & 5563 & 885.5 & 717.1 & 1118.0 & 493 & 399 & 622 \\
\hline 31181 & Millmerran & 2546 & 745.1 & 609.7 & 941.7 & 190 & 155 & 240 \\
\hline 31182 & Pittsworth & 4233 & 646.4 & 528.5 & 814.0 & 274 & 224 & 345 \\
\hline 31183 & Wambo & 12192 & 1030.4 & 837.7 & 1287.7 & 1256 & 1021 & 1570 \\
\hline 31184 & Clifton - Greenmount & 3721 & 622.4 & 509.7 & 775.8 & 232 & 190 & 289 \\
\hline 31185 & Southern Downs - East & 3261 & 493.5 & 402.3 & 616.5 & 161 & 131 & 201 \\
\hline 31186 & Southern Downs - West & 3574 & 645.1 & 523.4 & 804.6 & 231 & 187 & 288 \\
\hline 31187 & Stanthorpe & 4144 & 1176.4 & 959.7 & 1450.7 & 487 & 398 & 601 \\
\hline 31188 & Stanthorpe Region & 4400 & 679.6 & 555.1 & 848.1 & 299 & 244 & 373 \\
\hline 31189 & Warwick & 11325 & 1250.9 & 1011.6 & 1556.4 & 1417 & 1146 & 1763 \\
\hline 31190 & Central Highlands - East & 5015 & 1420.6 & 1119.8 & 1828.8 & 712 & 562 & 917 \\
\hline 31191 & Central Highlands - West & 5788 & 599.0 & 496.4 & 770.8 & 347 & 287 & 446 \\
\hline 31192 & Emerald & 9080 & 903.4 & 741.8 & 1152.7 & 820 & 674 & 1047 \\
\hline 31205 & Berserker & 5188 & 1523.4 & 1233.2 & 1888.0 & 790 & 640 & 980 \\
\hline 31206 & Bouldercombe & 1333 & 419.2 & 343.0 & 525.1 & 56 & 46 & 70 \\
\hline 31207 & Emu Park & 4017 & 1134.5 & 921.2 & 1413.1 & 456 & 370 & 568 \\
\hline 31208 & Frenchville - Mount Archer & 6695 & 823.4 & 672.2 & 1025.7 & 551 & 450 & 687 \\
\hline 31209 & Glenlee - Rockyview & 3729 & 98.0 & 80.7 & 124.0 & 37 & 30 & 46 \\
\hline 31210 & Gracemere & 7766 & 1213.1 & 986.9 & 1523.4 & 942 & 766 & 1183 \\
\hline 31211 & Lakes Creek & 3530 & 1161.8 & 942.6 & 1440.9 & 410 & 333 & 509 \\
\hline
\end{tabular}




\begin{tabular}{|c|c|c|c|c|c|c|c|c|}
\hline \multirow[b]{2}{*}{$\begin{array}{l}\text { SA2_5DIGIT } \\
\text { CODE_2016 }\end{array}$} & \multirow[b]{2}{*}{ SA2_name } & \multicolumn{7}{|c|}{ Unit-level SAEs } \\
\hline & & $\begin{array}{r}\text { Unit-level_Probit_ } \\
\text { totalpopulation }\end{array}$ & $\begin{array}{r}\text { Unit-level_ } \\
\text { probit_ } \\
\text { RATE }\end{array}$ & $\begin{array}{r}\text { Unit-level_ } \\
\text { probit_ } \\
\text { RATE_ } \\
\text { LowerCl }\end{array}$ & $\begin{array}{r}\text { Unit-level_ } \\
\text { probit_ } \\
\text { RATE_ } \\
\text { UpperCl }\end{array}$ & $\begin{array}{r}\text { Unit-level_ } \\
\text { probit_ } \\
\text { number }\end{array}$ & $\begin{array}{c}\text { Unit-level_ } \\
\text { probit_ } \\
\text { number_- } \\
\text { LowerCl }\end{array}$ & $\begin{array}{r}\text { Unit-level_ } \\
\text { probit_ } \\
\text { number_ } \\
\text { UpperCl }\end{array}$ \\
\hline 31212 & Mount Morgan & 2322 & 1103.0 & 877.2 & 1358.0 & 256 & 204 & 315 \\
\hline 31213 & Norman Gardens & 7384 & 882.8 & 715.6 & 1104.7 & 652 & 528 & 816 \\
\hline 31214 & Park Avenue & 3870 & 1197.5 & 973.0 & 1481.9 & 463 & 377 & 574 \\
\hline 31215 & Parkhurst - Kawana & 4962 & 1216.1 & 985.9 & 1515.6 & 603 & 489 & 752 \\
\hline 31216 & Rockhampton - West & 4502 & 985.5 & 802.8 & 1220.0 & 444 & 361 & 549 \\
\hline 31217 & Rockhampton City & 2570 & 1483.3 & 1204.0 & 1827.2 & 381 & 309 & 470 \\
\hline 31218 & Rockhampton Region - East & 2551 & 326.6 & 267.2 & 409.5 & 83 & 68 & 104 \\
\hline 31219 & Rockhampton Region - North & 3151 & 372.9 & 305.4 & 468.0 & 117 & 96 & 147 \\
\hline 31220 & Rockhampton Region - West & 2144 & 310.1 & 255.7 & 391.7 & 66 & 55 & 84 \\
\hline 31222 & The Range - Allenstown & 6086 & 971.1 & 793.6 & 1201.1 & 591 & 483 & 731 \\
\hline 31223 & Yeppoon & 13161 & 958.7 & 782.9 & 1194.4 & 1262 & 1030 & 1572 \\
\hline 31224 & Broadbeach Waters & 6156 & 539.7 & 443.0 & 698.2 & 332 & 273 & 430 \\
\hline 31225 & Burleigh Heads & 7139 & 950.6 & 784.7 & 1198.5 & 679 & 560 & 856 \\
\hline 31226 & Burleigh Waters & 10955 & 578.6 & 475.1 & 738.2 & 634 & 521 & 809 \\
\hline 31227 & Mermaid Beach - Broadbeach & 10153 & 1356.8 & 1121.1 & 1717.3 & 1378 & 1138 & 1744 \\
\hline 31228 & Mermaid Waters & 9634 & 863.6 & 708.4 & 1092.3 & 832 & 682 & 1052 \\
\hline 31229 & Miami & 5548 & 1103.2 & 908.3 & 1386.3 & 612 & 504 & 769 \\
\hline 31230 & Coolangatta & 5038 & 1486.2 & 1219.7 & 1842.0 & 749 & 614 & 928 \\
\hline 31231 & Currumbin - Tugun & 8943 & 1038.7 & 855.0 & 1298.5 & 929 & 765 & 1161 \\
\hline 31232 & Currumbin Waters & 7014 & 710.9 & 579.9 & 891.1 & 499 & 407 & 625 \\
\hline 31233 & Elanora & 9348 & 551.9 & 448.8 & 701.7 & 516 & 420 & 656 \\
\hline 31234 & Palm Beach & 11409 & 1239.2 & 1020.4 & 1540.8 & 1414 & 1164 & 1758 \\
\hline 31235 & Arundel & 8087 & 836.6 & 683.7 & 1066.0 & 677 & 553 & 862 \\
\hline 31236 & Biggera Waters & 7041 & 1536.9 & 1261.5 & 1927.9 & 1082 & 888 & 1357 \\
\hline 31237 & Coombabah & 8361 & 1120.6 & 916.2 & 1403.2 & 937 & 766 & 1173 \\
\hline 31238 & Labrador & 14970 & 1699.7 & 1392.4 & 2109.0 & 2544 & 2084 & 3157 \\
\hline 31239 & Paradise Point - Hollywell & 7660 & 749.7 & 617.3 & 948.4 & 574 & 473 & 726 \\
\hline 31240 & Runaway Bay & 7530 & 816.7 & 670.1 & 1030.1 & 615 & 505 & 776 \\
\hline 31241 & Guanaba - Springbrook & 3336 & 449.8 & 368.5 & 567.1 & 150 & 123 & 189 \\
\hline 31242 & Tamborine - Canungra & 11095 & 441.9 & 362.4 & 555.6 & 490 & 402 & 616 \\
\hline 31243 & Currumbin Valley - Tallebudgera & 5463 & 257.4 & 209.7 & 330.9 & 141 & 115 & 181 \\
\hline 31244 & Mudgeeraba - Bonogin & 13382 & 536.2 & 439.2 & 682.8 & 717 & 588 & 914 \\
\hline 31245 & Reedy Creek - Andrews & 5746 & 589.3 & 483.1 & 753.7 & 339 & 278 & 433 \\
\hline 31246 & Carrara & 9661 & 799.1 & 656.1 & 1005.8 & 772 & 634 & 972 \\
\hline 31247 & Highland Park & 6418 & 600.5 & 491.0 & 758.6 & 385 & 315 & 487 \\
\hline 31248 & Nerang - Mount Nathan & 15841 & 1053.9 & 859.7 & 1313.6 & 1670 & 1362 & 2081 \\
\hline 31249 & Pacific Pines - Gaven & 13153 & 795.9 & 650.1 & 1027.2 & 1047 & 855 & 1351 \\
\hline 31250 & Worongary - Tallai & 6106 & 247.5 & 200.5 & 319.7 & 151 & 122 & 195 \\
\hline 31251 & Coomera & 9044 & 1336.2 & 1094.9 & 1715.8 & 1208 & 990 & 1552 \\
\hline 31252 & Helensvale & 13105 & 529.9 & 432.6 & 678.4 & 694 & 567 & 889 \\
\hline 31253 & Hope Island & 9089 & 595.5 & 491.6 & 767.8 & 541 & 447 & 698 \\
\hline 31254 & Jacobs Well - Alberton & 2835 & 618.0 & 505.6 & 785.5 & 175 & 143 & 223 \\
\hline 31255 & Ormeau - Yatala & 13830 & 644.2 & 526.5 & 834.4 & 891 & 728 & 1154 \\
\hline 31256 & Oxenford - Maudsland & 11704 & 644.0 & 527.1 & 821.3 & 754 & 617 & 961 \\
\hline 31257 & Pimpama & 6241 & 1497.8 & 1226.5 & 1919.9 & 935 & 765 & 1198 \\
\hline 31258 & Upper Coomera - Willow Vale & 21739 & 917.7 & 748.2 & 1186.4 & 1995 & 1626 & 2579 \\
\hline 31259 & Clear Island Waters & 3418 & 574.2 & 472.1 & 732.6 & 196 & 161 & 250 \\
\hline 31260 & Merrimac & 5528 & 1159.2 & 953.8 & 1457.1 & 641 & 527 & 805 \\
\hline 31261 & Robina & 18384 & 792.6 & 650.8 & 1019.6 & 1457 & 1196 & 1874 \\
\hline 31262 & Varsity Lakes & 11645 & 1271.8 & 1038.4 & 1616.4 & 1481 & 1209 & 1882 \\
\hline 31263 & Ashmore & 9433 & 766.9 & 625.6 & 971.8 & 723 & 590 & 917 \\
\hline 31264 & Molendinar & 5002 & 1033.0 & 841.1 & 1313.1 & 517 & 421 & 657 \\
\hline 31265 & Parkwood & 6900 & 778.7 & 631.2 & 999.6 & 537 & 436 & 690 \\
\hline 31267 & Benowa & 6779 & 574.4 & 472.1 & 732.0 & 389 & 320 & 496 \\
\hline 31268 & Bundall & 3514 & 649.3 & 533.8 & 830.1 & 228 & 188 & 292 \\
\hline 31269 & Main Beach & 3367 & 933.7 & 772.5 & 1181.6 & 314 & 260 & 398 \\
\hline 31270 & Surfers Paradise & 20557 & 1563.7 & 1283.8 & 1973.7 & 3215 & 2639 & 4057 \\
\hline
\end{tabular}




\begin{tabular}{|c|c|c|c|c|c|c|c|c|}
\hline \multirow[b]{2}{*}{$\begin{array}{l}\text { SA2_5DIGIT } \\
\text { CODE_2016 }\end{array}$} & \multirow[b]{2}{*}{ SA2_name } & \multicolumn{7}{|c|}{ Unit-level SAEs } \\
\hline & & $\begin{array}{r}\text { Unit-level_Probit_ } \\
\text { totalpopulation }\end{array}$ & $\begin{array}{r}\text { Unit-level_ } \\
\text { probit_ } \\
\text { RATE }\end{array}$ & $\begin{array}{r}\text { Unit-level_ } \\
\text { probit_ } \\
\text { RATE_- } \\
\text { LowerCl }\end{array}$ & $\begin{array}{c}\text { Unit-level_ } \\
\text { probit_ } \\
\text { RATE_ } \\
\text { UpperCl }\end{array}$ & $\begin{array}{r}\text { Unit-level_ } \\
\text { probit_ } \\
\text { number }\end{array}$ & $\begin{array}{r}\text { Unit-level_ } \\
\text { probit_ } \\
\text { number_ } \\
\text { LowerCl }\end{array}$ & $\begin{array}{c}\text { Unit-level_ } \\
\text { probit_ } \\
\text { number } \\
\text { UpperCl }\end{array}$ \\
\hline 31271 & Darra - Sumner & 3805 & 1059.6 & 860.9 & 1358.6 & 403 & 328 & 517 \\
\hline 31272 & Durack & 6136 & 1039.9 & 843.5 & 1308.8 & 638 & 518 & 803 \\
\hline 31273 & Forest Lake - Doolandella & 20707 & 709.0 & 578.1 & 913.3 & 1468 & 1197 & 1891 \\
\hline 31274 & Inala - Richlands & 13246 & 2004.9 & 1617.1 & 2496.0 & 2656 & 2142 & 3306 \\
\hline 31275 & Oxley (QId) & 5901 & 693.6 & 568.5 & 881.6 & 409 & 335 & 520 \\
\hline 31276 & Wacol & 5026 & 867.5 & 695.6 & 1082.9 & 436 & 350 & 544 \\
\hline 31277 & Boonah & 9166 & 614.3 & 500.1 & 765.8 & 563 & 458 & 702 \\
\hline 31278 & Esk & 4036 & 857.0 & 696.5 & 1055.7 & 346 & 281 & 426 \\
\hline 31280 & Lockyer Valley - East & 15104 & 771.5 & 621.6 & 968.0 & 1165 & 939 & 1462 \\
\hline 31281 & Lowood & 10327 & 914.3 & 740.7 & 1137.9 & 944 & 765 & 1175 \\
\hline 31282 & Rosewood & 9090 & 633.2 & 513.8 & 793.3 & 576 & 467 & 721 \\
\hline 31283 & Brassall & 8020 & 1442.8 & 1172.5 & 1803.8 & 1157 & 940 & 1447 \\
\hline 31284 & Bundamba & 6827 & 1265.9 & 1025.7 & 1589.8 & 864 & 700 & 1085 \\
\hline 31285 & Churchill - Yamanto & 4912 & 887.5 & 721.6 & 1128.9 & 436 & 354 & 555 \\
\hline 31286 & Ipswich - Central & 5073 & 1344.5 & 1090.1 & 1666.5 & 682 & 553 & 845 \\
\hline 31287 & Ipswich - East & 13618 & 1443.0 & 1171.6 & 1788.6 & 1965 & 1595 & 2436 \\
\hline 31288 & Ipswich - North & 3421 & 472.2 & 383.3 & 602.7 & 162 & 131 & 206 \\
\hline 31289 & Karalee - Barellan Point & 4026 & 201.4 & 166.9 & 258.6 & 81 & 67 & 104 \\
\hline 31290 & Karana Downs & 4428 & 267.0 & 218.5 & 344.2 & 118 & 97 & 152 \\
\hline 31291 & Leichhardt - One Mile & 5466 & 1929.2 & 1559.4 & 2390.3 & 1054 & 852 & 1307 \\
\hline 31292 & North Ipswich - Tivoli & 4909 & 1078.7 & 873.5 & 1343.4 & 530 & 429 & 659 \\
\hline 31293 & Raceview & 11013 & 1120.5 & 908.2 & 1412.4 & 1234 & 1000 & 1555 \\
\hline 31294 & Ripley & 3374 & 476.6 & 394.1 & 610.3 & 161 & 133 & 206 \\
\hline 31295 & Riverview & 2264 & 1834.4 & 1476.2 & 2269.6 & 415 & 334 & 514 \\
\hline 31296 & Bellbird Park - Brookwater & 9722 & 824.7 & 672.7 & 1062.5 & 802 & 654 & 1033 \\
\hline 31297 & Camira - Gailes & 7044 & 708.5 & 574.7 & 889.6 & 499 & 405 & 627 \\
\hline 31299 & Collingwood Park - Redbank & 6046 & 1088.0 & 880.6 & 1382.0 & 658 & 532 & 836 \\
\hline 31300 & Goodna & 7702 & 1584.8 & 1275.7 & 2004.5 & 1221 & 983 & 1544 \\
\hline 31302 & Redbank Plains & 13040 & 1510.9 & 1223.1 & 1928.8 & 1970 & 1595 & 2515 \\
\hline 31303 & Springfield & 4759 & 782.1 & 637.1 & 1011.4 & 372 & 303 & 481 \\
\hline 31304 & Springfield Lakes & 10576 & 890.4 & 732.6 & 1160.7 & 942 & 775 & 1228 \\
\hline 31305 & Beaudesert & 10554 & 1169.9 & 947.4 & 1456.5 & 1235 & 1000 & 1537 \\
\hline 31306 & Beenleigh & 6289 & 1888.5 & 1535.2 & 2329.6 & 1188 & 965 & 1465 \\
\hline 31307 & Eagleby & 9929 & 1720.4 & 1397.5 & 2142.2 & 1708 & 1388 & 2127 \\
\hline 31308 & Edens Landing - Holmview & 5395 & 1099.5 & 891.0 & 1401.0 & 593 & 481 & 756 \\
\hline 31309 & Mount Warren Park & 4361 & 810.6 & 658.5 & 1015.6 & 354 & 287 & 443 \\
\hline 31310 & Wolffdene - Bahrs Scrub & 4551 & 563.9 & 462.7 & 726.9 & 257 & 211 & 331 \\
\hline 31311 & Boronia Heights - Park Ridge & 9340 & 968.9 & 783.6 & 1220.6 & 905 & 732 & 1140 \\
\hline 31312 & Browns Plains & 5441 & 1193.3 & 971.0 & 1512.6 & 649 & 528 & 823 \\
\hline 31313 & Chambers Flat - Logan Reserve & 3855 & 645.3 & 524.8 & 826.5 & 249 & 202 & 319 \\
\hline 31314 & Crestmead & 8256 & 1230.5 & 992.2 & 1564.3 & 1016 & 819 & 1291 \\
\hline 31316 & Hillcrest & 6083 & 733.4 & 596.3 & 937.4 & 446 & 363 & 570 \\
\hline 31317 & Marsden & 9861 & 1421.5 & 1147.4 & 1806.7 & 1402 & 1131 & 1782 \\
\hline 31318 & Munruben - Park Ridge South & 3570 & 247.2 & 195.9 & 326.6 & 88 & 70 & 117 \\
\hline 31319 & Regents Park - Heritage Park & 11787 & 623.0 & 505.4 & 802.3 & 734 & 596 & 946 \\
\hline 31320 & Greenbank & 9369 & 255.9 & 206.3 & 331.4 & 240 & 193 & 310 \\
\hline 31321 & Jimboomba & 18367 & 450.2 & 366.2 & 577.1 & 827 & 673 & 1060 \\
\hline 31322 & Logan Village & 5304 & 279.2 & 229.5 & 352.8 & 148 & 122 & 187 \\
\hline 31323 & Bethania - Waterford & 8280 & 993.4 & 808.0 & 1260.3 & 823 & 669 & 1044 \\
\hline 31324 & Cornubia - Carbrook & 6497 & 304.4 & 247.5 & 392.0 & 198 & 161 & 255 \\
\hline 31325 & Loganholme - Tanah Merah & 8276 & 662.4 & 541.3 & 841.7 & 548 & 448 & 697 \\
\hline 31326 & Loganlea & 7760 & 1540.9 & 1237.8 & 1959.1 & 1196 & 961 & 1520 \\
\hline 31327 & Shailer Park & 8994 & 432.6 & 354.3 & 555.6 & 389 & 319 & 500 \\
\hline 31328 & Waterford West & 5431 & 1361.9 & 1101.5 & 1702.6 & 740 & 598 & 925 \\
\hline 31329 & Daisy Hill & 4970 & 617.4 & 503.6 & 784.8 & 307 & 250 & 390 \\
\hline 31330 & Kingston (Qld.) & 7611 & 1662.3 & 1333.8 & 2094.7 & 1265 & 1015 & 1594 \\
\hline 31331 & Logan Central & 4494 & 2110.3 & 1695.9 & 2650.4 & 948 & 762 & 1191 \\
\hline
\end{tabular}




\begin{tabular}{|c|c|c|c|c|c|c|c|c|}
\hline \multirow[b]{2}{*}{$\begin{array}{l}\text { SA2_5DIGIT } \\
\text { CODE_2016 }\end{array}$} & \multirow[b]{2}{*}{ SA2_name } & \multicolumn{7}{|c|}{ Unit-level SAES } \\
\hline & & $\begin{array}{r}\text { Unit-level_Probit_ } \\
\text { totalpopulation }\end{array}$ & $\begin{array}{r}\text { Unit-level_ } \\
\text { probit_ } \\
\text { RATE }\end{array}$ & $\begin{array}{r}\text { Unit-level_ } \\
\text { probit_ } \\
\text { RATE_ } \\
\text { LowerCl }\end{array}$ & $\begin{array}{r}\text { Unit-level_ } \\
\text { probit_ } \\
\text { RATE_ } \\
\text { UpperCl }\end{array}$ & $\begin{array}{r}\text { Unit-level_ } \\
\text { probit_ } \\
\text { number }\end{array}$ & $\begin{array}{c}\text { Unit-level_ } \\
\text { probit_ } \\
\text { number_- } \\
\text { LowerCl }\end{array}$ & $\begin{array}{r}\text { Unit-level_ } \\
\text { probit_ } \\
\text { number_ } \\
\text { UpperCl }\end{array}$ \\
\hline 31332 & Rochedale South - Priestdale & 11692 & 636.2 & 519.8 & 806.2 & 744 & 608 & 943 \\
\hline 31333 & Slacks Creek & 7737 & 1452.5 & 1171.7 & 1822.6 & 1124 & 907 & 1410 \\
\hline 31334 & Springwood & 7246 & 737.2 & 601.8 & 945.2 & 534 & 436 & 685 \\
\hline 31335 & Underwood & 4690 & 731.1 & 597.8 & 940.8 & 343 & 280 & 441 \\
\hline 31336 & Woodridge & 9155 & 2099.3 & 1691.6 & 2642.8 & 1922 & 1549 & 2420 \\
\hline 31337 & Bowen & 6877 & 1318.0 & 1068.1 & 1647.1 & 906 & 735 & 1133 \\
\hline 31338 & Broadsound - Nebo & 6066 & 724.9 & 604.0 & 947.6 & 440 & 366 & 575 \\
\hline 31339 & Clermont & 2575 & 671.0 & 557.5 & 859.4 & 173 & 144 & 221 \\
\hline 31340 & Collinsville & 2576 & 588.6 & 484.2 & 738.5 & 152 & 125 & 190 \\
\hline 31341 & Moranbah & 5758 & 963.2 & 802.2 & 1271.8 & 555 & 462 & 732 \\
\hline 31342 & Andergrove - Beaconsfield & 10519 & 1089.5 & 886.5 & 1355.7 & 1146 & 932 & 1426 \\
\hline 31343 & East Mackay & 2664 & 943.8 & 773.9 & 1183.4 & 251 & 206 & 315 \\
\hline 31344 & Eimeo - Rural View & 8103 & 1025.7 & 835.3 & 1303.2 & 831 & 677 & 1056 \\
\hline 31346 & Mackay & 2747 & 2053.4 & 1688.5 & 2515.7 & 564 & 464 & 691 \\
\hline 31348 & Mount Pleasant - Glenella & 7704 & 541.9 & 445.3 & 690.2 & 417 & 343 & 532 \\
\hline 31349 & North Mackay & 4557 & 1347.2 & 1092.4 & 1677.0 & 614 & 498 & 764 \\
\hline 31350 & Ooralea - Bakers Creek & 3615 & 534.4 & 438.6 & 694.9 & 193 & 159 & 251 \\
\hline 31351 & Pioneer Valley & 5589 & 534.9 & 437.6 & 675.9 & 299 & 245 & 378 \\
\hline 31352 & Sarina & 8381 & 693.5 & 560.0 & 876.1 & 581 & 469 & 734 \\
\hline 31353 & Seaforth - Calen & 5979 & 435.1 & 356.4 & 538.8 & 260 & 213 & 322 \\
\hline 31354 & Shoal Point - Bucasia & 3801 & 896.7 & 734.0 & 1122.3 & 341 & 279 & 427 \\
\hline 31355 & Slade Point & 2412 & 1168.2 & 942.4 & 1444.8 & 282 & 227 & 348 \\
\hline 31356 & South Mackay & 5081 & 1254.1 & 1024.8 & 1549.7 & 637 & 521 & 787 \\
\hline 31357 & Walkerston - Eton & 6087 & 471.2 & 384.7 & 597.5 & 287 & 234 & 364 \\
\hline 31358 & West Mackay & 4568 & 1018.2 & 836.6 & 1260.7 & 465 & 382 & 576 \\
\hline 31359 & Airlie - Whitsundays & 9750 & 846.9 & 699.7 & 1067.4 & 826 & 682 & 1041 \\
\hline 31361 & Proserpine & 6118 & 730.7 & 593.5 & 911.7 & 447 & 363 & 558 \\
\hline 31362 & Beachmere - Sandstone Point & 11637 & 938.2 & 762.1 & 1172.1 & 1092 & 887 & 1364 \\
\hline 31363 & Bribie Island & 15211 & 1084.9 & 882.0 & 1340.9 & 1650 & 1342 & 2040 \\
\hline 31364 & Burpengary - East & 3045 & 197.9 & 160.0 & 256.8 & 60 & 49 & 78 \\
\hline 31365 & Caboolture & 20098 & 1603.6 & 1300.7 & 1994.6 & 3223 & 2614 & 4009 \\
\hline 31366 & Caboolture - South & 14526 & 1737.4 & 1405.7 & 2180.3 & 2524 & 2042 & 3167 \\
\hline 31367 & Elimbah & 3037 & 208.6 & 168.7 & 275.1 & 63 & 51 & 84 \\
\hline 31368 & Morayfield - East & 6157 & 1323.3 & 1071.1 & 1670.2 & 815 & 660 & 1028 \\
\hline 31369 & Wamuran & 3011 & 294.1 & 240.0 & 380.7 & 89 & 72 & 115 \\
\hline 31370 & Kilcoy & 4088 & 759.9 & 618.4 & 958.0 & 311 & 253 & 392 \\
\hline 31371 & Woodford - D'Aguilar & 6273 & 489.2 & 396.1 & 614.8 & 307 & 249 & 386 \\
\hline 31372 & Burpengary & 10557 & 782.4 & 636.6 & 979.0 & 826 & 672 & 1034 \\
\hline 31373 & Deception Bay & 16927 & 1267.1 & 1022.6 & 1586.2 & 2145 & 1731 & 2685 \\
\hline 31374 & Morayfield & 3808 & 218.5 & 173.5 & 291.3 & 83 & 66 & 111 \\
\hline 31375 & Narangba & 12973 & 579.0 & 473.3 & 740.8 & 751 & 614 & 961 \\
\hline 31376 & Upper Caboolture & 2309 & 201.7 & 162.3 & 265.6 & 47 & 37 & 61 \\
\hline 31377 & Clontarf & 6502 & 1101.1 & 898.8 & 1365.2 & 716 & 584 & 888 \\
\hline 31378 & Margate - Woody Point & 9290 & 1608.9 & 1311.6 & 1991.1 & 1495 & 1218 & 1850 \\
\hline 31379 & Redcliffe & 8345 & 1641.8 & 1340.6 & 2029.3 & 1370 & 1119 & 1693 \\
\hline 31380 & Rothwell - Kippa-Ring & 13244 & 1205.2 & 978.3 & 1509.1 & 1596 & 1296 & 1999 \\
\hline 31382 & Albany Creek & 12046 & 370.4 & 304.1 & 472.5 & 446 & 366 & 569 \\
\hline 31383 & Cashmere & 13561 & 431.3 & 355.7 & 560.3 & 585 & 482 & 760 \\
\hline 31384 & Dayboro & 6297 & 223.2 & 183.3 & 283.7 & 141 & 115 & 179 \\
\hline 31385 & Eatons Hill & 5776 & 188.6 & 155.2 & 250.7 & 109 & 90 & 145 \\
\hline 31386 & The Hills District & 17422 & 370.7 & 305.3 & 474.1 & 646 & 532 & 826 \\
\hline 31387 & Samford Valley & 8761 & 173.5 & 143.0 & 221.6 & 152 & 125 & 194 \\
\hline 31388 & Dakabin - Kallangur & 17738 & 1183.6 & 965.8 & 1485.2 & 2099 & 1713 & 2634 \\
\hline 31389 & Murrumba Downs - Griffin & 12663 & 934.0 & 767.7 & 1194.5 & 1183 & 972 & 1513 \\
\hline 31390 & North Lakes - Mango Hill & 20921 & 893.5 & 733.9 & 1153.8 & 1869 & 1535 & 2414 \\
\hline 31391 & Bray Park & 7636 & 744.9 & 605.5 & 941.9 & 569 & 462 & 719 \\
\hline 31392 & Lawnton & 4650 & 1124.0 & 919.2 & 1397.5 & 523 & 427 & 650 \\
\hline
\end{tabular}




\begin{tabular}{|c|c|c|c|c|c|c|c|c|}
\hline \multirow[b]{2}{*}{$\begin{array}{l}\text { SA2_5DIGIT } \\
\text { CODE_2016 }\end{array}$} & \multirow[b]{2}{*}{ SA2_name } & \multicolumn{7}{|c|}{ Unit-level SAEs } \\
\hline & & $\begin{array}{r}\text { Unit-level_Probit_ } \\
\text { totalpopulation }\end{array}$ & $\begin{array}{r}\text { Unit-level_ } \\
\text { probit_ } \\
\text { RATE }\end{array}$ & $\begin{array}{r}\text { Unit-level_ } \\
\text { probit_ } \\
\text { RATE_ } \\
\text { LowerCl }\end{array}$ & $\begin{array}{r}\text { Unit-level_ } \\
\text { probit_ } \\
\text { RATE_ } \\
\text { UpperCl }\end{array}$ & $\begin{array}{r}\text { Unit-level_ } \\
\text { probit_ } \\
\text { number }\end{array}$ & $\begin{array}{c}\text { Unit-level_ } \\
\text { probit_ } \\
\text { number_ } \\
\text { LowerCl }\end{array}$ & $\begin{array}{r}\text { Unit-level_ } \\
\text { probit_ } \\
\text { number_ } \\
\text { UpperCl }\end{array}$ \\
\hline 31393 & Petrie & 6421 & 717.0 & 585.1 & 901.8 & 460 & 376 & 579 \\
\hline 31394 & Strathpine - Brendale & 9416 & 1013.6 & 828.9 & 1274.7 & 954 & 781 & 1200 \\
\hline 31395 & Aurukun & 832 & 5040.0 & 3799.0 & 6347.7 & 419 & 316 & 528 \\
\hline 31396 & Cape York & 5300 & 2509.0 & 1904.1 & 3206.2 & 1330 & 1009 & 1699 \\
\hline 31397 & Croydon - Etheridge & 791 & 542.6 & 438.6 & 696.2 & 43 & 35 & 55 \\
\hline 31398 & Kowanyama - Pormpuraaw & 1184 & 4749.9 & 3585.3 & 6014.6 & 562 & 425 & 712 \\
\hline 31399 & Northern Peninsula & 1634 & 4210.0 & 3145.4 & 5412.6 & 688 & 514 & 884 \\
\hline 31400 & Tablelands & 4813 & 547.0 & 446.3 & 678.7 & 263 & 215 & 327 \\
\hline 31401 & Torres & 2331 & 2017.3 & 1487.9 & 2726.2 & 470 & 347 & 635 \\
\hline 31402 & Torres Strait Islands & 2640 & 4337.0 & 3205.7 & 5615.0 & 1145 & 846 & 1482 \\
\hline 31403 & Weipa & 2635 & 725.4 & 577.3 & 1003.5 & 191 & 152 & 264 \\
\hline 31404 & Carpentaria & 3183 & 3088.0 & 2296.4 & 4008.7 & 983 & 731 & 1276 \\
\hline 31405 & Mount Isa & 12892 & 981.1 & 782.1 & 1260.1 & 1265 & 1008 & 1625 \\
\hline 31406 & Mount Isa Region & 2485 & 1028.7 & 806.7 & 1327.8 & 256 & 200 & 330 \\
\hline 31407 & Northern Highlands & 2297 & 761.0 & 627.2 & 956.8 & 175 & 144 & 220 \\
\hline 31408 & Barcaldine - Blackall & 3408 & 799.7 & 657.0 & 999.6 & 273 & 224 & 341 \\
\hline 31409 & Charleville & 3085 & 877.6 & 715.0 & 1087.9 & 271 & 221 & 336 \\
\hline 31410 & Far Central West & 1578 & 1077.4 & 866.5 & 1349.8 & 170 & 137 & 213 \\
\hline 31411 & Far South West & 2011 & 1078.2 & 856.4 & 1339.5 & 217 & 172 & 269 \\
\hline 31412 & Longreach & 2665 & 904.6 & 742.3 & 1140.3 & 241 & 198 & 304 \\
\hline 31413 & Buderim - North & 12973 & 730.6 & 597.5 & 914.6 & 948 & 775 & 1186 \\
\hline 31414 & Buderim - South & 12359 & 732.3 & 600.0 & 927.8 & 905 & 742 & 1147 \\
\hline 31415 & Mountain Creek & 8106 & 990.5 & 813.6 & 1262.8 & 803 & 660 & 1024 \\
\hline 31416 & Sippy Downs & 7755 & 1178.0 & 957.5 & 1493.6 & 914 & 743 & 1158 \\
\hline 31417 & Aroona - Currimundi & 7576 & 773.9 & 633.2 & 971.3 & 586 & 480 & 736 \\
\hline 31418 & Buddina - Minyama & 5013 & 868.5 & 711.7 & 1095.0 & 435 & 357 & 549 \\
\hline 31419 & Caloundra - Kings Beach & 5626 & 1604.4 & 1312.8 & 1996.1 & 903 & 739 & 1123 \\
\hline 31420 & Caloundra-West & 14908 & 815.4 & 664.5 & 1039.0 & 1216 & 991 & 1549 \\
\hline 31421 & Golden Beach - Pelican Waters & 9464 & 782.8 & 640.1 & 982.2 & 741 & 606 & 930 \\
\hline 31422 & Moffat Beach - Battery Hill & 6128 & 1035.2 & 849.4 & 1289.0 & 634 & 520 & 790 \\
\hline 31423 & Parrearra - Warana & 7363 & 906.5 & 743.6 & 1149.9 & 667 & 547 & 847 \\
\hline 31424 & Wurtulla - Birtinya & 5989 & 1016.3 & 835.8 & 1281.9 & 609 & 501 & 768 \\
\hline 31425 & Coolum Beach & 11053 & 973.1 & 797.5 & 1226.0 & 1076 & 881 & 1355 \\
\hline 31426 & Marcoola - Mudjimba & 8440 & 998.5 & 818.2 & 1265.1 & 843 & 691 & 1068 \\
\hline 31427 & Maroochydore - Kuluin & 15780 & 1385.0 & 1138.0 & 1727.1 & 2186 & 1796 & 2725 \\
\hline 31428 & Mooloolaba - Alexandra Headland & 9647 & 1192.8 & 982.4 & 1492.8 & 1151 & 948 & 1440 \\
\hline 31434 & Noosa Heads & 3635 & 770.1 & 633.2 & 972.8 & 280 & 230 & 354 \\
\hline 31435 & Noosaville & 7072 & 973.6 & 798.8 & 1220.2 & 689 & 565 & 863 \\
\hline 31437 & Sunshine Beach & 5009 & 908.0 & 750.5 & 1137.1 & 455 & 376 & 570 \\
\hline 31438 & Tewantin & 8203 & 991.7 & 808.8 & 1236.5 & 813 & 663 & 1014 \\
\hline 31439 & Beerwah & 6184 & 852.0 & 695.2 & 1067.0 & 527 & 430 & 660 \\
\hline 31440 & Caloundra Hinterland & 6849 & 703.8 & 574.9 & 874.0 & 482 & 394 & 599 \\
\hline 31441 & Glass House Mountains & 4513 & 458.4 & 373.9 & 581.2 & 207 & 169 & 262 \\
\hline 31442 & Landsborough & 7640 & 585.0 & 477.2 & 736.3 & 447 & 365 & 563 \\
\hline 31443 & Maroochy Hinterland & 5012 & 524.3 & 428.8 & 652.0 & 263 & 215 & 327 \\
\hline 31444 & Palmwoods & 7994 & 504.6 & 411.0 & 638.8 & 403 & 329 & 511 \\
\hline 31445 & Cambooya - Wyreema & 4843 & 372.8 & 306.0 & 470.4 & 181 & 148 & 228 \\
\hline 31446 & Darling Heights & 10398 & 1388.3 & 1127.6 & 1748.6 & 1444 & 1172 & 1818 \\
\hline 31447 & Drayton - Harristown & 7867 & 1443.7 & 1172.7 & 1788.3 & 1136 & 923 & 1407 \\
\hline 31448 & Gatton & 5862 & 1372.8 & 1116.6 & 1728.8 & 805 & 655 & 1013 \\
\hline 31449 & Gowrie (QId) & 4454 & 310.4 & 250.4 & 397.6 & 138 & 112 & 177 \\
\hline 31450 & Highfields & 9429 & 326.0 & 268.1 & 418.1 & 307 & 253 & 394 \\
\hline 31451 & Lockyer Valley - West & 8457 & 473.2 & 385.9 & 592.8 & 400 & 326 & 501 \\
\hline 31452 & Middle Ridge & 5275 & 397.9 & 327.3 & 513.5 & 210 & 173 & 271 \\
\hline 31453 & Newtown (QId) & 7339 & 1610.5 & 1317.3 & 1980.9 & 1182 & 967 & 1454 \\
\hline 31454 & North Toowoomba - Harlaxton & 4436 & 1503.6 & 1226.1 & 1859.3 & 667 & 544 & 825 \\
\hline 31455 & Rangeville & 6357 & 722.7 & 591.6 & 911.6 & 459 & 376 & 580 \\
\hline
\end{tabular}




\begin{tabular}{|c|c|c|c|c|c|c|c|c|}
\hline \multirow[b]{2}{*}{$\begin{array}{l}\text { SA2_5DIGIT } \\
\text { CODE_2016 }\end{array}$} & \multirow[b]{2}{*}{ SA2_name } & \multicolumn{7}{|c|}{ Unit-level SAEs } \\
\hline & & $\begin{array}{l}\text { Unit-level_Probit_ } \\
\text { totalpopulation }\end{array}$ & $\begin{array}{r}\text { Unit-level_ } \\
\text { probit_ } \\
\text { RATE }\end{array}$ & $\begin{array}{r}\text { Unit-level_ } \\
\text { probit_ } \\
\text { RATE_ } \\
\text { LowerCl }\end{array}$ & $\begin{array}{r}\text { Unit-level_ } \\
\text { probit_ } \\
\text { RATE_ } \\
\text { UpperCl }\end{array}$ & $\begin{array}{r}\text { Unit-level_ } \\
\text { probit_ } \\
\text { number }\end{array}$ & $\begin{array}{r}\text { Unit-level_ } \\
\text { probit_ } \\
\text { number_ } \\
\text { LowerCl }\end{array}$ & $\begin{array}{r}\text { Unit-level__ } \\
\text { probit_ } \\
\text { number_- } \\
\text { UpperCl }\end{array}$ \\
\hline 31456 & Toowoomba - Central & 10471 & 1421.5 & 1163.0 & 1757.7 & 1488 & 1218 & 1841 \\
\hline 31457 & Toowoomba - East & 7353 & 923.8 & 759.5 & 1149.6 & 679 & 558 & 845 \\
\hline 31458 & Toowoomba - West & 9481 & 642.9 & 526.2 & 817.9 & 610 & 499 & 775 \\
\hline 31459 & Wilsonton & 10178 & 1371.1 & 1111.7 & 1704.1 & 1395 & 1131 & 1734 \\
\hline 31460 & Ayr & 7094 & 1032.6 & 838.5 & 1271.7 & 733 & 595 & 902 \\
\hline 31461 & Burdekin & 6116 & 664.4 & 544.3 & 830.4 & 406 & 333 & 508 \\
\hline 31462 & Charters Towers & 5896 & 1156.3 & 931.7 & 1429.5 & 682 & 549 & 843 \\
\hline 31463 & Dalrymple & 2692 & 442.3 & 364.8 & 557.0 & 119 & 98 & 150 \\
\hline 31464 & Ingham & 3509 & 1049.0 & 848.5 & 1295.4 & 368 & 298 & 455 \\
\hline 31465 & Ingham Region & 5145 & 622.4 & 506.0 & 773.3 & 320 & 260 & 398 \\
\hline 31466 & Palm Island & 1561 & 4622.4 & 3364.0 & 6048.1 & 722 & 525 & 944 \\
\hline 31467 & Aitkenvale & 3626 & 1551.0 & 1255.5 & 1938.6 & 562 & 455 & 703 \\
\hline 31468 & Annandale & 7756 & 458.6 & 373.8 & 595.8 & 356 & 290 & 462 \\
\hline 31469 & Belgian Gardens - Pallarenda & 2529 & 1010.3 & 828.9 & 1242.8 & 255 & 210 & 314 \\
\hline 31470 & Bohle Plains & 5042 & 533.4 & 440.1 & 696.2 & 269 & 222 & 351 \\
\hline 31471 & Condon - Rasmussen & 7617 & 1434.8 & 1154.9 & 1786.6 & 1093 & 880 & 1361 \\
\hline 31472 & Cranbrook & 4624 & 1123.3 & 907.0 & 1402.2 & 519 & 419 & 648 \\
\hline 31473 & Deeragun & 15139 & 872.0 & 710.8 & 1115.4 & 1320 & 1076 & 1689 \\
\hline 31474 & Douglas & 6143 & 1217.1 & 994.0 & 1553.0 & 748 & 611 & 954 \\
\hline 31475 & Garbutt - West End & 5074 & 1841.0 & 1506.2 & 2246.6 & 934 & 764 & 1140 \\
\hline 31476 & Gulliver - Currajong - Vincent & 5717 & 1456.8 & 1170.0 & 1814.8 & 833 & 669 & 1038 \\
\hline 31477 & Heatley & 3070 & 1445.5 & 1161.9 & 1794.3 & 444 & 357 & 551 \\
\hline 31478 & Hermit Park - Rosslea & 3985 & 1770.8 & 1452.4 & 2186.8 & 706 & 579 & 871 \\
\hline 31479 & Hyde Park - Pimlico & 3529 & 1780.6 & 1453.2 & 2189.2 & 628 & 513 & 773 \\
\hline 31480 & Kelso & 7480 & 1177.6 & 944.5 & 1464.5 & 881 & 706 & 1095 \\
\hline 31481 & Kirwan - East & 5858 & 1338.7 & 1073.7 & 1667.3 & 784 & 629 & 977 \\
\hline 31482 & Kirwan-West & 11318 & 877.8 & 710.5 & 1124.1 & 994 & 804 & 1272 \\
\hline 31483 & Magnetic Island & 1873 & 1301.8 & 1075.3 & 1577.8 & 244 & 201 & 296 \\
\hline 31484 & Mount Louisa & 6562 & 895.4 & 728.1 & 1146.5 & 588 & 478 & 752 \\
\hline 31485 & Mundingburra & 2833 & 1172.4 & 958.8 & 1443.9 & 332 & 272 & 409 \\
\hline 31486 & Northern Beaches & 4836 & 466.5 & 381.3 & 583.4 & 226 & 184 & 282 \\
\hline 31487 & Oonoonba & 4784 & 868.4 & 717.0 & 1106.3 & 415 & 343 & 529 \\
\hline 31488 & South Townsville - Railway Estate & 4153 & 1355.6 & 1111.1 & 1681.2 & 563 & 461 & 698 \\
\hline 31489 & Townsville - South & 3284 & 293.7 & 241.4 & 369.1 & 96 & 79 & 121 \\
\hline 31490 & Townsville City - North Ward & 7300 & 1323.6 & 1095.2 & 1657.9 & 966 & 799 & 1210 \\
\hline 31491 & Wulguru - Roseneath & 4930 & 867.7 & 698.7 & 1076.9 & 428 & 344 & 531 \\
\hline 31492 & Ashfield - Kepnock & 3928 & 1168.9 & 952.4 & 1442.8 & 459 & 374 & 567 \\
\hline 31493 & Bargara - Burnett Heads & 12707 & 945.4 & 768.7 & 1185.0 & 1201 & 977 & 1506 \\
\hline 31494 & Branyan - Kensington & 3406 & 558.4 & 457.6 & 698.9 & 190 & 156 & 238 \\
\hline 31495 & Bundaberg & 4836 & 2258.6 & 1838.5 & 2765.2 & 1092 & 889 & 1337 \\
\hline 31496 & Bundaberg East - Kalkie & 4046 & 1199.9 & 974.8 & 1480.1 & 485 & 394 & 599 \\
\hline 31497 & Bundaberg North - Gooburrum & 5679 & 995.4 & 807.1 & 1235.8 & 565 & 458 & 702 \\
\hline 31498 & Bundaberg Region - North & 6762 & 605.8 & 490.8 & 758.6 & 410 & 332 & 513 \\
\hline 31499 & Bundaberg Region - South & 7612 & 672.5 & 548.2 & 832.2 & 512 & 417 & 633 \\
\hline 31500 & Millbank - Avoca & 5812 & 1127.5 & 915.9 & 1398.9 & 655 & 532 & 813 \\
\hline 31501 & Svensson Heights - Norville & 4384 & 1387.6 & 1129.3 & 1701.0 & 608 & 495 & 746 \\
\hline 31502 & Walkervale - Avenell Heights & 8192 & 1402.9 & 1137.2 & 1729.4 & 1149 & 932 & 1417 \\
\hline 31503 & Gayndah - Mundubbera & 5157 & 872.9 & 711.3 & 1089.9 & 450 & 367 & 562 \\
\hline 31504 & Gin Gin & 4015 & 682.8 & 554.6 & 843.6 & 274 & 223 & 339 \\
\hline 31505 & Kingaroy & 7565 & 1365.5 & 1110.9 & 1694.5 & 1033 & 840 & 1282 \\
\hline 31506 & Kingaroy Region - North & 7068 & 1484.3 & 1164.8 & 1843.0 & 1049 & 823 & 1303 \\
\hline 31507 & Kingaroy Region - South & 2988 & 483.5 & 389.0 & 618.0 & 144 & 116 & 185 \\
\hline 31508 & Monto - Eidsvold & 2825 & 813.2 & 666.9 & 995.6 & 230 & 188 & 281 \\
\hline 31509 & Nanango & 7526 & 892.4 & 723.2 & 1096.8 & 672 & 544 & 825 \\
\hline 31511 & Cooloola & 5021 & 1182.4 & 963.0 & 1453.9 & 594 & 484 & 730 \\
\hline 31512 & Gympie - North & 10658 & 1506.4 & 1226.6 & 1852.6 & 1605 & 1307 & 1974 \\
\hline 31513 & Gympie - South & 5000 & 1121.2 & 912.6 & 1377.7 & 561 & 456 & 689 \\
\hline
\end{tabular}




\begin{tabular}{|c|c|c|c|c|c|c|c|c|}
\hline \multirow[b]{2}{*}{$\begin{array}{l}\text { SA2_5DIGIT } \\
\text { CODE_2016 }\end{array}$} & \multirow[b]{2}{*}{ SA2_name } & \multicolumn{7}{|c|}{ Unit-level SAEs } \\
\hline & & $\begin{array}{r}\text { Unit-level_Probit_ } \\
\text { totalpopulation }\end{array}$ & $\begin{array}{r}\text { Unit-level_ } \\
\text { probit_ } \\
\text { RATE }\end{array}$ & $\begin{array}{r}\text { Unit-level_ } \\
\text { probit_ } \\
\text { RATE_- } \\
\text { LowerCl }\end{array}$ & $\begin{array}{c}\text { Unit-level_ } \\
\text { probit_ } \\
\text { RATE_ } \\
\text { UpperCl }\end{array}$ & $\begin{array}{r}\text { Unit-level_ } \\
\text { probit_ } \\
\text { number }\end{array}$ & $\begin{array}{r}\text { Unit-level_ } \\
\text { probit_ } \\
\text { number_ } \\
\text { LowerCl }\end{array}$ & $\begin{array}{c}\text { Unit-level_ } \\
\text { probit_ } \\
\text { number } \\
\text { UpperCl }\end{array}$ \\
\hline 31514 & Gympie Region & 14165 & 543.4 & 440.4 & 678.8 & 770 & 624 & 962 \\
\hline 31515 & Kilkivan & 2790 & 689.0 & 563.6 & 846.9 & 192 & 157 & 236 \\
\hline 31516 & Booral - River Heads & 3496 & 634.6 & 515.1 & 789.2 & 222 & 180 & 276 \\
\hline 31517 & Craignish - Dundowran Beach & 3644 & 372.4 & 299.8 & 476.8 & 136 & 109 & 174 \\
\hline 31518 & Pialba - Eli Waters & 10884 & 1197.8 & 969.8 & 1493.8 & 1304 & 1056 & 1626 \\
\hline 31519 & Point Vernon & 4409 & 1171.1 & 948.6 & 1450.9 & 516 & 418 & 640 \\
\hline 31520 & Torquay - Scarness - Kawungan & 11869 & 1549.5 & 1260.7 & 1899.7 & 1839 & 1496 & 2255 \\
\hline 31521 & Urangan - Wondunna & 9652 & 1201.1 & 977.8 & 1485.0 & 1159 & 944 & 1433 \\
\hline 31522 & Burrum - Fraser & 7363 & 890.3 & 720.2 & 1102.3 & 656 & 530 & 812 \\
\hline 31523 & Granville & 2428 & 1160.4 & 946.0 & 1407.3 & 282 & 230 & 342 \\
\hline 31524 & Maryborough (Q|d) & 14215 & 1308.3 & 1060.5 & 1603.2 & 1860 & 1507 & 2279 \\
\hline 31525 & Maryborough Region - South & 6720 & 579.4 & 471.2 & 713.1 & 389 & 317 & 479 \\
\hline 31526 & Tinana & 4139 & 682.6 & 555.8 & 850.6 & 283 & 230 & 352 \\
\hline 31527 & Redland Islands & 7282 & 1397.9 & 1138.3 & 1699.6 & 1018 & 829 & 1238 \\
\hline 31528 & Banana & 6222 & 664.7 & 546.3 & 840.7 & 414 & 340 & 523 \\
\hline 31529 & Biloela & 4149 & 799.6 & 656.4 & 1011.4 & 332 & 272 & 420 \\
\hline 31530 & Agnes Water - Miriam Vale & 4524 & 636.2 & 519.7 & 786.7 & 288 & 235 & 356 \\
\hline 31531 & Boyne Island - Tannum Sands & 6880 & 708.0 & 580.9 & 898.8 & 487 & 400 & 618 \\
\hline 31533 & Clinton - New Auckland & 9290 & 1037.1 & 847.4 & 1311.0 & 963 & 787 & 1218 \\
\hline 31534 & Gladstone & 4579 & 1500.0 & 1226.1 & 1868.6 & 687 & 561 & 856 \\
\hline 31535 & Gladstone Hinterland & 8297 & 490.4 & 397.1 & 628.8 & 407 & 329 & 522 \\
\hline 31536 & Kin Kora - Sun Valley & 2589 & 795.7 & 651.0 & 1011.8 & 206 & 169 & 262 \\
\hline 31538 & Telina - Toolooa & 4247 & 878.5 & 718.6 & 1112.7 & 373 & 305 & 473 \\
\hline 31539 & West Gladstone & 3540 & 1261.4 & 1028.8 & 1568.8 & 447 & 364 & 555 \\
\hline 31540 & Southport - North & 12507 & 2115.2 & 1731.2 & 2644.8 & 2646 & 2165 & 3308 \\
\hline 31541 & Southport - South & 14124 & 1468.4 & 1199.9 & 1842.9 & 2074 & 1695 & 2603 \\
\hline 31542 & Scarborough - Newport - Moreton Island & 9791 & 909.9 & 742.8 & 1132.2 & 891 & 727 & 1109 \\
\hline 31543 & Peregian Beach - Marcus Beach & 2838 & 885.7 & 729.6 & 1110.1 & 251 & 207 & 315 \\
\hline 31544 & Peregian Springs & 4991 & 844.0 & 694.9 & 1083.3 & 421 & 347 & 541 \\
\hline 31545 & Bli Bli & 6290 & 570.7 & 466.3 & 716.8 & 359 & 293 & 451 \\
\hline 31546 & Diddillibah - Rosemount & 2883 & 409.6 & 333.7 & 518.6 & 118 & 96 & 150 \\
\hline 31547 & Eumundi - Yandina & 7925 & 568.7 & 463.6 & 714.8 & 451 & 367 & 566 \\
\hline 31548 & Nambour & 15156 & 1109.5 & 904.4 & 1374.9 & 1682 & 1371 & 2084 \\
\hline 31549 & Noosa Hinterland & 16600 & 511.4 & 417.9 & 641.4 & 849 & 694 & 1065 \\
\hline 41001 & Adelaide & 13549 & 1706.8 & 1389.5 & 2167.1 & 2313 & 1883 & 2936 \\
\hline 41002 & North Adelaide & 6122 & 1027.2 & 844.9 & 1306.8 & 629 & 517 & 800 \\
\hline 41003 & Adelaide Hills & 5338 & 244.3 & 201.3 & 306.0 & 130 & 107 & 163 \\
\hline 41004 & Aldgate - Stirling & 13151 & 219.0 & 180.9 & 276.6 & 288 & 238 & 364 \\
\hline 41005 & Hahndorf - Echunga & 3459 & 368.4 & 303.2 & 463.6 & 127 & 105 & 160 \\
\hline 41006 & Lobethal - Woodside & 6967 & 481.5 & 395.8 & 603.2 & 335 & 276 & 420 \\
\hline 41007 & Mount Barker & 12961 & 966.5 & 792.7 & 1201.8 & 1253 & 1027 & 1558 \\
\hline 41008 & Mount Barker Region & 4801 & 313.2 & 257.5 & 390.6 & 150 & 124 & 188 \\
\hline 41009 & Nairne & 3720 & 670.6 & 551.7 & 837.2 & 249 & 205 & 311 \\
\hline 41010 & Uraidla - Summertown & 4163 & 291.0 & 240.9 & 367.1 & 121 & 100 & 153 \\
\hline 41011 & Burnside - Wattle Park & 14584 & 570.6 & 469.9 & 721.7 & 832 & 685 & 1053 \\
\hline 41012 & Glenside - Beaumont & 7524 & 352.9 & 290.5 & 454.0 & 265 & 219 & 342 \\
\hline 41013 & Toorak Gardens & 12471 & 811.6 & 666.4 & 1022.5 & 1012 & 831 & 1275 \\
\hline 41014 & Athelstone & 7357 & 351.4 & 289.3 & 440.4 & 259 & 213 & 324 \\
\hline 41015 & Paradise - Newton & 15912 & 1005.4 & 823.7 & 1252.9 & 1600 & 1311 & 1994 \\
\hline 41016 & Rostrevor - Magill & 17267 & 886.0 & 726.7 & 1109.3 & 1530 & 1255 & 1915 \\
\hline 41017 & Norwood (SA) & 8324 & 1424.2 & 1174.0 & 1778.2 & 1186 & 977 & 1480 \\
\hline 41018 & Payneham - Felixstow & 10066 & 1199.8 & 982.8 & 1499.3 & 1208 & 989 & 1509 \\
\hline 41019 & St Peters - Marden & 10349 & 944.5 & 777.1 & 1182.6 & 977 & 804 & 1224 \\
\hline 41020 & Nailsworth - Broadview & 4726 & 994.3 & 820.5 & 1242.6 & 470 & 388 & 587 \\
\hline 41021 & Prospect & 11367 & 922.2 & 755.1 & 1166.3 & 1048 & 858 & 1326 \\
\hline 41022 & Walkerville & 6073 & 781.4 & 641.0 & 982.5 & 475 & 389 & 597 \\
\hline 41023 & Goodwood - Millswood & 13964 & 894.0 & 736.9 & 1121.3 & 1248 & 1029 & 1566 \\
\hline
\end{tabular}




\begin{tabular}{|c|c|c|c|c|c|c|c|c|}
\hline \multirow[b]{2}{*}{$\begin{array}{l}\text { SA2_5DIGIT } \\
\text { CODE_2016 }\end{array}$} & \multirow[b]{2}{*}{ SA2_name } & \multicolumn{7}{|c|}{ Unit-level SAEs } \\
\hline & & $\begin{array}{l}\text { Unit-level_Probit_ } \\
\text { totalpopulation }\end{array}$ & $\begin{array}{r}\text { Unit-level_ } \\
\text { probit_ } \\
\text { RATE }\end{array}$ & $\begin{array}{r}\text { Unit-level_ } \\
\text { probit_ } \\
\text { RATE_ } \\
\text { LowerCl }\end{array}$ & $\begin{array}{r}\text { Unit-level_ } \\
\text { probit_ } \\
\text { RATE_ } \\
\text { UpperCl }\end{array}$ & $\begin{array}{r}\text { Unit-level_ } \\
\text { probit_ } \\
\text { number }\end{array}$ & $\begin{array}{r}\text { Unit-level_ } \\
\text { probit_ } \\
\text { number_ } \\
\text { LowerCl }\end{array}$ & $\begin{array}{r}\text { Unit-level__ } \\
\text { probit_ } \\
\text { number_- } \\
\text { UpperCl }\end{array}$ \\
\hline 41024 & Unley - Parkside & 16131 & 816.6 & 671.5 & 1027.9 & 1317 & 1083 & 1658 \\
\hline 41025 & Gawler - North & 6796 & 475.4 & 391.8 & 596.0 & 323 & 266 & 405 \\
\hline 41026 & Gawler - South & 15474 & 1081.8 & 884.1 & 1333.9 & 1674 & 1368 & 2064 \\
\hline 41027 & Lewiston - Two Wells & 4289 & 294.1 & 239.7 & 367.4 & 126 & 103 & 158 \\
\hline 41028 & Craigmore - Blakeview & 13303 & 785.5 & 641.3 & 983.3 & 1045 & 853 & 1308 \\
\hline 41029 & Davoren Park & 12199 & 1754.3 & 1423.4 & 2173.9 & 2140 & 1736 & 2652 \\
\hline 41030 & Elizabeth & 7882 & 2344.1 & 1898.3 & 2874.4 & 1848 & 1496 & 2266 \\
\hline 41031 & Elizabeth East & 9893 & 1298.2 & 1053.4 & 1594.2 & 1284 & 1042 & 1577 \\
\hline 41032 & Munno Para West - Angle Vale & 8373 & 1138.0 & 930.9 & 1423.7 & 953 & 779 & 1192 \\
\hline 41033 & One Tree Hill & 1992 & 128.4 & 105.9 & 163.2 & 26 & 21 & 33 \\
\hline 41034 & Smithfield - Elizabeth North & 9137 & 2042.4 & 1660.4 & 2495.6 & 1866 & 1517 & 2280 \\
\hline 41035 & Virginia - Waterloo Corner & 3356 & 430.3 & 351.6 & 542.4 & 144 & 118 & 182 \\
\hline 41036 & Enfield - Blair Athol & 18132 & 1582.2 & 1287.1 & 1979.0 & 2869 & 2334 & 3588 \\
\hline 41037 & Northgate - Oakden - Gilles Plains & 19410 & 942.3 & 770.1 & 1172.4 & 1829 & 1495 & 2276 \\
\hline 41038 & Windsor Gardens & 16047 & 1246.3 & 1020.8 & 1554.3 & 2000 & 1638 & 2494 \\
\hline 41040 & Ingle Farm & 11712 & 902.4 & 734.2 & 1118.4 & 1057 & 860 & 1310 \\
\hline 41041 & Para Hills & 11274 & 674.4 & 550.0 & 840.3 & 760 & 620 & 947 \\
\hline 41043 & Parafield Gardens & 12992 & 964.0 & 783.0 & 1199.0 & 1252 & 1017 & 1558 \\
\hline 41044 & Paralowie & 12512 & 811.2 & 658.0 & 1017.0 & 1015 & 823 & 1272 \\
\hline 41046 & Salisbury & 13724 & 1442.5 & 1173.2 & 1785.7 & 1980 & 1610 & 2451 \\
\hline 41047 & Salisbury East & 13666 & 801.4 & 652.9 & 995.4 & 1095 & 892 & 1360 \\
\hline 41048 & Salisbury North & 12579 & 1255.0 & 1023.1 & 1545.0 & 1579 & 1287 & 1943 \\
\hline 41049 & Golden Grove & 8095 & 706.2 & 578.8 & 878.6 & 572 & 469 & 711 \\
\hline 41050 & Greenwith & 6759 & 678.4 & 555.5 & 842.6 & 458 & 375 & 569 \\
\hline 41051 & Highbury - Dernancourt & 8201 & 379.2 & 311.5 & 477.8 & 311 & 255 & 392 \\
\hline 41052 & Hope Valley - Modbury & 13267 & 1055.9 & 862.0 & 1313.2 & 1401 & 1144 & 1742 \\
\hline 41053 & Modbury Heights & 14859 & 550.4 & 452.2 & 682.2 & 818 & 672 & 1014 \\
\hline 41054 & Redwood Park & 12301 & 345.3 & 283.1 & 434.1 & 425 & 348 & 534 \\
\hline 41055 & St Agnes - Ridgehaven & 9973 & 578.1 & 474.9 & 719.3 & 577 & 474 & 717 \\
\hline 41056 & Brighton (SA) & 11080 & 724.9 & 595.2 & 907.8 & 803 & 660 & 1006 \\
\hline 41057 & Glenelg (SA) & 16242 & 1019.2 & 841.3 & 1269.9 & 1655 & 1366 & 2063 \\
\hline 41058 & Edwardstown & 10917 & 1342.7 & 1100.9 & 1667.8 & 1466 & 1202 & 1821 \\
\hline 41059 & Hallett Cove & 9691 & 362.7 & 299.5 & 458.0 & 352 & 290 & 444 \\
\hline 41060 & Marino - Seaview Downs & 7245 & 445.2 & 366.0 & 558.0 & 323 & 265 & 404 \\
\hline 41061 & Mitchell Park & 12373 & 1517.9 & 1242.0 & 1869.5 & 1878 & 1537 & 2313 \\
\hline 41062 & Morphettville & 11866 & 1247.4 & 1022.0 & 1541.0 & 1480 & 1213 & 1829 \\
\hline 41063 & Sheidow Park - Trott Park & 7586 & 319.0 & 263.6 & 404.1 & 242 & 200 & 307 \\
\hline 41064 & Warradale & 12098 & 1302.0 & 1065.3 & 1620.9 & 1575 & 1289 & 1961 \\
\hline 41065 & Belair & 3643 & 342.0 & 280.4 & 428.4 & 125 & 102 & 156 \\
\hline 41066 & Bellevue Heights & 6068 & 675.0 & 548.4 & 856.1 & 410 & 333 & 519 \\
\hline 41067 & Blackwood & 9090 & 317.9 & 261.2 & 398.2 & 289 & 237 & 362 \\
\hline 41068 & Colonel Light Gardens & 11965 & 701.8 & 576.8 & 878.8 & 840 & 690 & 1052 \\
\hline 41069 & Mitcham (SA) & 12354 & 506.9 & 418.6 & 635.1 & 626 & 517 & 785 \\
\hline 41070 & Panorama & 6465 & 917.6 & 751.6 & 1150.0 & 593 & 486 & 743 \\
\hline 41071 & Aberfoyle Park & 9152 & 500.8 & 410.4 & 625.5 & 458 & 376 & 572 \\
\hline 41072 & Aldinga & 11184 & 996.0 & 814.8 & 1238.5 & 1114 & 911 & 1385 \\
\hline 41073 & Christie Downs & 7192 & 1763.2 & 1438.5 & 2148.9 & 1268 & 1035 & 1545 \\
\hline 41074 & Christies Beach & 8060 & 1299.9 & 1063.5 & 1604.4 & 1048 & 857 & 1293 \\
\hline 41075 & Clarendon & 2077 & 153.5 & 126.8 & 195.9 & 32 & 26 & 41 \\
\hline 41076 & Coromandel Valley & 3223 & 177.0 & 147.0 & 225.6 & 57 & 47 & 73 \\
\hline 41077 & Flagstaff Hill & 8218 & 308.1 & 252.6 & 390.5 & 253 & 208 & 321 \\
\hline 41078 & Hackham - Onkaparinga Hills & 4915 & 571.1 & 466.5 & 705.3 & 281 & 229 & 347 \\
\hline 41079 & Hackham West - Huntfield Heights & 5839 & 1595.0 & 1303.8 & 1939.3 & 931 & 761 & 1132 \\
\hline 41080 & Happy Valley & 10544 & 485.1 & 397.7 & 606.4 & 511 & 419 & 639 \\
\hline 41083 & McLaren Vale & 4651 & 410.6 & 338.8 & 513.8 & 191 & 158 & 239 \\
\hline 41084 & Morphett Vale - East & 10731 & 1039.8 & 850.5 & 1280.0 & 1116 & 913 & 1374 \\
\hline 41085 & Morphett Vale - West & 7434 & 1227.0 & 1003.8 & 1505.5 & 912 & 746 & 1119 \\
\hline
\end{tabular}




\begin{tabular}{|c|c|c|c|c|c|c|c|c|}
\hline \multirow[b]{2}{*}{$\begin{array}{l}\text { SA2_5DIGIT } \\
\text { CODE_2016 }\end{array}$} & \multirow[b]{2}{*}{ SA2_name } & \multicolumn{7}{|c|}{ Unit-level SAES } \\
\hline & & $\begin{array}{r}\text { Unit-level_Probit_ } \\
\text { totalpopulation }\end{array}$ & $\begin{array}{r}\text { Unit-level_ } \\
\text { probit_ } \\
\text { RATE }\end{array}$ & $\begin{array}{r}\text { Unit-level_ } \\
\text { probit_ } \\
\text { RATE_ } \\
\text { LowerCl }\end{array}$ & $\begin{array}{r}\text { Unit-level_ } \\
\text { probit_ } \\
\text { RATE_ } \\
\text { UpperCl }\end{array}$ & $\begin{array}{r}\text { Unit-level_ } \\
\text { probit_ } \\
\text { number }\end{array}$ & $\begin{array}{c}\text { Unit-level_ } \\
\text { probit_ } \\
\text { number_- } \\
\text { LowerCl }\end{array}$ & $\begin{array}{r}\text { Unit-level_ } \\
\text { probit_ } \\
\text { number_ } \\
\text { UpperCl }\end{array}$ \\
\hline 41086 & Reynella & 7984 & 741.4 & 608.5 & 918.5 & 592 & 486 & 733 \\
\hline 41087 & Seaford (SA) & 16721 & 948.2 & 776.7 & 1180.3 & 1586 & 1299 & 1974 \\
\hline 41088 & Willunga & 2661 & 350.9 & 289.4 & 436.9 & 93 & 77 & 116 \\
\hline 41089 & Woodcroft & 8779 & 518.5 & 425.5 & 646.9 & 455 & 374 & 568 \\
\hline 41090 & Beverley & 6106 & 1030.0 & 844.8 & 1281.4 & 629 & 516 & 782 \\
\hline 41091 & Flinders Park & 11642 & 977.1 & 801.6 & 1216.9 & 1138 & 933 & 1417 \\
\hline 41092 & Henley Beach & 11829 & 740.9 & 610.4 & 926.6 & 876 & 722 & 1096 \\
\hline 41093 & Hindmarsh - Brompton & 14355 & 1333.2 & 1091.6 & 1663.6 & 1914 & 1567 & 2388 \\
\hline 41094 & Royal Park - Hendon - Albert Park & 4743 & 1092.7 & 892.7 & 1342.3 & 518 & 423 & 637 \\
\hline 41095 & Seaton - Grange & 13103 & 1103.3 & 902.1 & 1367.8 & 1446 & 1182 & 1792 \\
\hline 41096 & West Lakes & 11750 & 800.3 & 655.9 & 994.1 & 940 & 771 & 1168 \\
\hline 41097 & Woodville - Cheltenham & 13873 & 1188.8 & 970.1 & 1484.2 & 1649 & 1346 & 2059 \\
\hline 41099 & Largs Bay - Semaphore & 11612 & 986.1 & 807.8 & 1224.3 & 1145 & 938 & 1422 \\
\hline 41100 & North Haven & 11412 & 1019.0 & 832.1 & 1255.3 & 1163 & 950 & 1433 \\
\hline 41101 & Port Adelaide & 8744 & 1338.5 & 1092.5 & 1650.6 & 1170 & 955 & 1443 \\
\hline 41102 & The Parks & 14656 & 1627.7 & 1322.7 & 2021.2 & 2386 & 1938 & 2962 \\
\hline 41105 & Fulham & 2149 & 662.0 & 545.7 & 819.6 & 142 & 117 & 176 \\
\hline 41106 & Lockleys & 10325 & 998.4 & 821.1 & 1251.7 & 1031 & 848 & 1292 \\
\hline 41107 & Plympton & 19808 & 1219.6 & 1001.5 & 1528.8 & 2416 & 1984 & 3028 \\
\hline 41108 & Richmond (SA) & 13478 & 1402.1 & 1145.2 & 1762.7 & 1890 & 1543 & 2376 \\
\hline 41109 & West Beach & 3952 & 699.6 & 578.1 & 883.8 & 276 & 228 & 349 \\
\hline 41110 & Barossa - Angaston & 4670 & 527.0 & 433.9 & 656.5 & 246 & 203 & 307 \\
\hline 41111 & Light & 6779 & 483.3 & 395.6 & 602.0 & 328 & 268 & 408 \\
\hline 41112 & Lyndoch & 4597 & 368.0 & 302.3 & 460.1 & 169 & 139 & 212 \\
\hline 41113 & Mallala & 2465 & 404.4 & 329.4 & 514.0 & 100 & 81 & 127 \\
\hline 41114 & Nuriootpa & 5078 & 882.1 & 723.6 & 1092.4 & 448 & 367 & 555 \\
\hline 41115 & Tanunda & 3556 & 717.7 & 592.1 & 890.8 & 255 & 211 & 317 \\
\hline 41116 & Clare & 3001 & 838.9 & 691.4 & 1035.7 & 252 & 207 & 311 \\
\hline 41117 & Gilbert Valley & 3733 & 581.5 & 478.5 & 719.3 & 217 & 179 & 269 \\
\hline 41118 & Goyder & 3160 & 627.0 & 514.8 & 779.6 & 198 & 163 & 246 \\
\hline 41119 & Wakefield - Barunga West & 7179 & 741.7 & 609.4 & 917.8 & 532 & 437 & 659 \\
\hline 41120 & Jamestown & 3521 & 601.4 & 494.3 & 747.6 & 212 & 174 & 263 \\
\hline 41121 & Peterborough - Mount Remarkable & 4206 & 600.9 & 490.8 & 740.6 & 253 & 206 & 311 \\
\hline 41122 & Port Pirie & 10722 & 1251.5 & 1017.0 & 1534.7 & 1342 & 1090 & 1646 \\
\hline 41123 & Port Pirie Region & 2492 & 624.3 & 510.2 & 772.2 & 156 & 127 & 192 \\
\hline 41124 & Kadina & 4014 & 838.4 & 684.1 & 1038.9 & 337 & 275 & 417 \\
\hline 41125 & Moonta & 3772 & 936.9 & 762.2 & 1157.9 & 353 & 288 & 437 \\
\hline 41126 & Wallaroo & 3205 & 1296.4 & 1057.9 & 1595.7 & 415 & 339 & 511 \\
\hline 41127 & Yorke Peninsula - North & 5433 & 771.6 & 626.0 & 953.5 & 419 & 340 & 518 \\
\hline 41128 & Yorke Peninsula - South & 3029 & 596.2 & 489.0 & 735.8 & 181 & 148 & 223 \\
\hline 41129 & Ceduna & 1845 & 1259.6 & 997.3 & 1583.7 & 232 & 184 & 292 \\
\hline 41130 & Eyre Peninsula & 4824 & 651.9 & 533.7 & 814.4 & 314 & 257 & 393 \\
\hline 41131 & Kimba - Cleve - Franklin Harbour & 3096 & 604.5 & 499.0 & 751.8 & 187 & 154 & 233 \\
\hline 41132 & Le Hunte - Elliston & 1638 & 655.1 & 542.6 & 815.3 & 107 & 89 & 134 \\
\hline 41133 & Port Lincoln & 11443 & 1136.2 & 925.5 & 1400.2 & 1300 & 1059 & 1602 \\
\hline 41134 & West Coast (SA) & 2506 & 905.0 & 715.4 & 1152.7 & 227 & 179 & 289 \\
\hline 41136 & Whyalla & 16301 & 1442.6 & 1176.0 & 1762.0 & 2352 & 1917 & 2872 \\
\hline 41138 & APY Lands & 1629 & 3996.4 & 2934.7 & 5231.0 & 651 & 478 & 852 \\
\hline 41139 & Coober Pedy & 1361 & 965.0 & 759.1 & 1238.4 & 131 & 103 & 169 \\
\hline 41140 & Quorn - Lake Gilles & 1596 & 703.2 & 567.7 & 872.0 & 112 & 91 & 139 \\
\hline 41141 & Outback & 2099 & 1000.8 & 798.4 & 1268.7 & 210 & 168 & 266 \\
\hline 41142 & Port Augusta & 10005 & 1305.9 & 1043.8 & 1613.1 & 1307 & 1044 & 1614 \\
\hline 41143 & Roxby Downs & 2691 & 724.0 & 609.4 & 963.6 & 195 & 164 & 259 \\
\hline 41144 & Goolwa - Port Elliot & 8796 & 999.2 & 816.2 & 1232.1 & 879 & 718 & 1084 \\
\hline 41145 & Kangaroo Island & 3503 & 785.3 & 650.3 & 956.6 & 275 & 228 & 335 \\
\hline 41146 & Strathalbyn & 5447 & 787.9 & 644.4 & 977.0 & 429 & 351 & 532 \\
\hline 41147 & Strathalbyn Region & 5685 & 407.2 & 332.6 & 513.6 & 232 & 189 & 292 \\
\hline
\end{tabular}




\begin{tabular}{|c|c|c|c|c|c|c|c|c|}
\hline \multirow[b]{2}{*}{$\begin{array}{l}\text { SA2_5DIGIT } \\
\text { CODE_2016 }\end{array}$} & \multirow[b]{2}{*}{ SA2_name } & \multicolumn{7}{|c|}{ Unit-level SAEs } \\
\hline & & $\begin{array}{r}\text { Unit-level_Probit_ } \\
\text { totalpopulation }\end{array}$ & $\begin{array}{r}\text { Unit-level_ } \\
\text { probit_ } \\
\text { RATE }\end{array}$ & $\begin{array}{c}\text { Unit-level_ } \\
\text { probit_ } \\
\text { RATE_ } \\
\text { LowerCl }\end{array}$ & $\begin{array}{c}\text { Unit-level_ } \\
\text { probit_ } \\
\text { RATE_- } \\
\text { UpperCl }\end{array}$ & $\begin{array}{r}\text { Unit-level_ } \\
\text { probit_ } \\
\text { number }\end{array}$ & $\begin{array}{c}\text { Unit-level_ } \\
\text { probit_ } \\
\text { number- } \\
\text { LowerCl }\end{array}$ & $\begin{array}{r}\text { Unit-level_ } \\
\text { probit_ } \\
\text { number_ } \\
\text { UpperCl }\end{array}$ \\
\hline 41148 & Victor Harbor & 11438 & 1025.4 & 839.1 & 1260.9 & 1173 & 960 & 1442 \\
\hline 41149 & Yankalilla & 4459 & 702.2 & 575.6 & 869.9 & 313 & 257 & 388 \\
\hline 41150 & Grant & 4416 & 388.2 & 320.9 & 482.6 & 171 & 142 & 213 \\
\hline 41151 & Kingston - Robe & 2800 & 821.8 & 677.6 & 1021.3 & 230 & 190 & 286 \\
\hline 41152 & Millicent & 4044 & 973.0 & 795.5 & 1192.1 & 393 & 322 & 482 \\
\hline 41154 & Naracoorte & 4550 & 813.6 & 671.4 & 1019.1 & 370 & 305 & 464 \\
\hline 41155 & Naracoorte Region & 1594 & 589.6 & 489.6 & 742.6 & 94 & 78 & 118 \\
\hline 41156 & Penola & 2284 & 718.8 & 593.3 & 899.3 & 164 & 136 & 205 \\
\hline 41157 & Tatiara & 4964 & 692.5 & 571.3 & 870.2 & 344 & 284 & 432 \\
\hline 41158 & Wattle Range & 2400 & 401.6 & 331.0 & 503.1 & 96 & 79 & 121 \\
\hline 41159 & Barmera & 5027 & 877.0 & 714.0 & 1076.6 & 441 & 359 & 541 \\
\hline 41160 & Berri & 3124 & 1604.8 & 1311.8 & 1962.7 & 501 & 410 & 613 \\
\hline 41161 & Karoonda - Lameroo & 2305 & 582.6 & 482.1 & 725.8 & 134 & 111 & 167 \\
\hline 41162 & Loxton & 4090 & 866.7 & 709.5 & 1068.9 & 354 & 290 & 437 \\
\hline 41163 & Loxton Region & 1282 & 577.4 & 478.1 & 712.2 & 74 & 61 & 91 \\
\hline 41164 & Mannum & 4921 & 688.8 & 565.2 & 847.0 & 339 & 278 & 417 \\
\hline 41165 & Murray Bridge & 13741 & 1375.2 & 1117.8 & 1700.8 & 1890 & 1536 & 2337 \\
\hline 41166 & Murray Bridge Region & 2806 & 448.4 & 363.7 & 568.7 & 126 & 102 & 160 \\
\hline 41167 & Renmark & 3587 & 1474.1 & 1205.6 & 1812.0 & 529 & 432 & 650 \\
\hline 41168 & Renmark Region & 3674 & 474.8 & 390.7 & 595.8 & 174 & 144 & 219 \\
\hline 41169 & The Coorong & 4065 & 898.9 & 732.7 & 1110.4 & 365 & 298 & 451 \\
\hline 41170 & Waikerie & 5227 & 798.8 & 654.7 & 982.2 & 418 & 342 & 513 \\
\hline 41171 & Mawson Lakes - Globe Derby Park & 10229 & 970.2 & 796.8 & 1243.1 & 992 & 815 & 1272 \\
\hline 41172 & Pooraka - Cavan & 6107 & 1046.2 & 851.0 & 1303.5 & 639 & 520 & 796 \\
\hline 41173 & Mount Gambier - East & 10805 & 1096.0 & 896.8 & 1349.5 & 1184 & 969 & 1458 \\
\hline 41174 & Mount Gambier - West & 10481 & 1271.9 & 1042.5 & 1560.9 & 1333 & 1093 & 1636 \\
\hline 51001 & Augusta & 3898 & 753.0 & 622.0 & 941.0 & 294 & 242 & 367 \\
\hline 51002 & Busselton & 19033 & 920.6 & 753.6 & 1146.5 & 1752 & 1434 & 2182 \\
\hline 51003 & Busselton Region & 7030 & 522.8 & 433.0 & 669.3 & 368 & 304 & 470 \\
\hline 51004 & Margaret River & 6068 & 847.2 & 698.7 & 1067.4 & 514 & 424 & 648 \\
\hline 51005 & Australind - Leschenault & 12334 & 561.0 & 458.7 & 707.2 & 692 & 566 & 872 \\
\hline 51007 & Capel & 3779 & 545.7 & 449.4 & 678.5 & 206 & 170 & 256 \\
\hline 51008 & College Grove - Carey Park & 5232 & 1325.6 & 1078.4 & 1636.1 & 694 & 564 & 856 \\
\hline 51009 & Collie & 6576 & 790.0 & 639.3 & 974.2 & 519 & 420 & 641 \\
\hline 51010 & Dardanup & 2298 & 421.3 & 344.8 & 536.3 & 97 & 79 & 123 \\
\hline 51012 & Eaton - Pelican Point & 8504 & 663.4 & 542.1 & 839.1 & 564 & 461 & 714 \\
\hline 51014 & Harvey & 6709 & 692.6 & 563.8 & 873.7 & 465 & 378 & 586 \\
\hline 51015 & East Bunbury - Glen Iris & 5228 & 1024.3 & 838.0 & 1271.4 & 535 & 438 & 665 \\
\hline 51016 & Waroona & 3082 & 637.1 & 516.7 & 801.1 & 196 & 159 & 247 \\
\hline 51017 & Bridgetown - Boyup Brook & 4780 & 641.4 & 526.2 & 793.2 & 307 & 252 & 379 \\
\hline 51018 & Donnybrook - Balingup & 4390 & 495.5 & 406.6 & 616.0 & 218 & 178 & 270 \\
\hline 51019 & Manjimup & 4097 & 955.4 & 775.6 & 1190.9 & 391 & 318 & 488 \\
\hline 51020 & Pemberton & 3788 & 638.3 & 524.5 & 787.4 & 242 & 199 & 298 \\
\hline 51021 & Dawesville - Bouvard & 5101 & 541.5 & 442.4 & 678.6 & 276 & 226 & 346 \\
\hline 51022 & Falcon - Wannanup & 6545 & 782.4 & 638.7 & 983.7 & 512 & 418 & 644 \\
\hline 51023 & Greenfields & 7500 & 1195.5 & 965.1 & 1494.7 & 897 & 724 & 1121 \\
\hline 51024 & Halls Head - Erskine & 13773 & 706.1 & 576.1 & 887.7 & 973 & 793 & 1223 \\
\hline 51025 & Mandurah & 7264 & 1859.1 & 1517.5 & 2294.9 & 1350 & 1102 & 1667 \\
\hline 51026 & Mandurah - East & 4375 & 599.8 & 489.7 & 755.6 & 262 & 214 & 331 \\
\hline 51027 & Mandurah - North & 12651 & 689.6 & 562.6 & 871.5 & 872 & 712 & 1102 \\
\hline 51028 & Mandurah - South & 8000 & 1056.9 & 858.0 & 1310.5 & 846 & 686 & 1048 \\
\hline 51029 & Pinjarra & 7078 & 801.5 & 651.5 & 1002.0 & 567 & 461 & 709 \\
\hline 51030 & City Beach & 4994 & 288.3 & 238.6 & 372.1 & 144 & 119 & 186 \\
\hline 51031 & Claremont (WA) & 6576 & 725.4 & 597.6 & 921.2 & 477 & 393 & 606 \\
\hline 51032 & Cottesloe & 5577 & 468.8 & 392.2 & 603.1 & 261 & 219 & 336 \\
\hline 51033 & Floreat & 5661 & 199.7 & 165.9 & 263.1 & 113 & 94 & 149 \\
\hline 51034 & Mosman Park - Peppermint Grove & 8037 & 793.1 & 655.5 & 992.3 & 637 & 527 & 798 \\
\hline
\end{tabular}




\begin{tabular}{|c|c|c|c|c|c|c|c|c|}
\hline \multirow[b]{2}{*}{$\begin{array}{l}\text { SA2_5DIGIT } \\
\text { CODE_2016 }\end{array}$} & \multirow[b]{2}{*}{ SA2_name } & \multicolumn{7}{|c|}{ Unit-level SAES } \\
\hline & & $\begin{array}{r}\text { Unit-level_Probit_ } \\
\text { totalpopulation }\end{array}$ & $\begin{array}{r}\text { Unit-level_ } \\
\text { probit_ } \\
\text { RATE }\end{array}$ & $\begin{array}{r}\text { Unit-level_ } \\
\text { probit_ } \\
\text { RATE_ } \\
\text { LowerCl }\end{array}$ & $\begin{array}{r}\text { Unit-level_ } \\
\text { probit_ } \\
\text { RATE_ } \\
\text { UpperCl }\end{array}$ & $\begin{array}{r}\text { Unit-level_ } \\
\text { probit_ } \\
\text { number }\end{array}$ & $\begin{array}{c}\text { Unit-level_ } \\
\text { probit_ } \\
\text { number_- } \\
\text { LowerCl }\end{array}$ & $\begin{array}{r}\text { Unit-level_ } \\
\text { probit_ } \\
\text { number_ } \\
\text { UpperCl }\end{array}$ \\
\hline 51035 & Nedlands - Dalkeith - Crawley & 14767 & 768.9 & 628.3 & 981.1 & 1135 & 928 & 1449 \\
\hline 51036 & Swanbourne - Mount Claremont & 6521 & 446.7 & 371.6 & 557.0 & 291 & 242 & 363 \\
\hline 51038 & Mount Hawthorn - Leederville & 8115 & 657.0 & 545.7 & 838.3 & 533 & 443 & 680 \\
\hline 51039 & Mount Lawley - Inglewood & 13365 & 810.1 & 669.8 & 1023.1 & 1083 & 895 & 1367 \\
\hline 51040 & North Perth & 7050 & 692.9 & 571.8 & 886.8 & 489 & 403 & 625 \\
\hline 51041 & Perth City & 27369 & 1241.5 & 1026.0 & 1588.1 & 3398 & 2808 & 4347 \\
\hline 51042 & Subiaco - Shenton Park & 13059 & 924.5 & 764.9 & 1167.1 & 1207 & 999 & 1524 \\
\hline 51043 & Wembley - West Leederville - Glendalough & 13955 & 954.0 & 789.5 & 1212.7 & 1331 & 1102 & 1692 \\
\hline 51044 & Bassendean - Eden Hill - Ashfield & 11757 & 826.5 & 672.6 & 1036.6 & 972 & 791 & 1219 \\
\hline 51045 & Bayswater - Embleton - Bedford & 18059 & 835.7 & 683.8 & 1051.7 & 1509 & 1235 & 1899 \\
\hline 51046 & Maylands & 10329 & 1318.3 & 1089.8 & 1658.9 & 1362 & 1126 & 1714 \\
\hline 51047 & Morley & 17389 & 773.1 & 631.3 & 986.8 & 1344 & 1098 & 1716 \\
\hline 51048 & Noranda & 6471 & 415.4 & 338.9 & 530.4 & 269 & 219 & 343 \\
\hline 51049 & Chidlow & 4014 & 119.3 & 98.1 & 151.5 & 48 & 39 & 61 \\
\hline 51050 & Glen Forrest - Darlington & 5365 & 195.6 & 161.9 & 245.8 & 105 & 87 & 132 \\
\hline 51051 & Helena Valley - Koongamia & 4079 & 440.1 & 360.0 & 549.7 & 180 & 147 & 224 \\
\hline 51053 & Mundaring & 9703 & 265.2 & 216.4 & 334.6 & 257 & 210 & 325 \\
\hline 51054 & Swan View - Greenmount - Midvale & 9464 & 706.5 & 571.3 & 883.4 & 669 & 541 & 836 \\
\hline 51056 & Ballajura & 14392 & 555.8 & 448.6 & 703.9 & 800 & 646 & 1013 \\
\hline 51057 & Beechboro & 13692 & 575.9 & 466.9 & 728.0 & 788 & 639 & 997 \\
\hline 51058 & Bullsbrook & 3902 & 319.2 & 261.2 & 408.3 & 125 & 102 & 159 \\
\hline 51059 & Ellenbrook & 25161 & 518.5 & 423.6 & 657.8 & 1305 & 1066 & 1655 \\
\hline 51060 & Gidgegannup & 2091 & 185.9 & 154.0 & 235.6 & 39 & 32 & 49 \\
\hline 51061 & Hazelmere - Guildford & 3142 & 470.8 & 385.7 & 595.4 & 148 & 121 & 187 \\
\hline 51062 & Lockridge - Kiara & 8002 & 644.0 & 521.5 & 808.4 & 515 & 417 & 647 \\
\hline 51065 & Middle Swan - Herne Hill & 4171 & 723.7 & 590.2 & 907.6 & 302 & 246 & 379 \\
\hline 51066 & Midland - Guildford & 8446 & 1260.8 & 1032.3 & 1571.3 & 1065 & 872 & 1327 \\
\hline 51067 & Stratton - Jane Brook & 5033 & 603.2 & 489.9 & 757.0 & 304 & 247 & 381 \\
\hline 51068 & The Vines & 7217 & 276.9 & 226.6 & 355.1 & 200 & 164 & 256 \\
\hline 51070 & Craigie - Beldon & 7473 & 652.0 & 538.0 & 818.5 & 487 & 402 & 612 \\
\hline 51071 & Currambine - Kinross & 10455 & 441.2 & 363.6 & 565.0 & 461 & 380 & 591 \\
\hline 51072 & Duncraig & 11421 & 250.4 & 206.3 & 321.5 & 286 & 236 & 367 \\
\hline 51073 & Greenwood - Warwick & 10260 & 402.0 & 330.1 & 512.1 & 412 & 339 & 525 \\
\hline 51074 & Heathridge - Connolly & 8016 & 500.1 & 411.0 & 634.1 & 401 & 329 & 508 \\
\hline 51075 & Hillarys & 8305 & 285.1 & 236.0 & 367.7 & 237 & 196 & 305 \\
\hline 51076 & Iluka - Burns Beach & 6475 & 111.6 & 93.5 & 148.8 & 72 & 61 & 96 \\
\hline 51077 & Joondalup - Edgewater & 10949 & 784.7 & 645.0 & 998.3 & 859 & 706 & 1093 \\
\hline 51078 & Kingsley & 10088 & 321.5 & 264.4 & 406.2 & 324 & 267 & 410 \\
\hline 51079 & Mullaloo - Kallaroo & 8468 & 297.2 & 245.1 & 381.7 & 252 & 208 & 323 \\
\hline 51080 & Ocean Reef & 6089 & 218.5 & 181.0 & 285.8 & 133 & 110 & 174 \\
\hline 51081 & Padbury & 6167 & 440.4 & 363.2 & 563.0 & 272 & 224 & 347 \\
\hline 51082 & Sorrento - Marmion & 7440 & 247.3 & 204.8 & 317.6 & 184 & 152 & 236 \\
\hline 51083 & Woodvale & 7271 & 216.6 & 178.9 & 278.5 & 158 & 130 & 203 \\
\hline 51084 & Balcatta - Hamersley & 12254 & 786.6 & 646.0 & 990.3 & 964 & 792 & 1213 \\
\hline 51085 & Balga - Mirrabooka & 15154 & 1349.8 & 1092.8 & 1702.9 & 2045 & 1656 & 2581 \\
\hline 51086 & Dianella & 19385 & 685.0 & 560.6 & 864.9 & 1328 & 1087 & 1677 \\
\hline 51088 & Innaloo - Doubleview & 13212 & 946.3 & 779.1 & 1186.5 & 1250 & 1029 & 1568 \\
\hline 51089 & Karrinyup - Gwelup - Carine & 15077 & 329.9 & 272.2 & 418.9 & 497 & 410 & 632 \\
\hline 51090 & Nollamara - Westminster & 14238 & 1287.1 & 1054.8 & 1628.1 & 1833 & 1502 & 2318 \\
\hline 51092 & Scarborough & 12304 & 886.7 & 735.8 & 1131.7 & 1091 & 905 & 1392 \\
\hline 51093 & Stirling - Osborne Park & 10979 & 719.6 & 593.8 & 910.3 & 790 & 652 & 999 \\
\hline 51094 & Trigg - North Beach - Watermans Bay & 5753 & 673.1 & 555.2 & 841.6 & 387 & 319 & 484 \\
\hline 51095 & Tuart Hill - Joondanna & 9780 & 1221.1 & 1006.9 & 1538.6 & 1194 & 985 & 1505 \\
\hline 51096 & Wembley Downs - Churchlands - Woodlands & 10508 & 385.0 & 319.3 & 492.7 & 405 & 336 & 518 \\
\hline 51097 & Yokine - Coolbinia - Menora & 12855 & 928.1 & 763.9 & 1164.8 & 1193 & 982 & 1497 \\
\hline 51098 & Alexander Heights - Koondoola & 9131 & 761.3 & 616.2 & 957.0 & 695 & 563 & 874 \\
\hline 51099 & Butler - Merriwa - Ridgewood & 16534 & 1005.2 & 817.3 & 1269.8 & 1662 & 1351 & 2100 \\
\hline
\end{tabular}




\begin{tabular}{|c|c|c|c|c|c|c|c|c|}
\hline \multirow[b]{2}{*}{$\begin{array}{l}\text { SA2_5DIGIT } \\
\text { CODE_2016 }\end{array}$} & \multirow[b]{2}{*}{ SA2_name } & \multicolumn{7}{|c|}{ Unit-level SAEs } \\
\hline & & $\begin{array}{r}\text { Unit-level_Probit_ } \\
\text { totalpopulation }\end{array}$ & $\begin{array}{r}\text { Unit-level_ } \\
\text { probit_ } \\
\text { RATE }\end{array}$ & $\begin{array}{r}\text { Unit-level_ } \\
\text { probit_ } \\
\text { RATE_ } \\
\text { LowerCl }\end{array}$ & $\begin{array}{c}\text { Unit-level_ } \\
\text { probit_ } \\
\text { RATE_ } \\
\text { UpperCl }\end{array}$ & $\begin{array}{r}\text { Unit-level_ } \\
\text { probit_ } \\
\text { number }\end{array}$ & $\begin{array}{r}\text { Unit-level_ } \\
\text { probit_ } \\
\text { number_- } \\
\text { LowerCl }\end{array}$ & $\begin{array}{c}\text { Unit-level_ } \\
\text { probit_ } \\
\text { number_ } \\
\text { UpperCl }\end{array}$ \\
\hline 51100 & Carramar & 11749 & 488.1 & 399.3 & 619.7 & 573 & 469 & 728 \\
\hline 51101 & Clarkson & 9622 & 909.0 & 741.2 & 1152.8 & 875 & 713 & 1109 \\
\hline 51102 & Girrawheen & 6603 & 1190.1 & 960.5 & 1501.1 & 786 & 634 & 991 \\
\hline 51103 & Madeley - Darch - Landsdale & 18522 & 314.0 & 256.5 & 406.6 & 582 & 475 & 753 \\
\hline 51104 & Marangaroo & 8263 & 585.2 & 474.5 & 738.3 & 484 & 392 & 610 \\
\hline 51105 & Mindarie - Quinns Rocks - Jindalee & 13899 & 445.1 & 366.0 & 569.6 & 619 & 509 & 792 \\
\hline 51107 & Tapping - Ashby - Sinagra & 9373 & 355.1 & 292.8 & 457.9 & 333 & 274 & 429 \\
\hline 51108 & Wanneroo & 19336 & 544.7 & 445.1 & 693.0 & 1053 & 861 & 1340 \\
\hline 51110 & Armadale - Wungong - Brookdale & 14082 & 1280.8 & 1038.7 & 1588.0 & 1804 & 1463 & 2236 \\
\hline 51112 & Camillo - Champion Lakes & 4207 & 783.4 & 636.4 & 982.5 & 330 & 268 & 413 \\
\hline 51113 & Forrestdale - Harrisdale - Piara Waters & 13584 & 319.9 & 264.4 & 417.1 & 435 & 359 & 567 \\
\hline 51114 & Kelmscott & 8142 & 819.2 & 668.2 & 1024.7 & 667 & 544 & 834 \\
\hline 51115 & Mount Nasura - Mount Richon - Bedfordale & 6169 & 218.5 & 179.2 & 274.7 & 135 & 111 & 169 \\
\hline 51116 & Roleystone & 5366 & 158.9 & 130.8 & 200.2 & 85 & 70 & 107 \\
\hline 51117 & Seville Grove & 7209 & 634.4 & 512.1 & 807.7 & 457 & 369 & 582 \\
\hline 51118 & Belmont - Ascot - Redcliffe & 11271 & 1034.9 & 846.9 & 1304.6 & 1166 & 955 & 1470 \\
\hline 51119 & East Victoria Park - Carlisle & 13271 & 1167.8 & 958.6 & 1475.1 & 1550 & 1272 & 1958 \\
\hline 51122 & Rivervale - Kewdale - Cloverdale & 20032 & 1162.8 & 948.4 & 1478.7 & 2329 & 1900 & 2962 \\
\hline 51123 & Victoria Park - Lathlain - Burswood & 11877 & 1125.0 & 928.8 & 1437.3 & 1336 & 1103 & 1707 \\
\hline 51124 & Bentley - Wilson - St James & 16909 & 1640.7 & 1333.0 & 2071.8 & 2774 & 2254 & 3503 \\
\hline 51125 & Canning Vale - West & 7740 & 262.9 & 214.6 & 344.0 & 203 & 166 & 266 \\
\hline 51127 & Cannington - Queens Park & 14075 & 1149.9 & 939.8 & 1475.8 & 1618 & 1323 & 2077 \\
\hline 51128 & Parkwood - Ferndale - Lynwood & 10975 & 604.5 & 493.5 & 770.4 & 663 & 542 & 846 \\
\hline 51129 & Riverton - Shelley - Rossmoyne & 10496 & 619.4 & 507.8 & 792.8 & 650 & 533 & 832 \\
\hline 51131 & Willetton & 13878 & 447.0 & 366.3 & 577.5 & 620 & 508 & 801 \\
\hline 51132 & Beckenham - Kenwick - Langford & 14557 & 884.8 & 720.3 & 1122.9 & 1288 & 1049 & 1635 \\
\hline 51133 & Canning Vale - East & 17381 & 383.8 & 314.8 & 498.9 & 667 & 547 & 867 \\
\hline 51134 & Gosnells & 15331 & 992.0 & 805.9 & 1236.4 & 1521 & 1236 & 1895 \\
\hline 51135 & Huntingdale - Southern River & 13670 & 441.7 & 359.8 & 563.7 & 604 & 492 & 771 \\
\hline 51136 & Maddington - Orange Grove - Martin & 10494 & 876.5 & 712.5 & 1097.9 & 920 & 748 & 1152 \\
\hline 51137 & Thornlie & 17878 & 608.0 & 494.8 & 770.1 & 1087 & 885 & 1377 \\
\hline 51138 & Forrestfield - Wattle Grove & 13953 & 568.3 & 462.6 & 722.2 & 793 & 646 & 1008 \\
\hline 51139 & High Wycombe & 9261 & 530.7 & 433.2 & 677.3 & 491 & 401 & 627 \\
\hline 51140 & Kalamunda - Maida Vale - Gooseberry Hill & 11668 & 298.5 & 245.0 & 377.8 & 348 & 286 & 441 \\
\hline 51141 & Lesmurdie - Bickley - Carmel & 8734 & 284.5 & 231.9 & 360.9 & 248 & 203 & 315 \\
\hline 51142 & Byford & 11119 & 329.1 & 270.1 & 422.3 & 366 & 300 & 470 \\
\hline 51143 & Mundijong & 4800 & 221.7 & 182.0 & 285.2 & 106 & 87 & 137 \\
\hline 51144 & Serpentine - Jarrahdale & 3430 & 267.8 & 218.7 & 344.4 & 92 & 75 & 118 \\
\hline 51145 & Como & 11570 & 1098.2 & 903.8 & 1388.0 & 1271 & 1046 & 1606 \\
\hline 51146 & Manning - Waterford & 9081 & 808.9 & 658.4 & 1017.8 & 735 & 598 & 924 \\
\hline 51147 & South Perth - Kensington & 13298 & 840.1 & 693.5 & 1072.0 & 1117 & 922 & 1426 \\
\hline 51148 & Banjup & 12306 & 404.5 & 332.5 & 524.6 & 498 & 409 & 646 \\
\hline 51152 & Coogee & 6817 & 300.1 & 246.7 & 385.7 & 205 & 168 & 263 \\
\hline 51153 & Coolbellup & 6392 & 978.8 & 800.6 & 1217.5 & 626 & 512 & 778 \\
\hline 51154 & Hamilton Hill & 8282 & 1080.6 & 887.3 & 1342.9 & 895 & 735 & 1112 \\
\hline 51158 & North Coogee & 1890 & 311.2 & 261.1 & 405.8 & 59 & 49 & 77 \\
\hline 51159 & South Lake - Cockburn Central & 9092 & 701.4 & 574.4 & 886.0 & 638 & 522 & 806 \\
\hline 51160 & Spearwood & 8089 & 773.4 & 636.3 & 972.5 & 626 & 515 & 787 \\
\hline 51161 & Success - Hammond Park & 10652 & 566.8 & 465.8 & 730.3 & 604 & 496 & 778 \\
\hline 51163 & Yangebup & 5647 & 590.1 & 481.6 & 737.1 & 333 & 272 & 416 \\
\hline 51164 & East Fremantle & 5628 & 447.7 & 370.4 & 569.6 & 252 & 208 & 321 \\
\hline 51165 & Fremantle & 12027 & 943.7 & 778.7 & 1174.5 & 1135 & 937 & 1413 \\
\hline 51166 & Fremantle - South & 11381 & 859.7 & 703.6 & 1073.0 & 978 & 801 & 1221 \\
\hline 51169 & Bertram - Wellard (West) & 9727 & 608.0 & 497.6 & 773.4 & 591 & 484 & 752 \\
\hline 51170 & Calista & 5699 & 1136.7 & 924.3 & 1403.3 & 648 & 527 & 800 \\
\hline 51174 & Parmelia - Orelia & 8202 & 986.7 & 802.9 & 1226.2 & 809 & 659 & 1006 \\
\hline 51175 & Applecross - Ardross & 8686 & 479.8 & 396.7 & 620.8 & 417 & 345 & 539 \\
\hline
\end{tabular}




\begin{tabular}{|c|c|c|c|c|c|c|c|c|}
\hline \multirow[b]{2}{*}{$\begin{array}{l}\text { SA2_5DIGIT } \\
\text { CODE_2016 }\end{array}$} & \multirow[b]{2}{*}{ SA2_name } & \multicolumn{7}{|c|}{ Unit-level SAEs } \\
\hline & & $\begin{array}{r}\text { Unit-level_Probit_ } \\
\text { totalpopulation }\end{array}$ & $\begin{array}{r}\text { Unit-level_ } \\
\text { probit_ } \\
\text { RATE }\end{array}$ & $\begin{array}{r}\text { Unit-level_ } \\
\text { probit_ } \\
\text { RATE_- } \\
\text { LowerCl }\end{array}$ & $\begin{array}{c}\text { Unit-level_ } \\
\text { probit_ } \\
\text { RATE_ } \\
\text { UpperCl }\end{array}$ & $\begin{array}{r}\text { Unit-level_ } \\
\text { probit_ } \\
\text { number }\end{array}$ & $\begin{array}{r}\text { Unit-level_ } \\
\text { probit_ } \\
\text { number_ } \\
\text { LowerCl }\end{array}$ & $\begin{array}{c}\text { Unit-level_ } \\
\text { probit_ } \\
\text { number } \\
\text { UpperCl }\end{array}$ \\
\hline 51176 & Bateman & 2961 & 435.0 & 358.8 & 565.9 & 129 & 106 & 168 \\
\hline 51177 & Bicton - Palmyra & 10589 & 726.5 & 599.7 & 905.7 & 769 & 635 & 959 \\
\hline 51178 & Booragoon & 11438 & 580.7 & 477.7 & 738.0 & 664 & 546 & 844 \\
\hline 51179 & Bull Creek & 6156 & 603.8 & 494.8 & 766.7 & 372 & 305 & 472 \\
\hline 51180 & Leeming & 8511 & 255.9 & 211.7 & 330.1 & 218 & 180 & 281 \\
\hline 51181 & Melville & 12364 & 427.3 & 354.6 & 542.3 & 528 & 438 & 670 \\
\hline 51182 & Murdoch - Kardinya & 10263 & 618.0 & 503.5 & 792.7 & 634 & 517 & 814 \\
\hline 51183 & Willagee & 3640 & 1420.3 & 1157.9 & 1745.0 & 517 & 421 & 635 \\
\hline 51184 & Winthrop & 4736 & 204.7 & 168.3 & 270.1 & 97 & 80 & 128 \\
\hline 51185 & Baldivis & 22379 & 516.3 & 422.9 & 664.5 & 1156 & 946 & 1487 \\
\hline 51186 & Cooloongup & 6564 & 838.4 & 678.3 & 1053.9 & 550 & 445 & 692 \\
\hline 51187 & Port Kennedy & 9642 & 676.5 & 550.5 & 858.6 & 652 & 531 & 828 \\
\hline 51188 & Rockingham & 12352 & 1093.7 & 893.5 & 1359.8 & 1351 & 1104 & 1680 \\
\hline 51190 & Safety Bay - Shoalwater & 8855 & 815.2 & 667.6 & 1017.0 & 722 & 591 & 901 \\
\hline 51191 & Singleton - Golden Bay - Secret Harbour & 13158 & 474.7 & 390.1 & 607.4 & 625 & 513 & 799 \\
\hline 51192 & Waikiki & 9115 & 706.0 & 575.2 & 889.3 & 644 & 524 & 811 \\
\hline 51193 & Warnbro & 7945 & 790.7 & 644.6 & 991.4 & 628 & 512 & 788 \\
\hline 51225 & Albany & 10893 & 1199.3 & 984.7 & 1477.0 & 1306 & 1073 & 1609 \\
\hline 51226 & Albany Region & 2542 & 474.8 & 392.8 & 597.2 & 121 & 100 & 152 \\
\hline 51227 & Bayonet Head - Lower King & 3442 & 587.8 & 480.8 & 743.8 & 202 & 166 & 256 \\
\hline 51228 & Denmark & 4337 & 812.8 & 671.0 & 1002.8 & 353 & 291 & 435 \\
\hline 51229 & Gnowangerup & 2043 & 696.9 & 577.2 & 873.8 & 142 & 118 & 179 \\
\hline 51230 & Katanning & 3348 & 866.4 & 701.2 & 1092.3 & 290 & 235 & 366 \\
\hline 51231 & Kojonup & 2997 & 706.5 & 574.8 & 892.3 & 212 & 172 & 267 \\
\hline 51232 & Little Grove - Elleker & 2824 & 396.5 & 326.7 & 493.4 & 112 & 92 & 139 \\
\hline 51233 & McKail - Willyung & 7599 & 885.1 & 723.2 & 1099.0 & 673 & 550 & 835 \\
\hline 51234 & Plantagenet & 3862 & 714.7 & 584.8 & 892.4 & 276 & 226 & 345 \\
\hline 51236 & Chittering & 4072 & 262.0 & 215.9 & 331.5 & 107 & 88 & 135 \\
\hline 51237 & Cunderdin & 3084 & 751.8 & 610.9 & 937.0 & 232 & 188 & 289 \\
\hline 51238 & Dowerin & 2929 & 794.7 & 653.0 & 987.8 & 233 & 191 & 289 \\
\hline 51239 & Gingin - Dandaragan & 6268 & 536.6 & 441.0 & 679.6 & 336 & 276 & 426 \\
\hline 51240 & Merredin & 3768 & 851.8 & 693.3 & 1072.6 & 321 & 261 & 404 \\
\hline 51241 & Moora & 3519 & 728.5 & 595.9 & 915.9 & 256 & 210 & 322 \\
\hline 51242 & Mukinbudin & 2389 & 667.1 & 547.5 & 839.4 & 159 & 131 & 201 \\
\hline 51243 & Northam & 8410 & 791.6 & 637.1 & 990.4 & 666 & 536 & 833 \\
\hline 51244 & Toodyay & 3479 & 363.9 & 298.6 & 451.8 & 127 & 104 & 157 \\
\hline 51245 & York - Beverley & 4038 & 569.3 & 461.6 & 713.5 & 230 & 186 & 288 \\
\hline 51246 & Brookton & 2743 & 772.3 & 626.8 & 959.1 & 212 & 172 & 263 \\
\hline 51247 & Kulin & 3059 & 727.8 & 598.2 & 910.2 & 223 & 183 & 278 \\
\hline 51248 & Murray & 1874 & 661.4 & 540.8 & 835.8 & 124 & 101 & 157 \\
\hline 51249 & Narrogin & 3436 & 939.2 & 760.2 & 1168.8 & 323 & 261 & 402 \\
\hline 51250 & Wagin & 3624 & 647.0 & 531.8 & 809.9 & 234 & 193 & 294 \\
\hline 51251 & Dalyellup & 6082 & 789.9 & 644.8 & 994.4 & 480 & 392 & 605 \\
\hline 51252 & Gelorup - Stratham & 2201 & 87.3 & 72.6 & 112.1 & 19 & 16 & 25 \\
\hline 51253 & South Bunbury - Bunbury & 9327 & 973.2 & 800.7 & 1211.8 & 908 & 747 & 1130 \\
\hline 51254 & Withers - Usher & 3855 & 1647.4 & 1330.9 & 2028.1 & 635 & 513 & 782 \\
\hline 51255 & Alkimos - Eglinton & 5586 & 567.3 & 468.2 & 720.7 & 317 & 262 & 403 \\
\hline 51256 & Carabooda - Pinjar & 596 & 539.5 & 440.4 & 710.3 & 32 & 26 & 42 \\
\hline 51257 & Two Rocks & 2185 & 579.8 & 474.9 & 720.5 & 127 & 104 & 157 \\
\hline 51258 & Yanchep & 6227 & 657.4 & 535.3 & 827.8 & 409 & 333 & 515 \\
\hline 51259 & Beeliar - Wattleup & 6024 & 557.3 & 457.4 & 704.6 & 336 & 276 & 424 \\
\hline 51260 & Jandakot & 2058 & 215.3 & 177.9 & 277.7 & 44 & 37 & 57 \\
\hline 51261 & Casuarina - Wandi & 4873 & 233.9 & 194.0 & 299.8 & 114 & 95 & 146 \\
\hline 51262 & Broome & 9829 & 1215.4 & 972.2 & 1551.4 & 1195 & 956 & 1525 \\
\hline 51263 & Derby - West Kimberley & 5246 & 2997.7 & 2271.5 & 3815.9 & 1573 & 1192 & 2002 \\
\hline 51264 & Halls Creek & 2134 & 3214.0 & 2429.3 & 4059.8 & 686 & 518 & 866 \\
\hline 51265 & Kununurra & 4965 & 1823.8 & 1409.0 & 2330.0 & 905 & 700 & 1157 \\
\hline
\end{tabular}




\begin{tabular}{|c|c|c|c|c|c|c|c|c|}
\hline \multirow[b]{2}{*}{$\begin{array}{l}\text { SA2_5DIGIT } \\
\text { CODE_2016 }\end{array}$} & \multirow[b]{2}{*}{ SA2_name } & \multicolumn{7}{|c|}{ Unit-level SAES } \\
\hline & & $\begin{array}{r}\text { Unit-level_Probit_ } \\
\text { totalpopulation }\end{array}$ & $\begin{array}{r}\text { Unit-level_ } \\
\text { probit_ } \\
\text { RATE }\end{array}$ & $\begin{array}{r}\text { Unit-level_ } \\
\text { probit_ } \\
\text { RATE_ } \\
\text { LowerCl }\end{array}$ & $\begin{array}{r}\text { Unit-level_ } \\
\text { probit_ } \\
\text { RATE_ } \\
\text { UpperCl }\end{array}$ & $\begin{array}{r}\text { Unit-level_ } \\
\text { probit_ } \\
\text { number }\end{array}$ & $\begin{array}{c}\text { Unit-level_ } \\
\text { probit_ } \\
\text { number_- } \\
\text { LowerCl }\end{array}$ & $\begin{array}{r}\text { Unit-level_ } \\
\text { probit_ } \\
\text { number_ } \\
\text { UpperCl }\end{array}$ \\
\hline 51266 & Roebuck & 1524 & 3286.8 & 2495.6 & 4130.3 & 501 & 380 & 629 \\
\hline 51267 & East Pilbara & 5800 & 748.3 & 553.9 & 974.5 & 434 & 321 & 565 \\
\hline 51268 & Newman & 3056 & 942.9 & 765.3 & 1272.8 & 288 & 234 & 389 \\
\hline 51269 & Port Hedland & 3171 & 821.6 & 682.7 & 1090.8 & 261 & 216 & 346 \\
\hline 51270 & South Hedland & 6616 & 1257.1 & 1000.2 & 1653.2 & 832 & 662 & 1094 \\
\hline 51271 & Ashburton (WA) & 10569 & 457.2 & 369.6 & 610.9 & 483 & 391 & 646 \\
\hline 51272 & Karratha & 10859 & 1059.1 & 864.1 & 1402.4 & 1150 & 938 & 1523 \\
\hline 51273 & Roebourne & 4236 & 1033.1 & 806.1 & 1357.7 & 438 & 341 & 575 \\
\hline 51274 & Esperance & 8761 & 830.1 & 675.9 & 1044.3 & 727 & 592 & 915 \\
\hline 51275 & Esperance Region & 2667 & 654.8 & 541.2 & 836.9 & 175 & 144 & 223 \\
\hline 51276 & Carnarvon & 3722 & 1252.4 & 993.1 & 1579.1 & 466 & 370 & 588 \\
\hline 51277 & Exmouth & 3139 & 918.5 & 747.0 & 1176.2 & 288 & 234 & 369 \\
\hline 51278 & Boulder & 5109 & 840.2 & 675.1 & 1069.5 & 429 & 345 & 546 \\
\hline 51279 & Kalgoorlie & 10094 & 758.4 & 617.1 & 974.3 & 766 & 623 & 984 \\
\hline 51280 & Kalgoorlie - North & 6166 & 656.9 & 538.9 & 849.9 & 405 & 332 & 524 \\
\hline 51282 & Kambalda - Coolgardie - Norseman & 3354 & 833.6 & 668.1 & 1057.0 & 280 & 224 & 355 \\
\hline 51283 & Leinster - Leonora & 3531 & 2077.6 & 1555.6 & 2693.6 & 734 & 549 & 951 \\
\hline 51285 & Geraldton & 9060 & 1359.8 & 1100.5 & 1673.4 & 1232 & 997 & 1516 \\
\hline 51286 & Geraldton - East & 5704 & 813.2 & 641.0 & 1020.8 & 464 & 366 & 582 \\
\hline 51287 & Geraldton - North & 5384 & 660.0 & 532.8 & 843.0 & 355 & 287 & 454 \\
\hline 51288 & Geraldton - South & 7087 & 780.4 & 636.1 & 989.8 & 553 & 451 & 701 \\
\hline 51289 & Irwin & 2637 & 837.1 & 686.8 & 1034.4 & 221 & 181 & 273 \\
\hline 51290 & Meekatharra & 2400 & 1125.1 & 863.1 & 1438.4 & 270 & 207 & 345 \\
\hline 51291 & Morawa & 2939 & 837.7 & 682.1 & 1053.3 & 246 & 200 & 310 \\
\hline 51292 & Northampton - Mullewa - Greenough & 4392 & 738.4 & 597.5 & 922.5 & 324 & 262 & 405 \\
\hline 61001 & Bridgewater - Gagebrook & 5074 & 2313.1 & 1857.5 & 2837.3 & 1174 & 942 & 1440 \\
\hline 61002 & Brighton - Pontville & 4012 & 580.0 & 475.2 & 716.6 & 233 & 191 & 287 \\
\hline 61003 & Old Beach - Otago & 3284 & 290.5 & 241.0 & 365.0 & 95 & 79 & 120 \\
\hline 61004 & Bellerive - Rosny & 4650 & 866.9 & 712.0 & 1077.2 & 403 & 331 & 501 \\
\hline 61005 & Cambridge & 5728 & 247.7 & 203.6 & 310.1 & 142 & 117 & 178 \\
\hline 61006 & Geilston Bay - Risdon & 2478 & 546.2 & 447.2 & 674.0 & 135 & 111 & 167 \\
\hline 61007 & Howrah - Tranmere & 7989 & 483.5 & 395.9 & 606.7 & 386 & 316 & 485 \\
\hline 61008 & Lindisfarne - Rose Bay & 5832 & 708.5 & 578.5 & 884.0 & 413 & 337 & 516 \\
\hline 61009 & Mornington - Warrane & 3654 & 1592.2 & 1294.2 & 1957.5 & 582 & 473 & 715 \\
\hline 61010 & Risdon Vale & 2412 & 927.5 & 755.7 & 1132.1 & 224 & 182 & 273 \\
\hline 61011 & Rokeby & 4393 & 1691.7 & 1364.3 & 2092.2 & 743 & 599 & 919 \\
\hline 61012 & South Arm & 3130 & 246.0 & 201.9 & 310.3 & 77 & 63 & 97 \\
\hline 61013 & Austins Ferry - Granton & 3011 & 545.0 & 439.0 & 686.7 & 164 & 132 & 207 \\
\hline 61014 & Berriedale - Chigwell & 4190 & 1066.8 & 870.5 & 1305.3 & 447 & 365 & 547 \\
\hline 61015 & Claremont (Tas.) & 5962 & 1293.4 & 1053.9 & 1586.5 & 771 & 628 & 946 \\
\hline 61016 & Derwent Park - Lutana & 3200 & 1427.4 & 1164.0 & 1765.1 & 457 & 372 & 565 \\
\hline 61017 & Glenorchy & 8594 & 1659.2 & 1349.2 & 2030.9 & 1426 & 1159 & 1745 \\
\hline 61018 & Montrose - Rosetta & 3862 & 957.0 & 780.5 & 1170.8 & 370 & 301 & 452 \\
\hline 61019 & Moonah & 4145 & 1523.1 & 1246.4 & 1870.0 & 631 & 517 & 775 \\
\hline 61020 & New Norfolk & 5075 & 1184.6 & 960.6 & 1452.5 & 601 & 487 & 737 \\
\hline 61021 & West Moonah & 2986 & 1336.9 & 1090.4 & 1659.4 & 399 & 326 & 495 \\
\hline 61022 & Kingston - Huntingfield & 8436 & 985.0 & 803.7 & 1219.7 & 831 & 678 & 1029 \\
\hline 61023 & Kingston Beach - Blackmans Bay & 7846 & 615.0 & 503.3 & 768.8 & 483 & 395 & 603 \\
\hline 61024 & Margate - Snug & 5538 & 451.0 & 369.1 & 565.1 & 250 & 204 & 313 \\
\hline 61026 & Taroona - Bonnet Hill & 2683 & 442.3 & 366.4 & 549.0 & 119 & 98 & 147 \\
\hline 61027 & Hobart & 6547 & 1592.2 & 1307.3 & 1989.8 & 1042 & 856 & 1303 \\
\hline 61028 & Lenah Valley - Mount Stuart & 6437 & 674.5 & 553.5 & 846.5 & 434 & 356 & 545 \\
\hline 61029 & Mount Nelson - Dynnyrne & 3694 & 839.0 & 685.1 & 1056.0 & 310 & 253 & 390 \\
\hline 61030 & New Town & 4832 & 1223.9 & 1006.6 & 1509.4 & 591 & 486 & 729 \\
\hline 61031 & Sandy Bay & 9539 & 1202.4 & 981.9 & 1517.0 & 1147 & 937 & 1447 \\
\hline 61032 & South Hobart - Fern Tree & 4698 & 886.3 & 726.0 & 1110.3 & 416 & 341 & 522 \\
\hline 61033 & West Hobart & 4554 & 1046.7 & 861.6 & 1309.1 & 477 & 392 & 596 \\
\hline
\end{tabular}




\begin{tabular}{|c|c|c|c|c|c|c|c|c|}
\hline \multirow[b]{2}{*}{$\begin{array}{l}\text { SA2_5DIGIT } \\
\text { CODE_2016 }\end{array}$} & \multirow[b]{2}{*}{ SA2_name } & \multicolumn{7}{|c|}{ Unit-level SAEs } \\
\hline & & $\begin{array}{l}\text { Unit-level_Probit_ } \\
\text { totalpopulation }\end{array}$ & $\begin{array}{r}\text { Unit-level_ } \\
\text { probit_ } \\
\text { RATE }\end{array}$ & $\begin{array}{r}\text { Unit-level_ } \\
\text { probit_ } \\
\text { RATE_ } \\
\text { LowerCl }\end{array}$ & $\begin{array}{r}\text { Unit-level_ } \\
\text { probit_ } \\
\text { RATE_ } \\
\text { UpperCl }\end{array}$ & $\begin{array}{r}\text { Unit-level_ } \\
\text { probit_ } \\
\text { number }\end{array}$ & $\begin{array}{r}\text { Unit-level_ } \\
\text { probit_ } \\
\text { number_ } \\
\text { LowerCl }\end{array}$ & $\begin{array}{r}\text { Unit-level_ } \\
\text { probit_ } \\
\text { number_ } \\
\text { UpperCl }\end{array}$ \\
\hline 61034 & Dodges Ferry - Lewisham & 5578 & 650.4 & 529.6 & 805.4 & 363 & 295 & 449 \\
\hline 61035 & Sorell - Richmond & 6634 & 741.0 & 604.3 & 915.2 & 492 & 401 & 607 \\
\hline 61036 & Invermay & 2476 & 2110.5 & 1727.5 & 2584.8 & 523 & 428 & 640 \\
\hline 61037 & Kings Meadows - Punchbowl & 3242 & 1157.1 & 939.3 & 1439.4 & 375 & 305 & 467 \\
\hline 61038 & Launceston & 3997 & 1323.3 & 1089.4 & 1641.4 & 529 & 435 & 656 \\
\hline 61039 & Legana & 3098 & 409.6 & 336.1 & 518.1 & 127 & 104 & 161 \\
\hline 61040 & Mowbray & 2941 & 2072.7 & 1680.9 & 2585.3 & 610 & 494 & 760 \\
\hline 61041 & Newnham - Mayfield & 7007 & 1616.6 & 1313.6 & 1986.7 & 1133 & 920 & 1392 \\
\hline 61042 & Newstead & 3858 & 1143.6 & 941.0 & 1398.0 & 441 & 363 & 539 \\
\hline 61043 & Norwood (Tas.) & 2964 & 643.2 & 523.9 & 793.5 & 191 & 155 & 235 \\
\hline 61044 & Prospect Vale - Blackstone & 4968 & 769.0 & 629.7 & 945.7 & 382 & 313 & 470 \\
\hline 61045 & Ravenswood & 2715 & 2111.6 & 1712.4 & 2568.6 & 573 & 465 & 697 \\
\hline 61046 & Riverside & 4923 & 775.0 & 633.6 & 964.9 & 382 & 312 & 475 \\
\hline 61047 & South Launceston & 3603 & 1535.5 & 1256.2 & 1900.3 & 553 & 453 & 685 \\
\hline 61048 & Summerhill - Prospect & 3566 & 1096.3 & 893.9 & 1351.4 & 391 & 319 & 482 \\
\hline 61049 & Trevallyn & 3384 & 753.1 & 620.7 & 934.6 & 255 & 210 & 316 \\
\hline 61050 & Waverley - St Leonards & 2656 & 1046.2 & 855.7 & 1280.4 & 278 & 227 & 340 \\
\hline 61051 & West Launceston & 3113 & 887.4 & 730.7 & 1097.1 & 276 & 227 & 342 \\
\hline 61052 & Youngtown - Relbia & 3577 & 707.5 & 577.0 & 876.1 & 253 & 206 & 313 \\
\hline 61053 & Beauty Point - Beaconsfield & 2937 & 735.3 & 595.8 & 906.1 & 216 & 175 & 266 \\
\hline 61054 & Deloraine & 4344 & 819.6 & 671.0 & 1007.7 & 356 & 291 & 438 \\
\hline 61055 & Grindelwald - Lanena & 4376 & 423.0 & 347.2 & 522.8 & 185 & 152 & 229 \\
\hline 61056 & Hadspen - Carrick & 2447 & 507.5 & 417.2 & 626.8 & 124 & 102 & 153 \\
\hline 61057 & Westbury & 3116 & 680.5 & 555.6 & 844.6 & 212 & 173 & 263 \\
\hline 61058 & Dilston - Lilydale & 3039 & 324.7 & 264.9 & 406.3 & 99 & 81 & 123 \\
\hline 61059 & George Town & 5159 & 1173.9 & 955.0 & 1437.6 & 606 & 493 & 742 \\
\hline 61060 & Longford & 3136 & 984.9 & 802.5 & 1218.1 & 309 & 252 & 382 \\
\hline 61061 & Northern Midlands & 2785 & 862.9 & 708.5 & 1078.2 & 240 & 197 & 300 \\
\hline 61062 & Perth - Evandale & 3895 & 529.2 & 432.4 & 654.7 & 206 & 168 & 255 \\
\hline 61064 & St Helens - Scamander & 4675 & 916.3 & 750.0 & 1116.4 & 428 & 351 & 522 \\
\hline 61065 & Central Highlands & 1580 & 747.2 & 607.9 & 935.4 & 118 & 96 & 148 \\
\hline 61066 & Derwent Valley & 2368 & 460.7 & 374.0 & 575.1 & 109 & 89 & 136 \\
\hline 61067 & Southern Midlands & 4637 & 553.9 & 451.4 & 684.9 & 257 & 209 & 318 \\
\hline 61069 & Bruny Island - Kettering & 2248 & 420.8 & 347.8 & 517.7 & 95 & 78 & 116 \\
\hline 61070 & Cygnet & 3264 & 615.8 & 501.2 & 762.2 & 201 & 164 & 249 \\
\hline 61071 & Geeveston - Dover & 2852 & 677.5 & 549.6 & 839.6 & 193 & 157 & 239 \\
\hline 61072 & Huonville - Franklin & 6303 & 606.2 & 494.2 & 747.6 & 382 & 312 & 471 \\
\hline 61073 & Forestier - Tasman & 1807 & 568.8 & 464.5 & 701.5 & 103 & 84 & 127 \\
\hline 61074 & Triabunna - Bicheno & 3312 & 853.7 & 696.3 & 1052.6 & 283 & 231 & 349 \\
\hline 61075 & Acton - Upper Burnie & 2410 & 1634.2 & 1335.4 & 1991.3 & 394 & 322 & 480 \\
\hline 61076 & Burnie - Ulverstone Region & 3814 & 425.3 & 347.9 & 530.1 & 162 & 133 & 202 \\
\hline 61077 & Burnie - Wivenhoe & 2810 & 1575.7 & 1287.9 & 1922.5 & 443 & 362 & 540 \\
\hline 61078 & Parklands - Camdale & 4790 & 1299.0 & 1055.0 & 1591.7 & 622 & 505 & 762 \\
\hline 61079 & Penguin - Sulphur Creek & 3833 & 673.8 & 550.8 & 828.3 & 258 & 211 & 317 \\
\hline 61080 & Romaine - Havenview & 2594 & 843.8 & 686.4 & 1036.5 & 219 & 178 & 269 \\
\hline 61081 & Somerset & 2949 & 1051.1 & 853.9 & 1289.2 & 310 & 252 & 380 \\
\hline 61082 & Ulverstone & 5217 & 1123.5 & 914.1 & 1371.6 & 586 & 477 & 716 \\
\hline 61083 & West Ulverstone & 3224 & 1114.8 & 908.1 & 1355.0 & 359 & 293 & 437 \\
\hline 61084 & Wynyard & 4683 & 1266.1 & 1026.4 & 1543.3 & 593 & 481 & 723 \\
\hline 61085 & Devonport & 10517 & 1537.2 & 1254.4 & 1876.1 & 1617 & 1319 & 1973 \\
\hline 61086 & East Devonport & 3593 & 1582.9 & 1279.1 & 1947.2 & 569 & 460 & 700 \\
\hline 61087 & Latrobe & 3370 & 1059.1 & 862.8 & 1299.3 & 357 & 291 & 438 \\
\hline 61088 & Miandetta - Don & 2551 & 654.7 & 533.6 & 814.0 & 167 & 136 & 208 \\
\hline 61089 & Port Sorell & 4314 & 692.9 & 566.0 & 864.3 & 299 & 244 & 373 \\
\hline 61090 & Quoiba - Spreyton & 2202 & 452.2 & 370.0 & 566.6 & 100 & 81 & 125 \\
\hline 61091 & Sheffield - Railton & 4714 & 542.1 & 439.5 & 670.7 & 256 & 207 & 316 \\
\hline 61092 & Turners Beach - Forth & 2342 & 425.3 & 344.5 & 539.8 & 100 & 81 & 126 \\
\hline
\end{tabular}




\begin{tabular}{|c|c|c|c|c|c|c|c|c|}
\hline \multirow[b]{2}{*}{$\begin{array}{l}\text { SA2_5DIGIT } \\
\text { CODE_2016 }\end{array}$} & \multirow[b]{2}{*}{ SA2_name } & \multicolumn{7}{|c|}{ Unit-level SAEs } \\
\hline & & $\begin{array}{r}\text { Unit-level_Probit_ } \\
\text { totalpopulation }\end{array}$ & $\begin{array}{r}\text { Unit-level_ } \\
\text { probit_ } \\
\text { RATE }\end{array}$ & $\begin{array}{r}\text { Unit-level_ } \\
\text { probit_ } \\
\text { RATE_- } \\
\text { LowerCl }\end{array}$ & $\begin{array}{r}\text { Unit-level_ } \\
\text { probit_ } \\
\text { RATE_ } \\
\text { UpperCl }\end{array}$ & $\begin{array}{r}\text { Unit-level_ } \\
\text { probit_ } \\
\text { number }\end{array}$ & $\begin{array}{r}\text { Unit-level_ } \\
\text { probit_ } \\
\text { number_ } \\
\text { LowerCl }\end{array}$ & $\begin{array}{r}\text { Unit-level } \\
\text { probit } \\
\text { number } \\
\text { UpperCl }\end{array}$ \\
\hline 61093 & King Island & 1179 & 668.1 & 557.1 & 841.1 & 79 & 66 & 99 \\
\hline 61094 & North West & 2901 & 672.1 & 548.1 & 847.0 & 195 & 159 & 246 \\
\hline 61095 & Smithton & 2906 & 1079.4 & 875.7 & 1329.3 & 314 & 254 & 386 \\
\hline 61096 & Waratah & 2715 & 510.7 & 411.9 & 636.2 & 139 & 112 & 173 \\
\hline 61097 & West Coast (Tas.) & 3132 & 887.8 & 727.8 & 1099.5 & 278 & 228 & 344 \\
\hline 61099 & Flinders and Cape Barren Islands & 678 & 1335.6 & 1083.3 & 1657.9 & 91 & 73 & 112 \\
\hline 61100 & Scottsdale - Bridport & 5019 & 851.5 & 695.5 & 1051.8 & 427 & 349 & 528 \\
\hline 71002 & Darwin City & 5478 & 901.9 & 754.4 & 1181.5 & 494 & 413 & 647 \\
\hline 71004 & Fannie Bay - The Gardens & 2683 & 765.4 & 637.2 & 987.0 & 205 & 171 & 265 \\
\hline 71005 & Larrakeyah & 2971 & 829.7 & 696.9 & 1087.8 & 247 & 207 & 323 \\
\hline 71006 & Ludmilla - The Narrows & 1965 & 1254.7 & 980.7 & 1600.5 & 247 & 193 & 315 \\
\hline 71007 & Parap & 2061 & 888.1 & 741.9 & 1155.9 & 183 & 153 & 238 \\
\hline 71008 & Stuart Park & 3341 & 836.0 & 697.6 & 1099.9 & 279 & 233 & 367 \\
\hline 71009 & Woolner - Bayview - Winnellie & 2197 & 633.1 & 534.6 & 848.0 & 139 & 117 & 186 \\
\hline 71010 & Alawa & 1610 & 659.9 & 534.7 & 869.0 & 106 & 86 & 140 \\
\hline 71011 & Anula & 1670 & 566.1 & 455.1 & 733.0 & 95 & 76 & 122 \\
\hline 71012 & Berrimah & 924 & 1012.6 & 800.3 & 1280.5 & 94 & 74 & 118 \\
\hline 71013 & Brinkin - Nakara & 2805 & 544.4 & 444.2 & 713.8 & 153 & 125 & 200 \\
\hline 71016 & Coconut Grove & 2432 & 1387.7 & 1136.5 & 1735.7 & 337 & 276 & 422 \\
\hline 71018 & Jingili & 1300 & 523.5 & 423.6 & 676.8 & 68 & 55 & 88 \\
\hline 71019 & Karama & 3615 & 989.0 & 792.4 & 1253.7 & 358 & 286 & 453 \\
\hline 71020 & Leanyer & 3516 & 711.7 & 581.4 & 913.0 & 250 & 204 & 321 \\
\hline 71021 & Lyons (NT) & 3175 & 576.2 & 488.2 & 772.4 & 183 & 155 & 245 \\
\hline 71022 & Malak - Marrara & 3489 & 803.6 & 650.7 & 1016.0 & 280 & 227 & 354 \\
\hline 71023 & Millner & 1969 & 965.4 & 797.6 & 1227.2 & 190 & 157 & 242 \\
\hline 71024 & Moil & 1465 & 718.4 & 580.2 & 932.5 & 105 & 85 & 137 \\
\hline 71025 & Nightcliff & 2957 & 1014.3 & 840.1 & 1307.8 & 300 & 248 & 387 \\
\hline 71026 & Rapid Creek & 2506 & 1007.1 & 826.1 & 1288.4 & 252 & 207 & 323 \\
\hline 71027 & Tiwi & 1944 & 755.1 & 603.6 & 978.6 & 147 & 117 & 190 \\
\hline 71028 & Wagaman & 1624 & 842.2 & 676.4 & 1107.6 & 137 & 110 & 180 \\
\hline 71029 & Wanguri & 1404 & 553.4 & 449.1 & 702.9 & 78 & 63 & 99 \\
\hline 71030 & Wulagi & 1745 & 672.6 & 545.4 & 863.8 & 117 & 95 & 151 \\
\hline 71031 & Howard Springs & 5962 & 157.2 & 126.1 & 202.2 & 94 & 75 & 121 \\
\hline 71032 & Humpty Doo & 6393 & 268.9 & 220.8 & 351.0 & 172 & 141 & 224 \\
\hline 71034 & Virginia & 2550 & 482.0 & 397.3 & 629.8 & 123 & 101 & 161 \\
\hline 71035 & Weddell & 3363 & 365.1 & 298.3 & 461.4 & 123 & 100 & 155 \\
\hline 71036 & Bakewell & 2235 & 817.4 & 667.2 & 1060.4 & 183 & 149 & 237 \\
\hline 71037 & Driver & 2085 & 976.7 & 785.7 & 1251.8 & 204 & 164 & 261 \\
\hline 71038 & Durack - Marlow Lagoon & 3022 & 595.3 & 491.8 & 804.8 & 180 & 149 & 243 \\
\hline 71039 & Gray & 2364 & 1483.1 & 1201.2 & 1819.3 & 351 & 284 & 430 \\
\hline 71040 & Moulden & 2050 & 1637.8 & 1302.5 & 2025.7 & 336 & 267 & 415 \\
\hline 71041 & Palmerston - North & 2910 & 560.1 & 466.1 & 760.9 & 163 & 136 & 221 \\
\hline 71042 & Palmerston - South & 2101 & 628.7 & 524.9 & 817.9 & 132 & 110 & 172 \\
\hline 71043 & Rosebery - Bellamack & 4457 & 819.3 & 682.2 & 1072.2 & 365 & 304 & 478 \\
\hline 71044 & Woodroffe & 2338 & 1019.2 & 831.9 & 1265.8 & 238 & 195 & 296 \\
\hline 71045 & Charles & 2987 & 1069.3 & 839.6 & 1366.9 & 319 & 251 & 408 \\
\hline 71046 & East Side & 3725 & 1048.6 & 837.0 & 1338.9 & 391 & 312 & 499 \\
\hline 71047 & Flynn (NT) & 3120 & 948.6 & 764.9 & 1203.4 & 296 & 239 & 375 \\
\hline 71048 & Larapinta & 3354 & 918.7 & 733.2 & 1175.4 & 308 & 246 & 394 \\
\hline 71049 & Mount Johns & 2866 & 808.3 & 662.6 & 1054.2 & 232 & 190 & 302 \\
\hline 71050 & Petermann - Simpson & 1937 & 2130.4 & 1649.4 & 2747.9 & 413 & 319 & 532 \\
\hline 71051 & Ross & 1896 & 935.4 & 727.4 & 1192.6 & 177 & 138 & 226 \\
\hline 71052 & Sandover - Plenty & 2963 & 2745.3 & 2034.3 & 3531.4 & 813 & 603 & 1046 \\
\hline 71053 & Tanami & 1911 & 3852.6 & 2900.9 & 4896.4 & 736 & 554 & 936 \\
\hline 71054 & Yuendumu - Anmatjere & 1324 & 4597.3 & 3403.1 & 5918.1 & 609 & 451 & 784 \\
\hline 71055 & Barkly & 1663 & 3494.2 & 2576.4 & 4537.1 & 581 & 428 & 755 \\
\hline 71056 & Tennant Creek & 2123 & 2208.7 & 1668.0 & 2858.6 & 469 & 354 & 607 \\
\hline
\end{tabular}




\begin{tabular}{|c|c|c|c|c|c|c|c|c|}
\hline \multirow[b]{2}{*}{$\begin{array}{l}\text { SA2_5DIGIT } \\
\text { CODE_2016 }\end{array}$} & \multirow[b]{2}{*}{ SA2_name } & \multicolumn{7}{|c|}{ Unit-level SAEs } \\
\hline & & $\begin{array}{r}\text { Unit-level_Probit_ } \\
\text { totalpopulation }\end{array}$ & $\begin{array}{r}\text { Unit-level_ } \\
\text { probit_ } \\
\text { RATE }\end{array}$ & $\begin{array}{r}\text { Unit-level_ } \\
\text { probit_ } \\
\text { RATE_- } \\
\text { LowerCl }\end{array}$ & $\begin{array}{r}\text { Unit-level_ } \\
\text { probit_ } \\
\text { RATE_ } \\
\text { UpperCl }\end{array}$ & $\begin{array}{r}\text { Unit-level_ } \\
\text { probit_ } \\
\text { number }\end{array}$ & $\begin{array}{r}\text { Unit-level_ } \\
\text { probit_ } \\
\text { number_ } \\
\text { LowerCl }\end{array}$ & $\begin{array}{c}\text { Unit-level_ } \\
\text { probit_ } \\
\text { number } \\
\text { UpperCl }\end{array}$ \\
\hline 71057 & Alligator & 3382 & 1174.0 & 915.3 & 1500.9 & 397 & 310 & 508 \\
\hline 71058 & Daly & 1209 & 3101.7 & 2302.7 & 3990.2 & 375 & 278 & 482 \\
\hline 71059 & Thamarrurr & 1621 & 4136.7 & 3049.5 & 5351.0 & 671 & 494 & 867 \\
\hline 71060 & Tiwi Islands & 1757 & 4813.3 & 3661.7 & 6018.6 & 846 & 643 & 1057 \\
\hline 71061 & West Arnhem & 3288 & 4135.7 & 3018.5 & 5440.7 & 1360 & 992 & 1789 \\
\hline 71062 & Anindilyakwa & 1731 & 2768.4 & 1963.9 & 3868.2 & 479 & 340 & 670 \\
\hline 71063 & East Arnhem & 4936 & 4538.0 & 3275.4 & 6000.3 & 2240 & 1617 & 2962 \\
\hline 71064 & Nhulunbuy & 2011 & 1012.4 & 841.5 & 1357.1 & 204 & 169 & 273 \\
\hline 71065 & Elsey & 1588 & 3539.6 & 2641.7 & 4529.9 & 562 & 420 & 719 \\
\hline 71066 & Gulf & 2688 & 3627.0 & 2625.4 & 4808.5 & 975 & 706 & 1293 \\
\hline 71067 & Katherine & 6967 & 1085.4 & 852.1 & 1394.6 & 756 & 594 & 972 \\
\hline 71068 & Victoria River & 1608 & 3350.7 & 2468.8 & 4357.5 & 539 & 397 & 701 \\
\hline 81001 & Aranda & 1772 & 445.1 & 364.9 & 576.0 & 79 & 65 & 102 \\
\hline 81002 & Belconnen & 5771 & 1470.1 & 1211.6 & 1873.6 & 848 & 699 & 1081 \\
\hline 81003 & Bruce & 5996 & 1100.3 & 905.6 & 1417.1 & 660 & 543 & 850 \\
\hline 81004 & Charnwood & 2231 & 1053.9 & 863.5 & 1305.3 & 235 & 193 & 291 \\
\hline 81005 & Cook & 2180 & 620.2 & 509.7 & 789.1 & 135 & 111 & 172 \\
\hline 81006 & Dunlop & 5100 & 451.0 & 370.8 & 568.2 & 230 & 189 & 290 \\
\hline 81007 & Evatt & 4005 & 524.6 & 427.2 & 668.9 & 210 & 171 & 268 \\
\hline 81008 & Florey & 3747 & 1043.6 & 855.1 & 1303.7 & 391 & 320 & 489 \\
\hline 81009 & Flynn (ACT) & 2514 & 377.1 & 309.3 & 481.9 & 95 & 78 & 121 \\
\hline 81010 & Fraser & 1504 & 241.0 & 198.4 & 303.3 & 36 & 30 & 46 \\
\hline 81011 & Giralang & 2462 & 485.0 & 395.9 & 625.5 & 119 & 97 & 154 \\
\hline 81013 & Hawker & 2277 & 614.2 & 510.3 & 768.9 & 140 & 116 & 175 \\
\hline 81014 & Higgins & 2283 & 635.4 & 523.6 & 787.1 & 145 & 120 & 180 \\
\hline 81015 & Holt & 3552 & 945.0 & 778.0 & 1164.9 & 336 & 276 & 414 \\
\hline 81016 & Kaleen & 5642 & 635.3 & 518.2 & 811.0 & 358 & 292 & 458 \\
\hline 81017 & Latham & 2694 & 586.3 & 482.7 & 730.2 & 158 & 130 & 197 \\
\hline 81019 & Macgregor (ACT) & 4928 & 468.6 & 385.9 & 598.1 & 231 & 190 & 295 \\
\hline 81020 & Macquarie & 2064 & 1129.8 & 930.7 & 1419.1 & 233 & 192 & 293 \\
\hline 81021 & McKellar & 2142 & 522.3 & 423.9 & 663.7 & 112 & 91 & 142 \\
\hline 81022 & Melba & 2321 & 614.3 & 501.5 & 775.8 & 143 & 116 & 180 \\
\hline 81023 & Page & 2395 & 998.3 & 815.9 & 1261.1 & 239 & 195 & 302 \\
\hline 81024 & Scullin & 2213 & 1015.5 & 831.9 & 1280.0 & 225 & 184 & 283 \\
\hline 81025 & Spence & 1910 & 609.1 & 496.0 & 769.3 & 116 & 95 & 147 \\
\hline 81026 & Weetangera & 1917 & 300.8 & 247.7 & 389.1 & 58 & 47 & 75 \\
\hline 81034 & Amaroo & 4005 & 420.3 & 348.6 & 542.7 & 168 & 140 & 217 \\
\hline 81035 & Bonner & 4432 & 523.5 & 434.7 & 677.3 & 232 & 193 & 300 \\
\hline 81036 & Casey & 4117 & 406.9 & 339.5 & 528.8 & 168 & 140 & 218 \\
\hline 81037 & Crace & 3264 & 503.9 & 421.4 & 653.7 & 164 & 138 & 213 \\
\hline 81038 & Forde & 2890 & 348.8 & 290.1 & 460.9 & 101 & 84 & 133 \\
\hline 81039 & Franklin & 4800 & 832.3 & 688.5 & 1075.4 & 400 & 330 & 516 \\
\hline 81040 & Gungahlin & 4733 & 1059.0 & 872.7 & 1376.4 & 501 & 413 & 651 \\
\hline 81044 & Harrison & 5463 & 803.1 & 665.9 & 1045.4 & 439 & 364 & 571 \\
\hline 81046 & Ngunnawal & 7696 & 636.8 & 527.9 & 807.1 & 490 & 406 & 621 \\
\hline 81047 & Nicholls & 5258 & 261.3 & 216.1 & 340.1 & 137 & 114 & 179 \\
\hline 81048 & Palmerston & 4235 & 685.0 & 564.0 & 874.3 & 290 & 239 & 370 \\
\hline 81049 & Acton & 2018 & 0.0 & 0.0 & 0.0 & 0 & 0 & 0 \\
\hline 81050 & Ainslie & 3986 & 1163.1 & 950.3 & 1450.9 & 464 & 379 & 578 \\
\hline 81051 & Braddon & 4912 & 1359.0 & 1122.1 & 1736.8 & 668 & 551 & 853 \\
\hline 81053 & Civic & 3967 & 596.1 & 493.7 & 779.2 & 236 & 196 & 309 \\
\hline 81054 & Dickson & 1759 & 1399.3 & 1149.9 & 1784.4 & 246 & 202 & 314 \\
\hline 81055 & Downer & 2868 & 1197.4 & 977.6 & 1521.0 & 343 & 280 & 436 \\
\hline 81056 & Hackett & 2225 & 778.5 & 640.6 & 976.6 & 173 & 143 & 217 \\
\hline 81057 & Lyneham & 4210 & 1285.5 & 1061.8 & 1625.6 & 541 & 447 & 684 \\
\hline 81058 & O'Connor (ACT) & 4279 & 1196.4 & 980.8 & 1509.9 & 512 & 420 & 646 \\
\hline 81060 & Turner & 3505 & 1457.7 & 1198.7 & 1865.1 & 511 & 420 & 654 \\
\hline
\end{tabular}




\begin{tabular}{|c|c|c|c|c|c|c|c|c|}
\hline \multirow[b]{2}{*}{$\begin{array}{l}\text { SA2_5DIGIT } \\
\text { CODE_2016 }\end{array}$} & \multirow[b]{2}{*}{ SA2_name } & \multicolumn{7}{|c|}{ Unit-level SAEs } \\
\hline & & $\begin{array}{r}\text { Unit-level_Probit_ } \\
\text { totalpopulation }\end{array}$ & $\begin{array}{r}\text { Unit-level_ } \\
\text { probit_ } \\
\text { RATE }\end{array}$ & $\begin{array}{r}\text { Unit-level_ } \\
\text { probit_ } \\
\text { RATE_- } \\
\text { LowerCl }\end{array}$ & $\begin{array}{c}\text { Unit-level_ } \\
\text { probit_ } \\
\text { RATE_ } \\
\text { UpperCl }\end{array}$ & $\begin{array}{r}\text { Unit-level_ } \\
\text { probit_ } \\
\text { number }\end{array}$ & $\begin{array}{r}\text { Unit-level_ } \\
\text { probit_ } \\
\text { number_ } \\
\text { LowerCl }\end{array}$ & $\begin{array}{r}\text { Unit-level_ } \\
\text { probit_ } \\
\text { number_- } \\
\text { UpperCl }\end{array}$ \\
\hline 81061 & Watson & 4448 & 987.8 & 815.5 & 1254.0 & 439 & 363 & 558 \\
\hline 81062 & Deakin & 2167 & 473.8 & 393.6 & 598.7 & 103 & 85 & 130 \\
\hline 81063 & Forrest & 1291 & 502.1 & 422.0 & 649.8 & 65 & 54 & 84 \\
\hline 81064 & Griffith (ACT) & 3650 & 844.9 & 703.7 & 1064.1 & 308 & 257 & 388 \\
\hline 81067 & Narrabundah & 4573 & 1010.7 & 831.3 & 1256.6 & 462 & 380 & 575 \\
\hline 81069 & Red Hill (ACT) & 2381 & 620.2 & 512.3 & 784.8 & 148 & 122 & 187 \\
\hline 81070 & Yarralumla & 2228 & 488.0 & 409.1 & 610.8 & 109 & 91 & 136 \\
\hline 81071 & Banks & 3624 & 457.2 & 374.8 & 579.1 & 166 & 136 & 210 \\
\hline 81072 & Bonython & 2937 & 749.2 & 614.5 & 950.8 & 220 & 180 & 279 \\
\hline 81073 & Calwell & 4356 & 413.8 & 341.6 & 524.9 & 180 & 149 & 229 \\
\hline 81074 & Chisholm & 3906 & 533.5 & 436.2 & 664.7 & 208 & 170 & 260 \\
\hline 81075 & Conder & 3857 & 426.5 & 349.7 & 535.4 & 165 & 135 & 206 \\
\hline 81076 & Fadden & 2247 & 121.1 & 101.4 & 159.8 & 27 & 23 & 36 \\
\hline 81077 & Gilmore & 2044 & 690.7 & 566.2 & 861.3 & 141 & 116 & 176 \\
\hline 81078 & Gordon (ACT) & 5814 & 574.0 & 467.5 & 727.0 & 334 & 272 & 423 \\
\hline 81079 & Gowrie (ACT) & 2303 & 395.7 & 325.2 & 500.4 & 91 & 75 & 115 \\
\hline 81080 & Greenway & 1560 & 1015.4 & 838.9 & 1321.9 & 158 & 131 & 206 \\
\hline 81081 & Isabella Plains & 3304 & 514.1 & 422.5 & 654.2 & 170 & 140 & 216 \\
\hline 81082 & Kambah & 11224 & 629.6 & 512.3 & 791.1 & 707 & 575 & 888 \\
\hline 81083 & Macarthur & 1107 & 104.1 & 87.3 & 141.1 & 12 & 10 & 16 \\
\hline 81084 & Monash & 4312 & 478.3 & 392.6 & 609.9 & 206 & 169 & 263 \\
\hline 81086 & Oxley (ACT) & 1296 & 667.1 & 539.3 & 852.6 & 86 & 70 & 110 \\
\hline 81087 & Richardson & 2255 & 759.6 & 620.9 & 942.2 & 171 & 140 & 212 \\
\hline 81088 & Theodore & 2861 & 472.7 & 385.4 & 599.8 & 135 & 110 & 172 \\
\hline 81090 & Wanniassa & 5720 & 592.7 & 482.6 & 747.0 & 339 & 276 & 427 \\
\hline 81091 & Chapman & 2018 & 196.8 & 163.4 & 251.8 & 40 & 33 & 51 \\
\hline 81092 & Duffy & 2310 & 514.4 & 423.0 & 648.5 & 119 & 98 & 150 \\
\hline 81093 & Fisher & 2189 & 512.2 & 425.0 & 635.1 & 112 & 93 & 139 \\
\hline 81094 & Holder & 1950 & 489.0 & 402.9 & 627.8 & 95 & 79 & 122 \\
\hline 81095 & Rivett & 2355 & 854.8 & 697.1 & 1061.8 & 201 & 164 & 250 \\
\hline 81096 & Stirling & 1673 & 459.7 & 377.4 & 584.2 & 77 & 63 & 98 \\
\hline 81097 & Waramanga & 1959 & 859.2 & 704.3 & 1061.0 & 168 & 138 & 208 \\
\hline 81098 & Weston & 2741 & 476.9 & 395.6 & 600.6 & 131 & 108 & 165 \\
\hline 81099 & Chifley & 1874 & 845.4 & 699.9 & 1070.9 & 158 & 131 & 201 \\
\hline 81100 & Curtin & 3968 & 486.9 & 402.7 & 622.0 & 193 & 160 & 247 \\
\hline 81101 & Farrer & 2477 & 403.6 & 332.2 & 516.4 & 100 & 82 & 128 \\
\hline 81102 & Garran & 2617 & 525.9 & 438.3 & 668.0 & 138 & 115 & 175 \\
\hline 81103 & Hughes & 2263 & 547.7 & 450.4 & 689.3 & 124 & 102 & 156 \\
\hline 81104 & Isaacs & 1858 & 369.9 & 302.8 & 484.6 & 69 & 56 & 90 \\
\hline 81105 & Lyons (ACT) & 2455 & 1192.3 & 985.4 & 1494.0 & 293 & 242 & 367 \\
\hline 81106 & Mawson & 2556 & 1005.6 & 828.5 & 1270.6 & 257 & 212 & 325 \\
\hline 81107 & O'Malley & 775 & 133.6 & 112.4 & 179.8 & 10 & 9 & 14 \\
\hline 81108 & Pearce & 1965 & 640.4 & 528.5 & 805.4 & 126 & 104 & 158 \\
\hline 81109 & Phillip & 2455 & 1150.6 & 960.1 & 1480.1 & 282 & 236 & 363 \\
\hline 81110 & Torrens & 1679 & 576.1 & 472.7 & 735.1 & 97 & 79 & 123 \\
\hline 81113 & Canberra East & 730 & 1306.6 & 1079.6 & 1599.2 & 95 & 79 & 117 \\
\hline 81124 & Campbell & 2523 & 643.2 & 528.5 & 831.0 & 162 & 133 & 210 \\
\hline 81125 & Duntroon & 1577 & 135.0 & 119.2 & 180.7 & 21 & 19 & 28 \\
\hline 81127 & Reid & 1363 & 1722.5 & 1423.4 & 2117.9 & 235 & 194 & 289 \\
\hline 81129 & Barton & 1199 & 663.6 & 556.6 & 888.7 & 80 & 67 & 107 \\
\hline 81131 & Kingston (ACT) & 3748 & 885.0 & 741.8 & 1158.3 & 332 & 278 & 434 \\
\hline 81135 & Coombs & 1288 & 248.4 & 205.3 & 318.7 & 32 & 26 & 41 \\
\hline 81139 & Wright & 2151 & 303.9 & 256.1 & 399.3 & 65 & 55 & 86 \\
\hline
\end{tabular}




\begin{tabular}{|c|c|c|c|c|c|c|c|c|c|c|c|c|c|c|c|}
\hline \multirow[b]{2}{*}{$\begin{array}{l}\text { SA3_ } \\
\text { CODE_2016 }\end{array}$} & \multirow[b]{2}{*}{ SA3_NAME_2016 } & \multicolumn{7}{|c|}{ Unit-level SAES } & \multicolumn{7}{|c|}{ Area-level SAEs } \\
\hline & & $\begin{array}{l}\text { Unit-level_Probit_ } \\
\text { totalpopulation }\end{array}$ & $\begin{array}{r}\text { Unit-level_ } \\
\text { probit_RATE }\end{array}$ & $\begin{array}{r}\text { Unit- } \\
\text { level_probit_ } \\
\text { RATE_- } \\
\text { LowerCl }\end{array}$ & $\begin{array}{r}\text { Unit- } \\
\text { level_probit_- } \\
\text { RATE_ } \\
\text { UpperCl }\end{array}$ & $\begin{array}{r}\text { Unit- } \\
\text { level_probit_ } \\
\text { number }\end{array}$ & $\begin{array}{l}\text { Unit- } \\
\text { level_probit_ } \\
\text { number_- } \\
\text { LowerCl }\end{array}$ & $\begin{array}{r}\text { Unit- } \\
\text { level_probit_ } \\
\text { number_- } \\
\text { UpperCl }\end{array}$ & $\begin{array}{l}\text { Area-level_FH_ } \\
\text { totalpopulation }\end{array}$ & $\begin{array}{c}\text { Area-level_- } \\
\text { FH_RATE }\end{array}$ & $\begin{array}{c}\text { Area-level_- } \\
\text { FH_RATE_- } \\
\text { LowerCl }\end{array}$ & $\begin{array}{l}\text { Area-level_- } \\
\text { FH_RATE_- } \\
\text { UpperCl }\end{array}$ & $\begin{array}{l}\text { Area-level_ } \\
\text { FH_number }\end{array}$ & $\begin{array}{r}\text { Area-level_ } \\
\text { FH_number_- } \\
\text { LowerCl }\end{array}$ & $\begin{array}{r}\text { Area-level_ } \\
\text { FH_number- } \\
\text { Uppercl }\end{array}$ \\
\hline 80110 & Molonglo & 3448 & 298.0 & 249.2 & 387.0 & 103 & 86 & 133 & 3602.00 & 201.0 & 7.8 & 647.0 & 72 & 3 & 233 \\
\hline 80109 & Woden Valley & 26924 & 714.7 & 589.2 & 908.7 & 1924 & 1586 & 2447 & 28617.00 & 934.6 & 453.2 & 1548.0 & 2675 & 1297 & 4430 \\
\hline 80108 & Weston Creek & 17193 & 571.7 & 469.4 & 716.7 & 983 & 807 & 1232 & 18340.00 & 382.5 & 134.4 & 677.0 & 702 & 247 & 1242 \\
\hline 80107 & Tuggeranong & 64741 & 560.1 & 457.5 & 707.0 & 3626 & 2962 & 4577 & 68450.00 & 536.8 & 111.6 & 1056.8 & 3675 & 764 & 7234 \\
\hline 80106 & South Canberra & 21282 & 772.3 & 640.3 & 981.7 & 1644 & 1363 & 2089 & 23076.00 & 677.1 & 244.6 & 1238.5 & 1563 & 565 & 2858 \\
\hline 80105 & North Canberra & 43628 & 1047.8 & 861.7 & 1329.9 & 4571 & 3759 & 5802 & 46393.00 & 2030.6 & 1059.7 & 3211.1 & 9420 & 4916 & 14897 \\
\hline 80104 & Gungahlin & 51619 & 624.5 & 516.2 & 805.2 & 3224 & 2665 & 4156 & 53955.00 & 381.5 & 56.8 & 921.8 & 2058 & 307 & 4974 \\
\hline 80103 & Canberra East & 1384 & 865.3 & 714.6 & 1071.5 & 120 & 99 & 148 & 1448.00 & 5328.4 & 3750.4 & 7015.0 & 772 & 543 & 1016 \\
\hline 80101 & Belconnen & 73723 & 767.0 & 628.8 & 970.8 & 5655 & 4636 & 7157 & 77996.00 & 905.6 & 495.0 & 1898.0 & 7063 & 3861 & 14803 \\
\hline 70205 & Katherine & 12853 & 2218.7 & 1656.9 & 2886.6 & 2852 & 2130 & 3710 & 13903.00 & 2842.5 & 1807.1 & 3572.5 & 3952 & 2512 & 4967 \\
\hline 70204 & East Arnhem & 8679 & 3366.4 & 2448.7 & 4498.5 & 2922 & 2125 & 3904 & 9303.00 & 4583.3 & 3134.7 & 5420.5 & 4264 & 2916 & 5043 \\
\hline 70203 & Daly - Tiwi - West Arnhem & 11264 & 3265.9 & 2433.1 & 4209.4 & 3679 & 2741 & 4742 & 11996.00 & 5302.0 & 3757.0 & 6414.2 & 6360 & 4507 & 7694 \\
\hline 70202 & Barkly & 3776 & 2793.0 & 2084.1 & 3616.7 & 1055 & 787 & 1366 & 4158.00 & 4524.0 & 3168.0 & 5621.9 & 1881 & 1317 & 2338 \\
\hline 70201 & Alice Springs & 26079 & 1688.3 & 1298.4 & 2160.3 & 4403 & 3386 & 5634 & 28347.00 & 901.7 & 401.3 & 1620.9 & 2556 & 1137 & 4595 \\
\hline 70104 & Palmerston & 23560 & 940.5 & 766.3 & 1203.2 & 2216 & 1806 & 2835 & 25019.00 & 1869.5 & 661.2 & 3283.6 & 4677 & 1654 & 8215 \\
\hline 70103 & Litchfield & 18282 & 286.8 & 233.5 & 370.8 & 524 & 427 & 678 & 19345.00 & 1472.2 & 658.2 & 2279.3 & 2848 & 1273 & 4409 \\
\hline 70102 & Darwin Suburbs & 40129 & 850.6 & 691.5 & 1088.5 & 3413 & 2775 & 4368 & 42669.00 & 1402.3 & 769.7 & 2308.1 & 5983 & 3284 & 9849 \\
\hline 70101 & Darwin City & 20717 & 880.8 & 728.5 & 1150.8 & 1825 & 1509 & 2384 & 22252.00 & 409.0 & 130.7 & 1009.7 & 910 & 291 & 2247 \\
\hline 60403 & West Coast & 12824 & 811.2 & 660.2 & 1008.6 & 1040 & 847 & 1293 & 13967.00 & 1037.9 & 465.5 & 2160.7 & 1450 & 650 & 3018 \\
\hline 60402 & Devonport & 33609 & 1047.4 & 851.6 & 1288.3 & 3520 & 2862 & 4330 & 36503.00 & 1016.4 & 335.7 & 2130.0 & 3710 & 1225 & 7775 \\
\hline 60401 & Burnie - Ulverstone & 36338 & 1102.3 & 896.7 & 1347.7 & 4005 & 3259 & 4897 & 39209.00 & 1472.7 & 643.7 & 2298.8 & 5774 & 2524 & 9013 \\
\hline 60303 & South East Coast & 5121 & 736.8 & 601.3 & 908.6 & 377 & 308 & 465 & 5903.00 & 899.4 & 369.2 & 1511.5 & 531 & 218 & 892 \\
\hline 60302 & Huon - Bruny Island & 14672 & 607.8 & 493.1 & 754.1 & 892 & 724 & 1106 & 15819.00 & 2016.0 & 870.7 & 3254.0 & 3189 & 1377 & 5147 \\
\hline 60301 & Central Highlands (Tas.) & 8596 & 588.1 & 477.7 & 729.6 & 506 & 411 & 627 & 9193.00 & 1145.4 & 590.9 & 1949.0 & 1053 & 543 & 1792 \\
\hline 60203 & North East & 28400 & 857.5 & 699.5 & 1056.2 & 2435 & 1987 & 3000 & 30863.00 & 1225.6 & 626.8 & 2184.1 & 3782 & 1934 & 6741 \\
\hline 60202 & Meander Valley - West Tamar & 17217 & 638.9 & 521.7 & 789.3 & 1100 & 898 & 1359 & 18675.00 & 1089.8 & 562.7 & 1798.1 & 2035 & 1051 & 3358 \\
\hline 60201 & Launceston & 62086 & 1180.5 & 963.3 & 1456.1 & 7329 & 5981 & 9040 & 66508.00 & 1210.9 & 715.2 & 1992.4 & 8053 & 4757 & 13251 \\
\hline 60106 & Sorell - Dodges Ferry & 12210 & 698.6 & 569.0 & 864.2 & 853 & 695 & 1055 & 13128.00 & 1449.5 & 826.5 & 2202.8 & 1903 & 1085 & 2892 \\
\hline 60105 & Hobart Inner & 40301 & 1104.4 & 904.9 & 1382.8 & 4451 & 3647 & 5573 & 43320.00 & 1371.0 & 754.3 & 2326.4 & 5939 & 3268 & 10078 \\
\hline 60104 & Hobart - South and West & 24514 & 688.8 & 562.9 & 857.7 & 1688 & 1380 & 2103 & 26168.00 & 1036.8 & 564.3 & 1824.6 & 2713 & 1477 & 4775 \\
\hline 60103 & Hobart - North West & 41027 & 1288.8 & 1048.2 & 1584.4 & 5288 & 4301 & 6500 & 43407.00 & 2817.9 & 1681.9 & 3788.8 & 12232 & 7301 & 16446 \\
\hline 60102 & Hobart - North East & 40275 & 783.2 & 637.6 & 971.0 & 3154 & 2568 & 3911 & 43111.00 & 1052.3 & 592.7 & 1659.2 & 4537 & 2555 & 7153 \\
\hline 60101 & Brighton & 12373 & 1259.0 & 1016.2 & 1545.9 & 1558 & 1257 & 1913 & 13092.00 & 2809.4 & 1602.3 & 4168.5 & 3678 & 2098 & 5457 \\
\hline 51104 & Mid West & 39599 & 939.6 & 755.2 & 1176.6 & 3721 & 2991 & 4659 & 43347.00 & 1492.0 & 897.3 & 2621.8 & 6468 & 3890 & 11365 \\
\hline 51103 & Goldfields & 28255 & 928.5 & 736.6 & 1193.1 & 2624 & 2081 & 3371 & 30419.00 & 1343.0 & 709.5 & 2033.9 & 4085 & 2158 & 6187 \\
\hline 51102 & Gascoyne & 6864 & 1096.7 & 878.4 & 1387.8 & 753 & 603 & 953 & 7543.00 & 1369.2 & 662.5 & 2240.5 & 1033 & 500 & 1690 \\
\hline 51101 & Esperance & 11421 & 800.1 & 653.8 & 1007.9 & 914 & 747 & 1151 & 12751.00 & 1522.9 & 1261.4 & 1852.2 & 1942 & 1608 & 2362 \\
\hline
\end{tabular}




\begin{tabular}{|c|c|c|c|c|c|c|c|c|c|c|c|c|c|c|c|}
\hline \multirow[b]{2}{*}{$\begin{array}{l}\text { SA3_ } \\
\text { CODE_2016 }\end{array}$} & \multirow[b]{2}{*}{ SA3_NAME_2016 } & \multicolumn{7}{|c|}{ Unit-level SAES } & \multicolumn{7}{|c|}{ Area-level SAES } \\
\hline & & $\begin{array}{l}\text { Unit-level_Probit_ } \\
\text { totalpopulation }\end{array}$ & $\begin{array}{c}\text { Unit-level_ } \\
\text { probit_RATE }\end{array}$ & $\begin{array}{r}\text { Unit- } \\
\text { level_probit_- } \\
\text { RATE_- } \\
\text { LowerCl }\end{array}$ & $\begin{array}{r}\text { Unit- } \\
\text { level_probit- } \\
\text { RATE- } \\
\text { UpperCl }\end{array}$ & $\begin{array}{r}\text { Unit- } \\
\text { level_probit_ } \\
\text { number }\end{array}$ & $\begin{array}{r}\text { Unit- } \\
\text { level_probit_ } \\
\text { number_- } \\
\text { LowerCl }\end{array}$ & $\begin{array}{r}\text { Unit- } \\
\text { level_probit_ } \\
\text { number_- } \\
\text { UpperCl }\end{array}$ & $\begin{array}{l}\text { Area-level_FH_ } \\
\text { totalpopulation }\end{array}$ & $\begin{array}{c}\text { Area-level_ } \\
\text { FH_RATE }\end{array}$ & $\begin{array}{c}\text { Area-level_ } \\
\text { FH_RATE_ } \\
\text { LowerCl }\end{array}$ & $\begin{array}{l}\text { Area-level_ } \\
\text { FH_RATE_- } \\
\text { UpperCl }\end{array}$ & $\begin{array}{l}\text { Area-level_ } \\
\text { FH_number }\end{array}$ & $\begin{array}{l}\text { Area-level_ } \\
\text { FH_number_- } \\
\text { LowerCl }\end{array}$ & $\begin{array}{r}\text { Area-level_- } \\
\text { FH_number_- } \\
\text { UpperCl }\end{array}$ \\
\hline 51003 & West Pilbara & 25665 & 814.5 & 657.1 & 1077.0 & 2090 & 1687 & 2764 & 27464.00 & 436.5 & 109.3 & 908.7 & 1199 & 300 & 2496 \\
\hline 51002 & East Pilbara & 18642 & 976.8 & 771.7 & 1287.5 & 1821 & 1439 & 2400 & 20021.00 & 738.3 & 339.3 & 1275.1 & 1478 & 679 & 2553 \\
\hline 51001 & Kimberley & 23697 & 2073.4 & 1596.9 & 2636.5 & 4913 & 3784 & 6248 & 25987.00 & 3236.7 & 2289.8 & 4389.1 & 8411 & 5950 & 11406 \\
\hline 50903 & Wheat Belt - South & 14747 & 776.2 & 632.3 & 967.7 & 1145 & 933 & 1427 & 16240.00 & 2222.5 & 1373.1 & 3262.1 & 3609 & 2230 & 5298 \\
\hline 50902 & Wheat Belt - North & 41963 & 650.6 & 528.9 & 815.6 & 2730 & 2219 & 3422 & 45804.00 & 1312.6 & 790.5 & 1954.8 & 6012 & 3621 & 8954 \\
\hline 50901 & Albany & 43894 & 858.5 & 702.9 & 1066.5 & 3768 & 3085 & 4681 & 48071.00 & 764.6 & 316.4 & 1533.3 & 3676 & 1521 & 7371 \\
\hline 50705 & Rockingham & 90017 & 711.5 & 580.6 & 897.5 & 6405 & 5226 & 8079 & 97184.00 & 1266.5 & 672.8 & 2121.4 & 12308 & 6538 & 20617 \\
\hline 50704 & Melville & 79341 & 553.9 & 455.1 & 702.3 & 4395 & 3611 & 5572 & 83497.00 & 510.8 & 173.4 & 1102.9 & 4265 & 1448 & 9209 \\
\hline 50703 & Kwinana & 28583 & 766.4 & 624.4 & 958.9 & 2191 & 1785 & 2741 & 30238.00 & 1859.5 & 1049.9 & 2875.4 & 5623 & 3175 & 8695 \\
\hline 50702 & Fremantle & 29054 & 817.3 & 671.4 & 1021.5 & 2374 & 1951 & 2968 & 31126.00 & 1242.9 & 537.3 & 2305.5 & 3869 & 1672 & 7176 \\
\hline 50701 & Cockburn & 77256 & 642.6 & 526.8 & 811.8 & 4964 & 4070 & 6272 & 81501.00 & 483.6 & 105.2 & 1013.5 & 3942 & 857 & 8260 \\
\hline 50607 & South Perth & 33950 & 934.2 & 767.1 & 1182.7 & 3172 & 2604 & 4015 & 35943.00 & 952.7 & 341.3 & 1460.3 & 3424 & 1227 & 5249 \\
\hline 50606 & Serpentine - Jarrahdale & 19351 & 303.7 & 248.5 & 390.3 & 588 & 481 & 755 & 20468.00 & 798.7 & 187.3 & 1589.9 & 1635 & 383 & 3254 \\
\hline 50605 & Kalamunda & 43626 & 436.3 & 356.0 & 554.4 & 1904 & 1553 & 2419 & 46286.00 & 610.6 & 239.0 & 1211.1 & 2826 & 1106 & 5606 \\
\hline 50604 & Gosnells & 89314 & 682.1 & 555.3 & 862.6 & 6092 & 4959 & 7704 & 93418.00 & 908.5 & 289.9 & 1879.1 & 8487 & 2708 & 17554 \\
\hline 50603 & Canning & 74087 & 885.8 & 722.1 & 1129.1 & 6562 & 5350 & 8365 & 77477.00 & 597.4 & 185.5 & 1198.2 & 4629 & 1438 & 9283 \\
\hline 50602 & Belmont - Victoria Park & 56474 & 1131.7 & 926.9 & 1436.5 & 6391 & 5235 & 8113 & 59971.00 & 696.3 & 345.9 & 1279.5 & 4176 & 2074 & 7673 \\
\hline 50601 & Armadale & 58771 & 676.4 & 550.1 & 848.7 & 3975 & 3233 & 4988 & 61891.00 & 1029.2 & 439.0 & 1779.1 & 6370 & 2717 & 11011 \\
\hline 50503 & Wanneroo & 137619 & 624.6 & 508.9 & 792.2 & 8595 & 7003 & 10902 & 144789.00 & 454.3 & 162.2 & 886.4 & 6577 & 2349 & 12834 \\
\hline 50502 & Stirling & 151494 & 861.8 & 707.1 & 1087.8 & 13055 & 10712 & 16480 & 159599.00 & 766.9 & 278.8 & 1286.8 & 12240 & 4450 & 20537 \\
\hline 50501 & Joondalup & 118873 & 387.4 & 318.8 & 494.2 & 4606 & 3790 & 5875 & 125174.00 & 265.6 & 69.2 & 558.1 & 3324 & 866 & 6986 \\
\hline 50403 & Swan & 95279 & 594.1 & 483.2 & 749.4 & 5660 & 4604 & 7140 & 100505.00 & 675.5 & 214.5 & 1181.6 & 6789 & 2156 & 11876 \\
\hline 50402 & Mundaring & 32631 & 391.1 & 317.5 & 491.1 & 1276 & 1036 & 1602 & 34638.00 & 908.3 & 373.6 & 1621.5 & 3146 & 1294 & 5617 \\
\hline 50401 & Bayswater - Bassendean & 64001 & 857.5 & 701.9 & 1083.2 & 5488 & 4492 & 6932 & 67401.00 & 1017.0 & 500.9 & 1708.5 & 6855 & 3376 & 11516 \\
\hline 50302 & Perth City & 82931 & 979.3 & 809.6 & 1246.0 & 8122 & 6714 & 10333 & 88025.00 & 899.0 & 519.2 & 1436.2 & 7914 & 4571 & 12642 \\
\hline 50301 & Cottesloe - Claremont & 52147 & 593.5 & 488.5 & 754.5 & 3095 & 2547 & 3935 & 55283.00 & 586.7 & 172.2 & 1218.8 & 3243 & 952 & 6738 \\
\hline 50201 & Mandurah & 72283 & 913.6 & 743.1 & 1141.7 & 6604 & 5372 & 8253 & 79174.00 & 1577.5 & 845.1 & 2470.5 & 12490 & 6691 & 19560 \\
\hline 50103 & Manjimup & 17056 & 685.7 & 560.0 & 851.1 & 1170 & 955 & 1452 & 18683.00 & 1292.5 & 525.5 & 2359.1 & 2415 & 982 & 4408 \\
\hline 50102 & Bunbury & 75208 & 804.2 & 656.1 & 1003.4 & 6048 & 4934 & 7546 & 81577.00 & 842.0 & 539.1 & 1230.7 & 6869 & 4397 & 10039 \\
\hline 50101 & Augusta - Margaret River - Busselton & 36039 & 821.4 & 674.5 & 1028.4 & 2960 & 2431 & 3706 & 40311.00 & 931.1 & 501.7 & 1632.9 & 3753 & 2022 & 6582 \\
\hline 40703 & Murray and Mallee & 53875 & 1005.2 & 819.5 & 1241.5 & 5415 & 4415 & 6689 & 57715.00 & 885.2 & 676.4 & 1158.0 & 5109 & 3904 & 6683 \\
\hline 40702 & Limestone Coast & 48327 & 918.4 & 753.5 & 1135.1 & 4439 & 3641 & 5485 & 52480.00 & 843.5 & 374.9 & 1510.0 & 4427 & 1967 & 7924 \\
\hline 40701 & Fleurieu - Kangaroo Island & 39321 & 848.7 & 693.9 & 1048.3 & 3337 & 2728 & 4122 & 42945.00 & 1394.4 & 518.4 & 2180.6 & 5988 & 2226 & 9365 \\
\hline 40602 & Outback - North and East & 19386 & 1379.8 & 1083.3 & 1745.1 & 2675 & 2100 & 3383 & 21126.00 & 2425.5 & 1578.0 & 3354.0 & 5124 & 3334 & 7086 \\
\hline 40601 & Eyre Peninsula and South West & 41728 & 1132.6 & 920.7 & 1397.3 & 4726 & 3842 & 5831 & 45609.00 & 1977.6 & 1397.8 & 2591.6 & 9020 & 6375 & 11820 \\
\hline 40504 & Yorke Peninsula & 19457 & 887.6 & 722.9 & 1095.8 & 1727 & 1406 & 2132 & 21497.00 & 2597.5 & 1884.5 & 3363.2 & 5584 & 4051 & 7230 \\
\hline 40503 & Mid North & 20931 & 951.3 & 774.3 & 1168.7 & 1991 & 1621 & 2446 & 22589.00 & 2067.7 & 1151.0 & 3313.4 & 4671 & 2600 & 7485 \\
\hline 40502 & Lower North & 17076 & 717.9 & 589.5 & 889.1 & 1226 & 1007 & 1518 & 18527.00 & 1760.3 & 765.8 & 3083.0 & 3261 & 1419 & 5712 \\
\hline
\end{tabular}




\begin{tabular}{|c|c|c|c|c|c|c|c|c|c|c|c|c|c|c|c|}
\hline \multirow[b]{2}{*}{$\begin{array}{l}\text { SA3_ } \\
\text { CODE_2016 }\end{array}$} & \multirow[b]{2}{*}{ SA3_NAME_2016 } & \multicolumn{7}{|c|}{ Unit-level SAES } & \multicolumn{7}{|c|}{ Area-level SAES } \\
\hline & & $\begin{array}{l}\text { Unit-level_Probit_ } \\
\text { totalpopulation }\end{array}$ & $\begin{array}{l}\text { Unit-level_ } \\
\text { probit_RATE }\end{array}$ & $\begin{array}{r}\text { Unit- } \\
\text { level_probit_ } \\
\text { RATE_- } \\
\text { LowerCl } \\
\end{array}$ & $\begin{array}{r}\text { Unit- } \\
\text { level_probit_ } \\
\text { RATE_- } \\
\text { UpperCl } \\
\end{array}$ & $\begin{array}{r}\text { Unit- } \\
\text { level_probit_ } \\
\text { number } \\
\end{array}$ & $\begin{array}{r}\text { Unit- } \\
\text { level_probit_ } \\
\text { number_- } \\
\text { LowerCl } \\
\end{array}$ & $\begin{array}{r}\text { Unit- } \\
\text { level_probit_ } \\
\text { number_- } \\
\text { UpperCl } \\
\end{array}$ & $\begin{array}{l}\text { Area-level_FH_ } \\
\text { totalpopulation }\end{array}$ & $\begin{array}{c}\text { Area-level_ } \\
\text { FH_RATE } \\
\end{array}$ & $\begin{array}{c}\text { Area-level_ } \\
\text { FH_RATE_ } \\
\text { LowerCl }\end{array}$ & $\begin{array}{r}\text { Area-level_ } \\
\text { FH_RATE_ } \\
\text { UpperCl }\end{array}$ & $\begin{array}{l}\text { Area-level_ } \\
\text { FH_number }\end{array}$ & $\begin{array}{r}\text { Area-level_ } \\
\text { FH_number_- } \\
\text { LowerCl }\end{array}$ & $\begin{array}{r}\text { Area-level_ } \\
\text { FH_number_- } \\
\text { UpperCl }\end{array}$ \\
\hline 40501 & Barossa & 27146 & 583.6 & 478.7 & 726.3 & 1584 & 1299 & 1972 & 28734.00 & 104.5 & 1.3 & 288.9 & 300 & 4 & 830 \\
\hline 40403 & West Torrens & 49726 & 1164.9 & 955.1 & 1461.7 & 5793 & 4749 & 7268 & 52220.00 & 1293.5 & 650.5 & 2185.5 & 6755 & 3397 & 11413 \\
\hline 40402 & Port Adelaide - West & 46423 & 1265.6 & 1031.6 & 1566.4 & 5875 & 4789 & 7272 & 48869.00 & 638.3 & 289.5 & 974.1 & 3119 & 1415 & 4760 \\
\hline 40401 & Charles Sturt & 87399 & 1046.3 & 856.5 & 1302.2 & 9144 & 7486 & 11381 & 91757.00 & 1232.0 & 468.7 & 2284.1 & 11304 & 4301 & 20958 \\
\hline 40304 & Onkaparinga & 129378 & 852.0 & 697.1 & 1052.9 & 11023 & 9018 & 13622 & 136586.00 & 1133.2 & 583.5 & 2002.5 & 15478 & 7970 & 27352 \\
\hline 40303 & Mitcham & 49599 & 587.7 & 481.6 & 737.7 & 2915 & 2389 & 3659 & 52355.00 & 319.0 & 47.7 & 737.1 & 1670 & 250 & 3859 \\
\hline 40302 & Marion & 71778 & 1024.5 & 839.4 & 1271.1 & 7353 & 6025 & 9124 & 75478.00 & 1277.4 & 606.1 & 1953.2 & 9641 & 4575 & 14743 \\
\hline 40301 & Holdfast Bay & 27324 & 904.7 & 745.6 & 1128.2 & 2472 & 2037 & 3083 & 29229.00 & 1011.2 & 317.8 & 2035.8 & 2956 & 929 & 5950 \\
\hline 40205 & Tea Tree Gully & 73453 & 627.5 & 514.0 & 781.4 & 4609 & 3775 & 5740 & 77190.00 & 559.4 & 194.3 & 1069.2 & 4318 & 1500 & 8253 \\
\hline 40204 & Salisbury & 104888 & 993.4 & 808.5 & 1237.0 & 10419 & 8480 & 12974 & 109630.00 & 1052.0 & 661.0 & 1613.3 & 11533 & 7246 & 17687 \\
\hline 40203 & Port Adelaide - East & 53592 & 1257.0 & 1025.2 & 1569.1 & 6737 & 5494 & 8409 & 55947.00 & 1373.5 & 811.7 & 2107.8 & 7684 & 4541 & 11792 \\
\hline 40202 & Playford & 66143 & 1415.3 & 1150.0 & 1747.3 & 9361 & 7607 & 11557 & 69498.00 & 3214.8 & 1955.6 & 4337.0 & 22342 & 13591 & 30142 \\
\hline 40201 & Gawler - Two Wells & 26565 & 797.5 & 652.5 & 986.9 & 2119 & 1733 & 2622 & 28047.00 & 1064.8 & 173.6 & 2227.1 & 2986 & 487 & 6246 \\
\hline 40107 & Unley & 30091 & 855.8 & 704.1 & 1075.7 & 2575 & 2119 & 3237 & 31736.00 & 659.9 & 154.6 & 1404.2 & 2094 & 491 & 4456 \\
\hline 40106 & Prospect - Walkerville & 22173 & 900.4 & 738.7 & 1134.3 & 1996 & 1638 & 2515 & 23482.00 & 677.5 & 196.6 & 1500.1 & 1591 & 462 & 3522 \\
\hline 40105 & Norwood - Payneham - St Peters & 28732 & 1179.6 & 969.6 & 1474.0 & 3389 & 2786 & 4235 & 30306.00 & 1155.8 & 560.4 & 1671.5 & 3503 & 1698 & 5066 \\
\hline 40104 & Campbelltown (SA) & 40538 & 841.1 & 689.5 & 1050.6 & 3410 & 2795 & 4259 & 42271.00 & 1113.6 & 327.1 & 1968.3 & 4707 & 1383 & 8320 \\
\hline 40103 & Burnside & 34573 & 615.1 & 505.6 & 778.0 & 2126 & 1748 & 2690 & 36414.00 & 675.2 & 197.5 & 1279.7 & 2459 & 719 & 4660 \\
\hline 40102 & Adelaide Hills & 54566 & 492.0 & 403.7 & 615.1 & 2685 & 2203 & 3356 & 57959.00 & 917.0 & 355.8 & 1686.6 & 5315 & 2062 & 9775 \\
\hline 40101 & Adelaide City & 19668 & 1496.9 & 1220.6 & 1902.3 & 2944 & 2401 & 3741 & 20851.00 & 1737.2 & 857.0 & 2846.5 & 3622 & 1787 & 5935 \\
\hline 31905 & Maryborough & 34865 & 1010.2 & 818.8 & 1241.8 & 3522 & 2855 & 4329 & 37411.00 & 1045.8 & 547.9 & 1819.1 & 3912 & 2050 & 6806 \\
\hline 31904 & Hervey Bay & 43956 & 1182.2 & 959.6 & 1462.4 & 5196 & 4218 & 6428 & 47102.00 & 1891.0 & 1120.0 & 2818.8 & 8907 & 5276 & 13277 \\
\hline 31903 & Gympie - Cooloola & 37632 & 1000.8 & 813.4 & 1235.7 & 3766 & 3061 & 4650 & 40444.00 & 1869.7 & 868.9 & 2963.9 & 7562 & 3514 & 11987 \\
\hline 31902 & Burnett & 37146 & 1055.4 & 849.3 & 1308.2 & 3920 & 3155 & 4860 & 39779.00 & 2003.2 & 1278.1 & 2934.0 & 7969 & 5084 & 11671 \\
\hline 31901 & Bundaberg & 67366 & 1104.2 & 896.5 & 1366.6 & 7439 & 6039 & 9206 & 72182.00 & 1808.7 & 1218.0 & 2638.1 & 13056 & 8792 & 19042 \\
\hline 31802 & Townsville & 139056 & 1105.1 & 897.7 & 1384.8 & 15367 & 12483 & 19257 & 149084.00 & 1452.0 & 633.4 & 2341.8 & 21647 & 9443 & 34913 \\
\hline 31801 & Charters Towers - Ayr - Ingham & 32011 & 1055.9 & 837.3 & 1324.0 & 3380 & 2680 & 4238 & 34165.00 & 452.8 & 187.9 & 943.3 & 1547 & 642 & 3223 \\
\hline 31701 & Toowoomba & 112186 & 999.9 & 814.4 & 1249.2 & 11217 & 9136 & 14014 & 119244.00 & 1216.8 & 595.9 & 2154.1 & 14510 & 7105 & 25686 \\
\hline 31608 & Noosa Hinterland & 16600 & 511.4 & 417.9 & 641.4 & 849 & 694 & 1065 & 17848.00 & 1039.5 & 675.1 & 1520.5 & 1855 & 1205 & 2714 \\
\hline 31607 & Nambour & 32262 & 808.2 & 658.4 & 1007.9 & 2608 & 2124 & 3252 & 34296.00 & 635.8 & 194.6 & 1242.3 & 2180 & 667 & 4261 \\
\hline 31606 & Sunshine Coast Hinterland & 38190 & 627.1 & 511.2 & 785.7 & 2395 & 1952 & 3001 & 40650.00 & 947.5 & 422.5 & 1713.5 & 3852 & 1718 & 6965 \\
\hline 31605 & Noosa & 31744 & 928.4 & 761.5 & 1166.6 & 2947 & 2417 & 3703 & 33993.00 & 794.9 & 265.8 & 1645.9 & 2702 & 904 & 5595 \\
\hline 31603 & Maroochy & 44926 & 1178.6 & 967.5 & 1477.3 & 5295 & 4346 & 6637 & 48062.00 & 870.8 & 387.3 & 1465.4 & 4185 & 1861 & 7043 \\
\hline 31602 & Caloundra & 62060 & 945.3 & 773.3 & 1189.2 & 5866 & 4799 & 7380 & 66073.00 & 873.6 & 212.1 & 1838.0 & 5772 & 1402 & 12144 \\
\hline 31601 & Buderim & 41196 & 868.5 & 709.8 & 1098.8 & 3578 & 2924 & 4527 & 43800.00 & 1014.7 & 361.2 & 1759.2 & 4444 & 1582 & 7705 \\
\hline 31503 & Outback - South & 12750 & 945.5 & 767.3 & 1180.5 & 1206 & 978 & 1505 & 14250.00 & 1772.3 & 1187.1 & 2673.3 & 2526 & 1692 & 3809 \\
\hline 31502 & Outback - North & 20871 & 1289.1 & 1003.8 & 1659.4 & 2691 & 2095 & 3463 & 22648.00 & 2038.8 & 1099.3 & 2940.7 & 4617 & 2490 & 6660 \\
\hline 31501 & Far North & 22153 & 2327.4 & 1755.3 & 3000.9 & 5156 & 3889 & 6648 & 24140.00 & 5245.2 & 3490.8 & 6641.1 & 12662 & 8427 & 16032 \\
\hline
\end{tabular}




\begin{tabular}{|c|c|c|c|c|c|c|c|c|c|c|c|c|c|c|c|}
\hline \multirow[b]{2}{*}{$\begin{array}{l}\text { SA3_ } \\
\text { CODE_2016 }\end{array}$} & \multirow[b]{2}{*}{ SA3_NAME_2016 } & \multicolumn{7}{|c|}{ Unit-level SAES } & \multicolumn{7}{|c|}{ Area-level SAES } \\
\hline & & $\begin{array}{l}\text { Unit-level_Probit_ } \\
\text { totalpopulation }\end{array}$ & $\begin{array}{l}\text { Unit-level_- } \\
\text { probit_RATE }\end{array}$ & $\begin{array}{r}\text { Unit- } \\
\text { level_probit_ } \\
\text { RATE_- } \\
\text { LowerCl } \\
\end{array}$ & $\begin{array}{r}\text { Unit- } \\
\text { level_probit_ } \\
\text { RATE_- } \\
\text { UpperCl } \\
\end{array}$ & $\begin{array}{r}\text { Unit- } \\
\text { level_probit_ } \\
\text { number } \\
\end{array}$ & $\begin{array}{r}\text { Unit- } \\
\text { level_probit_ } \\
\text { number_- } \\
\text { LowerCl } \\
\end{array}$ & $\begin{array}{r}\text { Unit- } \\
\text { level_probit_ } \\
\text { number_- } \\
\text { UpperCl } \\
\end{array}$ & $\begin{array}{l}\text { Area-level_FH_ } \\
\text { totalpopulation }\end{array}$ & $\begin{array}{c}\text { Area-level_ } \\
\text { FH_RATE } \\
\end{array}$ & $\begin{array}{c}\text { Area-level_ } \\
\text { FH_RATE_ } \\
\text { LowerCl }\end{array}$ & $\begin{array}{r}\text { Area-level_ } \\
\text { FH_RATE_ } \\
\text { UpperCl }\end{array}$ & $\begin{array}{l}\text { Area-level_ } \\
\text { FH_number }\end{array}$ & $\begin{array}{r}\text { Area-level_ } \\
\text { FH_number_ } \\
\text { LowerCl } \\
\end{array}$ & $\begin{array}{r}\text { Area-level_ } \\
\text { FH_number_- } \\
\text { UpperCl } \\
\end{array}$ \\
\hline 31403 & Strathpine & 28129 & 902.2 & 736.8 & 1131.4 & 2538 & 2072 & 3182 & 29516.00 & 1496.9 & 637.4 & 2382.9 & 4418 & 1881 & 7033 \\
\hline 31402 & North Lakes & 51327 & 1007.4 & 825.4 & 1282.3 & 5170 & 4236 & 6582 & 53763.00 & 1299.1 & 821.9 & 2000.3 & 6985 & 4419 & 10754 \\
\hline 31401 & The Hills District & 63866 & 331.3 & 272.5 & 425.7 & 2116 & 1741 & 2718 & 67102.00 & 160.6 & 42.8 & 365.5 & 1078 & 287 & 2452 \\
\hline 31305 & Redcliffe & 47175 & 1285.7 & 1047.4 & 1597.7 & 6065 & 4941 & 7537 & 49649.00 & 2138.1 & 1313.5 & 3011.6 & 10615 & 6522 & 14952 \\
\hline 31304 & Narangba - Burpengary & 46576 & 832.1 & 673.7 & 1048.3 & 3876 & 3138 & 4883 & 49006.00 & 748.3 & 251.1 & 1211.7 & 3667 & 1231 & 5938 \\
\hline 31303 & Caboolture Hinterland & 10371 & 585.9 & 475.8 & 738.3 & 608 & 493 & 766 & 10926.00 & 1669.2 & 822.2 & 2562.7 & 1824 & 898 & 2800 \\
\hline 31302 & Caboolture & 49885 & 1369.2 & 1108.9 & 1714.2 & 6830 & 5532 & 8551 & 52314.00 & 2579.4 & 1639.5 & 3570.0 & 13494 & 8577 & 18676 \\
\hline 31301 & Bribie - Beachmere & 26843 & 1020.9 & 829.2 & 1268.0 & 2740 & 2226 & 3404 & 28621.00 & 1923.1 & 1100.6 & 2666.2 & 5504 & 3150 & 7631 \\
\hline 31203 & Whitsunday & 15864 & 810.5 & 665.3 & 1017.9 & 1286 & 1055 & 1615 & 17401.00 & 588.5 & 153.9 & 1554.6 & 1024 & 268 & 2705 \\
\hline 31202 & Mackay & 82244 & 886.1 & 722.4 & 1108.6 & 7288 & 5941 & 9118 & 91208.00 & 641.6 & 295.8 & 1181.2 & 5852 & 2698 & 10774 \\
\hline 31201 & Bowen Basin - North & 23860 & 938.9 & 772.2 & 1201.8 & 2240 & 1842 & 2868 & 25913.00 & 846.6 & 291.8 & 1514.7 & 2194 & 756 & 3925 \\
\hline 31106 & Springwood - Kingston & 57589 & 1251.4 & 1011.3 & 1579.0 & 7207 & 5824 & 9093 & 60031.00 & 1762.3 & 1026.7 & 2595.5 & 10579 & 6163 & 15581 \\
\hline 31105 & Loganlea - Carbrook & 45243 & 863.4 & 699.7 & 1094.8 & 3906 & 3166 & 4953 & 47317.00 & 982.1 & 589.2 & 1860.4 & 4647 & 2788 & 8803 \\
\hline 31104 & Jimboomba & 33039 & 367.8 & 299.1 & 471.1 & 1215 & 988 & 1556 & 34702.00 & 663.3 & 174.4 & 1468.8 & 2302 & 605 & 5097 \\
\hline 31103 & Browns Plains & 58198 & 947.8 & 767.1 & 1205.6 & 5516 & 4464 & 7017 & 60677.00 & 2513.9 & 1833.3 & 3496.9 & 15253 & 11124 & 21218 \\
\hline 31102 & Beenleigh & 30534 & 1338.9 & 1087.6 & 1674.3 & 4088 & 3321 & 5112 & 32119.00 & 2607.8 & 1728.3 & 3749.1 & 8376 & 5551 & 12042 \\
\hline 31101 & Beaudesert & 10554 & 1169.9 & 947.4 & 1456.5 & 1235 & 1000 & 1537 & 11150.00 & 1972.0 & 1259.3 & 2723.3 & 2199 & 1404 & 3036 \\
\hline 31004 & Springfield - Redbank & 58890 & 1108.4 & 899.3 & 1416.6 & 6527 & 5296 & 8342 & 61537.00 & 2249.3 & 1008.4 & 3437.4 & 13842 & 6205 & 21153 \\
\hline 31003 & Ipswich Inner & 77346 & 1157.8 & 938.4 & 1446.7 & 8955 & 7258 & 11190 & 81369.00 & 2234.9 & 1599.5 & 3195.9 & 18185 & 13015 & 26005 \\
\hline 31002 & Ipswich Hinterland & 47729 & 756.0 & 612.1 & 943.4 & 3609 & 2921 & 4503 & 50392.00 & 1713.2 & 937.1 & 2540.6 & 8633 & 4722 & 12803 \\
\hline 31001 & Forest Lake - Oxley & 54817 & 1104.3 & 894.3 & 1393.2 & 6053 & 4902 & 7637 & 56977.00 & 1856.3 & 864.5 & 2892.1 & 10576 & 4926 & 16478 \\
\hline 30910 & Surfers Paradise & 34209 & 1213.3 & 996.6 & 1534.6 & 4151 & 3409 & 5250 & 36121.00 & 428.2 & 65.0 & 1101.1 & 1547 & 235 & 3977 \\
\hline 30909 & Southport & 47959 & 1358.3 & 1109.3 & 1708.8 & 6514 & 5320 & 8195 & 50198.00 & 1414.0 & 699.7 & 2338.4 & 7098 & 3513 & 11738 \\
\hline 30908 & Robina & 38969 & 970.8 & 795.6 & 1237.0 & 3783 & 3100 & 4820 & 40788.00 & 873.2 & 317.1 & 1751.3 & 3561 & 1294 & 7143 \\
\hline 30907 & Ormeau - Oxenford & 87583 & 827.3 & 676.4 & 1063.9 & 7246 & 5924 & 9318 & 91622.00 & 988.9 & 523.7 & 1803.3 & 9061 & 4799 & 16522 \\
\hline 30906 & Nerang & 51175 & 786.5 & 642.2 & 995.0 & 4025 & 3287 & 5092 & 53528.00 & 737.4 & 342.3 & 1124.4 & 3947 & 1832 & 6019 \\
\hline 30905 & Mudgeeraba - Tallebudgera & 24594 & 490.6 & 401.4 & 625.9 & 1207 & 987 & 1539 & 25757.00 & 38.7 & 9.9 & 90.7 & 100 & 26 & 234 \\
\hline 30904 & Gold Coast Hinterland & 14425 & 446.2 & 365.6 & 561.9 & 644 & 527 & 811 & 15166.00 & 443.0 & 145.6 & 866.4 & 672 & 221 & 1314 \\
\hline 30903 & Gold Coast - North & 53646 & 1200.0 & 983.3 & 1502.7 & 6437 & 5275 & 8061 & 56428.00 & 1227.1 & 480.2 & 2398.9 & 6924 & 2710 & 13537 \\
\hline 30902 & Coolangatta & 41756 & 990.8 & 813.0 & 1236.5 & 4137 & 3395 & 5163 & 44386.00 & 629.3 & 193.2 & 1439.6 & 2793 & 858 & 6390 \\
\hline 30901 & Broadbeach - Burleigh & 49582 & 911.1 & 749.8 & 1153.9 & 4517 & 3718 & 5721 & 52507.00 & 555.8 & 227.6 & 970.1 & 2918 & 1195 & 5094 \\
\hline 30805 & Gladstone & 43967 & 892.2 & 727.8 & 1123.8 & 3923 & 3200 & 4941 & 47685.00 & 693.4 & 248.7 & 1537.3 & 3307 & 1186 & 7331 \\
\hline 30804 & Biloela & 10364 & 731.0 & 600.2 & 923.2 & 758 & 622 & 957 & 11147.00 & 421.6 & 147.4 & 1194.6 & 470 & 164 & 1332 \\
\hline 30803 & Rockhampton & 84979 & 973.7 & 790.5 & 1212.0 & 8274 & 6718 & 10299 & 92558.00 & 1624.0 & 1076.5 & 2464.4 & 15032 & 9964 & 22810 \\
\hline 30801 & Central Highlands (Qld) & 19882 & 957.0 & 774.9 & 1226.4 & 1903 & 1541 & 2438 & 21713.00 & 1274.4 & 526.9 & 2143.5 & 2767 & 1144 & 4654 \\
\hline 30703 & Granite Belt & 30426 & 942.5 & 765.5 & 1171.4 & 2868 & 2329 & 3564 & 32557.00 & 1304.1 & 620.9 & 2023.5 & 4246 & 2021 & 6588 \\
\hline 30702 & Darling Downs - East & 30958 & 868.4 & 705.3 & 1088.5 & 2688 & 2183 & 3370 & 33283.00 & 726.7 & 365.7 & 1322.6 & 2419 & 1217 & 4402 \\
\hline 30701 & Darling Downs (West) - Maranoa & 31744 & 912.5 & 743.7 & 1143.4 & 2897 & 2361 & 3630 & 34562.00 & 1267.6 & 567.4 & 2242.0 & 4381 & 1961 & 7749 \\
\hline
\end{tabular}




\begin{tabular}{|c|c|c|c|c|c|c|c|c|c|c|c|c|c|c|c|}
\hline \multirow[b]{2}{*}{$\begin{array}{l}\text { SA3_ } \\
\text { CODE_2016 }\end{array}$} & \multirow[b]{2}{*}{ SA3_NAME_2016 } & \multicolumn{7}{|c|}{ Unit-level SAES } & \multicolumn{7}{|c|}{ Area-level SAEs } \\
\hline & & $\begin{array}{l}\text { Unit-level_Probit_ } \\
\text { totalpopulation }\end{array}$ & $\begin{array}{l}\text { Unit-level_- } \\
\text { probit_RATE }\end{array}$ & $\begin{array}{r}\text { Unit- } \\
\text { level_probit_ } \\
\text { RATE_- } \\
\text { LowerCl }\end{array}$ & $\begin{array}{r}\text { Unit- } \\
\text { level_probit_ } \\
\text { RATE_- } \\
\text { UpperCl }\end{array}$ & $\begin{array}{l}\text { Unit- } \\
\text { level_probit_ } \\
\text { number }\end{array}$ & $\begin{array}{r}\text { Unit- } \\
\text { level_probit_ } \\
\text { number_- } \\
\text { LowerCl }\end{array}$ & $\begin{array}{r}\text { Unit- } \\
\text { level_probit_ } \\
\text { number_- } \\
\text { UpperCl }\end{array}$ & $\begin{array}{l}\text { Area-level_FH_ } \\
\text { totalpopulation }\end{array}$ & $\begin{array}{l}\text { Area-level_ } \\
\text { FH_RATE }\end{array}$ & $\begin{array}{l}\text { Area-level_- } \\
\text { FH_RATE_- } \\
\text { LowerCl }\end{array}$ & $\begin{array}{l}\text { Area-level_ } \\
\text { FH_RATE_- } \\
\text { UpperCI }\end{array}$ & $\begin{array}{l}\text { Area-level_- } \\
\text { FH_number }\end{array}$ & $\begin{array}{r}\text { Area-level_ } \\
\text { FH_number_ } \\
\text { LowerCl }\end{array}$ & $\begin{array}{l}\text { Area-level- } \\
\text { FH_number- } \\
\text { UpperCl }\end{array}$ \\
\hline 30605 & Tablelands (East) - Kuranda & 30658 & 996.8 & 799.9 & 1240.2 & 3056 & 2452 & 3802 & 32890.00 & 2332.1 & 1296.1 & 3229.7 & 7670 & 4263 & 10622 \\
\hline 30604 & Port Douglas - Daintree & 9136 & 956.4 & 775.4 & 1202.8 & 874 & 708 & 1099 & 9706.00 & 325.6 & 205.6 & 455.5 & 316 & 200 & 442 \\
\hline 30603 & Innisfail - Cassowary Coast & 26275 & 1256.5 & 986.3 & 1593.0 & 3302 & 2592 & 4186 & 27990.00 & 2242.8 & 1430.5 & 3006.2 & 6278 & 4004 & 8414 \\
\hline 30602 & Cairns - South & 75277 & 1364.6 & 1099.6 & 1702.9 & 10272 & 8277 & 12819 & 80185.00 & 1586.6 & 939.9 & 2369.8 & 12723 & 7537 & 19003 \\
\hline 30601 & Cairns - North & 39065 & 867.6 & 709.4 & 1095.9 & 3389 & 2771 & 4281 & 41792.00 & 749.5 & 257.8 & 1581.6 & 3132 & 1077 & 6610 \\
\hline 30504 & Brisbane Inner - West & 43605 & 925.5 & 761.6 & 1188.9 & 4036 & 3321 & 5184 & 46437.00 & 984.6 & 413.9 & 1640.7 & 4572 & 1922 & 7619 \\
\hline 30503 & Brisbane Inner - North & 69300 & 1119.8 & 923.5 & 1426.9 & 7760 & 6400 & 9888 & 73612.00 & 788.5 & 227.0 & 1431.0 & 5804 & 1671 & 10534 \\
\hline 30502 & Brisbane Inner - East & 31113 & 910.5 & 753.2 & 1162.7 & 2833 & 2344 & 3617 & 33289.00 & 484.4 & 168.4 & 1078.7 & 1612 & 560 & 3591 \\
\hline 30501 & Brisbane Inner & 58414 & 1361.3 & 1120.7 & 1738.4 & 7952 & 6546 & 10155 & 62154.00 & 738.9 & 283.0 & 1356.7 & 4592 & 1759 & 8433 \\
\hline 30404 & The Gap - Enoggera & 37607 & 720.8 & 591.1 & 910.7 & 2711 & 2223 & 3425 & 39625.00 & 772.4 & 382.4 & 1322.9 & 3061 & 1515 & 5242 \\
\hline 30403 & Sherwood - Indooroopilly & 41199 & 1204.2 & 982.2 & 1540.2 & 4961 & 4046 & 6345 & 43564.00 & 979.2 & 500.8 & 1668.8 & 4266 & 2182 & 7270 \\
\hline 30402 & Kenmore - Brookfield - Moggill & 34076 & 317.3 & 260.1 & 411.1 & 1081 & 886 & 1401 & 35864.00 & 252.3 & 40.0 & 589.5 & 905 & 144 & 2114 \\
\hline 30401 & Centenary & 24890 & 399.8 & 328.8 & 515.9 & 995 & 818 & 1284 & 26001.00 & 443.4 & 138.8 & 861.6 & 1153 & 361 & 2240 \\
\hline 30306 & Sunnybank & 39307 & 886.2 & 718.1 & 1145.5 & 3483 & 2822 & 4503 & 40948.00 & 1082.8 & 424.4 & 1893.7 & 4434 & 1738 & 7754 \\
\hline 30305 & Rocklea - Acacia Ridge & 45175 & 738.0 & 601.0 & 946.7 & 3334 & 2715 & 4277 & 46942.00 & 343.5 & 124.3 & 735.5 & 1612 & 583 & 3452 \\
\hline 30304 & Nathan & 30382 & 910.3 & 743.2 & 1157.9 & 2766 & 2258 & 3518 & 31852.00 & 875.6 & 318.7 & 1793.5 & 2789 & 1015 & 5713 \\
\hline 30303 & Mt Gravatt & 56076 & 851.2 & 693.7 & 1088.1 & 4773 & 3890 & 6101 & 58580.00 & 845.0 & 317.0 & 1934.5 & 4950 & 1857 & 11332 \\
\hline 30302 & Holland Park - Yeronga & 57288 & 1219.2 & 1003.0 & 1541.6 & 6985 & 5746 & 8831 & 60340.00 & 1157.0 & 692.4 & 1876.5 & 6981 & 4178 & 11323 \\
\hline 30301 & Carindale & 38979 & 646.8 & 532.1 & 825.6 & 2521 & 2074 & 3218 & 40893.00 & 500.8 & 143.4 & 1033.0 & 2048 & 586 & 4224 \\
\hline 30204 & Sandgate & 44953 & 953.3 & 778.1 & 1201.0 & 4285 & 3498 & 5399 & 47054.00 & 666.9 & 295.3 & 1286.0 & 3138 & 1389 & 6051 \\
\hline 30203 & Nundah & 30735 & 985.9 & 811.9 & 1249.1 & 3030 & 2495 & 3839 & 32401.00 & 802.0 & 312.2 & 1704.5 & 2598 & 1011 & 5523 \\
\hline 30202 & Chermside & 54143 & 986.7 & 809.2 & 1245.0 & 5342 & 4381 & 6741 & 56801.00 & 961.3 & 417.1 & 1800.8 & 5460 & 2369 & 10229 \\
\hline 30201 & Bald Hills - Everton Park & 31711 & 570.0 & 467.9 & 728.5 & 1808 & 1484 & 2310 & 33195.00 & 549.8 & 211.9 & 1083.7 & 1825 & 703 & 3597 \\
\hline 30103 & Wynnum - Manly & 51520 & 752.7 & 616.9 & 950.4 & 3878 & 3179 & 4897 & 54454.00 & 668.6 & 225.3 & 1353.2 & 3641 & 1227 & 7368 \\
\hline 30102 & Cleveland - Stradbroke & 63804 & 753.2 & 615.0 & 944.4 & 4806 & 3924 & 6026 & 67563.00 & 911.3 & 442.9 & 1598.6 & 6157 & 2992 & 10801 \\
\hline 30101 & Capalaba & 55016 & 630.0 & 514.8 & 792.5 & 3466 & 2832 & 4360 & 57713.00 & 673.4 & 305.4 & 1169.0 & 3887 & 1762 & 6747 \\
\hline 21704 & Warnambool & 37749 & 850.8 & 697.9 & 1055.9 & 3212 & 2635 & 3986 & 40621.00 & 802.0 & 502.3 & 973.5 & 3258 & 2040 & 3955 \\
\hline 21703 & Colac - Corangamite & 27951 & 726.0 & 595.1 & 897.4 & 2029 & 1663 & 2508 & 30400.00 & 95.6 & 28.4 & 196.6 & 291 & 86 & 598 \\
\hline 21701 & Glenelg - Southern Grampians & 27203 & 745.3 & 609.8 & 920.9 & 2027 & 1659 & 2505 & 29626.00 & 1461.6 & 917.7 & 2292.6 & 4330 & 2719 & 6792 \\
\hline 21603 & Shepparton & 47714 & 930.7 & 757.0 & 1158.7 & 4441 & 3612 & 5528 & 50999.00 & 1357.5 & 704.5 & 2004.5 & 6923 & 3593 & 10223 \\
\hline 21602 & Moira & 21959 & 764.7 & 625.7 & 946.1 & 1679 & 1374 & 2078 & 23970.00 & 1093.2 & 289.0 & 2098.5 & 2620 & 693 & 5030 \\
\hline 21601 & Campaspe & 28305 & 754.2 & 615.8 & 935.0 & 2135 & 1743 & 2646 & 30565.00 & 1307.0 & 730.4 & 2355.3 & 3995 & 2232 & 7199 \\
\hline 21503 & Murray River - Swan Hill & 28568 & 769.0 & 627.2 & 954.5 & 2197 & 1792 & 2727 & 30726.00 & 1791.7 & 1016.3 & 2485.3 & 5505 & 3123 & 7636 \\
\hline 21502 & Mildura & 40835 & 1034.5 & 842.2 & 1280.7 & 4224 & 3439 & 5230 & 43652.00 & 1281.1 & 938.7 & 1712.3 & 5592 & 4098 & 7474 \\
\hline 21501 & Grampians & 45358 & 738.0 & 603.7 & 910.9 & 3348 & 2738 & 4132 & 48992.00 & 2469.9 & 1559.0 & 3220.3 & 12100 & 7638 & 15777 \\
\hline 21402 & Mornington Peninsula & 118519 & 627.2 & 514.3 & 782.5 & 7434 & 6096 & 9274 & 128160.00 & 987.2 & 514.6 & 1753.3 & 12652 & 6594 & 22471 \\
\hline 21401 & Frankston & 104063 & 863.8 & 708.1 & 1077.7 & 8989 & 7369 & 11215 & 109108.00 & 1198.8 & 605.1 & 1886.4 & 13079 & 6602 & 20582 \\
\hline 21305 & Wyndham & 161854 & 725.5 & 592.2 & 929.0 & 11742 & 9585 & 15036 & 167283.00 & 718.6 & 359.1 & 1367.3 & 12022 & 6007 & 22872 \\
\hline
\end{tabular}




\begin{tabular}{|c|c|c|c|c|c|c|c|c|c|c|c|c|c|c|c|}
\hline \multirow[b]{2}{*}{$\begin{array}{l}\text { SA3_ } \\
\text { CODE_2016 }\end{array}$} & \multirow[b]{2}{*}{ SA3_NAME_2016 } & \multicolumn{7}{|c|}{ Unit-level SAES } & \multicolumn{7}{|c|}{ Area-level SAES } \\
\hline & & $\begin{array}{l}\text { Unit-level_Probit_ } \\
\text { totalpopulation }\end{array}$ & $\begin{array}{c}\text { Unit-level_ } \\
\text { probit_RATE }\end{array}$ & $\begin{array}{r}\text { Unit- } \\
\text { level_probit_- } \\
\text { RATE_- } \\
\text { LowerCl }\end{array}$ & $\begin{array}{r}\text { Unit- } \\
\text { level_probit- } \\
\text { RATE- } \\
\text { UpperCl }\end{array}$ & $\begin{array}{r}\text { Unit- } \\
\text { level_probit_ } \\
\text { number }\end{array}$ & $\begin{array}{r}\text { Unit- } \\
\text { level_probit_ } \\
\text { number_- } \\
\text { LowerCl }\end{array}$ & $\begin{array}{r}\text { Unit- } \\
\text { level_probit_ } \\
\text { number_- } \\
\text { UpperCl }\end{array}$ & $\begin{array}{l}\text { Area-level_FH_ } \\
\text { totalpopulation }\end{array}$ & $\begin{array}{c}\text { Area-level_ } \\
\text { FH_RATE }\end{array}$ & $\begin{array}{c}\text { Area-level_ } \\
\text { FH_RATE_ } \\
\text { LowerCl }\end{array}$ & $\begin{array}{l}\text { Area-level_ } \\
\text { FH_RATE_- } \\
\text { UpperCl }\end{array}$ & $\begin{array}{l}\text { Area-level_ } \\
\text { FH_number }\end{array}$ & $\begin{array}{l}\text { Area-level_- } \\
\text { FH_number- } \\
\text { LowerCl }\end{array}$ & $\begin{array}{r}\text { Area-level_- } \\
\text { FH_number_- } \\
\text { UpperCl }\end{array}$ \\
\hline 21304 & Melton - Bacchus Marsh & 112403 & 592.7 & 483.2 & 747.1 & 6662 & 5431 & 8398 & 116248.00 & 539.6 & 160.4 & 1178.5 & 6273 & 1865 & 13700 \\
\hline 21303 & Maribyrnong & 66358 & 1187.2 & 974.1 & 1504.2 & 7878 & 6464 & 9981 & 69094.00 & 904.3 & 444.4 & 1425.8 & 6248 & 3071 & 9851 \\
\hline 21302 & Hobsons Bay & 65654 & 679.1 & 558.6 & 859.3 & 4458 & 3667 & 5642 & 68460.00 & 1056.6 & 447.1 & 1868.7 & 7233 & 3061 & 12793 \\
\hline 21301 & Brimbank & 146370 & 779.5 & 633.7 & 992.9 & 11410 & 9275 & 14533 & 151388.00 & 487.5 & 264.1 & 810.3 & 7381 & 3999 & 12267 \\
\hline 21205 & Monash & 142051 & 769.9 & 628.7 & 988.3 & 10936 & 8930 & 14039 & 147480.00 & 957.8 & 475.3 & 1631.7 & 14126 & 7009 & 24064 \\
\hline 21204 & Dandenong & 148701 & 950.9 & 773.8 & 1212.6 & 14140 & 11506 & 18032 & 153682.00 & 1177.4 & 495.7 & 2119.4 & 18095 & 7618 & 32571 \\
\hline 21203 & Casey - South & 122963 & 530.2 & 432.1 & 676.3 & 6520 & 5314 & 8316 & 127070.00 & 1027.9 & 578.4 & 1799.7 & 13061 & 7350 & 22869 \\
\hline 21202 & Casey - North & 100749 & 597.4 & 486.7 & 760.0 & 6019 & 4904 & 7657 & 104395.00 & 598.4 & 208.6 & 1186.5 & 6247 & 2178 & 12387 \\
\hline 21201 & Cardinia & 69243 & 600.9 & 492.3 & 758.6 & 4161 & 3409 & 5253 & 72534.00 & 532.9 & 208.2 & 1023.4 & 3866 & 1510 & 7423 \\
\hline 21105 & Yarra Ranges & 114049 & 411.0 & 336.6 & 515.9 & 4688 & 3839 & 5883 & 120454.00 & 603.7 & 195.6 & 1210.2 & 7272 & 2356 & 14578 \\
\hline 21104 & Whitehorse - East & 47794 & 578.3 & 475.9 & 734.6 & 2764 & 2274 & 3511 & 49821.00 & 799.9 & 230.7 & 1422.0 & 3985 & 1149 & 7085 \\
\hline 21103 & Maroondah & 85505 & 629.5 & 517.3 & 793.6 & 5383 & 4423 & 6786 & 89430.00 & 348.0 & 118.8 & 733.1 & 3112 & 1062 & 6556 \\
\hline 21102 & Manningham - East & 20211 & 226.4 & 186.8 & 288.3 & 458 & 378 & 583 & 21290.00 & 300.0 & 47.2 & 722.5 & 639 & 100 & 1538 \\
\hline 21101 & Knox & 121987 & 509.2 & 417.8 & 643.8 & 6212 & 5096 & 7854 & 127094.00 & 497.4 & 208.5 & 891.1 & 6321 & 2651 & 11326 \\
\hline 21005 & Tullamarine - Broadmeadows & 120027 & 783.9 & 633.8 & 996.0 & 9409 & 7607 & 11955 & 123769.00 & 1034.2 & 335.3 & 1777.3 & 12801 & 4150 & 21997 \\
\hline 21004 & Sunbury & 30247 & 535.5 & 439.0 & 673.3 & 1620 & 1328 & 2037 & 31608.00 & 849.6 & 405.6 & 1389.1 & 2685 & 1282 & 4391 \\
\hline 21003 & Moreland - North & 59381 & 832.6 & 681.4 & 1061.4 & 4944 & 4046 & 6303 & 61452.00 & 992.4 & 359.9 & 1878.9 & 6098 & 2212 & 11546 \\
\hline 21002 & Macedon Ranges & 21883 & 302.8 & 248.8 & 382.1 & 663 & 544 & 836 & 23256.00 & 409.8 & 119.5 & 730.0 & 953 & 278 & 1698 \\
\hline 21001 & Keilor & 46459 & 438.8 & 361.0 & 557.9 & 2039 & 1677 & 2592 & 48513.00 & 217.7 & 92.8 & 499.5 & 1056 & 450 & 2423 \\
\hline 20904 & Whittlesea - Wallan & 162260 & 645.2 & 525.9 & 821.7 & 10468 & 8533 & 13333 & 167699.00 & 682.1 & 254.2 & 1228.8 & 11438 & 4262 & 20607 \\
\hline 20903 & Nillumbik - Kinglake & 49697 & 206.9 & 170.3 & 261.9 & 1028 & 846 & 1302 & 52274.00 & 468.5 & 167.7 & 965.1 & 2449 & 877 & 5045 \\
\hline 20902 & Darebin - North & 76596 & 1064.3 & 870.3 & 1344.1 & 8152 & 6666 & 10295 & 79663.00 & 1323.5 & 634.2 & 2121.0 & 10543 & 5052 & 16896 \\
\hline 20901 & Banyule & 95327 & 642.4 & 527.6 & 809.3 & 6124 & 5030 & 7714 & 99847.00 & 958.8 & 445.9 & 1650.7 & 9574 & 4452 & 16482 \\
\hline 20804 & Stonnington - East & 32687 & 750.0 & 617.4 & 961.0 & 2452 & 2018 & 3141 & 34290.00 & 460.7 & 171.9 & 1018.4 & 1580 & 589 & 3492 \\
\hline 20803 & Kingston & 91100 & 623.1 & 514.6 & 782.8 & 5676 & 4688 & 7132 & 95525.00 & 621.8 & 152.5 & 1369.2 & 5940 & 1457 & 13079 \\
\hline 20802 & Glen Eira & 116413 & 786.9 & 649.0 & 1003.3 & 9161 & 7556 & 11680 & 121354.00 & 755.7 & 226.7 & 1387.5 & 9171 & 2751 & 16838 \\
\hline 20801 & Bayside & 74513 & 471.1 & 390.5 & 595.8 & 3510 & 2910 & 4439 & 78680.00 & 463.7 & 125.9 & 879.0 & 3648 & 991 & 6916 \\
\hline 20703 & Whitehorse - West & 82140 & 859.7 & 702.0 & 1097.6 & 7062 & 5766 & 9016 & 85601.00 & 1241.6 & 476.6 & 2127.0 & 10629 & 4079 & 18207 \\
\hline 20702 & Manningham - West & 73432 & 488.5 & 401.1 & 628.1 & 3587 & 2945 & 4612 & 76315.00 & 852.4 & 171.8 & 1576.0 & 6505 & 1311 & 12027 \\
\hline 20701 & Boroondara & 131937 & 614.4 & 507.8 & 787.9 & 8107 & 6700 & 10395 & 138435.00 & 823.7 & 396.2 & 1396.5 & 11402 & 5485 & 19333 \\
\hline 20607 & Yarra & 73403 & 1251.8 & 1034.1 & 1590.9 & 9189 & 7590 & 11678 & 77661.00 & 1240.5 & 573.1 & 2299.6 & 9634 & 4451 & 17859 \\
\hline 20606 & Stonnington - West & 53285 & 1138.5 & 945.4 & 1450.1 & 6066 & 5038 & 7727 & 56678.00 & 1099.2 & 386.4 & 1845.9 & 6230 & 2190 & 10462 \\
\hline 20605 & Port Phillip & 84267 & 1144.7 & 951.9 & 1447.6 & 9646 & 8021 & 12199 & 89081.00 & 989.2 & 613.0 & 1609.4 & 8812 & 5461 & 14337 \\
\hline 20604 & Melbourne City & 122014 & 1634.2 & 1331.4 & 2101.2 & 19939 & 16245 & 25637 & 127239.00 & 1576.4 & 703.6 & 2542.9 & 20059 & 8953 & 32355 \\
\hline 20603 & Essendon & 53205 & 1007.9 & 831.0 & 1270.9 & 5363 & 4421 & 6762 & 55665.00 & 766.3 & 244.2 & 1456.4 & 4266 & 1359 & 8107 \\
\hline 20602 & Darebin - South & 41605 & 976.8 & 806.3 & 1237.4 & 4064 & 3354 & 5148 & 43635.00 & 1058.9 & 390.0 & 2412.9 & 4620 & 1702 & 10529 \\
\hline 20601 & Brunswick - Coburg & 71019 & 1070.8 & 880.8 & 1366.5 & 7605 & 6255 & 9705 & 74336.00 & 1101.0 & 427.7 & 1824.5 & 8185 & 3179 & 13563 \\
\hline 20505 & Wellington & 32509 & 735.2 & 602.2 & 908.9 & 2390 & 1958 & 2955 & 35261.00 & 1934.8 & 1153.5 & 2759.0 & 6822 & 4067 & 9729 \\
\hline
\end{tabular}




\begin{tabular}{|c|c|c|c|c|c|c|c|c|c|c|c|c|c|c|c|}
\hline \multirow[b]{2}{*}{$\begin{array}{l}\text { SA3_ } \\
\text { CODE_2016 }\end{array}$} & \multirow[b]{2}{*}{ SA3_NAME_2016 } & \multicolumn{7}{|c|}{ Unit-level SAES } & \multicolumn{7}{|c|}{ Area-level SAES } \\
\hline & & $\begin{array}{r}\text { Unit-level_Probit__ } \\
\text { totalpopulation }\end{array}$ & $\begin{array}{l}\text { Unit-level_ } \\
\text { probit_RATE }\end{array}$ & $\begin{array}{r}\text { Unit- } \\
\text { level_probit_- } \\
\text { RATE_- } \\
\text { LowerCl }\end{array}$ & $\begin{array}{r}\text { Unit- } \\
\text { level_probit_- } \\
\text { RATE_- } \\
\text { UpperCl }\end{array}$ & $\begin{array}{r}\text { Unit- } \\
\text { level_probit_ } \\
\text { number }\end{array}$ & $\begin{array}{r}\text { Unit- } \\
\text { level_probit- } \\
\text { number- } \\
\text { LowerCl }\end{array}$ & $\begin{array}{r}\text { Unit- } \\
\text { level_probit_ } \\
\text { number_- } \\
\text { UpperCl }\end{array}$ & $\begin{array}{l}\text { Area-level_FH_ } \\
\text { totalpopulation }\end{array}$ & $\begin{array}{c}\text { Area-level_ } \\
\text { FH_RATE }\end{array}$ & $\begin{array}{l}\text { Area-level_- } \\
\text { FH_RATE_- } \\
\text { LowerCl }\end{array}$ & $\begin{array}{l}\text { Area-level_ } \\
\text { FH_RATE_ } \\
\text { UpperCl }\end{array}$ & $\begin{array}{l}\text { Area-level_- } \\
\text { FH_number }\end{array}$ & $\begin{array}{l}\text { Area-level_ } \\
\text { FH_number_- } \\
\text { LowerCl }\end{array}$ & $\begin{array}{r}\text { Area-level_ } \\
\text { FH_number_- } \\
\text { UpperCl }\end{array}$ \\
\hline 20504 & Latrobe Valley & 55889 & 935.7 & 763.1 & 1151.6 & 5229 & 4265 & 6436 & 59864.00 & 1351.3 & 914.5 & 2190.2 & 8090 & 5475 & 13112 \\
\hline 20503 & Gippsland - South West & 46700 & 765.0 & 626.9 & 945.3 & 3573 & 2927 & 4415 & 51172.00 & 862.9 & 330.7 & 1614.0 & 4415 & 1692 & 8259 \\
\hline 20502 & Gippsland - East & 34441 & 804.7 & 655.6 & 994.1 & 2771 & 2258 & 3424 & 38002.00 & 1269.5 & 585.5 & 2224.1 & 4824 & 2225 & 8452 \\
\hline 20501 & Baw Baw & 36729 & 643.7 & 527.2 & 799.0 & 2364 & 1936 & 2935 & 39339.00 & 1244.6 & 584.4 & 2001.6 & 4896 & 2299 & 7874 \\
\hline 20403 & Wodonga - Alpine & 52414 & 863.0 & 706.7 & 1072.4 & 4524 & 3704 & 5621 & 56962.00 & 1199.5 & 618.9 & 1940.2 & 6832 & 3525 & 11052 \\
\hline 20402 & Wangaratta - Benalla & 35404 & 808.6 & 662.4 & 993.9 & 2863 & 2345 & 3519 & 38155.00 & 654.5 & 143.6 & 1762.6 & 2497 & 548 & 6725 \\
\hline 20401 & Upper Goulburn Valley & 41184 & 657.7 & 539.1 & 817.2 & 2709 & 2220 & 3366 & 44657.00 & 1095.4 & 456.5 & 2106.8 & 4892 & 2039 & 9408 \\
\hline 20303 & Surf Coast - Bellarine Peninsula & 52816 & 574.3 & 472.2 & 720.9 & 3033 & 2494 & 3808 & 57897.00 & 645.1 & 198.5 & 1127.5 & 3735 & 1149 & 6528 \\
\hline 20302 & Geelong & 146081 & 930.2 & 761.3 & 1158.7 & 13588 & 11122 & 16927 & 154468.00 & 619.0 & 388.1 & 1069.2 & 9562 & 5995 & 16516 \\
\hline 20301 & Barwon-West & 13932 & 307.0 & 252.1 & 385.7 & 428 & 351 & 537 & 14778.00 & 341.6 & 63.9 & 863.2 & 505 & 94 & 1276 \\
\hline 20203 & Loddon - Elmore & 8806 & 467.1 & 381.7 & 580.6 & 411 & 336 & 511 & 9466.00 & 1798.6 & 1096.8 & 2642.6 & 1703 & 1038 & 2501 \\
\hline 20202 & Heathcote - Castlemaine - Kyneton & 36616 & 483.6 & 396.6 & 599.2 & 1771 & 1452 & 2194 & 39069.00 & 900.3 & 451.2 & 1362.3 & 3517 & 1763 & 5322 \\
\hline 20201 & Bendigo & 71597 & 1043.3 & 851.8 & 1295.1 & 7470 & 6099 & 9272 & 76248.00 & 2110.7 & 1206.9 & 2903.9 & 16093 & 9202 & 22141 \\
\hline 20103 & Maryborough - Pyrenees & 19941 & 640.0 & 522.4 & 786.2 & 1276 & 1042 & 1568 & 21251.00 & 1520.9 & 1036.8 & 2205.6 & 3232 & 2203 & 4687 \\
\hline 20102 & Creswick - Daylesford - Ballan & 21796 & 464.7 & 381.3 & 574.0 & 1013 & 831 & 1251 & 23424.00 & 935.6 & 514.1 & 1645.0 & 2191 & 1204 & 3853 \\
\hline 20101 & Ballarat & 78510 & 1055.6 & 863.7 & 1306.7 & 8288 & 6781 & 10259 & 83857.00 & 1169.5 & 760.2 & 1689.6 & 9807 & 6375 & 14168 \\
\hline 12802 & Sutherland - Menai - Heathcote & 83054 & 351.7 & 289.9 & 444.9 & 2921 & 2408 & 3695 & 86301.00 & 312.8 & 98.0 & 755.5 & 2699 & 846 & 6520 \\
\hline 12801 & Cronulla - Miranda - Caringbah & 85960 & 529.0 & 437.5 & 670.6 & 4547 & 3761 & 5764 & 90052.00 & 607.9 & 247.7 & 1203.2 & 5475 & 2230 & 10835 \\
\hline 12703 & Liverpool & 88361 & 940.5 & 763.3 & 1188.1 & 8311 & 6745 & 10498 & 91094.00 & 1341.3 & 673.5 & 2179.4 & 12218 & 6135 & 19853 \\
\hline 12702 & Fairfield & 146092 & 1097.2 & 882.3 & 1390.2 & 16029 & 12890 & 20309 & 150689.00 & 1812.2 & 1135.6 & 2772.4 & 27308 & 17112 & 41777 \\
\hline 12701 & Bringelly - Green Valley & 76457 & 727.3 & 585.6 & 926.0 & 5561 & 4477 & 7080 & 78800.00 & 656.4 & 255.6 & 1523.8 & 5173 & 2014 & 12007 \\
\hline 12602 & Ryde - Hunters Hill & 108433 & 808.1 & 666.2 & 1029.1 & 8762 & 7224 & 11159 & 112295.00 & 1109.7 & 304.8 & 2094.7 & 12462 & 3423 & 23523 \\
\hline 12601 & Pennant Hills - Epping & 37613 & 487.7 & 401.5 & 632.4 & 1834 & 1510 & 2379 & 38919.00 & 546.6 & 123.0 & 1199.7 & 2127 & 479 & 4669 \\
\hline 12504 & Parramatta & 110240 & 1013.4 & 833.6 & 1298.3 & 11172 & 9189 & 14313 & 113536.00 & 800.8 & 441.1 & 1112.2 & 9092 & 5008 & 12627 \\
\hline 12503 & Merrylands - Guildford & 114769 & 1085.1 & 878.9 & 1374.2 & 12454 & 10087 & 15772 & 118534.00 & 1503.1 & 669.2 & 2386.9 & 17817 & 7932 & 28293 \\
\hline 12502 & Carlingford & 52057 & 805.9 & 659.3 & 1019.6 & 4195 & 3432 & 5308 & 53856.00 & 1047.3 & 486.4 & 1914.7 & 5641 & 2620 & 10312 \\
\hline 12501 & Auburn & 71856 & 1092.6 & 888.7 & 1415.0 & 7851 & 6386 & 10168 & 74016.00 & 1417.4 & 886.1 & 2055.2 & 10491 & 6558 & 15211 \\
\hline 12405 & St Marys & 41332 & 823.3 & 667.8 & 1042.6 & 3403 & 2760 & 4309 & 42869.00 & 804.0 & 363.9 & 1362.6 & 3447 & 1560 & 5841 \\
\hline 12404 & Richmond - Windsor & 28457 & 865.5 & 705.9 & 1086.4 & 2463 & 2009 & 3091 & 29628.00 & 1574.7 & 720.5 & 2771.0 & 4666 & 2135 & 8210 \\
\hline 12403 & Penrith & 105636 & 733.8 & 598.4 & 926.5 & 7751 & 6321 & 9787 & 109650.00 & 1015.8 & 480.3 & 1933.8 & 11139 & 5266 & 21204 \\
\hline 12401 & Blue Mountains & 59253 & 547.1 & 447.1 & 683.0 & 3242 & 2649 & 4047 & 62660.00 & 296.3 & 119.2 & 525.1 & 1857 & 747 & 3290 \\
\hline 12303 & Wollondilly & 30745 & 412.4 & 336.0 & 521.7 & 1268 & 1033 & 1604 & 32182.00 & 340.6 & 105.2 & 752.5 & 1096 & 338 & 2422 \\
\hline 12302 & Campbelltown (NSW) & 120009 & 953.0 & 771.1 & 1200.3 & 11436 & 9254 & 14404 & 124384.00 & 1610.4 & 879.1 & 2520.9 & 20031 & 10935 & 31357 \\
\hline 12301 & Camden & 45862 & 439.7 & 358.8 & 563.0 & 2017 & 1645 & 2582 & 47524.00 & 25.7 & 0.8 & 84.8 & 122 & 4 & 403 \\
\hline 12203 & Warringah & 115292 & 516.1 & 428.3 & 659.2 & 5951 & 4938 & 7600 & 120331.00 & 558.5 & 247.1 & 1080.2 & 6721 & 2974 & 12998 \\
\hline 12202 & Pittwater & 45813 & 335.3 & 277.9 & 431.9 & 1536 & 1273 & 1979 & 48686.00 & 384.9 & 99.7 & 926.6 & 1874 & 486 & 4511 \\
\hline 12201 & Manly & 32313 & 549.6 & 460.2 & 712.3 & 1776 & 1487 & 2302 & 34024.00 & 263.8 & 46.3 & 551.9 & 898 & 158 & 1878 \\
\hline 12104 & North Sydney - Mosman & 76589 & 717.1 & 601.9 & 926.9 & 5492 & 4610 & 7099 & 80745.00 & 663.2 & 226.0 & 1430.2 & 5355 & 1825 & 11548 \\
\hline
\end{tabular}




\begin{tabular}{|c|c|c|c|c|c|c|c|c|c|c|c|c|c|c|c|}
\hline \multirow[b]{2}{*}{$\begin{array}{l}\text { SA3_ } \\
\text { CODE_2016 }\end{array}$} & \multirow[b]{2}{*}{ SA3_NAME_2016 } & \multicolumn{7}{|c|}{ Unit-level SAES } & \multicolumn{7}{|c|}{ Area-level SAEs } \\
\hline & & $\begin{array}{l}\text { Unit-level_Probit, } \\
\text { totalpopulation }\end{array}$ & $\begin{array}{l}\text { Unit-level_ } \\
\text { probit_RATE }\end{array}$ & $\begin{array}{r}\text { Unit- } \\
\text { level_probit_- } \\
\text { RATE_- } \\
\text { LowerCl }\end{array}$ & $\begin{array}{r}\text { Unit- } \\
\text { level_probit_ } \\
\text { RATE_- } \\
\text { UpperCl }\end{array}$ & $\begin{array}{l}\text { Unit- } \\
\text { level_probit_ } \\
\text { number }\end{array}$ & $\begin{array}{l}\text { Unit- } \\
\text { level_probit_ } \\
\text { number_- } \\
\text { LowerCl }\end{array}$ & $\begin{array}{r}\text { Unit- } \\
\text { level_probit_. } \\
\text { number_- } \\
\text { UpperCl }\end{array}$ & $\begin{array}{l}\text { Area-level_FH_ } \\
\text { totalpopulation }\end{array}$ & $\begin{array}{l}\text { Area-level_ } \\
\text { FH_RATE }\end{array}$ & $\begin{array}{l}\text { Area-level_- } \\
\text { FH_RATE_- } \\
\text { LowerCl }\end{array}$ & $\begin{array}{l}\text { Area-level_ } \\
\text { FH_RATE_ } \\
\text { UpperCl }\end{array}$ & $\begin{array}{l}\text { Area-level_ } \\
\text { FH_number }\end{array}$ & $\begin{array}{l}\text { Area-level_ } \\
\text { FH_number_ } \\
\text { LowerCl }\end{array}$ & $\begin{array}{l}\text { Area-level_- } \\
\text { FH_number- } \\
\text { UpperCl }\end{array}$ \\
\hline 12103 & Ku-ring-gai & 90693 & 301.6 & 249.9 & 392.9 & 2736 & 2267 & 3564 & 94429.00 & 321.7 & 53.5 & 745.7 & 3038 & 505 & 7042 \\
\hline 12102 & Hornsby & 61760 & 547.9 & 452.7 & 698.7 & 3384 & 2796 & 4315 & 64157.00 & 720.4 & 165.7 & 1364.3 & 4622 & 1063 & 8753 \\
\hline 12101 & Chatswood - Lane Cove & 87461 & 648.7 & 539.1 & 838.9 & 5674 & 4715 & 7337 & 91068.00 & 470.0 & 157.2 & 965.1 & 4280 & 1431 & 8789 \\
\hline 12003 & Strathfield - Burwood - Ashfield & 125532 & 963.5 & 790.9 & 1240.5 & 12095 & 9929 & 15572 & 130015.00 & 965.8 & 421.6 & 1675.7 & 12557 & 5481 & 21787 \\
\hline 12002 & Leichhardt & 43432 & 745.1 & 620.1 & 947.0 & 3236 & 2693 & 4113 & 45808.00 & 609.0 & 153.3 & 1284.0 & 2790 & 702 & 5882 \\
\hline 12001 & Canada Bay & 68377 & 686.6 & 567.6 & 884.9 & 4695 & 3881 & 6050 & 71270.00 & 497.4 & 110.4 & 965.6 & 3545 & 786 & 6882 \\
\hline 11904 & Kogarah - Rockdale & 111965 & 850.5 & 697.3 & 1095.1 & 9522 & 7807 & 12262 & 115516.00 & 781.4 & 289.0 & 1716.4 & 9026 & 3339 & 19827 \\
\hline 11903 & Hurstville & 102796 & 851.9 & 695.8 & 1085.4 & 8757 & 7152 & 11157 & 106030.00 & 948.7 & 582.9 & 1444.5 & 10059 & 6180 & 15316 \\
\hline 11902 & Canterbury & 104969 & 1092.8 & 890.5 & 1394.7 & 11471 & 9347 & 14640 & 108032.00 & 610.2 & 407.4 & 979.4 & 6592 & 4401 & 10581 \\
\hline 11901 & Bankstown & 130524 & 960.3 & 779.1 & 1210.0 & 12535 & 10169 & 15793 & 134745.00 & 1110.9 & 705.0 & 1749.7 & 14969 & 9500 & 23577 \\
\hline 11802 & Eastern Suburbs - South & 115003 & 1024.2 & 840.5 & 1308.0 & 11779 & 9666 & 15042 & 119685.00 & 1458.8 & 689.6 & 2347.9 & 17460 & 8253 & 28100 \\
\hline 11801 & Eastern Suburbs - North & 101384 & 719.4 & 599.8 & 930.3 & 7293 & 6081 & 9432 & 106580.00 & 664.7 & 345.0 & 1105.7 & 7084 & 3676 & 11784 \\
\hline 11703 & Sydney Inner City & 190312 & 1330.2 & 1092.7 & 1706.1 & 25315 & 20796 & 32470 & 199577.00 & 1223.6 & 512.1 & 1881.2 & 24421 & 10221 & 37544 \\
\hline 11702 & Marrickville - Sydenham - Petersham & 44901 & 936.9 & 771.3 & 1201.6 & 4207 & 3463 & 5395 & 46958.00 & 880.4 & 452.1 & 1715.6 & 4134 & 2123 & 8056 \\
\hline 11701 & Botany & 37425 & 1029.6 & 845.2 & 1308.9 & 3853 & 3163 & 4898 & 38781.00 & 1265.1 & 508.2 & 2365.3 & 4906 & 1971 & 9173 \\
\hline 11603 & Mount Druitt & 82501 & 1138.7 & 914.9 & 1440.6 & 9395 & 7548 & 11885 & 85036.00 & 2023.0 & 1175.7 & 2769.6 & 17203 & 9997 & 23551 \\
\hline 11602 & Blacktown - North & 68221 & 452.1 & 369.0 & 588.9 & 3085 & 2517 & 4017 & 70000.00 & 333.4 & 64.6 & 1181.5 & 2334 & 452 & 8270 \\
\hline 11601 & Blacktown & 104046 & 887.1 & 721.1 & 1125.6 & 9230 & 7503 & 11712 & 107287.00 & 813.3 & 365.4 & 1379.3 & 8726 & 3921 & 14798 \\
\hline 11504 & Rouse Hill - McGraths Hill & 24204 & 287.0 & 235.7 & 377.0 & 695 & 571 & 912 & 25062.00 & 67.4 & 0.0 & 300.8 & 169 & 0 & 754 \\
\hline 11503 & Hawkesbury & 18791 & 259.6 & 212.5 & 329.0 & 488 & 399 & 618 & 19728.00 & 279.0 & 38.3 & 924.4 & 550 & 76 & 1824 \\
\hline 11502 & Dural - Wisemans Ferry & 20371 & 290.4 & 238.1 & 372.9 & 592 & 485 & 760 & 21274.00 & 332.3 & 80.5 & 749.1 & 707 & 171 & 1594 \\
\hline 11501 & Baulkham Hills & 111204 & 341.6 & 280.8 & 442.4 & 3799 & 3123 & 4919 & 114755.00 & 115.2 & 8.1 & 327.6 & 1322 & 93 & 3759 \\
\hline 11402 & Southern Highlands & 37041 & 554.3 & 453.9 & 695.1 & 2053 & 1681 & 2575 & 39471.00 & 407.4 & 88.6 & 1021.6 & 1608 & 350 & 4032 \\
\hline 11401 & Shoalhaven & 76919 & 870.8 & 707.5 & 1079.7 & 6698 & 5442 & 8305 & 83207.00 & 1640.7 & 922.1 & 2415.7 & 13652 & 7672 & 20100 \\
\hline 11303 & Wagga Wagga & 69711 & 912.5 & 743.8 & 1134.5 & 6361 & 5185 & 7908 & 74810.00 & 1168.1 & 597.0 & 1783.7 & 8738 & 4466 & 13344 \\
\hline 11302 & Tumut - Tumbarumba & 10901 & 762.2 & 623.1 & 942.4 & 831 & 679 & 1027 & 11835.00 & 1365.4 & 1239.6 & 1495.1 & 1616 & 1467 & 1769 \\
\hline 11301 & Griffith - Murrumbidgee (West) & 35760 & 858.7 & 698.9 & 1075.4 & 3071 & 2499 & 3845 & 38210.00 & 503.9 & 330.8 & 651.3 & 1925 & 1264 & 2489 \\
\hline 11203 & Tweed Valley & 71750 & 897.3 & 729.7 & 1119.3 & 6438 & 5236 & 8031 & 76058.00 & 686.9 & 275.8 & 1175.4 & 5224 & 2098 & 8940 \\
\hline 11202 & Richmond Valley - Hinterland & 54025 & 1015.5 & 823.6 & 1253.9 & 5486 & 4450 & 6774 & 57190.00 & 1778.0 & 1043.6 & 2782.3 & 10169 & 5968 & 15912 \\
\hline 11201 & Richmond Valley - Coastal & 61097 & 934.4 & 763.5 & 1165.4 & 5709 & 4665 & 7120 & 65267.00 & 1469.7 & 705.9 & 2457.4 & 9592 & 4607 & 16038 \\
\hline 11103 & Newcastle & 128143 & 1086.4 & 887.1 & 1356.3 & 13921 & 11368 & 17380 & 136131.00 & 736.5 & 322.6 & 1333.5 & 10026 & 4391 & 18153 \\
\hline 11102 & Lake Macquarie - West & 57854 & 760.8 & 616.8 & 949.0 & 4402 & 3569 & 5490 & 61526.00 & 677.6 & 230.5 & 1402.9 & 4169 & 1418 & 8631 \\
\hline 11101 & Lake Macquarie - East & 92549 & 763.9 & 622.6 & 949.2 & 7070 & 5762 & 8784 & 98048.00 & 319.1 & 78.0 & 667.1 & 3128 & 764 & 6541 \\
\hline 11004 & Tamworth - Gunnedah & 60067 & 979.1 & 791.0 & 1218.6 & 5881 & 4751 & 7320 & 64215.00 & 1741.3 & 923.2 & 2515.4 & 11182 & 5928 & 16153 \\
\hline 11003 & Moree - Narrabri & 18565 & 1172.0 & 933.5 & 1462.0 & 2176 & 1733 & 2714 & 20053.00 & 2616.8 & 1422.7 & 4245.4 & 5247 & 2853 & 8513 \\
\hline 11002 & Inverell - Tenterfield & 29078 & 976.4 & 789.3 & 1205.4 & 2839 & 2295 & 3505 & 31299.00 & 1682.7 & 1047.9 & 2649.6 & 5267 & 3280 & 8293 \\
\hline 11001 & Armidale & 27918 & 1055.1 & 855.2 & 1314.8 & 2946 & 2388 & 3671 & 30331.00 & 2154.9 & 1272.8 & 3065.7 & 6536 & 3861 & 9299 \\
\hline 10903 & Upper Murray exc. Albury & 31833 & 748.7 & 612.5 & 929.2 & 2383 & 1950 & 2958 & 34725.00 & 898.8 & 297.0 & 1658.8 & 3121 & 1031 & 5760 \\
\hline
\end{tabular}




\begin{tabular}{|c|c|c|c|c|c|c|c|c|c|c|c|c|c|c|c|}
\hline \multirow[b]{2}{*}{$\begin{array}{l}\text { SA3_ } \\
\text { CODE_2016 }\end{array}$} & \multirow[b]{2}{*}{ SA3_NAME_2016 } & \multicolumn{7}{|c|}{ Unit-level SAES } & \multicolumn{7}{|c|}{ Area-level SAES } \\
\hline & & $\begin{array}{r}\text { Unit-level_Probit_- } \\
\text { totalpopulation }\end{array}$ & $\begin{array}{r}\text { Unit-level_ } \\
\text { probit_RATE }\end{array}$ & $\begin{array}{r}\text { Unit- } \\
\text { level_probit_ } \\
\text { RATE_ } \\
\text { LowerCl } \\
\end{array}$ & $\begin{array}{r}\text { Unit- } \\
\text { level_probit_ } \\
\text { RATE_ } \\
\text { UpperCl } \\
\end{array}$ & $\begin{array}{r}\text { Unit- } \\
\text { level_probit_ } \\
\text { number }\end{array}$ & $\begin{array}{r}\text { Unit- } \\
\text { level_probit_ } \\
\text { number- } \\
\text { LowerCl }\end{array}$ & $\begin{array}{r}\text { Unit- } \\
\text { level_probit_- } \\
\text { number- } \\
\text { UpperCl }\end{array}$ & $\begin{array}{l}\text { Area-level_FH_ } \\
\text { totalpopulation }\end{array}$ & $\begin{array}{c}\text { Area-level_ } \\
\text { FH_RATE }\end{array}$ & $\begin{array}{c}\text { Area-level_- } \\
\text { FH_RATE_- } \\
\text { LowerCl }\end{array}$ & $\begin{array}{c}\text { Area-level_ } \\
\text { FH_RATE_- } \\
\text { UpperCl }\end{array}$ & $\begin{array}{l}\text { Area-level_- } \\
\text { FH_number }\end{array}$ & $\begin{array}{l}\text { Area-level_ } \\
\text { FH_number_- } \\
\text { LowerCl }\end{array}$ & $\begin{array}{l}\text { Area-level_- } \\
\text { FH_number- } \\
\text { Uppercl }\end{array}$ \\
\hline 10902 & Lower Murray & 9348 & 848.7 & 686.3 & 1053.1 & 793 & 642 & 984 & 10187.00 & 1535.8 & 943.1 & 2213.0 & 1564 & 961 & 2254 \\
\hline 10901 & Albury & 45948 & 1036.7 & 847.5 & 1283.3 & 4764 & 3894 & 5897 & 49457.00 & 816.6 & 345.0 & 1774.2 & 4038 & 1706 & 8775 \\
\hline 10805 & Taree - Gloucester & 41902 & 1033.8 & 835.5 & 1274.4 & 4332 & 3501 & 5340 & 44886.00 & 1608.7 & 953.6 & 2225.6 & 7221 & 4281 & 9990 \\
\hline 10804 & Port Macquarie & 61226 & 926.2 & 754.5 & 1150.0 & 5671 & 4620 & 7041 & 65460.00 & 1167.1 & 612.6 & 1917.9 & 7640 & 4010 & 12554 \\
\hline 10802 & Kempsey - Nambucca & 37509 & 1015.8 & 816.2 & 1252.4 & 3810 & 3062 & 4698 & 39985.00 & 2244.5 & 1548.7 & 2974.4 & 8975 & 6193 & 11893 \\
\hline 10801 & Great Lakes & 24870 & 965.1 & 783.7 & 1190.7 & 2400 & 1949 & 2961 & 26846.00 & 1238.9 & 427.0 & 2141.1 & 3326 & 1146 & 5748 \\
\hline 10704 & Wollongong & 100502 & 1020.2 & 833.5 & 1274.2 & 10253 & 8377 & 12806 & 106157.00 & 893.2 & 260.0 & 1465.1 & 9482 & 2760 & 15553 \\
\hline 10703 & Kiama-Shellharbour & 68727 & 748.4 & 608.8 & 935.7 & 5143 & 4184 & 6431 & 72629.00 & 349.7 & 73.9 & 665.7 & 2540 & 537 & 4835 \\
\hline 10701 & Dapto - Port Kembla & 58251 & 872.8 & 708.0 & 1084.1 & 5084 & 4124 & 6315 & 60941.00 & 1153.3 & 601.9 & 1691.9 & 7028 & 3668 & 10311 \\
\hline 10604 & Upper Hunter & 22317 & 989.5 & 804.8 & 1234.8 & 2208 & 1796 & 2756 & 23663.00 & 1462.2 & 823.6 & 2225.5 & 3460 & 1949 & 5266 \\
\hline 10603 & Port Stephens & 54721 & 836.9 & 680.3 & 1046.6 & 4580 & 3723 & 5727 & 58826.00 & 839.2 & 438.8 & 1457.9 & 4936 & 2581 & 8576 \\
\hline 10602 & Maitland & 54878 & 881.9 & 718.3 & 1101.1 & 4840 & 3942 & 6043 & 57920.00 & 614.5 & 227.1 & 1269.2 & 3559 & 1315 & 7351 \\
\hline 10601 & Lower Hunter & 65801 & 819.5 & 665.2 & 1020.0 & 5392 & 4377 & 6712 & 69736.00 & 921.1 & 584.8 & 1498.4 & 6424 & 4078 & 10449 \\
\hline 10503 & Dubbo & 51277 & 1000.3 & 802.0 & 1243.0 & 5129 & 4112 & 6374 & 55312.00 & 1417.3 & 631.9 & 2133.2 & 7839 & 3495 & 11799 \\
\hline 10502 & Broken Hill and Far West & 15324 & 874.4 & 702.1 & 1081.5 & 1340 & 1076 & 1657 & 16795.00 & 2013.6 & 777.5 & 3301.2 & 3382 & 1306 & 5544 \\
\hline 10501 & Bourke - Cobar - Coonamble & 17400 & 1286.9 & 1015.0 & 1602.8 & 2239 & 1766 & 2789 & 19044.00 & 3338.0 & 2011.5 & 4752.1 & 6357 & 3831 & 9050 \\
\hline 10402 & Coffs Harbour & 65874 & 1028.0 & 836.0 & 1277.1 & 6772 & 5507 & 8413 & 70387.00 & 1128.0 & 591.1 & 1659.5 & 7939 & 4161 & 11681 \\
\hline 10401 & Clarence Valley & 39315 & 950.9 & 771.3 & 1171.4 & 3738 & 3032 & 4605 & 42035.00 & 1772.5 & 985.6 & 2768.2 & 7451 & 4143 & 11636 \\
\hline 10304 & Orange & 42401 & 864.7 & 703.2 & 1078.7 & 3667 & 2982 & 4574 & 45312.00 & 925.6 & 464.4 & 1769.7 & 4194 & 2104 & 8019 \\
\hline 10303 & Lithgow - Mudgee & 35446 & 841.7 & 684.1 & 1044.5 & 2983 & 2425 & 3702 & 37861.00 & 1814.6 & 1055.8 & 2772.1 & 6870 & 3997 & 10495 \\
\hline 10302 & Lachlan Valley & 41416 & 901.3 & 729.7 & 1111.9 & 3733 & 3022 & 4605 & 44539.00 & 1684.7 & 1000.3 & 2485.9 & 7504 & 4455 & 11072 \\
\hline 10301 & Bathurst & 35186 & 898.2 & 731.2 & 1117.4 & 3160 & 2573 & 3932 & 37544.00 & 944.3 & 575.5 & 1568.8 & 3545 & 2161 & 5890 \\
\hline 10202 & Wyong & 121812 & 903.4 & 733.3 & 1129.3 & 11004 & 8932 & 13757 & 128498.00 & 1788.2 & 794.5 & 2563.1 & 22978 & 10209 & 32935 \\
\hline 10201 & Gosford & 131454 & 795.5 & 649.1 & 995.0 & 10457 & 8532 & 13080 & 138799.00 & 864.4 & 481.4 & 1212.3 & 11997 & 6682 & 16827 \\
\hline 10106 & Young - Yass & 26788 & 674.4 & 551.0 & 837.3 & 1806 & 1476 & 2243 & 28694.00 & 948.4 & 445.9 & 1565.0 & 2721 & 1279 & 4491 \\
\hline 10105 & Goulburn - Mulwaree & 27402 & 832.7 & 679.2 & 1034.2 & 2282 & 1861 & 2834 & 29164.00 & 1209.9 & 599.1 & 1860.4 & 3529 & 1747 & 5426 \\
\hline 10104 & South Coast & 54930 & 869.2 & 707.0 & 1074.6 & 4775 & 3884 & 5903 & 60036.00 & 1237.8 & 592.4 & 1815.9 & 7431 & 3556 & 10902 \\
\hline 10103 & Snowy Mountains & 14827 & 719.9 & 592.3 & 894.4 & 1067 & 878 & 1326 & 16092.00 & 682.2 & 205.9 & 1218.1 & 1098 & 331 & 1960 \\
\hline 10102 & Queanbeyan & 43414 & 639.9 & 526.1 & 806.3 & 2778 & 2284 & 3501 & 46099.00 & 745.7 & 140.3 & 1583.1 & 3438 & 647 & 7298 \\
\hline
\end{tabular}




\section{AHURi}

Australian Housing and Urban Research Institute Level 12, 460 Bourke Street

Melbourne VIC 3000

\section{Australia}

+61396602300

information@ahuri.edu.au

ahuri.edu.au

(2) twitter.com/AHURI_Research

f facebook.com/AHURI.AUS

in Australian Housing and Urban Research Institute 